\title{
Estado de las poblaciones de trucha en los ríos de la Comunidad Valenciana y caracterización de sus hábitats
}

Juan Diego Alcaraz Hernández 
DEPARTAMENTO DE INGENIERÍA HIDRÁULICA Y MEDIO AMBIENTE

\section{ESTADO DE LAS POBLACIONES DE}

\section{TRUCHA EN LOS RÍOS DE LA COMUNIDAD VALENCIANA Y} CARACTERIZACIÓN DE SUS HÁBITATS

Tesis doctoral

Presentada por:

Juan Diego Alcaraz Hernández

Dirigida por:

Francisco Martínez Capel

Valencia, 2011 


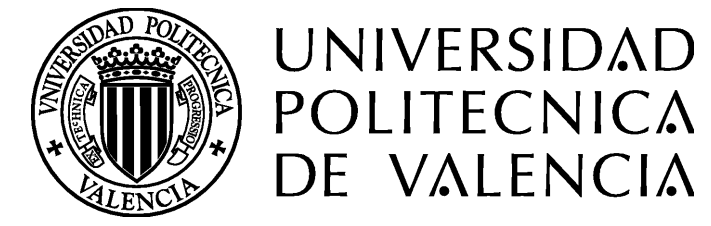

DEPARTAMENTO DE INGENIERÍA HIDRÁULICA Y MEDIO AMBIENTE

\section{ESTADO DE LAS POBLACIONES DE} TRUCHA EN LOS RÍOS DE LA COMUNIDAD VALENCIANA Y CARACTERIZACIÓN DE SUS HÁBITATS

Tesis doctoral

Presentada por:

Juan Diego Alcaraz Hernández

Dirigida por:

Francisco Martínez Capel 


\section{Esta editorial es miembro de la UNE, lo que garantiza la difusión y comercialización de sus publicaciones a nivel

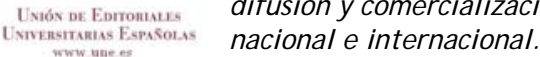

๑) J uan Diego Álcaraz Hernández, 2012

Primera edición, 2012

(c) de la presente edición:

Editorial Universitat Politècnica de València www. editorial.upv.es

ISBN: 978-84-8363-807-1 (versión impresa)

Ref. editorial: 5519

Queda prohibida la reproducción, distribución, comercialización, transformación, y en general, cualquier otra forma de explotación, por cualquier procedimiento, de todo o parte de los contenidos de esta obra sin autorización expresa y por escrito de sus autores. 


\section{A Gisela y Arturo.}

Mi pequeño clan. 


\section{AGRADECIMIENTOS}

Me acuerdo el día en el que conocí a Paco, mi tutor. Él acababa de llegar a la Universidad Politécnica de Valencia como profesor interino, era joven y apenas tenía unos pocos años más que yo. Iba buscando a una persona para trabajar con él. Bastaron unas pocas palabras para convencerme y juntos formamos un pequeño grupo de investigación muy joven, casi adolescentes, si nos comparamos con las largas trayectorias de los científicos. Se debió correr la voz de la creación de este nuevo grupo por lo largo y ancho del planeta, porque al poco llego desde las costas de Chile, un nuevo doctorando, Matías. Mano a mano, estuvimos trabajando durante más de año antes de que llegara Aina (para los amigos Divaina). Paco me introdujo en el fascinante mundo de los ríos y de los peces. A él le debo el que yo haya realizado esta tesis. Mis socios en esta empresa, Paco, Matías y Aina compartieron conmigo mis sueños y mis desvelos, solventados muchas veces con una copita de pacharán. Con el tiempo y poco a poco, el grupo fue creciendo paulatinamente aumentando la calidez humana. Las nuevas incorporaciones de Virginia, Marta, Manu, Rui, Rafa y Julia me aportaron nuevas ideas e ilusiones. A todos ellos, mil gracias.

En el largo peregrinaje que es el hacer una tesis me encontré por el camino a mucha gente, que sin pedir nada a cambio me ayudaron desinteresadamente, muchas veces sin que ni ellos lo supieran o se dieran cuenta. Entre ellos está la guardería forestal del Rincón de Ademuz, especialmente a los agentes medioambientales Germán Francés y José Urbano, que aportaron profesionalidad en los trabajos de campo. A Carlos Alonso González, por su ayuda en el cálculo de densidades. De la misma manera, quisiera mencionar a Toni Pradillo y Roberto Coll que consiguieron trasmitirme su gran pasión, la pesca. Además, quisiera agradecer a Roberto Coll por luchar, desde su blog pescaturia, por la dignidad de los ríos mediterráneos y por el estudio genético de las poblaciones de trucha común en ríos valencianos. A Mercedes Arenas, Consuelo Pérez, Pau Lucio, Rafa Casas, Rosa de la Salud, Pascual Puerto, Javier Izquierdo, Jaime Ramos, Laura Gómez, Fran Pardavila, Sasa Plestenjak y Bego Monroig (perdonadme si a alguien no nombro) por transformarse, en las infinitas salidas al campo, en tramperos por unos días para realizar la pesca eléctrica o incluso en buzos (sin escafandra). 
No quisiera olvidarme de Juan Theureau que desde la Consellería de Medio Ambiente, Agua, Urbanismo y Vivienda de la Generalitat Valenciana de la Generalitat Valenciana consiguió gran parte de la financiación para que esta aventura, que partió con un estudio para la administración, llegara a buen puerto. Como tampoco del profesor Derek H. Orgle (Northland Collage, EE.UU) que me ayudó en la compleja tarea de modelar las poblaciones de trucha mediante el programa estadístico $R$.

Por último agradecer a mi familia, mis padres y mis hermanas, que desde la más tierna infancia me apoyaron a superar las pequeñas dificultades de la vida. 


\section{ÍNDICE}

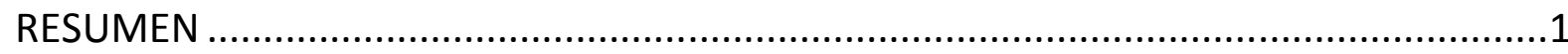

RESUM

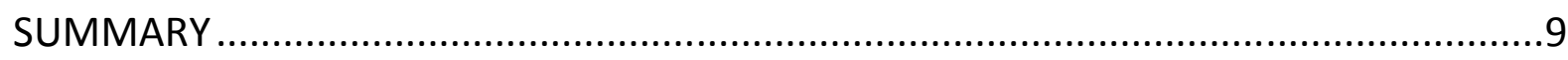

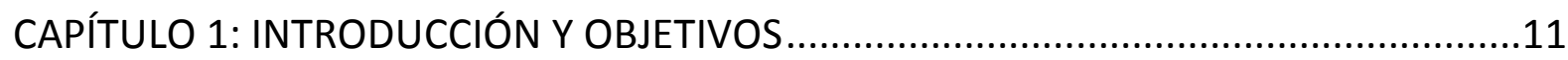

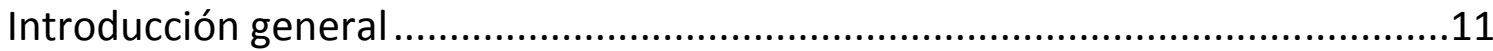

Objetivos Generales ...................................................................................

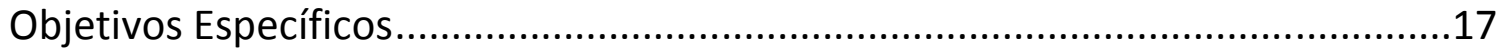

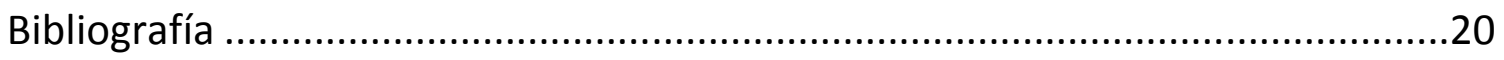

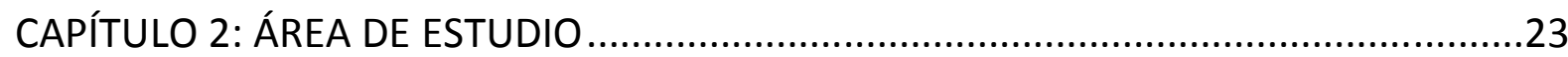

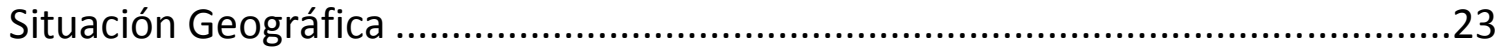

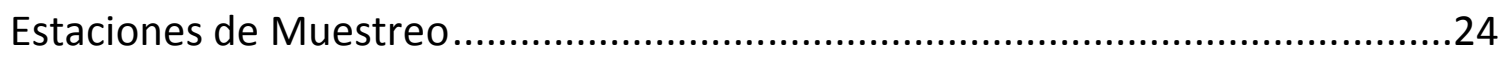

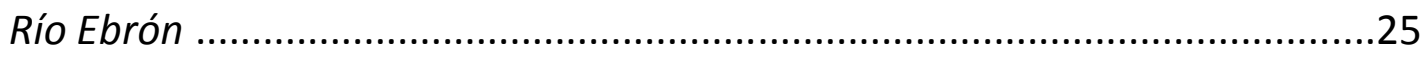

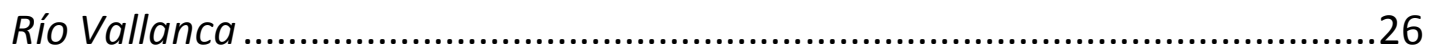

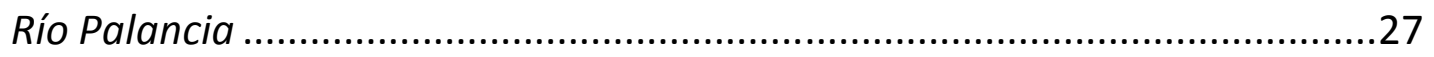

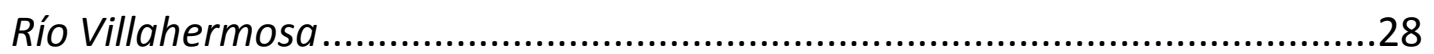

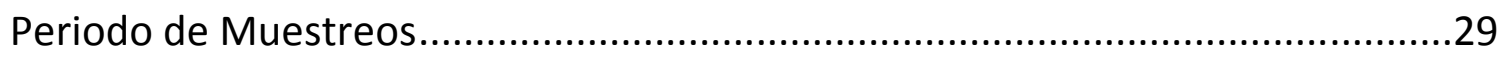

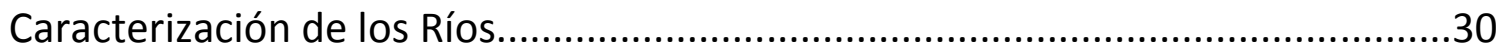

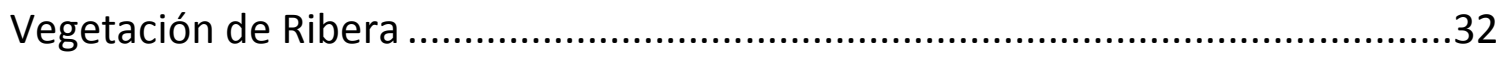

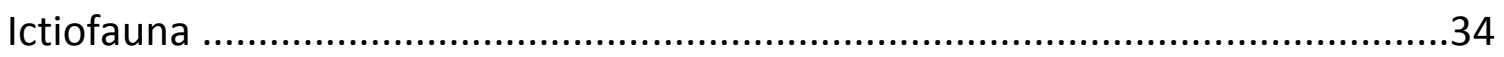

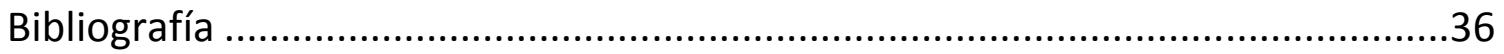

CAPÍTULO 3: ANÁLISIS DE LA VARIABILIDAD DEL HÁBITAT EN RIOS TRUCHEROS MEDITERRÁNEOS MEDIANTE SUS ATRIBUTOS FÍSICOS ............................................

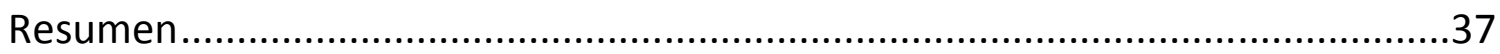

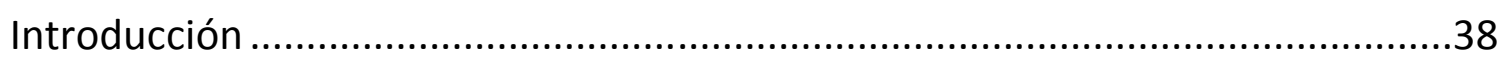

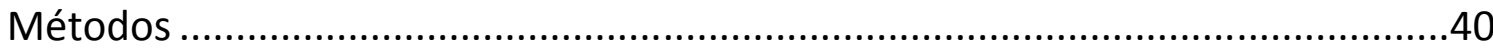

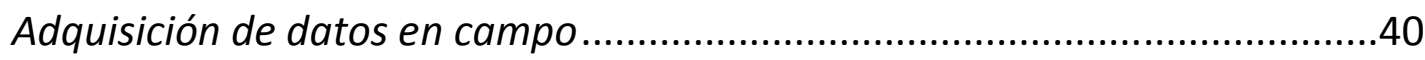

Análisis de los datos ..................................................................................

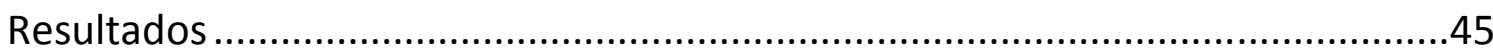

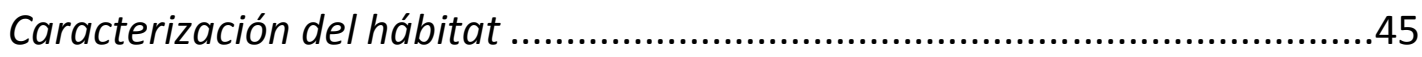

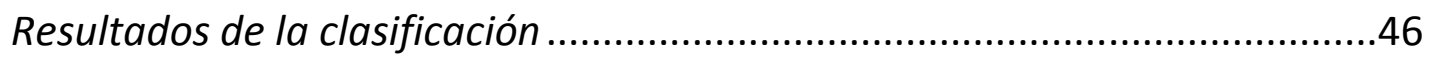

Asociación entre las unidades hidromorfológicas .........................................48

Caracterización de las clases con mayor variabilidad ....................................49

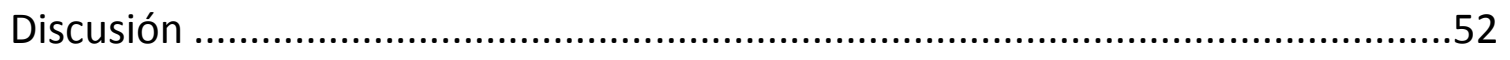

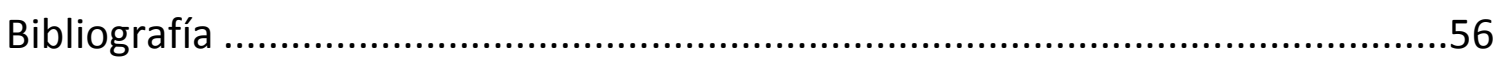



EN RÍOS MEDITERRÁNEOS; REVISIÓN Y COMPARACIÓN CON OTRAS POBLACIONES .61

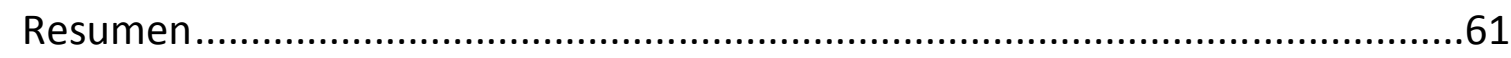

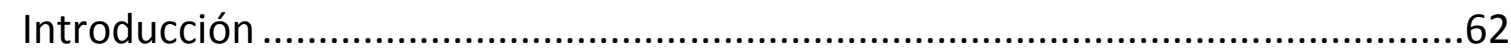

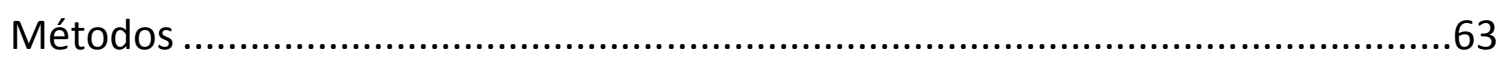

Adquisición de datos en campo ...................................................................63

Análisis de los datos ...............................................................................64

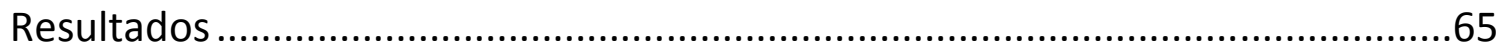

Asignación de edad ..........................................................................65

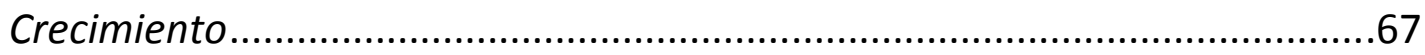

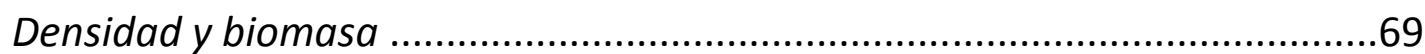

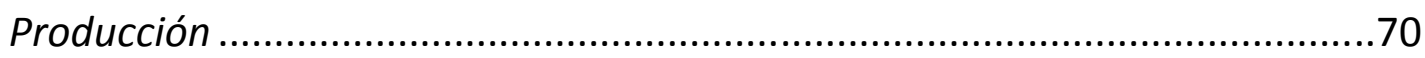

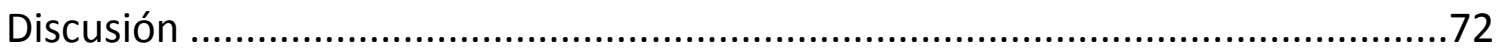

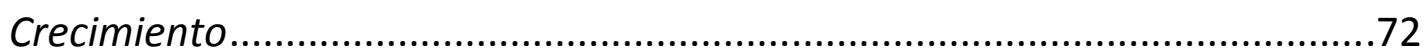

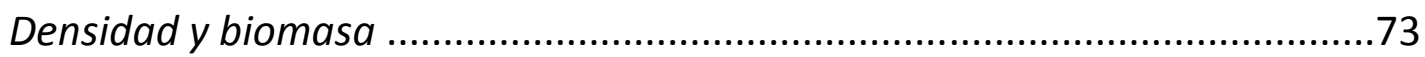

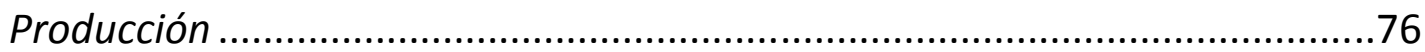

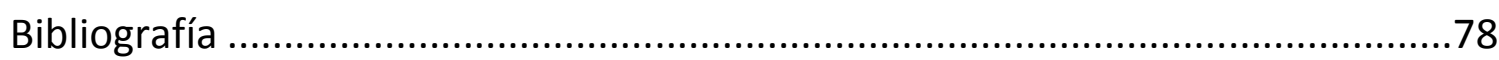

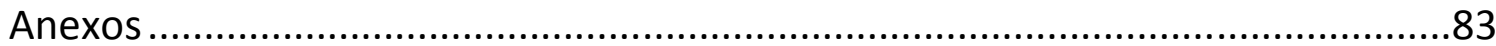

CAPÍTULO 5: MODELOS DE CRECIMIENTO Y RELACIONES DE DENSO-DEPENDENCIA DE LA TRUCHA COMÚN EN RÍOS MEDITERRÁNEOS .................................................85

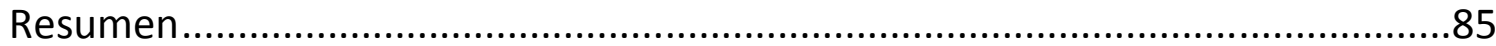

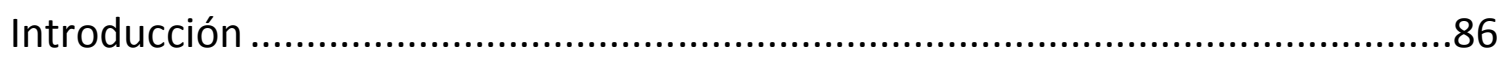

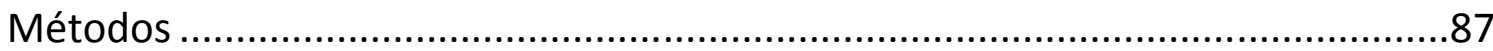

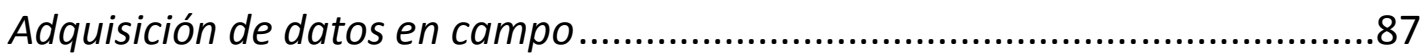

Análisis de los datos ...........................................................................8

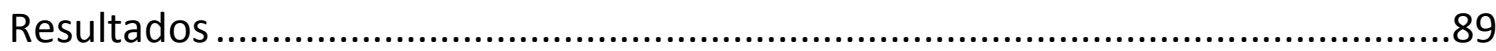

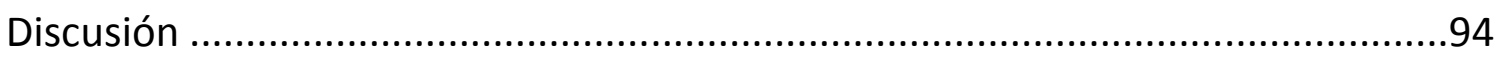

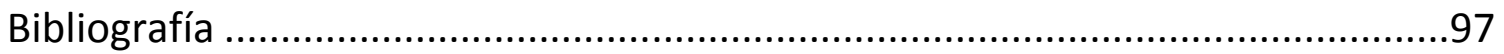

CAPÍTULO 6: RELACIONES CUALITATIVAS ENTRE DENSIDADES DE TRUCHA COMÚN Y LAS CARACTERÍSTICAS FÍSICAS DEL HÁBITAT. ANÁLISIS POR RÍOS .......................... 101

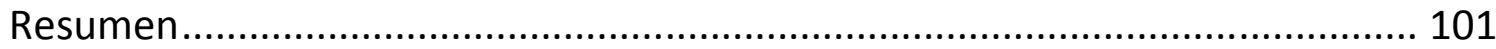

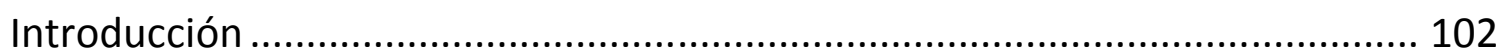

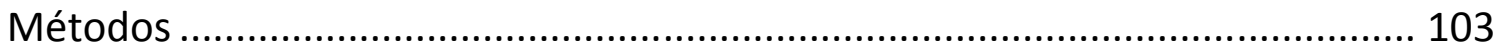

Adquisición de datos en campo ............................................................... 103

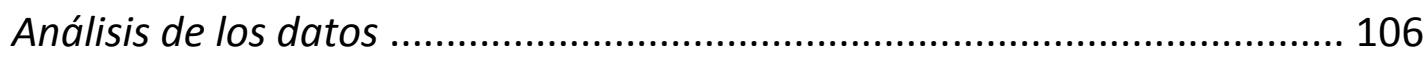

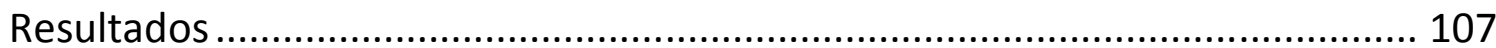

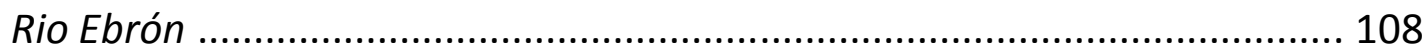

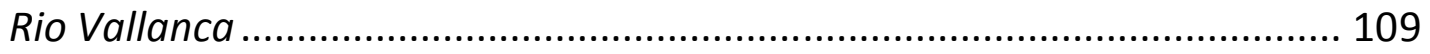




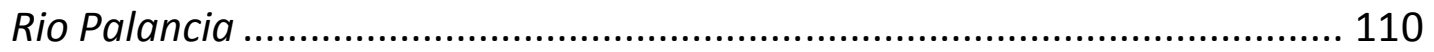

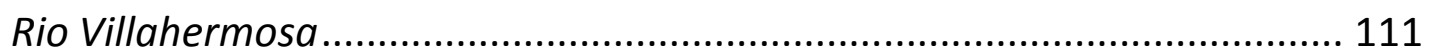

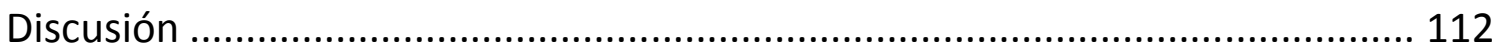

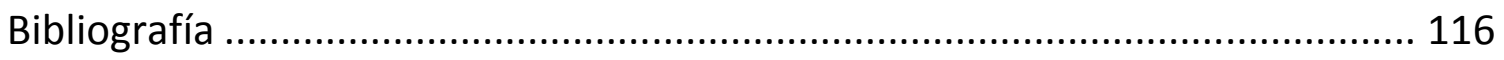

CAPÍTULO 7: ANÁLISIS DE LA DENSIDAD DE TRUCHA COMÚN SEGÚN MESOHÁBITATS

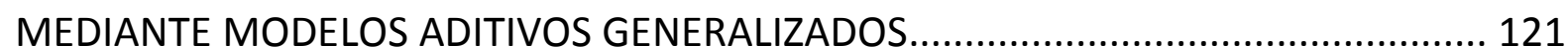

Resumen

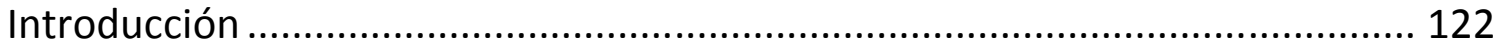

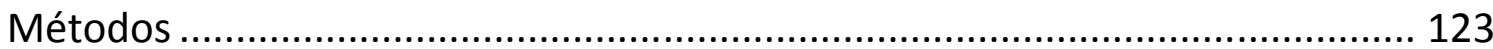

Adquisición de datos en campo ................................................................ 123

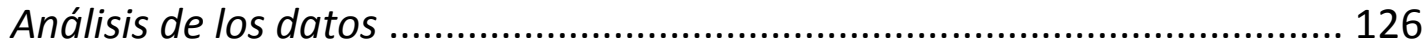

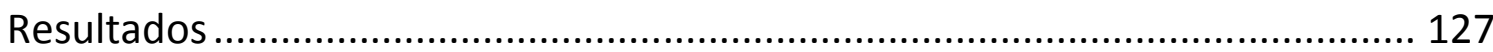

Análisis de los mesohábitats lentos......................................................... 127

Análisis de los mesohábitats rápidos ........................................................ 129

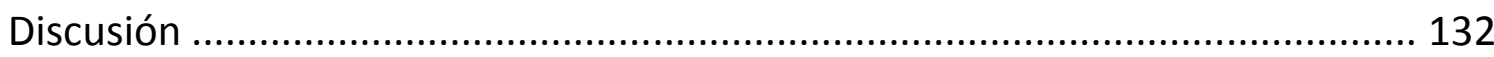

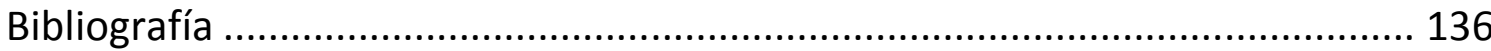

CAPÍTULO 8: IDONEIDAD DEL HÁBITAT DE LA TRUCHA COMÚN MEDIANTE ANÁLISIS DE LÓGICA DIFUSA EN RIOS MEDITERRÁNEOS ESPAÑOLES................................... 141

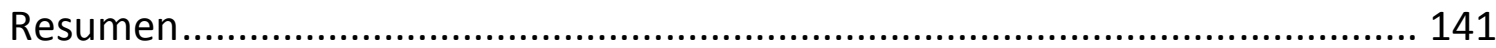

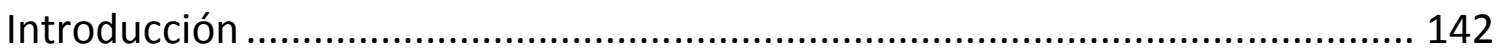

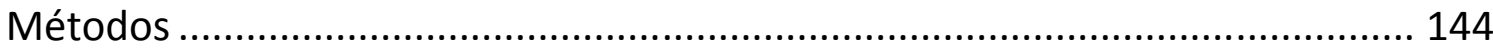

Adquisición de datos en campo ................................................................ 144

Parámetros de optimización del conjunto difuso......................................... 145

Modelación y optimización de la regla difusa............................................ 147

Modelación con Random Forests ............................................................. 149

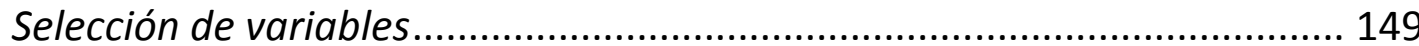

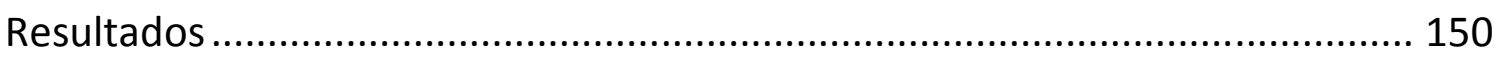

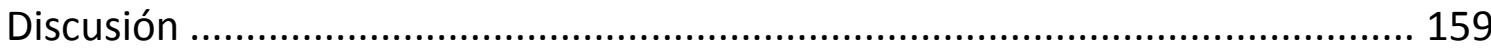

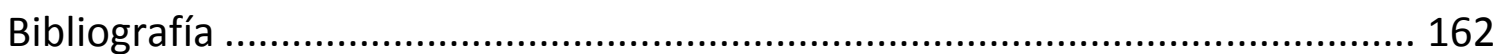

CAPÍTULO 9: CONCLUSIONES Y FUTURAS LÍNEAS DE INVESTIGACIÓN ...................... 167 


\section{RESUMEN}

Los estudios acerca de la ecología de los peces tienen como una de sus principales bases la evaluación de las poblaciones, encaminados a definir el conjunto de los individuos de una misma especie que vive en un espacio común. Por lo tanto, el análisis del hábitat es clave para la estructura de las poblaciones. Desde el punto de vista de la teoría jerárquica ecológica, los patrones biológicos que gobiernan a las poblaciones de peces de los ríos son controlados y ajustados por los patrones físicos del hábitat. Así pues, una descripción exacta de los ríos es un primer paso en la descripción de los requerimientos ecológicos de los organismos durante su vida así como en los procesos que influyen en su abundancia y distribución. En este sentido, esta tesis aporta un mayor conocimiento de las poblaciones de trucha común (Salmo trutta) y de sus hábitats en ríos mediterráneos.

El estudio se llevó a cabo en cuatro ríos de la Comunidad Valenciana (España) donde hoy en día la especie habita de forma natural; Ebrón y Vallanca (en la provincia de Valencia), Villahermosa y Palancia (en la provincia de Castellón). Los muestreos se realizaron entre los meses de Junio y Agosto entre los años 2003 y 2006. El primer año se establecieron dos estaciones de muestreo en cada río. En los restantes años se amplió a cuatro estaciones de muestreo en cada río. Se destaca el hecho de que en los dos últimos años de estudio (2005 y 2006) hubo una fuerte sequía que hizo que los tramos más altos de los ríos Vallanca y Villahermosa se secaran, perdiéndose tres de las dieciséis estaciones establecidas. En total se muestrearon 50 tramos en los cuatro años de muestreo.

Para la caracterización del hábitat se adaptó el protocolo de muestreo "Basinwide Visual Estimation Technique - BVET". Esta técnica consiste en estratificar visualmente el cauce según sus diferentes biotopos (unidades hidromorfológicas o mesohábitats), registrándose en ellos las distintas características hidromorfológicas. En este estudio se establecieron cuatro tipos de mesohábitats básicos; pozas, tablas, corrientes y rápidos. En cada mesohábitat se midieron en campo las siguientes variables: longitud del mesohábitat, anchura media del cauce, profundidad media, profundidad máxima y profundidad de vertedero. También se calculó el índice de refugio y la densidad de restos de madera sobre el cauce. Por último se estimó visualmente los porcentajes de sustrato, según la clasificación de la American Geophysical Union, sombreado sobre el cauce y recubrimiento de finos. Otras variables sintéticas como el volumen y la 
distancia relativa entre rápidos también fueron utilizadas en distintos análisis. En total se muestrearon 964 mesohábitats diferentes.

Por otro lado, las truchas fueron muestreadas mediante pesca eléctrica en cada mesohábitats. El tamaño de las poblaciones de peces fue estimado por capturas sucesivas, realizando como mínimo tres pasadas sin reemplazamiento, y a un esfuerzo constante, siempre con los mesohábitats cerrados con redes. En total se obtuvieron 1188 truchas de diferentes tallas en los cuatro años de muestreo. A todos los peces extraídos se les midió la longitud furcal y su peso. A la mayoría de los individuos de más de un año de edad se les extrajeron escamas para su posterior análisis. Las edades fueron establecida en el laboratorio mediante el análisis de las frecuencias de longitudes y verificadas mediante la lectura de las escamas de la muestra de peces.

Las variables de los mesohábitats nos han permitido la caracterización robusta de los hábitats. Gracias a las propiedades de la matriz de proximidad, se estudió la variabilidad de la clasificación. Para ello se calculó el índice de la fortaleza de la clasificación y se utilizó el escalado multidimensional métrico. Además, se identificaron y agruparon los factores que más influyen en la variabilidad de las clases. Todo esto ha permitido observar la homogeneidad y aislamiento de las clases establecidas a priori, detectando aquellas clases con mayor variabilidad. Los resultados indican que los ríos Villahermosa y Ebrón son más estables que Vallanca y Palancia, las corrientes y tablas son más estables que pozas y rápidos. Además, tanto los mesohábitats rápidos (corrientes y rápidos) como los mesohábitats lentos (pozas y tablas) tienden a agruparse. Por último, se detectaron los factores que más influyen en la variabilidad de las pozas en los ríos Vallanca y Palancia (los mesohábitats de mayor variabilidad).

Con respecto a las poblaciones de trucha común, se calcularon las longitudes, el peso y la tasa de crecimiento anual por clases de edad. También se calcularon las medias de las abundancias (densidad y biomasa), la producción, la tasa de renovación P/B y finalmente la relación longitud-peso y el crecimiento teórico de Von Bertalanffy. Para ello, se utilizaron métodos robustos en la estimación de las variables. Los resultados nos han permitido observar que el crecimiento en longitud de las truchas es grande, que hay una considerable variación en la densidad y biomasa media de los ríos, que la producción anual es baja y que la tasa de renovación anual presenta valores muy bajos en comparación con otras poblaciones trucheras en ríos de Europa y América. 
Además, se detectó una relación denso-dependiente entre la longitud y la densidad de las truchas inmaduras en los ríos Vallanca y Palancia.

Por otro lado, en cada río las densidades de trucha común son controladas por factores denso-independientes, cuya relevancia y jerarquía en la mayoría de los casos son desconocidas por los gestores medioambientales. La estratificación de los muestreos según tipos de mesohábitats nos permitió estudiar qué características físicas del mesohábitat tienen más relevancia en la variación de la densidad, tanto para la trucha inmadura ( $<2$ años) como la adulta ( $\geq 2$ años), en cada río de estudio. Para ello se realizó en cada río un análisis de correspondencia simple y se comprobaron las correlaciones por rangos de Spearman entre las densidades y las características físicas del hábitat. Se observa, gracias a las correlaciones de Spearman, que todas las variables del hábitat, salvo el sustrato fino, han sido correlacionadas significativamente con la densidad de trucha en algunos de los mapas del Ebrón, Vallanca y Villahermosa. No obstante, en cada río son diferentes las variables físicas correlacionadas con la densidad, excepto para la trucha adulta de los ríos Vallanca y Villahermosa ya que en ambos casos existe una correlación positiva con la profundidad y el volumen. Por el contrario, no se observó ninguna relación entre las densidades de trucha común y las variables físicas del río Palancia. Por lo tanto, los resultados reflejan la alta variabilidad local de cada uno de los ríos de estudio.

También se analizaron las relaciones existentes entre las densidades de adultos e inmaduras y las variables del hábitat para dos biotopos diferentes; primero para los mesohábitats lentos (pozas y tablas) y segundo para los mesohábitats rápidos (corrientes y rápidos). Mediante Modelos Aditivos Generalizados (GAM) se han evaluado el grado de relación entre las poblaciones de trucha y sus mesohábitats. Los resultados obtenidos nos muestran un alto grado de asociación entre la densidad de trucha adulta e inmadura y algunas de las principales características de los mesohábitats lentos y rápidos. Además, se observó por un lado, que la trucha inmadura disminuye de acuerdo al volumen en los dos tipos establecidos de mesohábitats y por otro, la adulta en los mesohábitats lentos se relaciona con la profundidad máxima y la distancia relativa entre rápidos, mientras que en los rápidos se relaciona con el índice de refugio. Estas cuatro variables predictivas podrían ser indicadoras de la territorialidad de la especie por la disponibilidad de alimento y refugio.

Finalmente, se utilizaron modelos de lógica difusa para el estudio de idoneidad del hábitat de la trucha común mediterránea. Posteriormente fueron comparados con 
modelos Random Forests. Para ello, se aplicó un algoritmo heurístico de "Nearest Ascent Hill-Climbing" en la optimización de las reglas difusas y de Random Forests. No se observaron diferencias significativas en la representación de los modelos entre el modelo óptimo difuso y el modelo Random Forests, y ambas aproximaciones seleccionaron la anchura del río, el índice de refugio y la velocidad de flujo como las variables más importantes para describir la idoneidad del hábitat de la trucha común. Además, los modelos difusos combinaron la relevancia ecológica con una aceptable interpretabilidad, mientras que fue limitada la transparencia de los modelos Random Forests. Por lo tanto, los modelos difusos podrían ser una herramienta de soporte en la evaluación de decisiones en la gestión de los ríos y aumentar la comunicación las partes interesadas. 


\section{RESUM}

Els estudis envers l'ecologia de peixos tenen com a una de les seues principals bases l'avaluació de les poblacions, encaminats a definir el conjunt dels individus d'una mateixa espècie i que viu a un espai comú. Per tant, l'anàlisi de l'hàbitat és la clau per a l'estructura de les poblacions. Des del punt de vista de la teoria jeràrquica ecològica, els patrons biològics que governen a les poblacions de peixos als rius són controlats i ajustats pels patrons físics de l'hàbitat. Així doncs, una descripció exacta dels rius és una primera passa en la descripció dels requeriments ecològics dels organismes durant la seua vida així com en els processos que influeixen en la seua abundància i distribució. En aquest sentit, aquesta tesi aporta un major coneixement de les poblacions de truita comuna (Salmo trutta) i dels seus hàbitats en rius mediterranis.

L'estudi va ser dut terme en quatre rius del País Valencià (Espanya) on huí dia l'espècie habita de forma natural; Ebrón i Vallanca (a la província de València), Villahermosa i Palància (a la província de Castelló). Els mostratges es realitzaren entre els mesos de Juny i Agost entre els anys 2003 i 2006. El primer any s'establiren dos estacions de mostratge a cadascun dels rius. Destaca el fet que als dos últims anys d'estudi (2005 i 2006) hi va haver una forta sequera que va fer que els trams més alts dels rius Vallanca i Villahermosa s'assecaren, perdent-se tres de les setze estacions establertes. En total es mostrejaren 50 trams en els quatre anys de mostratge.

Per a la caracterització de l'hàbitat va ser adaptat el protocol de mostratge "Basinwide Visual Estimation Technique - BVET". Aquesta tècnica consisteix en estratificar visualment la llera segons els seus diferents biòtops (unitats hidromorfològiques o mesohàbitats), donant-se en ells les distintes característiques hidromorfològiques. En aquest estudi s'establiren quatre tipus de mesohàbitats bàsics; tolles, planes, corrents i ràpids. En cadascun dels mesohàbitats s'amidaren en camp les següents variables: longitud del mesohàbitat, amplada mitjana de la llera, profunditat mitjana, profunditat màxima i profunditat d'abocador. També es va calcular l'índex de refugi i la densitat de restes de fusta dins de la llera. Finalment es va estimar visualment els percentatges de substrat, segons la classificació de l'American Geophysical Union, ombreig sobre la llera i recobriment per materials fins. Altres variables sintètiques com ara el volum i la distància relativa entre ràpids també varen ser emprades en distints 
Per altra banda, les truites foren mostrejades mitjançant pesca elèctrica en cada mesohàbitat. La mida de les poblacions de peixos fou estimada per captures successives, realitzant com a mínim tres passades sense reemplaçament, i amb un esforç constant, sempre amb els mesohàbitats tancats amb xarxes. En total es varen obtenir 1188 truites de diferents mides en els quatre anys de mostratge. A tots els peixos extrets se'ls amidà la longitud furcal i el seu pes. A la majoria dels individus de més d'un any d'edat se li varen extreure escates per a la seua posterior anàlisi. Les edats foren establertes en el laboratori mitjançant l'anàlisi de les freqüències de longituds i verificades mitjançant la lectura de les escates de la mostra de peixos.

Les variables dels mesohàbitats ens han permès la caracterització robusta dels hàbitats. Gràcies a les propietats e la matriu de proximitat, es va estudiar la variabilitat de la classificació. Per a açò es va calcular l'índex de fortalesa de la classificació i s'emprà l'escalat multidimensional mètric. A més, s'identificaren i agruparen els factors que més influeixen en la variabilitat de les lasses. Tot açò ha permès observar l'homogeneïtat i aïllament de les classes establertes a priori, detectant aquelles classes amb major variabilitat. Els resultats indiquen que els rius Villahermosa i Ebrón són més estables que no el Vallanca i Palància, les corrents i planes són més estables que tolles i ràpids. A més tant els mesohàbitats ràpids (corrents i ràpids) com els mesohàbitats lents (tolles i planes) es tendeixen a agrupar. Finalment, es detectaren els factors més influents en la variabilitat de les tolles en els rius Vallanca i Palància (els mesohàbitats de major variabilitat).

Pel que fa a les poblacions de truita comuna, es calcularen les longituds, el pes i el ràtio de creixement anual per classe d'edat. També es calcularen les mitjanes de les abundàncies (densitat i biomassa), la producció, el ràtio de renovació $P / B$, la relació entre la longitud i el pes (equació de Ricker) i les corbes de creixement de Von Bertalanffy. Per a açò, s'empraren mètodes robustos en l'estimació de les variables. Els resultats ens han permès observar que el creixement en la longitud de les truites és gran, que hi ha una considerable variació en densitat i biomassa mitjana dels rius, que la producció anual és baixa i que el ràtio de renovació anual presenta valors molt baixos en comparació amb altres poblacions de truita en rius d'Europa i Amèrica. $A$ més, es detectà una relació densodepenent entre la longitud i la densitat de les truites immadures en els rius Vallanca i Palància.

Per altra banda, en cadascun dels rius les densitats de truita comuna són controlades per factors denso-independents, la rellevància i jerarquia del quals, en la majoria dels caos, són desconeguts per els gestors mediambientals. L'estratificació dels 
mostratges segons tipus de mesohàbitats ens va permetre estudiar quines característiques físiques del mesohàbitat tenen major rellevància en la variació de la densitat, tant per a la truita inmadura ( $<2$ anys) com per a la adulta ( $\geq 2$ anys), en cadascun del rius estudiats. Per a açò es va realitzar per a cadascun del rius una anàlisi de correspondència simple i es comprovaren les correlacions per rangs de Spearman entre les densitats i les característiques físiques de l'hàbitat. S'observa, gràcies a les correlacions de Spearman, que totes les variables de I'hàbitat amb l'excepció del substrat fi, han estat correlacionades de forma significativament amb la densitat de truita en alguns dels mapes de l'Ebrón, Vallanca i Villahermosa. No obstant, en cadascun dels rius són diferents les variables físiques correlacionades amb la densitat, amb l'excepció de la truita adulta als rius Vallanca i Villahermosa on, en ambdós casos, existeix una correlació positiva amb la profunditat i el volum. Per contra, no es va observar cap relació entre les densitats de truita comuna i les variables físiques del riu Palància.

També s'analitzaren les relacions existents entre les densitats d'adults i inmadures i les variables de l'hàbitat per a dos biòtops diferents; primer per als mesohàbitats lents (tolles i planes) i segon per als mesohàbitats ràpids (corrents i ràpids). Mitjançant Models Additius Generalitzats (GAM) s'han avaluat el grau de relació entre les poblacions de truita i els seus mesohàbitats. Els resultats obtinguts ens mostren un alt grau d'associació entre la densitat de truita adulta e inmadura i algunes de els principals característiques dels mesohàbitats lents i ràpids. A més, s'observà per una banda, que la truita inmadura disminueix d'acord amb el volum en els dos tipus de mesohàbitat establerts i, per altra banda, l'adulta en els mesohàbitats lents es relaciona amb la profunditat màxima i la distància relativa entre ràpids, mentre que als ràpids es relaciona amb l'índex de refugi. Aquestes quatre variables predictives podrien ser indicadores de la territorialitat de l'espècie per la disponibilitat d'aliment i refugi.

Finalment, s'utilitzaren models de lògica difusa per a l'estudi d'idoneïtat de l'hàbitat de la truita comuna mediterrània. Posteriorment foren comparats amb models Random Forests. Per a açò, es va aplicar un algoritme heurístic de "Nearest Ascent Hill-Climbing" en la optimització de les regles difuses i de Random Forests. No es varen observar diferències significatives en la representació dels models entre el model òptim difús i el model Random Forests, i ambdues aproximacions seleccionaren l'amplada del riu, l'índex de refugi i la velocitat del flux com a les variables més importants per a descriure la idoneïtat de l'hàbitat de la truita comuna. A més, els models difusos combinaren la rellevància ecològica com una acceptable 
interpretabilitat mentre que fou limitada la transparència dels models Random Forests. Per tant, els models difusos podrien ser una eina de suport en l'avaluació de decisions en la gestió dels rius i augmentar la comunicació de les parts interessades. 


\section{SUMMARY}

In this thesis, the populations of brown trout (Salmo trutta) inhabiting the region of Valencia were studied and compared, as well as the characteristics of the habitats and the relations habitat-abundance, from different perspectives and with different statistical techniques. The study was done in the remaining populations of brown trout in the region, in rivers and streams with Mediterranean conditions and relevant habitat variability. The study was carried out in the 4 rivers where native brown populations exist, Ebron and Vallanca (Valencia province), Palancia and Villahermosa (Castellon province). The surveys took place during the summer, from the year 2003 to 2006.

The habitat characterization followed a field protocol adapted from the Basinwide Visual Estimation Technique, BVET, of common application in some areas of the United States of America by the U.S. Forest Service. In this case, 4 basic types of mesohabitats or hydromorphological units were identified, i.e. pool, glide, riffle and rapid. Every mesohabitat in the study sites (300 m long, around the units of electrofishing) was identified and characterized with these variables: length, mean width, mean depth, maximum depth, and depth of the tail crest in the pools. An index of cover designed in Spain was estimated, as well as the woody debris (number and size by classes). The percentages of substrate types were visually estimated, based on a simplified version of the classes of the American Geophysical Union. Other variables were derived in the laboratory, such as the volume of water in the mesohabitat and relative distance between riffles. Also mean velocity was estimated for the analyses of habitat by fuzzy logic. The total number of mesohabitat units sampled (physical properties) in the 4 years was of 964 .

The trout populations were sampled by electro-fishing by mesohabitats. The field method was the removal without replacement, with 3 passes, and the assessment was based on the method of Carle and Strub. The total number of trouts captured in the 4 years was of 1188 .

The habitat characterization allowed the analyses with robust statistical techniques. The classification of mesohabitats in the four classes was evaluated, based on the variability within and among classes. The variables more relevant for the habitat variability were identified. The results indicated that the rivers Villahermosa and 
Ebron were more stable and homogeneous than Vallanca and Palancia. The riffles and glides were more homogeneous than pools and rapids.

The length, weight, growth, density, biomass and production of the populations were evaluated and compared with other trout rivers where relevant monitoring were published. The calculations were based on robust statistical methods. The growth in length was large, and there was a notable variability in density and biomass among rivers. The annual production was low and the turnover ratio was very low, in comparison with other trout rivers in Europe and North America. Finally, the lengthweight relation (Ricker equation) and the growth curves following Von Bertalanffy model were calculated. A density-dependent relation was found between the fork length and small trout density in two rivers, Vallanca and Palancia.

In order to relate the habitat characteristics and the fish abundance, and to detect density-independent relations, a correspondence analysis was performed with Spearman ranks, including all the habitat variables and fish density. The results indicated that all the variables (except fine substrate) were relevant for fish density in some of the rivers (except the river Palancia), and the critical variables varied with the rivers. The results also indicated the high variability among study sites.

The relations habitat-abundance were also analyzed separately for inmatures $(<2$ years) and adults ( $\geq 2$ years), and separately for slow (pool/glide) and fast water (riffle/rapid) mesohabitats. With a multivariate approach, models of Generalized Additive Models (GAM) were calculated, and several relations were demonstrated. The density of inmatures trout was negatively related with the mesohabitat volume, both in slow and fast water habitats. The density of adult brown trout, in slow habitats, was positively related with maximum depth and the distance between riffles; in fast water habitats, the density increased with the cover index.

Finally, also fuzzy logic models of fish density were applied with mesohabitat variables, in comparison with random forests. There were no important differences in performance between the 2 approaches, both demonstrating the relevance of mean width, cover index and mean water velocity (at mesohabitat scale) to interpret the trout density. The fuzzy models combined the ecological relevance of the results with the model transparency, and they are easier to interpret for managers, therefore they mean a good tool to help in decision making about river restoration and management, for the conservation of the Mediterranean brown trout in the Iberian Peninsula. 


\section{CAPÍTULO 1}

\section{INTRODUCCIÓN Y OBJETIVOS}

\section{INTRODUCCIÓN GENERAL}

Los peces continentales son animales vertebrados que viven en nuestros ríos y que han despertado un interés variado a lo largo de la historia; desde un aspecto histórico-cultural al meramente de subsistencia como fuente de alimentación. Sin embargo en los dos últimos siglos, se ha desarrollado un creciente interés como elemento de manipulación e investigación en ciencias básicas o aplicadas, creándose una disciplina nueva llamada ictiología, que es la ciencia que estudia los peces (Granado-Lorencio, 2002). Ésta tiene como una de sus principales bases la evaluación de las poblaciones de peces, encaminados a definir el conjunto de los individuos de una misma especie que vive en un espacio común (García de Jalón et al., 1993).

Dentro del marco de la ictiología fluvial, la familia Salmonidae contiene los peces que más han interesado al hombre, debido a su interés gastronómico, económico así como deportivo. La trucha común (Salmo trutta) es una de las especies más estudiadas en la literatura científica mundial, debido en parte a su alta plasticidad ecológica que le ha hecho que la especie esté ampliamente distribuida por el mundo (MacCrimmon, 1968). En este sentido, Northcote y Lobón-Cerviá (2007) revisaron la literatura científica referente a la trucha en los últimos veinte años. Esta revisión pone de manifiesto el aumento de los estudios experimentales en las dos últimas décadas sobre las poblaciones de truchas en cuanto al estudio de los alevines y juveniles, al establecimiento de la estructura poblacional (con su edad, tamaño, crecimiento y producción) y los estudios que tratan sobre la interacción entre hábitats y truchas.

En la Península Ibérica existe un solo género autóctono, Salmo, que incluye al salmón del atlántico (Salmo salar), al reo y a la trucha común (Salmo trutta). Debido al gran desarrollo de las técnicas genéticas en los últimos tiempos y a su rápida aplicación a los peces, hoy en día sabemos cómo han evolucionado las poblaciones de truchas en la Península Ibérica. Machordom et al. (2000) muestran cinco linajes o distribuciones biogeográficas de las poblaciones de trucha autóctona, dependiendo del contenido genético haploide del ADN mitocondrial. Estos linajes corresponderían a las cuencas o 
ríos donde habitan; los ríos meridionales andaluces, los que desembocan en el mar Cantábrico y en el Mediterráneo y las cuencas del Duero y del Tajo.

Si nos centramos en el área geográfica de la Comunidad Valenciana, la familia Salmonidae solamente está representada por la especie Salmo trutta y correspondería al linaje mediterráneo, anteriormente mencionado. Se localiza en ríos de cabecera y en las últimas décadas el área de distribución en los ríos valencianos ha disminuido, aparentemente, de forma drástica (Alcaraz-Hernández et al., 2007). Hoy en día la especie sólo habita de forma natural los tramos altos de los ríos Ebrón y Vallanca (en la provincia de Valencia), Villahermosa y Palancia (en la provincia de Castellón). Un estudio genético sobre estas poblaciones, instado por la Consellería de Medio Ambiente, Agua, Urbanismo y Vivienda de la Comunidad Valenciana y realizado por el Departamento de Genética de la Universidad de Santiago de Compostela, ha demostrado que las truchas autóctonas conservan un linaje mediterráneo aproximadamente del 86\% en el Villahermosa, 80\% en el Palancia, $42 \%$ en el Ebrón y $58 \%$ en el Vallanca, frente a otros linajes alóctonos de origen atlántico $(14,20,0$ y $32 \%$ respectivamente) y adriático. También ha demostrado que, aun existiendo poblaciones autosostenidas en el Turia, el origen genético de la trucha procede del atlántico.

Posiblemente, la causa de esta disminución aparente de la especie se debe, en parte, a la gran actividad humana que altera los ecosistemas fluviales (Boon et al., 1992; González del Tánago y García de Jalón, 2001). Las perturbaciones observadas son, entre otras, la fuerte regulación de los caudales, la destrucción del hábitat, la contaminación de las aguas, la introducción de especies exóticas, la sobrepesca y la introducción de genes foráneos como resultado de repoblaciones artificiales (Almodóvar et al., 2004; Ayllón et al., 2009). Como se ha visto en la Comunidad Valenciana, la introducción de especies exóticas ha derivado en una introgresión genética en las poblaciones de trucha del mediterráneo. García-Marín et al. (1999) concretó una pérdida anual del $5 \%$ en la ascendencia genética autóctona de la trucha común del Pirineo oriental, cada vez que se repoblaba con trucha centroeuropea.

Por otro lado, muchos estudios se han centrado en observar y describir los procesos que desencadenan la disminución de las poblaciones de peces. El entendimiento de la ecología de los ríos ha ido evolucionando históricamente. Uno de los principales retos que se plantearon en las primeras investigaciones fue definir y entender los procesos y características que influyen sobre los sistemas fluviales, ya que la forma de un río y los procesos que se generan en ellos, se envuelven simultáneamente hacia 
un ajustamiento mutuo, la autoregulación. Si a esto le añadimos la fuerte influencia que ejercen sus características y procesos en la distribución y abundancia de los organismos acuáticos, se entiende el gran esfuerzo realizado por los investigadores en establecer diferentes tipos de clasificaciones en los sistemas fluviales. Hay que remontarse a finales del siglo XIX en el inicio de las clasificaciones de ríos, cuando Davis (1899) lo dividió según el estado de madurez en las etapas de juventud, madurez y senectud, pero fue a lo largo siglo XX, cuando se desarrollaron y se establecieron la mayoría de ellas (ver Rosgen, 1994). Fue Leopold et al. (1964) quienes describieron ocho variables observables que influyen directamente sobre los patrones morfológicos: anchura del cauce, profundidad, velocidad, pendiente, rugosidad de los materiales, descarga y tamaño de sedimentos, apuntando que un cambio en alguna de estas variables supone un ajustamiento de las otras en el río, alterando las características del cauce hasta establecerse de nuevo un equilibrio. No obstante, la mayoría de estas clasificaciones fueron establecidas por hidrólogos y geomorfólogos fluviales basándose en las leyes de la física y en los procesos fluviales relacionados. No siempre estas clasificaciones se ajustaban a los intereses en el estudio de la biología acuática, por lo que hubo investigadores que desarrollaron distintas clasificaciones de ríos más acorde a los organismos que los habitan (Bisson et al., 2006). Las primeras clasificaciones biológicas se establecieron en ríos europeos. Al principio se basaron en zonas marcadas por los cambios de las especies dominantes, como son los peces, desde la cabecera del río hasta su desembocadura (Hawkes, 1975). Progresivamente se han ido incluyendo los efectos de los procesos físicos y los tipos de perturbación que afectan a los cambios en la fauna (Statzner y Higler, 1986; Zalewski y Naiman, 1985), así como propiedades hidráulicas y geomorfológicas de los cauces para determinados tipos de organismos acuáticos (Sullivan et al., 1987; Hawkins et al., 1993; Stanford et al., 2005).

Por regla general, las investigaciones realizadas sobre los ecosistemas acuáticos están dominadas por estudios llevados a cabo en pequeñas áreas y en cortos periodos de tiempo. Esta tendencia está generalizada en ecología. May (1994) revisó la literatura ecológica publicada y concluyó que muy pocas investigaciones tenían una extensión espacial mayor de 10 metros o una durabilidad en el tiempo de más de un año. Un análisis amplio, múltiple y espacial puede proveer de conocimientos críticos sobre el funcionamiento del ecosistema y una información básica en la toma de decisiones. Por ejemplo, los peces pueden responder a diferentes fracciones del hábitat a diferentes niveles. Los estudios multivariantes pueden identificar estas fracciones, sugerir su importancia para los peces en diferentes épocas y distinguir los procesos naturales responsables de su mantenimiento y crecimiento. 
Este análisis multiescalar surge de la teoría jerárquica. Esta teoría formaliza la manera en que el ecosistema tiene distintos niveles a lo largo de dos ejes; el tiempo y el espacio. Además existen diversos subsistemas dispuestos jerárquicamente (O'Neill, 1989; Allen y Hoekstra, 1992). Cada nivel de jerarquía está diferenciado por procesos específicos y estructurales. Los niveles altos son conducidos por procesos más suaves que generan patrones espaciales más groseros y estables en el tiempo, mientras los niveles más bajos están conducidos por procesos más rápidos que generan patrones espaciales más finos e inestables en el tiempo. El concepto de limitación es una consecuencia importante en la disposición jerárquica, cada nivel está limitado por sus procesos bióticos y abióticos medioambientales y por sus recursos (O’Neill, 1989). El enfoque de que el hábitat es clave para la estructura de la comunidad y su organización, ha sido integrado en la ecología de los ríos, por ejemplo en el concepto de río continuo (Vannote et al., 1980) y procesos dominantes (Montgomery, 1999), y también en el marco jerárquico multiescalar de Frissell et al. (1986).

El entendimiento actual de los ríos ha incorporado un marco conceptual de factores generales relacionados a gran escala como el clima, la geología y la topografía en que influyen a los procesos geomorfológicos que dan forma a los canales de escalas intermedias y en consecuencia a menor escala crea y mantienen los hábitats de importancia para la biota (Allan, 2004). En este sentido, Frissell et al. (1986) asumieron la premisa de que los patrones biológicos de los ríos son controlados y ajustados por patrones físicos y que el mayor problema que presentan es el entendimiento de éstos a través del tiempo y el espacio. Así pues, ellos desarrollaron una clasificación jerárquica natural del hábitat aplicable a ríos pequeños con un orden menor de cuatro que van desde una escala grande espacial a nivel de cuenca vertiente (río) hasta escalas sucesivas más pequeñas como un segmento fluvial, el tramo o sector fluvial, los biotopos individuales del hábitat del canal, como por ejemplo las poza y los rápido (también conocido como unidades hidromorfológicas o mesohábitat) y el microhábitat (figura 1.1). Cada nivel de jerarquía se desarrolla y persiste predominantemente a una escala espaciotemporal específica. 

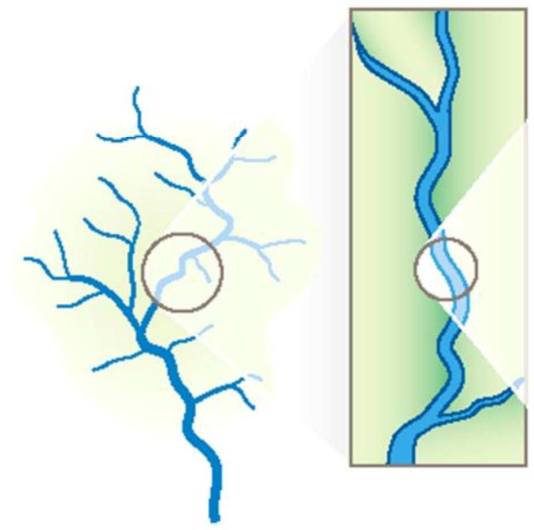

Segmentos de ríos

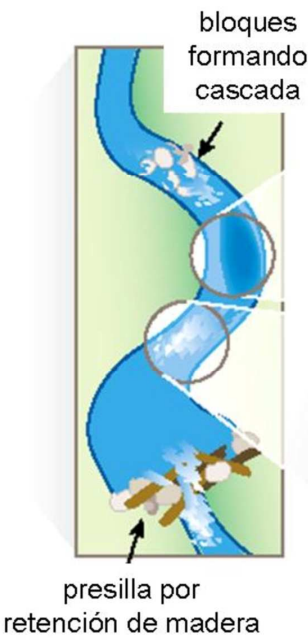

Tramos de ríos

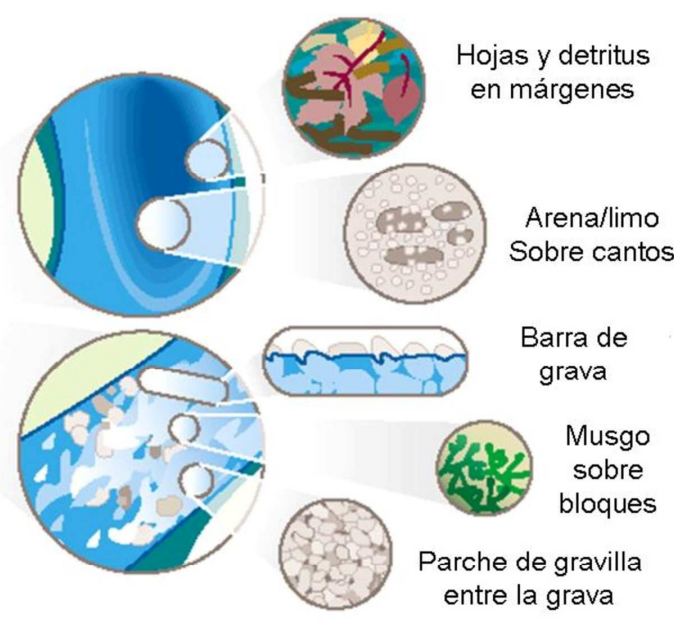

Mesohábitats

Microhábitats

Figura 1.1. Organización jerárquica de los sistemas acuáticos lóticos y su división en subsistemas del hábitat (figura adaptada de Frissell et al., 1986).

Hay varias razones para utilizar esta clasificación (Bisson et al., 2006). La primera puede ser simplemente la descripción de los cambios físicos en el tiempo en respuesta a los impactos humanos o los disturbios naturales (Buffington et al., 2003). Una segunda razón puede ser para muestrear distintas áreas de un río para su comparación y poder extrapolar resultados a otras áreas de similar características (Dolloff et al., 1993; Hankin y Reeves, 1988). Un tercer objetivo en la clasificación de los ríos puede ser determinar la idoneidad de un río para albergar alguna alteración del hábitat en respuesta a las actividades producidas por el hombre (Reice, 1994). Por último, una descripción exacta de los ríos y de sus unidades hidromorfológicas es un importante primer paso en la descripción de los requerimientos ecológicos de los organismos durante su vida así como los procesos que influyen en su abundancia y distribución (Schlosser, 1987). 


\section{MACROHÁBITAT}

MESOHÁBITAT

Transporte de sedimentos y transformación de la materia orgánica

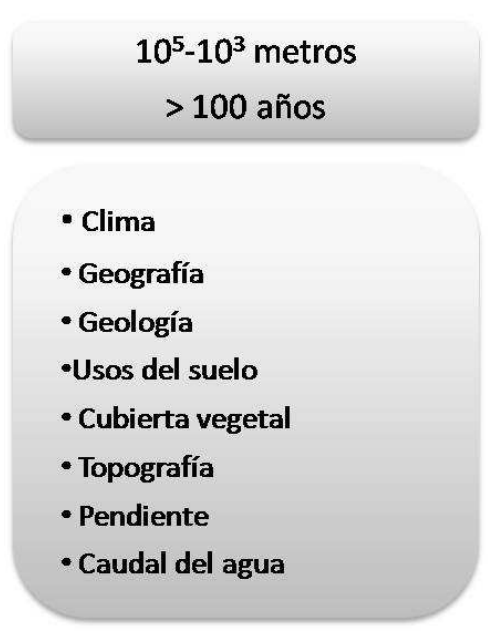

Caracterización del hábitat

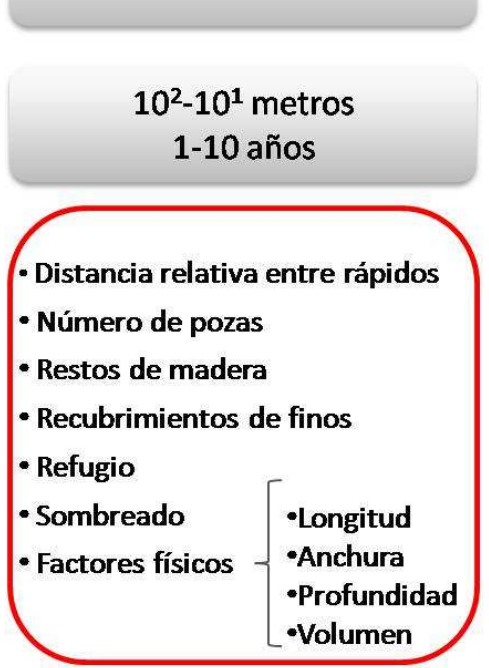

\section{MICROHÁBITAT}

Disponibilidad y uso del hábitat

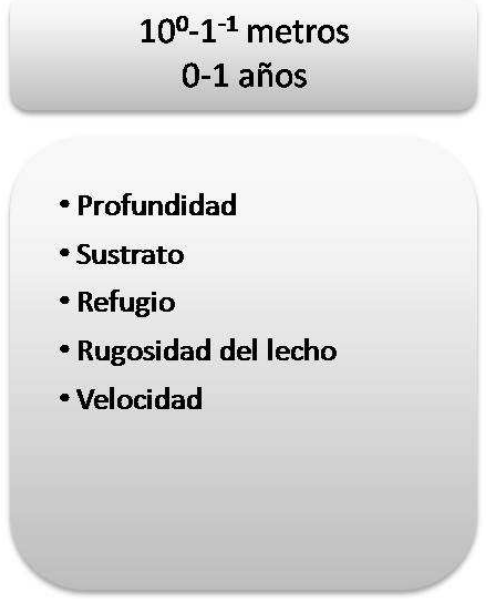

Figura 1.2. Esquema de los enfoques para el estudio del hábitat en los ríos y su relación con la distribución y abundancia de poblaciones de peces. En tres grupos se organizan los procesos, la escala espacio-temporal y las principales variables que afectan a los peces. Esta tesis esta desarrollada mediante la variables encuadradas en rojo (figura de elaboración propia adaptada de Frissell et al., 1986 y Bisson et al., 2006).

Por lo tanto, esta tesis pretende ahondar en el conocimiento de las poblaciones de trucha común en los ríos mediterráneos a través del estudio de sus hábitats, desde un prisma jerárquico como es el estudio de sus unidades hidromorfológicas o mesohábitat (figura 1.2). Así pues, esta investigación prosigue con estudios previos sobre trucha llevados a cabo por el recién creado Instituto de Investigación para la Gestión Integrada de Zonas Costeras de la Universidad Politécnica de Valencia (Alcaraz-Hernández et al., 2007 y 2009). Además, más allá del análisis de la trucha y de sus hábitats y gracias al uso de diferentes técnicas estadísticas para crear modelos de abundancia y distribución de la trucha común, un objetivo que subyace a esta tesis es el uso y comparación de distintos análisis aplicados al procesado de datos ecológicos. 


\section{OBJETIVOS GENERALES}

Siguiendo la línea argumentativa de la introducción, se pretende con esta tesis alcanzar principalmente tres objetivos:

- El primero de ellos es la caracterización de los ríos de la Comunidad Valenciana donde reside la trucha común mediterránea mediante sus atributos físicos.

- El segundo es caracterizar las poblaciones de trucha común mediterráneas y compararlas con otras poblaciones del mundo.

- Finalmente, se pretende comprender como las propiedades físicas del hábitat (a escala de mesohábitats) condicionan a las poblaciones de trucha, en el marco de un estudio multiespacial y sobre un periodo de tiempo de cuatro años, mediante análisis cualitativos y cuantitativos.

Para obtener estos tres objetivos generales, en cada uno de los capítulos $(3,4,5,6,7$ y 8) se ha planteado objetivos específicos, como se explica a continuación.

\section{OBJETIVOS ESPECÍFICOS}

En este primer capítulo se ha pretendido encuadrar los antecedentes científicos de estudios sobre la trucha común mediterránea. Para ello, se han compilado un conjunto de antecedentes de la especie a través de la literatura científica, con el fin de trazar una línea argumentativa clara que nos permita el entendimiento de la problemática de estudio.

El segundo capítulo sitúa a la trucha dentro de un contexto real (su área de estudio) mediante la descripción detallada de las características medioambientales más relevantes. En éste se ubican geográficamente tanto los ríos como sus tramos de estudio, se caracterizan éstos mediante sus atributos físicos y sus características químicas más relevantes de sus aguas. Por último, se describe tanto la vegetación de ribera de cada río como la comunidad de peces que lo habita.

A nivel específico, el capítulo 3 está dedicado exclusivamente a los cuatro ríos mediterráneos en donde se realizó la investigación, Ebrón, Vallanca, Palancia y Villahermosa. En él se analiza el hábitat a tres escalas diferentes, ríos, mesohábitats y río-mesohábitats. El objetivo general fue evaluar la clasificación del hábitat utilizada, según sus unidades hidromorfológicas en ríos trucheros mediterráneos del levante 
español. Concretamente, el primer objetivo fue desarrollar una metodología robusta para evaluar los tipos de hábitats utilizados en la clasificación, y el segundo objetivo fue reconocer los factores hidromorfológicos que más influyen en su variabilidad espacial. Para ello, se caracterizaron los ríos y sus unidades hidromorfológicas mediante sus atributos físicos, se midió la variabilidad y la fortaleza de su clasificación, analizando la matriz de proximidad, y se propuso un método para identificar los factores que más influyen en la variabilidad de las clases.

El capítulo 4 está pensado como un punto de partida en donde se establece el estatus de la trucha común de linaje mediterráneo, a través de sus rangos de crecimiento, densidad, biomasa y producción. Los objetivos fueron establecer los rangos del crecimiento, las densidades y biomasas y las producciones de cuatro poblaciones mediterráneas de trucha común, así como comparar dichas poblaciones de ríos mediterráneos del este de la Península con otras poblaciones del mundo. Para ello se realizó un seguimiento en la época estival durante cuatro años, se calcularon los parámetros poblacionales y se revisó la literatura científica comparando los resultados con otras poblaciones mundiales donde se realizaron seguimientos poblacionales relevantes.

En el capítulo 5 se muestra el crecimiento de las distintas poblaciones de trucha, y se explora la posible relación de denso-dependencia entre el crecimiento y la densidad de cada clase de edad. Para este fin, se analizaron la relación longitud-peso (ecuación de Ricker) y las curvas de crecimiento de Von Bertalanffy en los cuatro ríos de estudio. Además se contrastó la relación entre el crecimiento somático (según la longitud del pez) y la densidad.

El capítulo 6 ahonda en las relaciones que existen entre las características físicas y las densidades en cada río por separado. Este capítulo pretende contestar a las preguntas de si existe alguna relación entre las características físicas de los hábitats y las densidades de trucha para cada uno de los ríos estudiados, y si es así, qué características son las más destacables. Para esta finalidad, se distinguió entre densidad de trucha inmadura ( $<2$ años) y adulta ( $\geq 2$ años). Por otro lado, se aplicó la técnica estadística de análisis de correspondencias simple debido a que el número de individuos de la muestra disminuyó al aumentar la estratificación del estudio, a una escala de trabajo de río.

El capítulo 7 analiza cómo ciertas características físicas de los mesohábitats, con los datos de todos los ríos, influyen sobre las densidades de truchas inmaduras o de adultas. En concreto se intentó contestar a las siguientes cuestiones: ¿se puede 
obtener modelos multivariantes no lineales significativos de abundancia de trucha común, en función de las variables físicas a escala de mesohábitat? y ¿se observa algún patrón entre las distintas variables físicas de los distintos tipos de mesohábitat? Para este propósito se analizaron las densidades con los factores físicos en dos casos diferentes; específicamente para los mesohábitats lentos (pozas y corrientes), para los mesohábitats rápidos (corrientes y rápidos). Para ello, se aplicó los modelos generalizados aditivos (GAM) teniendo como variables respuesta la densidad de trucha inmadura y la adulta.

Por último, el capítulo 8 aplica el análisis de datos con técnicas estadísticas de reciente actualidad como son la lógica difusa y Random Forests para el desarrollo de los modelos de distribución de especies, en concreto, el estudio de idoneidad de la trucha común en la región mediterránea. El objetivo fue testar las reglas difusas de optimización en el desarrollo de modelos de distribución fiables y ecológicamente relevantes. Para ello, se comparó la selección de variables mediante la optimización de reglas difusas y de reglas Random Forests. Además, se evaluó la relevancia ecológica de los modelos desarrollados y se discutió su aplicabilidad. Estos modelos permiten predecir el efecto de diferentes impactos en el sistema fluvial y seleccionar la mejor opción de restauración. Debido a la universalidad y la flexibilidad a la aproximación de la realidad que se presenta en estos modelos, estos podrían aplicarse fácilmente a otras especies, así como a otros ríos y a otros niveles de escala. Por lo tanto, este enfoque podría ser una herramienta de apoyo en las decisiones de los gestores de los ríos y mejorar la comunicación entre las partes interesadas, debido a la sencillez lingüística de las reglas difusas.

Finalmente, en el capítulo 9 se recogen las conclusiones más relevantes obtenidas en los anteriores capítulos y que resumen, a modo de sumario, las ideas fundamentales derivadas de esta tesis. 


\section{BIBLIOGRAFÍA}

Alcaraz-Hernández, J.D., F. Martínez-Capel, M. Arenas Sáez, V. Garófano Gómez. 2009. Relationships between mesohabitat characteristics and brown trout populations in Mediterranean streams (Comunidad Valenciana, Spain). Proceedings of the VII International Symposium on Ecohydraulics. IAHR - Universidad de Concepción. Concepción (Chile).

Alcaraz-Hernández, J.D., F. Martínez-Capel, M. Peredo y A.B. Hernández-Mascarell. 2007. Relaciones entre densidades y biomasas de Salmo trutta fario y mediciones del mesohábitats en tramos trucheros de la Comunidad Valenciana. Limnetica 26: 159-167.

Allan, J.D. 2004. Landscapes and Riverscapes: The influence of land use on stream ecosistems. Annual Review of Ecology, Evolution, and Systematics 35: 257-284.

Allen, T.F.H. y T.W. Hoekstra. 1992. Toward a unified ecology: complexity in ecological systems. Columbia University Press, New York, New York.

Almodóvar, A. y Nicola, G.G. 2004. Angling impact on conservation of Spanish streamdwelling brown trout Salmo trutta. Fisheries Management and Ecology, 11: 173-182.

Ayllón, D., A. Almodóvar, G.G. Nicola y B. Elvira. 2009. Interactive effects of cover and hydraulics on brown trout habitat selection patterns. River Research and Applications 25: 1051-1065.

Bisson, P.A., J.M. Buffington y D.R. Montgomery. 2006. Valley segment, stream reaches, and channel units. En: F.R. Hauer y G. A. Lamberti, editors. Methods in stream ecology. Academic Press, San Diego, California, USA.

Boon, P.J., P. Calow y G.E. Petts. 1992 (eds). River conservation and management. John Wiley \& Sons Ltd.

Buffington, J.M., R.D. Woodsmith, D.B. Booth y D.R. Montgomery. 2003. Fluvial processes in puget sound rivers and the pacific northwest. En: D. R. Montgomery, S. Bolton, D. B. Booth y L. Wall (Eds.) Restoration of Puget Sound Rivers. University of Washington Press, Seattle, USA.

Davis, W.M., 1899. The geographical cycle. Geographical Journal 14: 481-504.

Dolloff, C.A., D.G Hankin y G.H. Reeves. 1993. Basinwide estimation of habitat and fish populations in streams. Gen. Tech. Rep. SE83. Asheville, NC: U.S. Department of Agriculture, Forest Service, Southeastern Forest Experiment Station. 25 pp. 
Frissell, C.A., W.J. Liss, C.E. Warren y M.D. Hurley. 1986. A hierarchical framework for stream habitat classification: viewing streams in a watershed context. Environmental Management 10: 199-214.

García de Jalón, D., M. Mayo, F. Hervella, E. Barceló y Fernández C. 1993. Principios y técnicas de gestión de la pesca en aguas continentales. Ediciones Mundi-Prensa.

García-Marín, J.L., N. Sanz y C. Pla. 1999. Erosion of the native genetic resources of brown trout in Spain. Ecology of Freshwater Fish 8: 151-158.

González del Tánago, M. y D. García de Jalón. 2001. Restauración de ríos y riberas. Fundación Conde del Valle Salazar. Escuela Técnica Superior de Ingenieros de Montes. Universidad Politécnica de Madrid. 319 pp.

Granado-Lorencio, C. 2002. Ecología de peces. Secretariado de Publicaciones, Universidad de Sevilla, Sevilla, 353 pp.

Hankin, D.G. y G.H. Reeves. 1988. Estimating total fish abundance and total habitat area in small streams based on visual estimation methods. Canadian Journal of Fisheries and Aquatic Sciences 45: 834-844.

Hawkes, H.A. 1975. River zonation and classification. En: B.A. Whitton (Ed.). River Ecology. Blackwell Scientific, Oxford, UK.

Hawkins, C.P., J.L. Kershner, P.A. Bisson, M.D. Bryant, L.M. Decker, S.V. Gregory, D.A. McCullough, C.K. Overton, G.H. Reever, R.J. Steedman y M.K. Young. 1993. A hierarchical approach to classifying stream habitat features. Fisheries 18: 3-12.

Leopold, L.B., M.G. Wolman y J.P. Miller. 1964. Fluvial processes in geomorphology. Freeman, San Francisco, CA, 522 pp.

MacCrimmon, H.R., T.L. Marshall y B.L. Gots. 1970. World distribution of brown trout, Salmo trutta: further observations. Journal Fisheries Research Board Canada 27(4): 811-818.

Machordom, A., J. Suárez, A. Almodóvar y J.M. Bautista. 2000. Mitochondrial haplotype variation and phylogeography of Iberian brown trout populations. Molecular Ecology 9: $1325-1338$

May, R.M. 1994. The effects of spatial scale on ecological questions and answers. En: R.J. Edwards, M. May, N.R. Webb (eds). Large-scale ecology and conservation biology. Blackwell Scientific Publications, London.

Montgomery, D.R. 1999. Process domains and the river continuum. Journal of the American Water Resources Association 35(2): 397-410. 
Northcote, T.G. y J. Lobón-Cerviá. 2007. Increasing experimental approaches in stream trout research - 1987-2006. Ecology of freshwater fish 349-361.

O’Neill, R.V. 1989. Perspectives in hierarchy and scale. En: Roughgarten J, May RM, Levin SA, editors. Perspectives in ecological theory. Princeton University Press, Princeton, New Jersey.

Reice, S.R. 1994. Nonequilibrium determinants of biological community structure. American Scientist 82: 424-435.

Rosgen, D.L. 1994. A classification of natural rivers. Catena 22: 169-199.

Schlosser, I.J. 1987. A conceptual framework for fish communities in small warmwater streams. En: W. J. Matthews y D. C. Heins (Eds.). Community and Evolutionary Ecology of North American Stream Fishes. University of Oklahoma Press, Norman, USA.

Stanford, J.A., M.S. Lorang y F.R. Hauer. 2005. The shifting hábitat mosaic of river ecosystems. Verhandlungen der Internationale Vereinigung für theoretische und angewandte Limnologie 29: 123-136.

Statzner, B. y B. Higler. 1986. Stream hydraulics as a major determinant of benthic invertebrate zonation patterns. Freshwater Biology 16: 127-139.

Sullivan, K., T.E. Lisle, C.A. Dolloff, G.E. Grant y L.M. Reid. 1987. Stream channels: the link between forests and fishes. En: E.O. Salo y T.W. Cundy (Ed.). Streamside Management: Forestry and Fishery Interactions. Contribution number 57, Institute of Forest Resources, University of Washington, Seattle, Washington, USA.

Vannote, R.L., G.W. Minshall, K.W. Cummins, J.R. Sedell y C.E. Cushing. 1980. The river continuum concept. Canadian Journal of Fisheries and Aquatic Sciences 37: 130-137.

Zalewski, M. y R.J. Naiman. 1985. The regulation of riverine fish communities by a continuum of abiotic-biotic factors. En: J.S. Alabaster (Ed.). Habitat modifications and freshwater fisheries. Butterworth, London, UK. 


\section{CAPÍTULO 2}

\section{ÁREA DE ESTUDIO}

\section{SITUACIÓN GEOGRÁFICA}

La investigación se ha desarrollado a lo largo de cuatro ríos de montaña, a una altura comprendida entre los 575 y 951 metros sobre el nivel del mar. Todos ellos nacen en la cordillera Ibérica - al S.E. de España - y desembocan en el mar Mediterráneo. En ellos se han seleccionado 16 tramos (cuatro tramos por río) dentro de la Comunidad Valenciana, teniéndose en cuenta que se daban las condiciones necesarias para el desarrollo de poblaciones naturales de la trucha común autóctona (figura 2.1.).

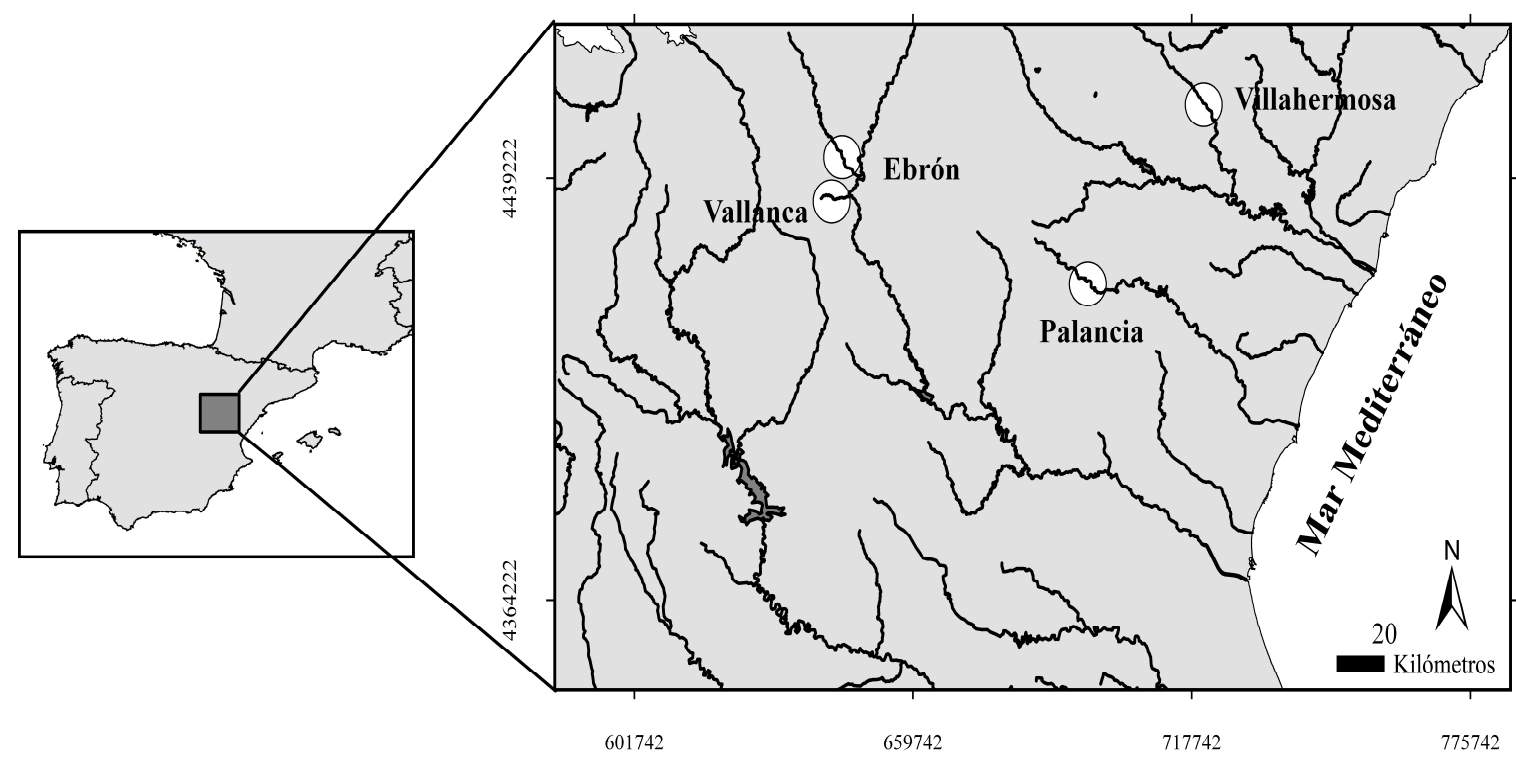

Figura 2.1. Mapa de localización de los ríos de estudio.

Los cuatro ríos de estudio son el Ebrón, Vallanca (o Bohilgues), Palancia y Villahermosa. El área de estudio de los ríos Vallanca y Ebrón se ubica en la comarca de "El Rincón de Ademuz", provincia de Valencia, ya que el primero nace y discurre enteramente en esta y el segundo pese a nacer en la provincia de Teruel entra a la Comunidad Valenciana por esta comarca. Por otro lado, el área de estudio del río Villahermosa se corresponde con la comarca de "El Alto Mijares", mientras que el río 
Palancia discurre por la comarca de "El Alto Palancia", ambos en la provincia de Castellón.

Todos los ríos estudiados son gestionados por la Confederación Hidrográfica del Júcar. El río Turia nace en los Montes Universales en la provincia de Teruel, y entra en la provincia de Valencia por el Rincón de Ademuz, en donde vierten sus tributarios Ebrón y Vallanca. Seguidamente deja tierras valencianas momentáneamente, para pasar por Cuenca y volver de nuevo a la provincia de Valencia, donde desemboca en el mar mediterráneo junto a la capital de la provincia.

El río Ebrón se emplaza entre las Comunidades de Aragón y de Valencia, siendo el principal afluente del Alto Turia en la comarca del Rincón de Ademuz. Asentado sobre la Sierra Javalambre (derivación del Sistema Ibérico), nace en la provincia de Teruel, penetra en el Rincón por la localidad de Cuesta del Rato, al Norte, y desemboca en el Turia en el término de Torrebaja. Unos cientos de metros más abajo en el río Turia, desemboca el río Vallanca, nacido más allá del término de Vallanca y que es incrementado en su curso por la Rambla de Negrón. Desemboca en el río Turia en el término de Ademuz.

El río Palancia nace en las estribaciones de la Sierra de Toro a 1618 metros de altitud, en la provincia de Castellón y limitando con la Comunidad de Aragón. Hasta su desembocadura cerca de la población de Sagunto, el río Palancia tiene una longitud de $85 \mathrm{~km}$. Los tramos trucheros se sitúan en los términos municipales de Bejís y Teresa, ubicados en la cabecera del río.

Por último, el río Villahermosa tiene su entrada en la Comunidad Valenciana por la provincia de Castellón y en sus comienzos en la provincia de Teruel recibe el nombre de Linares. Discurre encajonado al pie de la Sierra de Peñagolosa durante su trayecto de $60 \mathrm{~km}$, antes de desembocar, como principal afluente, en el río Mijares. Los términos municipales por los que discurre son Villahermosa del Río, Cedramán, Zucaina, Ludiente y Argelita.

\section{ESTACIONES DE MUESTREO}

La tabla 2.1 contiene las coordenadas UTM de los tramos de muestreo (huso 30 del Datum europeo 1950) así como su toponimia. En todos los ríos se establecieron cuatro tramos excepto en el Vallanca que fueron cinco. El motivo fue porque no se encontró una sucesión adecuada de mesohábitats lentos y rápidos de acuerdo con la 
metodología de los muestreos, por lo que se optó por la separación de unos metros de las dos estaciones. En todos los ríos el primer tramo es el más cercano al nacimiento, mientras que el cuarto es el más alejado.

Tabla 2.1. Coordenadas UTM de los tramos de muestreo así como su toponimia.

\begin{tabular}{|c|c|c|c|c|}
\hline \multirow{2}{*}{ Río } & \multirow{2}{*}{ TRAMO } & \multicolumn{2}{|c|}{ COORDENADAS } & \multirow{2}{*}{ TOPONIMIA } \\
\hline & & $x$ & $Y$ & \\
\hline \multirow{4}{*}{ Ebrón } & EB-1 & 643680 & 4445025 & Cuesta del Rato \\
\hline & EB-2 & 645225 & 4442762 & Minicentral de Castielfabib \\
\hline & EB-3 & 646046 & 4441285 & Los Santos \\
\hline & EB-4 & 647470 & 4440030 & Piscifactoría en Torrebaja \\
\hline \multirow{5}{*}{ Vallanca } & VA-1 & 641164 & 4436047 & Fuente La Teja \\
\hline & VA-2 & 643026 & 4435586 & Fuencaliente \\
\hline & VA-C3 & 645000 & 4435698 & Minicentral de Ademuz \\
\hline & VA-P3 & 645079 & 4435690 & Minicentral de Ademuz \\
\hline & VA-4 & 646426 & 4435932 & Ademuz \\
\hline \multirow{4}{*}{ Palancia } & PA-1 & 694345 & 4421349 & Las Torrecillas \\
\hline & PA-2 & 696812 & 4420750 & camino antiguo de Torás \\
\hline & PA-3 & 697599 & 4419537 & Cerro Molino \\
\hline & PA-4 & 699187 & 4418856 & Teresa \\
\hline \multirow{4}{*}{ Villahermosa } & VI-1 & 718192 & 4455305 & El Romeral \\
\hline & VI-2 & 720668 & 4452439 & Villahermosa \\
\hline & VI-3 & 721909 & 4450283 & Masía de Benages \\
\hline & VI-4 & 722694 & 4449592 & La Martina \\
\hline
\end{tabular}

\section{Río Ebrón}

El primer tramo de muestreo está ubicado en el término municipal de Cuesta del Rato (figura 2.2), junto al emplazamiento donde se realizan los campamentos de verano. La segunda zona de muestreo se encuentra aguas abajo de la minicentral hidroeléctrica en el término municipal de Castielfabib. El tercero se encuentra en la zona recreativa de Los Santos. El cuarta y último tramo está ubicado a la altura de la piscifactoría del término municipal de Torrebaja. 


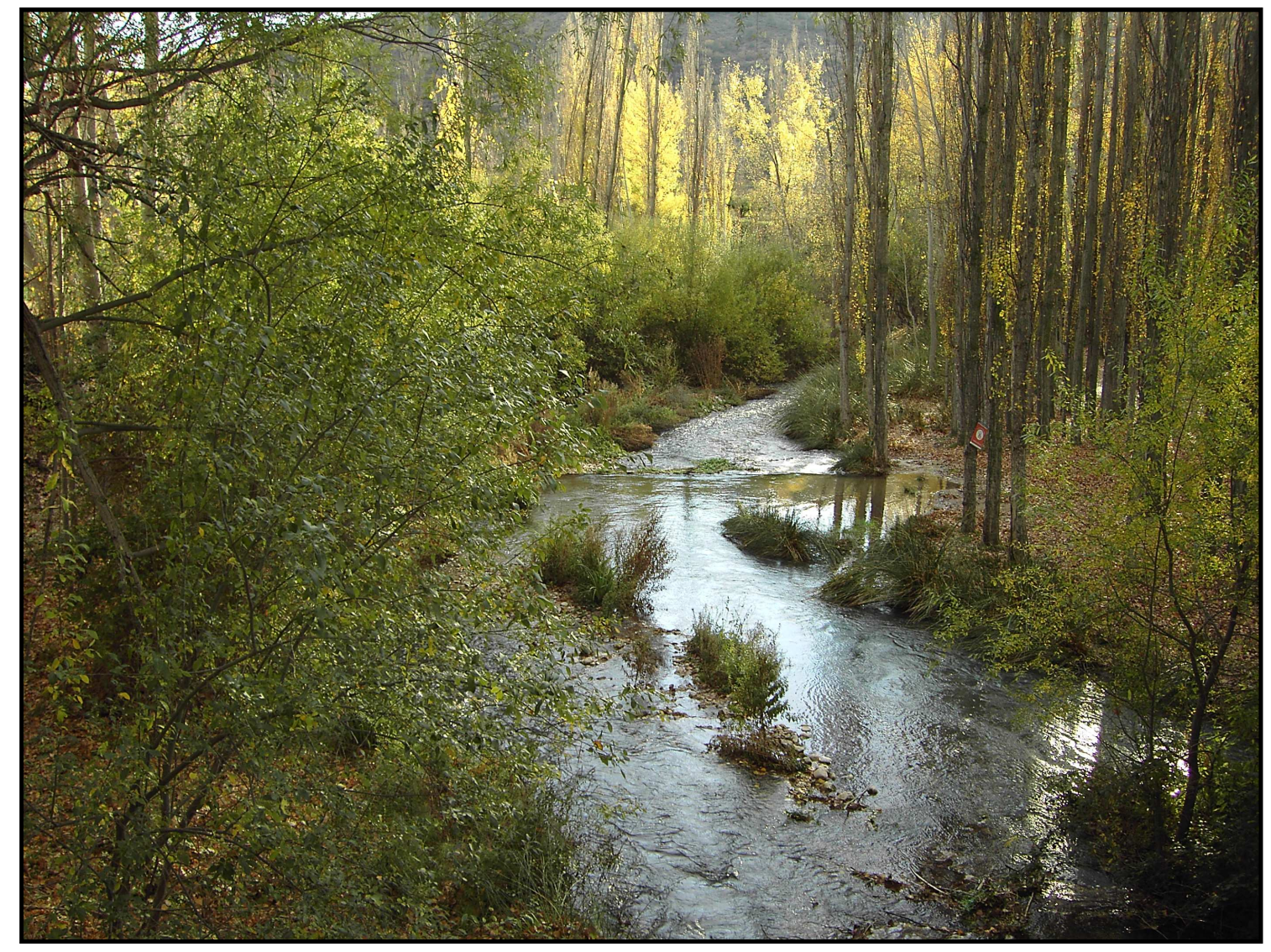

Figura 2.2. El río Ebrón al inicio del tramo 1 en Cuesta del Rato.

\section{Río Vallanca}

El primer tramo es el más cercano al nacimiento del río. Está ubicada cerca de la Fuente Romero en el término municipal de Vallanca. La segunda zona de estudio se encuentra en el paraje denominado Fuentecaliente, también en el municipio de Vallanca. La tercera zona está cerca de la central hidroeléctrica abandonada (figura 2.3). Por último, el cuarto y último tramo se estableció en el municipio de Ademuz cerca de la desembocadura. 


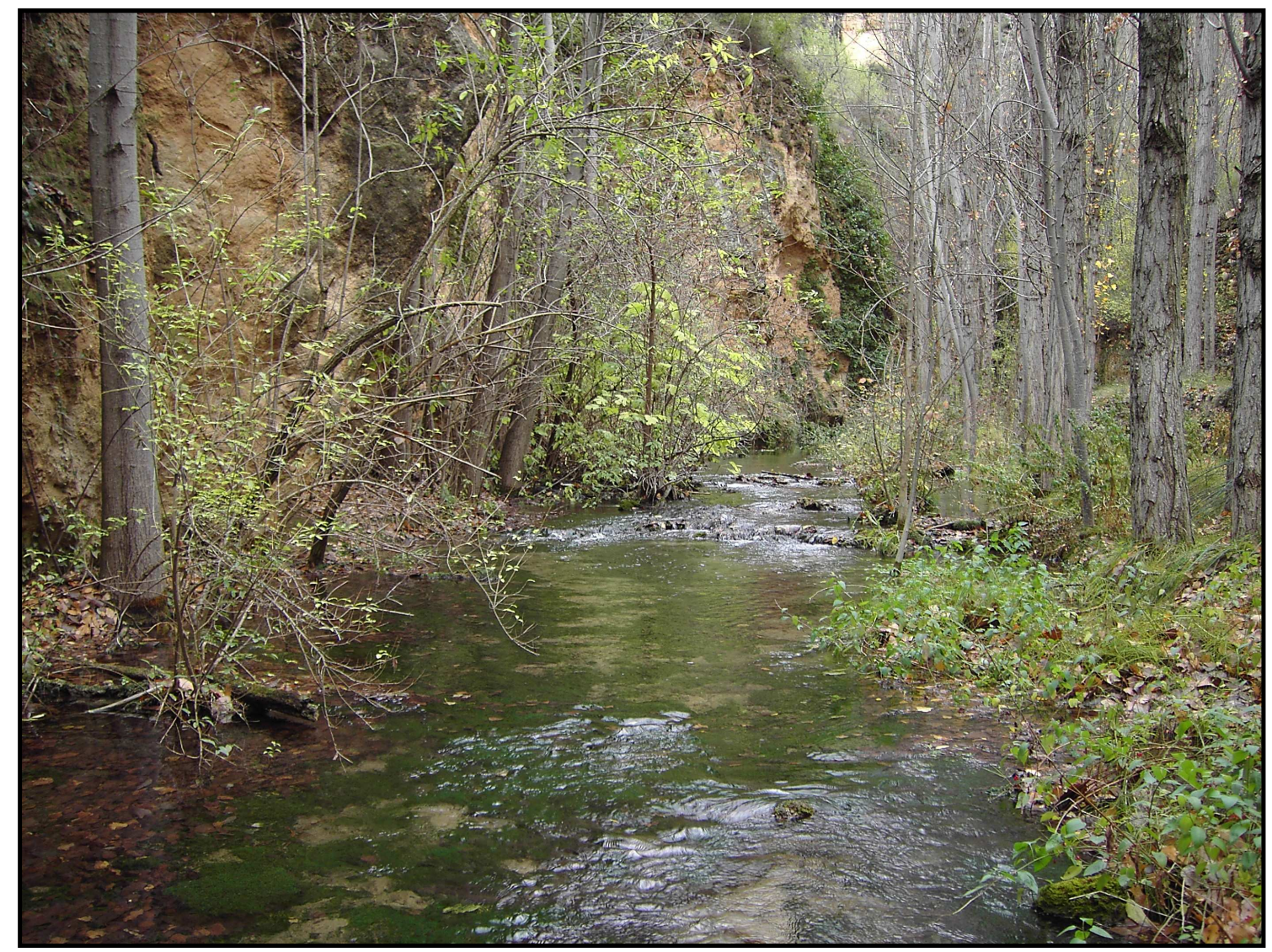

Figura 2.3. El río Vallanca al final del tramo 3 cerca de la central hidroeléctrica.

\section{Río Palancia}

La primera zona está situada en el paraje denominado La Solana (frente a Cerro Simón) del término municipal de Bejís. El segundo punto se encuentra situado en la intersección del río con el camino de Torás, en el paraje de Bejís denominado La Vega. El tercer tramo se encuentra dentro del término de Teresa, en el paraje conocido como Cerro Molino. La cuarta y última zona está ubicada, entre las vaguadas de la Peña Alta y Alto de la Palanca, también dentro del término municipal de Teresa (figura 2.4). 


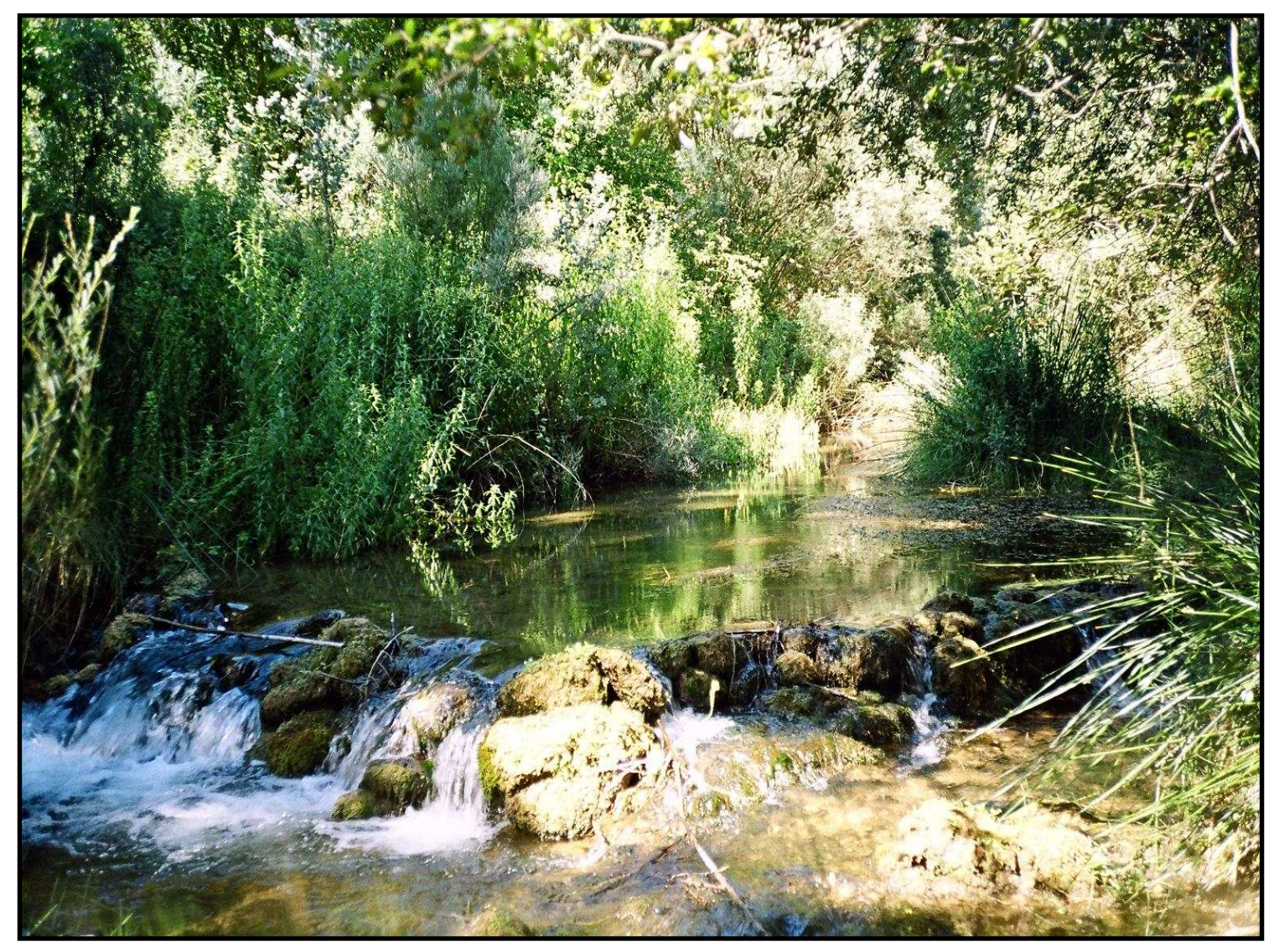

Figura 2.4. El río Palancia al final del tramo 4 en Teresa.

\section{Río Villahermosa}

La zona de muestreo seleccionada más cercana al nacimiento del río esta en el paraje conocido como El Romeral (figura 2.5). El segundo tramo se encuentra aguas abajo del vertido de la depuradora del término municipal de Villahermosa del Río. La tercera zona está situada junto a la Masía de Benagés. La cuarta y última zona y por tanto la más alejada del nacimiento del río está ubicada junto a una pedanía de Villahermosa denominada La Martina. 


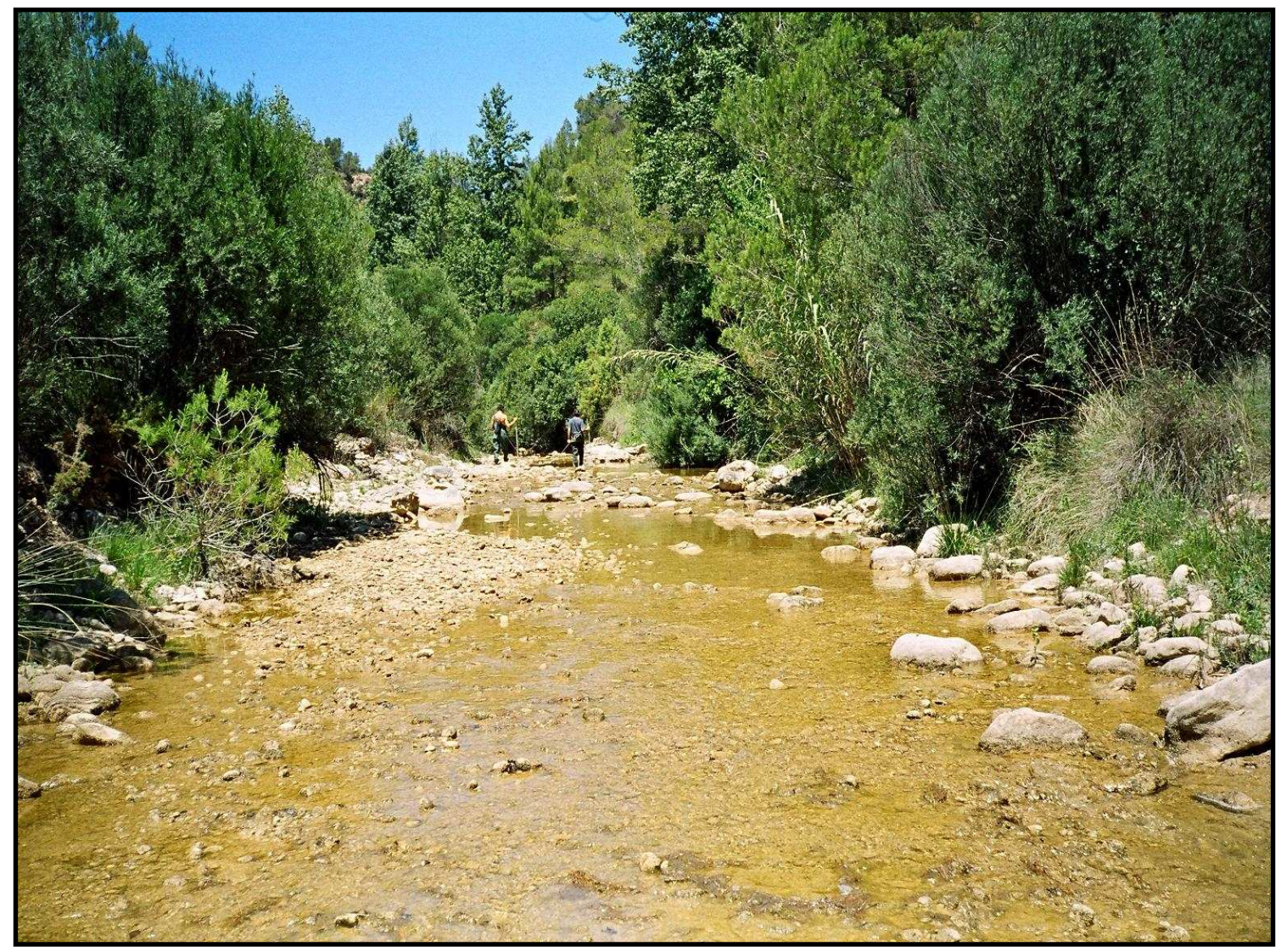

Figura 2.5. El río Villahermosa al inicio del tramo 1 en El Romeral.

\section{PERIODO DE MUESTREOS}

Los muestreos se realizaron entre los meses de Junio y Agosto entre los años 2003 y 2006 (tabla 2.2). El primer año se establecieron dos estaciones de muestreo en cada río. En los restantes años se amplió a cuatro estaciones de muestreo en cada río (en total 16 estaciones en 4 ríos). En todos los años de muestreo los cuatro ríos permanecieron vedados a la pesca deportiva. Todos los muestreos fueron realizados con caudal base y se destaca el hecho de que en los dos últimos años de estudio (2005 y 2006) hubo una fuerte sequía que hizo que los tramos más altos de los ríos Vallanca y Villahermosa se secaran, perdiéndose tres de las dieciséis estaciones establecidas. 
Tabla 2.2. Fechas de muestreos del hábitat (Háb) y biológicos (Bio) de los ríos Ebrón, Vallanca, Palancia y Villahermosa en los años 2003, 2004, 2005 y 2006.

\begin{tabular}{|c|c|c|c|c|c|c|c|c|c|}
\hline \multirow[t]{2}{*}{ Río } & \multirow{2}{*}{ Tramo } & \multicolumn{2}{|c|}{2003} & \multicolumn{2}{|c|}{2004} & \multicolumn{2}{|c|}{2005} & \multicolumn{2}{|c|}{2006} \\
\hline & & Háb & Bio & Háb & Bio & Háb & Bio & Háb & Bio \\
\hline \multirow{4}{*}{ 든 } & EB-1 & $10 \cdot 07$ & $10 \cdot 07$ & 21.07 & $05 \cdot 08$ & 14.07 & 11.07 & 24.07 & 03.08 \\
\hline & EB-2 & - & - & 21.07 & $05 \cdot 08$ & $14 \cdot 07$ & 11.07 & $24 \cdot 07$ & 03.08 \\
\hline & EB-3 & - & $11 \cdot 07$ & 21.07 & 06.08 & $14 \cdot 07$ & $12 \cdot 07$ & 23.07 & 04.08 \\
\hline & EB-4 & $09 \cdot 07$ & $11 \cdot 07$ & 22.07 & $02 \cdot 08$ & $14 \cdot 07$ & $13 \cdot 07$ & $24 \cdot 07$ & 04.08 \\
\hline \multirow{4}{*}{ 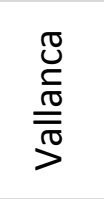 } & VA-1 & - & $28 \cdot 07$ & $20 \cdot 07$ & $03 \cdot 08$ & $15 \cdot 07$ & Seco & $24 \cdot 07$ & Seco \\
\hline & VA-2 & - & - & $20 \cdot 07$ & $03 \cdot 08$ & $13 \cdot 07$ & 14.07 & $27 \cdot 07$ & 01.08 \\
\hline & VA-3 & $19 \cdot 06$ & $24 \cdot 07$ & 21.07 & $04 \cdot 08$ & $15 \cdot 07$ & 14.07 & 28.07 & $02 \cdot 08$ \\
\hline & VA-4 & 11.06 & $24 \cdot 07$ & $20 \cdot 07$ & $04 \cdot 08$ & $15 \cdot 07$ & 14.07 & 28.07 & 01.08 \\
\hline \multirow{4}{*}{$\begin{array}{l}\frac{\pi}{0} \\
\frac{\pi}{\pi} \\
\frac{\pi}{\pi} \\
\Omega\end{array}$} & PA-1 & $30 \cdot 06$ & $30 \cdot 07$ & $14 \cdot 07$ & $27 \cdot 07$ & 24.06 & 04.07 & $18 \cdot 07$ & $07 \cdot 08$ \\
\hline & PA-2 & - & - & $14 \cdot 07$ & $27 \cdot 07$ & 28.06 & 05.07 & $18 \cdot 07$ & $07 \cdot 08$ \\
\hline & PA-3 & - & $29 \cdot 07$ & $14 \cdot 07$ & 28.07 & 29.06 & $06 \cdot 07$ & $20 \cdot 07$ & 08.08 \\
\hline & PA-4 & - & - & $15 \cdot 07$ & $29 \cdot 07$ & 21.06 & $05 \cdot 07$ & $21 \cdot 07$ & 09.08 \\
\hline \multirow{4}{*}{ 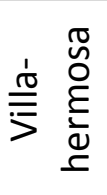 } & VI-1 & $02 \cdot 07$ & $01 \cdot 08$ & $20 \cdot 07$ & $31 \cdot 07$ & 29.06 & Seco & Seco & Seco \\
\hline & VI-2 & - & - & $13 \cdot 07$ & $31 \cdot 07$ & Seco & Seco & Seco & Seco \\
\hline & VI-3 & - & - & 09.07 & $29 \cdot 07$ & 29.06 & 07.07 & 23.07 & $10 \cdot 08$ \\
\hline & VI-4 & 02.07 & 31.07 & 09.07 & $30 \cdot 07$ & 29.06 & 08.07 & 23.07 & $10 \cdot 08$ \\
\hline
\end{tabular}

\section{CARACTERIZACIÓN DE LOS RÍOS}

Todos los tramos del estudio están ubicados en la cabecera de los ríos y no tiene ningún embalse o lago natural hacia aguas arriba. Según la clasificación de Strahler (1957), el orden fluvial en los ríos Ebrón y Vallanca es 2 y en los ríos Palancia y Villahermosa es 3 (tabla 2.3). Los ríos Ebrón y Vallanca desembocan en el Turia.

El Ebrón tiene $33 \mathrm{~km}$ de longitud y el Vallanca $15 \mathrm{~km}$, dándose las condiciones necesarias en la totalidad de ambos ríos para albergar poblaciones estables de trucha común. La anchura máxima de la longitud del agua que se midió durante el verano en el río Ebrón fue de $6.90 \mathrm{~m}$ y en el Vallanca de $5.67 \mathrm{~m}$. El río Palancia desemboca directamente en el mar Mediterráneo con una longitud aproximada de $84 \mathrm{~km}$, pero sólo los primeros $40 \mathrm{~km}$ cuentan con poblaciones estables de trucha. La anchura máxima medida en este río fue de $9.65 \mathrm{~m}$. Por último, el río Villahermosa vierte sus aguas en el Mijares teniendo una longitud de $55 \mathrm{~km}$, de los cuales los $33 \mathrm{~km}$ iniciales son aptos para la trucha, con una anchura máxima medida de $13.5 \mathrm{~m}$. En general, estos ríos son pequeños, de poca anchura media $(2.51-5.66 \mathrm{~m}) \mathrm{y}$ de escasa profundidad media $(0.26-0.49 \mathrm{~cm})$ (ver tabla 2.3$)$. 
Las pendientes de estos ríos son elevadas por tratarse de ríos de cabecera, situándose la media de todos ellos en $21.8 \mathrm{~m} \cdot \mathrm{km}^{-1} \pm S . D .4 .8$. La cuenca más pequeña es de $55 \mathrm{~km}^{2}$ en el tramo más alto del río Vallanca y la mayor es de $268 \mathrm{~km}^{2}$ en el tramo bajo del río Villahermosa, siendo la media de todos los puntos de muestreo de $175 \mathrm{~km}^{2} \pm$ S.D. 81.5 .

Tabla 2.3. Características de los distintos tramos trucheros objeto de estudio.

\begin{tabular}{|c|c|c|c|c|c|c|}
\hline Río & $\begin{array}{c}\text { Orden } \\
\text { de } \\
\text { Strahler }\end{array}$ & $\begin{array}{c}\text { Cuenca } \\
\left(\mathrm{Km}^{2}\right)\end{array}$ & $\begin{array}{c}\text { Anchura } \\
\text { media } \\
\text { (m) }\end{array}$ & $\begin{array}{c}\text { Profundidad } \\
\text { media (m) }\end{array}$ & $\begin{array}{l}\text { Tempera- } \\
\text { tura del } \\
\text { agua }(\stackrel{\circ}{ })\end{array}$ & $\begin{array}{l}\text { Caudal } \\
\text { medio } \\
\left(\mathrm{m}^{3} \cdot \mathrm{s}^{-1}\right)\end{array}$ \\
\hline Ebrón & 2 & 250 & 4.58 & 0.37 & 13.8 & 1.13 \\
\hline Vallanca & 2 & 123 & 2.51 & 0.26 & 13.1 & 0.35 \\
\hline Palancia & 3 & 204 & 5.66 & 0.49 & 13.7 & 0.26 \\
\hline Villahermosa & 3 & 268 & 5.40 & 0.28 & 12.8 & 1.08 \\
\hline
\end{tabular}

En las cuatro cuencas de los ríos, el porcentaje del uso del suelo forestal está entre el 77 y $95 \%$, siendo la media de $84 \% \pm$ S.D. 5.9. El resto del porcentaje de uso del suelo abarca las superficies urbanas y las zonas agrícolas. Las cuencas están formadas por rocas carbonatadas, abarcando un porcentaje medio del 96\% \pm S.D. 4.1. Esta naturaleza geológica influye directamente en la naturaleza fisicoquímica de sus aguas. La dureza media del agua durante los dos meses de trabajo fue de $\left.291.8 \mathrm{mg} \cdot\right|^{-1}$ de $\mathrm{CaCO}_{3} \pm$ S.D. 29.6. Esta dureza le da un carácter básico al agua, con un $\mathrm{pH}$ medio de $7.9 \pm$ S.D. 0.2. La conductividad media del agua fue de $55.5 \mu \mathrm{S} \cdot \mathrm{cm}^{-1} \pm$ S.D. 8.0. Además, se observó la calidad de las aguas de los ríos mediante análisis químicos en todos los tramos de estudio, durante la recogida de datos en los dos primeros años de muestreos de esta tesis (Alcaraz-Hernández et al., 2006). Los parámetros químicos que se estudiaron fueron nitritos, nitratos, amonio, ortofosfatos, cloruros, sulfatos y sólidos en suspensión. Ningún parámetro excedió el valor de tolerancia exigibles a las aguas continentales para especies salmonícolas que se recogen en el Real Decreto 927/1988, excepto los nitritos en el río Ebrón y nitritos, fosfatos y sólidos suspendidos en el tercer tramo del río Villahermosa (que está ubicado aguas abajo de la estación depuradora del pueblo homónimo).

Por otro lado, todos los ríos están ubicados en la misma zona bioclimática. El clima es típico mediterráneo con un régimen de caudales pluviales concentrado en los últimos meses de invierno y principios de primavera y con estiaje en los meses de verano, dándose las mayores fluctuaciones o incertidumbres en los meses de enero y marzo. La precipitación media anual varía entre $442 \mathrm{~mm}$ en el río Ebrón, $455 \mathrm{~mm}$ en el río Vallanca, $571 \mathrm{~mm}$ en el río Palancia y $583 \mathrm{~mm}$ en el río Villahermosa. Los caudales 
medios mensuales fueron proporcionados por la Confederación Hidrográfica del Júcar. Éstos fueron obtenidos mediante el programa de modelación de caudales Aquatool, ya que no existen estaciones de aforo donde se realizó el estudio (excepto en el río Ebrón). El caudal medio es de $1.13 \mathrm{~m}^{3} \cdot \mathrm{s}^{-1}$ en el río Ebrón, $0.35 \mathrm{~m}^{3} \cdot \mathrm{s}^{-1}$ en el Vallanca, $0.26 \mathrm{~m}^{3} \cdot \mathrm{s}^{-1}$ en el Palancia y $1.08 \mathrm{~m}^{3} \cdot \mathrm{s}^{-1}$ en el Villahermosa (ver tabla 2.2 ).

La temperatura del agua fue tomada mediante un registrador de datos (Minilog Vemco, Ltd; www.vemco.com) situado en el tramo medio de cada río. En un año se tomó un registro durante cada hora del día, siendo la temperatura media diaria como la media de las 24 horas del día. La temperatura media anual del agua es muy homogénea en los cuatro ríos con valores comprendidos entre los 12 y 14 oC (ver tabla 2.2), con oscilaciones muy suaves donde en invierno las mínimas no suelen bajar de los 5 으 y en verano no suelen superar los $20 \stackrel{\circ}{\circ}$, siendo la temperatura media de muestreo en los cuatro ríos de $15.7^{\circ} \mathrm{C} \pm$ S.D. 1.8. No obstante, el sombreado de los tramos es muy irregular ( $56 \% \pm S . D .24)$, propiciándose en muchos lugares una adecuada entrada de luz.

\section{VEGETACIÓN DE RIBERA}

La vegetación riparia es un tipo de vegetación higrófila, ya que la presencia de agua en el suelo condiciona las especies que pueden crecer sobre él. La vegetación de las riberas de estos ríos puede estar formada por vegetación arbolada formando bosques, junto con cañaverales, juncales y pastizales. Los primeros suelen representar la cadena de la serie edafohigrófila, mientras que juncares y pastizales pueden actuar como etapas de sustitución de aquellos (Costa, 1999).

La zonificación general teórica que siguen los bosques de ribera de los ríos estudiados está formada por franjas paralelas al cauce en donde los sauces forman una primera fila pegadas al cauce del río, seguidos por los chopos y finalmente por las olmos, dependiendo del grado de humedad de los suelos. La vegetación de ribera se incluye en la clase Querco-Fagetea y dentro de ellas las saucedas, choperas, olmedas y fresnedas se encuentran en el orden Populetalia albae (Costa, 1999).

Las saucedas son muy variadas, todas ellas clasificadas en la alianza Salicion triandrae-neotrichae (Roselló, 1994), repartida indistintamente por los transectos estudiados. Se encuentra Salix atrocinerea y Salix eleagnos en el río Villahermosa, 
Salix alba en el río Palancia, Salix atrocinerea y Salix alba en el río Ebrón y Salix fragilis en el río Vallanca.

Conforme nos alejamos del cauce, encontramos las choperas incluidas en la alianza Populion albae (Roselló, 1994) de Populus nigra, aunque también se puede encontrar Populus alba en zonas más termófilas. Es frecuente encontrar paralela a la línea de chopos, el olmo (Ulmus minor) acompañados por el almez (Celtis australis), nogal (Juglans regia) e higuera (Ficus carica) en los ríos de Vallanca, Ebrón y Palancia. Otros árboles detectados son el arce (Acer monspessulanum) en el río Vallanca y el avellano (Corylus avellana) en los ríos Ebrón y Palancia.

Debido al alto grado de transformación por el hombre de los suelos fluviosoles, en terrenos para la agricultura la flora se degrada, sucediéndoles vegetación de la clase Rhamno-Prunetea (Roselló, 1994) en donde aparecen especies como zarzas (Rubus ulmifolium), hiedras (Hedera helix), rubias (Rubia peregrina), madreselvas (Lonicera etrusca y L. implexa), majuelos (Crataegus monogyna), rosas (Rosa ssp.), aladierno (Rhamnus alaternus) y cornizos (Cornus sanguinea). Además se encontraron especies menos frecuentes en esta clase de vegetación como son saucos (Sambucus nigra), cerezos (Prunus avium), vides (Vitis vinifera) y zarzaparrilla (Smilax aspera) en el río Vallanca, espárragos (Asparagus acutifolius) en los ríos Vallanca y Palancia y manzanos (Pyrus malus) en los ríos Ebrón, Palancia y Villahermosa.

Si la degradación persiste se puede encontrar otra etapa serial de pastizales englobados en la clase Festuco-Brometea representada por el orden Brachypodietalia phoenicoidis (Roselló, 1994) con especies como Brachypodium phoenicoides, la cola de caballo (Equisetum arvense) en el río Vallanca y Palancia, la avena (Avena sterilis), y Dactylis glomerata en el río Vallanca y Villahermosa.

La vegetación presente en los suelos inundados temporalmente por aguas dulces pertenece a la clase denominada Isoeto-Nanojuncetea (Roselló, 1994). Las especies que se han detectado dentro de esta clase son los juncos (Juncus ssp. y Scirpus holoschoenus), el carrizo (Phragmites australis) en el río Ebrón, la enea (Thypha angustifolia) en el río Palancia y la caña (Arundo donax). Otras especies asociadas son los tréboles (Trifolium ssp.), berro (Rorippa nasturtium-aquaticum) en el río Vallanca, el berro (Nasturtium officinalis) en el río Palancia, las lechetreznas (Euphorbia ssp.) en el río Villahermosa. Además en el río Vallanca se encuentran presentes la ortiga mayor (Utica dioica), el lirio amarillo (Iris pseudacorus) y la adelfina pelosa (Ephilobium hirsutum). 
Por último podemos encontrar vegetación acuática sumergida en su totalidad o parte de sus estructuras en el cauce del río. Pertenecen a la clase Potamogetonetea pectinati (Roselló, 1994) con especies como Potamogeton nodosus en el río Villahermosa y Vallanca.

A continuación se describe el esquema sintaxonómico de la vegetación de ribera de los ríos estudiados:

- Clase QUERCO-FAGETEA Br.-BI \& Vlieger 1937

Or. Populetalia albae Br.-BI 1931

Al. Salicion triandrae-neotrichae Br.-BI \& O. Bolòs 1957

Al. Populion albae Br.-BI 1931

- Clase RHAMNO-PRUNETEA Rivas Goday \& Borja 1961

Or. Prunetalia spinosae R. Tx 1952

Al. Pruno-Rubion ulmifolii O. Bolòs 1954

- Clase FESTUCO-BROMETEA Br.-BI \& R. Tx. 1943

Or. Brachypodietalia phoenicoidis (Br-Bl. 1931) Molinier 1934

- Clase ISOETO-NANOJUNCETEA Br.-BI \& R. Tx. 1943

Or. Cyperetalia fusci (Klika 1935) Müller-Stoll \& Pietsch 1961 em. RivasGoday 1970

- Clase POtAMOgetonetea PECTINATI R. Tx. \& Preising 1942

Or. Magno-Potamogetonetalia (W. Koch 1926) Den Hartog \& Segal 1964

\section{ICTIOFAUNA}

La trucha común (Salmo trutta L.) es residente y también es la especie más abundante en casi todos los tramos donde se realizó el estudio. Junto a ella, también conviven otras especies menos frecuentes capturadas y registradas durante los cuatro años en que duraron los muestreos. 
Tanto en el río Ebrón como en el Vallanca se capturaron las mismas especies. En el tramo alto del Ebrón se capturó solamente trucha común, no obstante, hacia aguas abajo encontramos ocasionalmente individuos de barbo mediterráneo (Luciobarbus guiraonis, Steind.) y barbo colirojo (Barbus haasi, Mertens). En el tramo más bajo se capturaron escasos individuos de anguila (Anguilla anguilla L.) y trucha arco-iris (Oncorhynchus mykiss, Walbaum), posiblemente procedentes de antiguas repoblaciones. Por otro lado, en los tres primeros tramos del Vallanca sólo se detectó trucha común, encontrándose las demás especies en el tramo más bajo del río.

La trucha común del río Palancia convive con poblaciones autosostenibles de trucha arco-iris. En los tramos bajos también podemos encontrar poblaciones de bermejuelas (Achondrostoma arcasii, Steind.) y barbos mediterráneos y colirojos. Por último, en el río Villahermosa no se pescó ningún individuo de trucha arco-iris y en todos los tramos se encontraron poblaciones estables de trucha común, cacho levantino (Squalius valentinus, Doadrio \& Carmona), barbo mediterráneo y barbo colirojo. A continuación se describe el esquema sintaxonómico a nivel de familia de la ictiofauna presente en estos ríos:

- Familia Anguillidae

Anguilla anguilla (Linnaeus, 1758)

- Familia Salmonidae

Salmo trutta Linnaeus, 1758

Onchorrynchus mykiss (Walbaum, 1792)

- Familia Cyprinidae

Luciobarbus guiraonis Steindachner, 1866

Barbus haasi Mertens, 1925

Achondrostoma arcasii (Steindachner, 1866)

Squalius valentinus (Doadrio \& Carmona, 2006) 


\section{BIBLIOGRAFÍA}

Alcaraz-Hernández, J.D., F. Martínez-Capel, F., J. Ramos y Z. Hermosilla. 2006. Calidad de las aguas en tramos salmonícolas de la Comunidad Valenciana. Congreso Internacional: V Congreso Ibérico de Limnología. Póster. Universidad de Barcelona. Barcelona (España).

Costa, M. 1999. La vegetación y el paisaje en las tierras valencianas. Editorial Rueda, S.L., Madrid.

Roselló, R. 1994. Catálogo florístico y vegetación de la comarca natural del Alto Mijares (Castellón). Diputació de Castelló.

Strahler, A.N. 1957. Quantitative Analysis of Watershed Geomorphology. Transactions of the American Geophysical Union 38: 913-920. 


\section{CAPÍTULO 3}

\section{ANÁLISIS DE LA VARIABILIDAD DEL HÁBITAT EN RIOS TRUCHEROS MEDITERRÁNEOS MEDIANTE}

SUS ATRIBUTOS FÍSICOS

\section{Resumen}

Se han estudiado los hábitats de cuatro ríos mediterráneos en sus zonas de cabecera durante cuatro años de muestreo (2003-2006). Los hábitats se clasificaron en clases de mesohábitats siguiendo el protocolo de muestreo "Basinwide Visual Estimation Technique - BVET". Se midieron sus diferentes atributos físicos como la longitud, anchura, profundidad media y máxima, porcentaje de sustrato y volumen. Inicialmente, se utilizaron métodos robustos en la caracterización de las variables. Después, gracias a las propiedades de la matriz de proximidad, se estudió la variabilidad de la clasificación. Para ello se calculó el índice de la fortaleza de la clasificación y se utilizó el escalado multidimensional métrico, MDS. Finalmente, se identificaron y agruparon los factores que más influyen en la variabilidad de las clases. Todo esto ha permitido observar la homogeneidad y aislamiento de las clases establecidas a priori, detectando aquellas clases con mayor variabilidad. Los ríos Villahermosa y Ebrón son más homogéneos que Vallanca y Palancia, las corrientes y tablas son más homogéneas que pozas y rápidos. Además, tanto los mesohábitats rápidos (corrientes y rápidos) como los mesohábitats lentos (pozas y tablas) tienden a agruparse. Por último, se detectaron los factores que más influyen en la variabilidad de las pozas en los ríos Vallanca y Palancia (los mesohábitats de mayor variabilidad).

Palabras clave: Ríos mediterráneos, mesohábitat, unidades hidromorfológicas, similaridad, Península Ibérica. 


\section{INTRODUCCIÓN}

Los ríos son complejos sistemas naturales. El entendimiento y la predicción de los factores clave en los sistemas fluviales y cómo ellos influyen sobre sus aguas y los organismos que la habitan han sido un asunto central de quienes estudian, gestionan y usan los ríos (Wang et al., 2006). Tanto es así que durante las últimas décadas se han desarrollado multitud de clasificaciones para evaluar los ríos, ya sea para ser aplicados en la gestión ambiental, en el diseño de proyectos o en el cumplimiento del marco legislativo (Brenden et al., 2008). Una de sus principales aplicaciones es la identificación de los distintos estratos para mejorar la precisión del hábitat y las mediciones biológicas en los programas de muestreo (Hayes et al., 2003).

Gran parte de las clasificaciones que versan sobre los hábitats acuáticos se han realizado dentro del marco conceptual que considera los distintos vínculos existentes entre los organismos acuáticos y las características del sistema acuático desde una perspectiva jerárquica (González del Tánago y García de Jalón, 2006). Este marco enfatiza la relación del río con sus cuencas hidrográficas a través de un amplio rango de escalas espacio-temporales, ya que partiendo inicialmente del río como unidad básica, se van anidando de forma piramidal capas sucesivas relacionadas, como por ejemplo cuenca vertiente, segmento fluvial, tramo o sector fluvial, unidad hidromorfológica o mesohábitat y microhábitat, que interactúan para mantener la integridad funcional del río (Frissell et al., 1986). Gracias a este marco, se han desarrollado modelos jerárquicos que describen la relación espacial entre las diferentes unidades del río y las series biológicas obtenidas de los organismos acuáticos (Hawkins et al., 1993; Poff, 1997; Hawkins et al., 2000; Parsons et al., 2003), reconociendo que para un río particular, las relaciones biológicas se ejercen a través de un filtro múltiple escalar y espacial (Tonn, 1990; Poff, 1997).

Muchas de éstas clasificaciones están construidas a partir de las diferencias físicas y biológicas que hay entre las distintas unidades hidromorfológicas o mesohábitat (por ejemplo, pozas, tablas, corrientes o rápidos), delimitando áreas homogéneas en términos de geomorfología, biología y ecología. Fue a principios de los años 80 y a finales de los 90 cuando se empezaron a desarrollar las primeras clasificaciones a nivel de mesohábitat (Bisson et al., 1982; Frissell et al., 1986; Hankin y Reeves, 1988; Hawkins et al., 1993; Flosi y Reynolds, 1994; Roper y Scarnecchia, 1995; Vadas y Orth, 1998). Gracias a estas clasificaciones, se establecieron y aplicaron en EE.UU distintos programas nacionales de muestreo (ver por ejemplo Sowa et al., 2005; Stoddard et 
al., 2005; Seelbach et al., 2006). En Europa, no es hasta que se establece la Directiva Marco del Agua (European Commission, 2000) cuando muchos estados miembros de la UE establecen programas para la implantación y clasificación de las aguas superficiales (REFCOND, 2003; CEN, 2004). Por esta razón, podemos encontrar ya en diversos países algunos indices y protocolos de muestreo, en los cuales la clasificación y la diversidad de unidades hidromorfológicas constituyen una parte esencial (ver por ejemplo Raven et al., 1997; Lawa, 2000; Tickner et al., 2000; Pardo et al., 2002). Además, la clasificación de unidades hidromorfológicas se ha incorporado a los métodos para el estudio de caudales ambientales, con una escala de trabajo complementaria a la escala de microhabitat (Parasiewicz, 2001).

Una de las razones por la que se usa tanto esta clasificación es por la gran influencia que ejercen las unidades hidromorfológicas sobre los organismos acuáticos (Bisson et al., 2006). En este sentido son muchos los estudios realizados que comparan las unidades hidromorfológicas con la composición de macroinvertebrados (Brown y Brussock, 1991; Pardo y Armitage, 1997; Beisel et al., 1998), la comunidad de peces y su biomasa (Modde et al., 1991; Erös y Grossman, 2005; Schwartz y Herricks, 2008) o considera estos tipos de hábitats como una unidad básica de clasificación para estimaciones rápidas en la abundancia de los peces (Hankin y Reeves, 1988). Sin embargo, todavía no ha sido ampliamente testada la relevancia de las clasificaciones de ríos desarrollada a partir de criterios físicos o biológicos (Thomson et al., 2004; Clifford et al., 2006; Schwartz y Herricks, 2008). Por lo tanto, la necesidad de evaluar la homogeneidad (o variabilidad) de los mesohábitats es importante a la hora de establecer una correcta clasificación.

En este estudio se ha adaptado el protocolo de muestreo Basinwide Visual Estimation Technique (BVET) a ríos de cabecera mediterráneos. En estos se registraron independientemente todas las unidades hidromorfológicas encontradas a lo largo de diferentes tramos del río, tramos establecidos a priori para monitorear las distintas poblaciones de peces. El objetivo general de esta investigación es mejorar la clasificación del hábitat según sus unidades hidromorfológicas en ríos trucheros mediterráneos del levante español. Por lo tanto, este artículo pretende examinar la similaridad (o disimilaridad) de los diferentes tipos de mesohábitats encontrados en los ríos mediterráneos con el fin de evaluar la aplicabilidad del protocolo utilizado. Concretamente, el primer objetivo es desarrollar una metodología robusta para evaluar los tipos de hábitats utilizados en la clasificación; el segundo objetivo es 
reconocer los factores hidromorfológicos que más influyen en su variabilidad espacial.

\section{MÉTODOS}

\section{Adquisición de datos en campo}

Todos los muestreos se realizaron en los ríos Ebrón, Vallanca, Palancia y Villahermosa durante el mes de Julio, desde el año 2003 hasta el 2006, ambos inclusive, cuando el caudal de los ríos era bajo. Se establecieron cuatro tramos de muestreo en cada río de aproximadamente 300 metros para la caracterización del hábitat acuático. Durante los dos últimos años hubo una fuerte sequía que hizo que los tramos más altos de los ríos Vallanca y Villahermosa se secaran y no se pudo muestrear, por lo tanto se utilizó un total de 50 tramos en el análisis estadístico.

Para la caracterización del hábitat en ríos mediterráneos se adaptó el protocolo de muestreo "Basinwide Visual Estimation Technique - BVET" (Hankin y Reeves, 1988; Dolloff et al., 1993). Este protocolo se utiliza para estimar las poblaciones de peces en pequeños ríos mediante la estratificación del hábitat. Esta técnica consiste en estratificar visualmente el cauce según sus diferentes biotopos (unidades hidromorfológicas o mesohábitats), registrándose en ellos las distintas características hidromorfológicas. En este estudio se establecieron cuatro tipos de mesohábitats básicos; pozas, tablas, corrientes y rápidos. Otras unidades hidromorfológicas como las cascadas no fueron detectadas a lo largo de los tramos de estudio. El número de step (o escalones) y tramos secos fueron inferiores al $3 \%$ de la longitud total de los tramos, por lo que no fueron incluidos en este estudio. A continuación se describen los criterios seguidos en la clasificación de los cuatro mesohábitats:

- Pozas (P), con profundidades mayores de $0.6 \mathrm{~m}$ (producidas generalmente por erosiones locales), velocidades inferiores a la media del tramo y pendientes muy bajas.

- Tablas (T), con profundidades menores de $0.6 \mathrm{~m}$, velocidades similares a la media el tramo y sin turbulencias apreciables y con secciones trasversales aproximadamente simétricas.

- Corrientes (C), con aguas poco profundas con rizaduras superficiales, velocidades medias del agua inferiores a $0.4 \mathrm{~m} \cdot \mathrm{s}^{-1}$ y secciones trasversales 
aproximadamente simétricas, con un calado de magnitud similar al sustrato superficial.

- Rápidos (R), con aguas someras con velocidades mayores que la media del tramo, con abundantes turbulencias superficiales, elementos de sustrato grueso que sobresalen del agua y predominio del flujo supercrítico.

Además, en cada mesohábitat se midieron las siguientes variables: longitud del mesohábitat $(\mathrm{m})$, anchura media $(\mathrm{m})$ del cauce tomada como media de tres puntos que corresponden a $1 / 4,1 / 2$, y $3 / 4$ de la longitud total del mesohábitat, profundidad media $(\mathrm{m})$ tomada como promedio de nueve puntos correspondientes a la medida tomada en $1 / 4,1 / 2, y 3 / 4$ en cada transecto donde se midió la anchura y profundidad máxima $(\mathrm{m})$, lo que permitió calcular el volumen $\left(\mathrm{m}^{3}\right)$. Además se estimó visualmente el porcentaje de sustrato (\%) de los materiales gruesos (> $256 \mathrm{~mm}$ de diámetro), los materiales medios $(2-256 \mathrm{~mm})$ y los materiales finos $(<2 \mathrm{~mm})$. El sistema utilizado para la clasificación del sustrato se basaron en la clasificación empleada por Platts et al. (1983), quienes toman como referencia la terminología y clases de tamaño aceptadas por la American Geophysical Union.

\section{Análisis de los datos}

\section{Caracterización del hábitat}

Todos los análisis fueron realizados mediante el programa estadístico de libre acceso R (R Development Core Team, 2008). Para caracterizar el hábitat, se establecieron 16 clases según la combinación de cada tipo de mesohábitat (poza, tabla, corriente y rápido) y cada río (Ebrón, Vallanca, Palancia y Villahermosa). Para cada clase se calculó la media de la longitud, anchura, profundidad media, profundidad máxima y volumen mediante el estimador robusto de Huber, $T n$, así como su desviación estándar mediante la Desviación Absoluta Mediana Estandarizada, NMAD (García Pérez, 2005). La proporción de recorte en las medias robustas fue del $20 \%$. Además, las medias de estas variables fueron comparadas entre ríos según cada tipo de mesohábitat mediante el test paramétrico robusto ANOVA de Welch. En aquellas variables en las que se detectó diferencias significativas entre sus medias $(p<0.001)$ se aplicó un análisis post hoc (mediante el método generalizado de Yuen) para detectar las posibles diferencias entre ríos con un nivel de significación $\alpha=0.05$. 


\section{Test de la fortaleza de la clasificación}

Se calcularon las distancias euclídeas entre todas las posibles combinaciones de pares de individuos, distancia que se define, entre los individuos de las filas $i=\left(x_{i 1}, x_{i 2}, \ldots, x_{i p}\right)$ y $j=\left(x_{j 1}, x_{j 2}, \ldots, x_{j p}\right)$ como:

$$
d_{j k}=\sqrt{\sum_{i=1}^{p}\left(x_{i j}-x_{i k}\right)^{2}}
$$

A continuación, se examinó la variabilidad de mesohábitats mediante el test de la fortaleza de la clasificación desarrollado por Van Sickle (1997). Éste se basa en comparar la agrupación dentro de cada clase con respecto a la distancia media entre ellas. Para ello, se determina la disimilaridad interna para cada clase $(\bar{W} i)$ la media intra-clase $(\bar{W})$ y la media global inter-clases $(\bar{B})$; se entiende disimilaridad interna como la media de la distancias euclidianas entre pares de puntos obtenidas de la matriz de proximidad, construida a partir de las variables del hábitat físico. Esto se hizo separadamente para las 3 clasificaciones antes mencionadas.

El ratio $\overline{\mathrm{B}} / \overline{\mathrm{W}}$ proporciona una medida total de la fortaleza del sistema de clasificación desarrollado (Van Sickle, 1997). Los ratios iguales a 1 indican que no hay estructura de clasificación $(\bar{B}=\bar{W})$ y a medida que este ratio disminuye aumenta la estructura de clasificación. Por tratarse de una distancia de disimilitud, las clases W̄i serán más homogéneas con valores cercanos a 0 y más heterogéneas con valores próximos a 1 . Los resultados pueden representarse gráficamente en un dendrograma (Van Sickle y Hughes, 2000) para observar la variabilidad de cada clase. Consiste en un árbol con un tronco vertical (graficado a una distancia $\bar{B}$ sobre el eje perpendicular que mide la distancia euclídea) y con distintas ramas horizontales (que representan la distancia $\bar{W}$ i para cada clase). Mientras mayor sea la distancia entre la media intra-clase $i(\bar{W} i)$ y la media inter-clases $(\overline{\mathrm{B}})$ más compacta y aislada será la clase $i$ con respecto a la media de todo el muestreo $(\bar{B})$ y por lo tanto presentará menor variabilidad. Se estableció la significación estadística del test de la fuerza de la clasificación, basado en la hipótesis nula de "no estructura de clases" usando un test de aleatoridad ( $N=$ 1000; $p$ 0.001) mediante la técnica de remuestreo bootstrap (Goslee y Urban, 2007). En este primer análisis se establecieron tres pruebas de clasificación a la hora de establecer las clases y observar su variabilidad, (1) las clases Río que agrupa a todas las unidades hidromorfológicas de los ríos Ebrón (EB), Vallanca (VA), Palancia (PA) y Villahermosa (VI), (2) las clases Mesohábitat agrupando todas las unidades de todos los ríos en poza $(P)$, tabla $(T)$, corriente $(C)$ y rápidos $(R)$ y $(3)$ las clases Río- 
Mesohábitat como combinación de ambas (tabla 3.1). El test de fortaleza fue realizado mediante el paquete estadístico de R, EnvClass, programado por Snelder (com. pers.).

Tabla 3.1. Abreviaciones utilizadas en el estudio para las distintas clases establecidas.

\begin{tabular}{ccl}
\hline Clases & Abreviaturas & \multicolumn{1}{c}{ Descripción } \\
\hline \multirow{4}{*}{ Río } & EB & Ebrón \\
& VA & Vallanca \\
& PA & Palancia \\
VI & Villahermosa \\
Mesohábitat & P & Poza \\
& T & Tabla \\
& C & Corriente \\
& R & Rápidos \\
& EB-P & Ebrón-Poza \\
& EB-T & Ebrón-Tabla \\
& EB-C & Ebrón-Corriente \\
& EB-R & Ebrón-Rápido \\
& VA-P & Vallanca-Poza \\
& VA-T & Vallanca-Tabla \\
& VA-C & Vallanca-Corriente \\
& VA-R & Vallanca-Rápido \\
Río-Mesohábitat & PA-P & Palancia-Poza \\
& PA-T & Palancia-Tabla \\
& PA-C & Palancia-Corriente \\
& PA-R & Palancia-Rápido \\
& VI-P & Villahermosa-Poza \\
& VI-T & Villahermosa-Tabla \\
& VI-C & Villahermosa-Corriente \\
& VI-R & Villahermosa-Rápido \\
\hline & & \\
& &
\end{tabular}

\section{Asociación entre las unidades hidromorfológicas}

Después de haber analizado la variabilidad de las clases de las distintas clasificaciones, se utilizó el escalado multidimensional métrico (MDS) para ilustrar las agrupaciones que se dan entre las clases Río-Mesohábitat. El MDS es un método estadístico que posiciona objetos en un espacio multidimensional reducido de acuerdo con el rango de similitud entre parejas de objetos existentes en la matriz de proximidad (Digby y Kempton, 1987); de tal manera que, al representar la distancia de los puntos en dos dimensiones, los puntos más cercanos corresponderán a los 
elementos más similares. Para una mejor interpretación de los datos, sólo se dibujaron en el mapa bidimensional las posiciones media de cada clase.

\section{Caracterización de las clases con mayor variabilidad}

Finalmente, en aquellas clases que presentaron mayor variabilidad, se implementó la estrategia descrita por Lebart et al. (1995) para identificar y agrupar los factores que más influyen en la variabilidad de esas clases. Esta estrategia combina, en la exploración multivariada de los datos, métodos factoriales con análisis de conglomerados. La estrategia a seguir se puede resumir de la siguiente manera. Inicialmente, la utilización de las coordenadas factoriales permite tener un marco común en el proceso de formación de conglomerados. Para el proceso de clasificación, el análisis factorial constituye un pretratamiento que transforma los datos originales en variables continuas no correlacionadas. Seguidamente se forman conglomerados basados en un algoritmo mixto: clasificación jerárquica con el método de Ward y agregación alrededor de centros móviles (K-medias). El método de Ward utiliza la distancia entre clases que cumple con el objetivo de unir, en cada paso del proceso de aglomeración, las dos clases que incrementen menos la inercia intraclases. Por último, el algoritmo K-medias para la obtención de una partición directa de un conjunto de individuos requiere el número de clases por obtener y de puntos iniciales para cada una de ellas. La propuesta de Lebart et al. (1995) se utiliza para obtener una partición que minimice la inercia intra-clases. Esto se logra localmente usando la distancia euclidiana entre los individuos y los centros móviles utilizados para la agregación. En cada paso del algoritmo se actualizan los centros móviles calculando los centros de gravedad de la partición obtenida del paso anterior.

Con la aplicación de estos métodos se obtiene la partición del conjunto de datos y la caracterización de cada una de las clases según sus variables. Todas las operaciones fueron realizadas mediante el paquete estadístico de $\mathrm{R}$, FactorClass, programado por Pardo y Del Campo (2007). Para mejorar la interpretación de los datos, se representaron tanto los planos factoriales bidimensionales como diagramas de boxplot para la caracterización de cada grupo y de sus variables. Finalmente, las medias de cada variable fueron comparadas entre grupos de pozas mediante el test paramétrico robusto ANOVA de Welch. En aquellas variables en las que se detectó diferencias significativas entre sus medias $(p<0.005)$ se aplicó un análisis post hoc (mediante el método generalizado de Yuen) para detectar las posibles diferencias entre grupos de pozas con un nivel de significación $\alpha=0.05$. 


\section{RESULTADOS}

\section{Caracterización del hábitat}

En los cuatro años que duró el estudio (2003-2006) se muestrearon un total de 964 mesohábitats repartidos a lo largo de los cuatro ríos. La tabla 3.2 muestra el sumario de los valores medios en longitud, anchura, profundidad media y máxima y volumen de los diferentes mesohábitat identificados en los ríos Ebrón, Vallanca, Palancia y Villahermosa. En general, el Ebrón tiene los mesohábitats rápidos (corrientes y rápidos) más largos y el Vallanca tiene los mesohábitats más pequeños, excepto en la profundidad de los rápidos, ya que son más someros los del Villahermosa. Las pozas y los rápidos del Palancia son más anchos, así como las tablas y corrientes del Villahermosa. Se observa además, que los mesohábitats lentos de cada río no son consistentemente más anchos que los rápidos, debido al efecto de otros factores (como por ejemplo la pendiente y el sustrato). Por regla general, el Palancia posee los mesohábitats más profundos, aunque en algunos casos no hay diferencias relevantes con el Ebrón (según su profundidad media y máxima).

Estadísticamente, sólo las medias $\alpha$-recortadas muestrales de la profundidad media y volumen fueron similares en los cuatro ríos, para cada uno de los cuatro tipos de mesohábitats. Para las demás variables (longitud, anchura y profundidad máxima) se detectaron diferencias significativas entre las cuatro medias 0.2 -recortadas ( $p<$ 0.001). No obstante, el análisis post hoc de estas últimas variables detectó distintas agrupaciones entre ríos. El Ebrón, Palancia y Villahermosa presentaron medias similares $(p>0.05)$ en las longitudes de pozas y rápidos, las anchuras de tablas y rápidos y en las profundidades máximas de pozas y tablas. Podría dar la impresión de que el río Vallanca no comparte con el resto de los ríos ninguna de las características físicas del hábitat, sin embargo, se encontraron agrupaciones equivalentes $(p>0.05)$ de las longitudes de rápidos y tablas con el río Palancia y profundidades máxima en rápidos (con Ebrón y Palancia) y tablas (con Ebrón). 
Tabla 3.2. Descriptores estadísticos, Tn (NMAD), de las características físicas de los ríos Ebrón, Palancia, Vallanca y Villahermosa relativos a la longitud $(\mathrm{m})$, anchura $(\mathrm{m})$, profundidad media $\left(P_{\text {med }}, m\right)$, profundidad máxima $\left(P_{\text {máx }}, m\right)$ y volumen $\left(m^{3}\right)$ en los distintos tipos de mesohábitat.

\begin{tabular}{|c|c|c|c|c|}
\hline & EBRÓN & VALLANCA & PALANCIA & VILLAHERMOSA \\
\hline \multicolumn{5}{|c|}{ Poza } \\
\hline Longitud & $20.88(7.12)$ & $14.49(8.82)$ & 21.74 (13.49) & 29.06 (16.08) \\
\hline Anchura & $4.57(1.23)$ & $2.86(0.79)$ & $6.09(1.61)$ & $5.84(1.54)$ \\
\hline$P_{\text {med }}$ & $0.45(0.15)$ & $0.42(0.18)$ & $0.61(0.16)$ & $0.43(0.13)$ \\
\hline$P_{\text {máx }}$ & $0.98(0.30)$ & $0.70(0.21)$ & $1.10(0.28)$ & $0.97(0.32)$ \\
\hline Volumen & $45.46(30.27)$ & $17.43(11.36)$ & 86.41 (62.57) & 75.05 (45.99) \\
\hline \multicolumn{5}{|c|}{ Tabla } \\
\hline Longitud & $19.38(4.60)$ & 11.85 (5.19) & $23.77(10.38)$ & $31.45(14.01)$ \\
\hline Anchura & $4.45(1.80)$ & $2.23(0.51)$ & $4.17(0.68)$ & $5.46(1.74)$ \\
\hline$P_{\text {med }}$ & $0.31(0.14)$ & $0.21(0.11)$ & $0.39(0.16)$ & $0.25(0.07)$ \\
\hline$P_{\text {máx }}$ & $0.62(0.29)$ & $0.37(0.16)$ & $0.56(0.08)$ & $0.52(0.13)$ \\
\hline Volumen & $29.43(25.27)$ & $6.14(4.32)$ & $37.62(19.38)$ & $44.96(25.52)$ \\
\hline \multicolumn{5}{|c|}{ Corriente } \\
\hline Longitud & 30.06 (18.38) & $10.02(4.74)$ & $18.54(8.90)$ & 27.02 (16.75) \\
\hline Anchura & $4.51(1.47)$ & $2.30(0.56)$ & $4.34(0.95)$ & 5.25 (1.29) \\
\hline$P_{\text {med }}$ & $0.28(0.07)$ & $0.18(0.07)$ & $0.37(0.12)$ & $0.21(0.06)$ \\
\hline$P_{\text {máx }}$ & $0.49(0.24)$ & $0.31(0.12)$ & $0.57(0.16)$ & $0.38(0.13)$ \\
\hline Volumen & $45.61(39.82)$ & $4.84(3.51)$ & $30.38(18.76)$ & $29.20(17.23)$ \\
\hline \multicolumn{5}{|c|}{ Rápido } \\
\hline Longitud & $23.93(11.26)$ & $8.95(4.82)$ & $14.66(8.60)$ & $16.83(8.90)$ \\
\hline Anchura & $4.57(1.71)$ & $2.59(0.70)$ & $4.89(0.79)$ & $4.72(1.32)$ \\
\hline$P_{\text {med }}$ & $0.38(0.13)$ & $0.28(0.07)$ & $0.37(0.18)$ & $0.20(0.06)$ \\
\hline$P_{\text {máx }}$ & $0.60(0.21)$ & $0.46(0.08)$ & $0.61(0.21)$ & $0.34(0.10)$ \\
\hline Volumen & $38.30(18.12)$ & $7.19(5.66)$ & $25.21(13.58)$ & $17.08(12.14)$ \\
\hline
\end{tabular}

\section{Resultados de la clasificación}

Las tres pruebas de clasificación permitieron una comparación de la variabilidad de los hábitats estudiados en los cuatro ríos trucheros circum-mediterráneos. A nivel general, la estructura de clases en las tres pruebas de clasificación fueron significativas $(p<0.001)$. Sin embargo, los test de la fortaleza de la clasificación fueron poco satisfactorios. En la clasificación Río la fortaleza fue de $0.87(\overline{\mathrm{B}}=0.55, \overline{\mathrm{W}}$ $=0.48)$, en la de Mesohábitat fue de $0.89(\bar{B}=0.55, \bar{W}=0.49)$, mientras que en RíoMesohábitat fue de $0.80(\overline{\mathrm{B}}=0.54, \overline{\mathrm{W}}=0.43)$. Por otro lado, los dendrogramas generados mediante los test de clasificación muestran la variabilidad entre clases en las comparativas de Río, Mesohábitat y Río-Mesohábitat (figura 3.1). En las clases Río, las ramas del dendrograma son desiguales o heterogéneas. Los hábitat de los ríos Villahermosa y Ebrón son más homogéneos (con valores $\bar{W} i$ más pequeños, y por lo 
tanto, las ramas son más homogéneas y aisladas con respecto al tronco $\bar{B}$ ) que los ríos Vallanca y Palancia (figura 3.1.a). En las clases Mesohábitat, corrientes y tablas fueron más estables (menores $\overline{\mathrm{W}} \mathrm{i}$ ) que pozas (mayores $\overline{\mathrm{W}} \mathrm{i}$ ) y rápidos (figura 3.1.b).

(a) clase Río

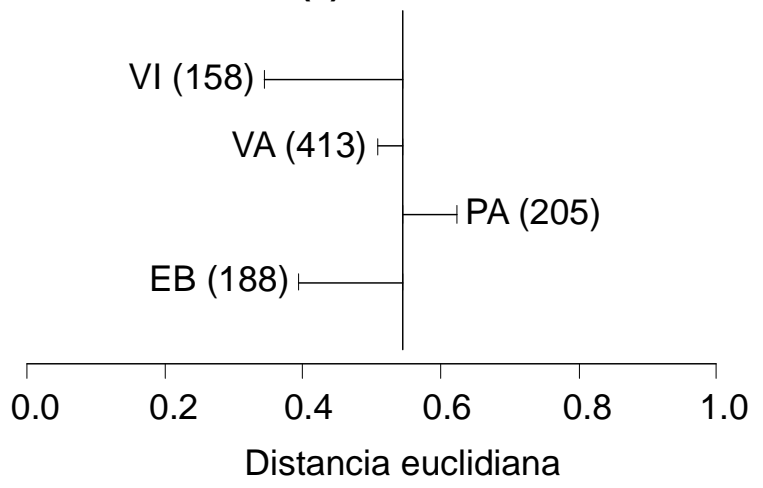

(b) clase Mesohábitat

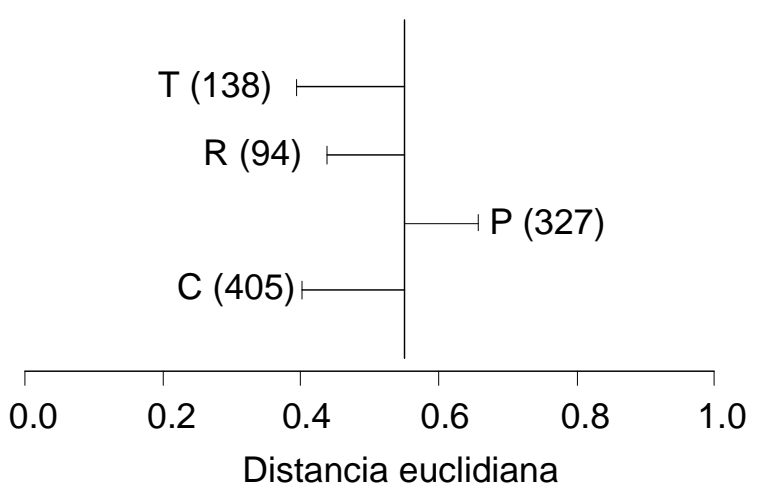

(c) clase Río-Mesohábitat

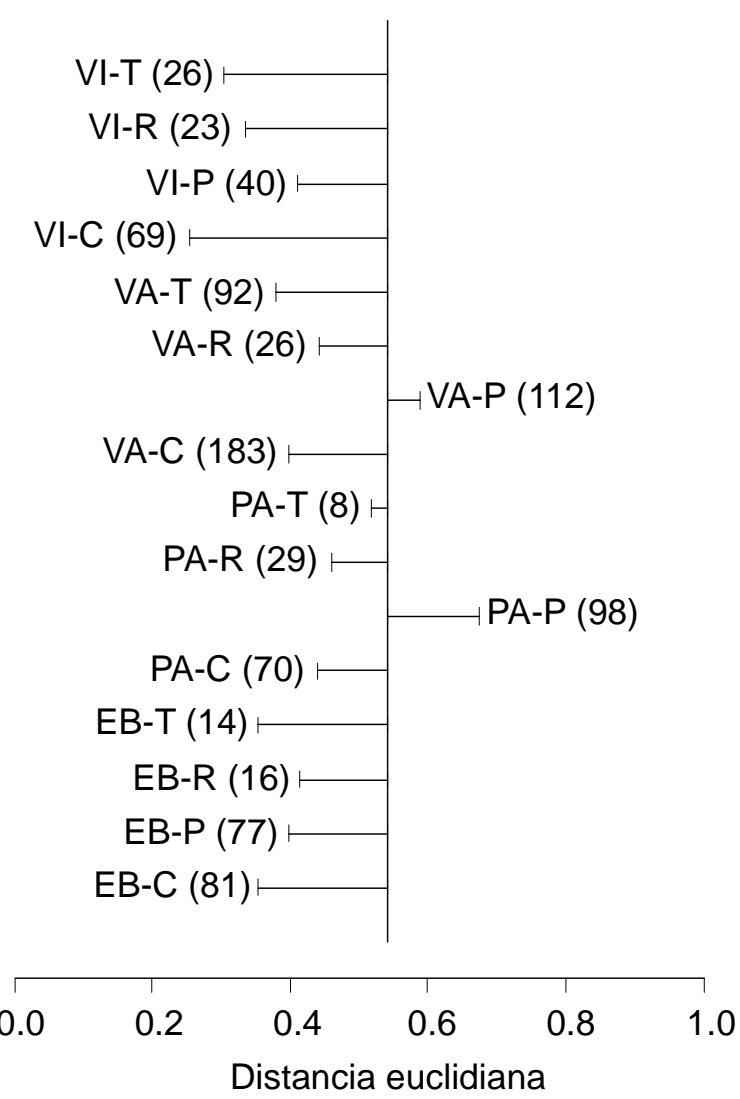

Figura 3.1. Dendrogramas obtenidos a partir del test de clasificación para las distintas pruebas establecidas (a) clases Río, (b) clases Mesohábitat y (c) clases Río-Mesohábitat. La distancia $\overline{\mathrm{B}}$ está representada por la base del tronco (línea vertical), mientras que las distancias $\bar{W} i$ las representan los extremos de las ramas (líneas horizontales). Entre paréntesis se indica el tamaño de muestra de cada grupo. Las abreviaturas están descritas en la tabla 3.1.

En general, las clases Río-Mesohábitat presentan la mayoría de valores de $\overline{\mathrm{W}} \mathrm{i}$ menores que $\overline{\mathrm{B}}$, por lo tanto, la variabilidad en cada clase es menor que la variabilidad media inter-clases (figura 3.1.c). Las corrientes y tablas de los ríos Villahermosa, Ebrón y Vallanca son más homogéneas que sus pozas y rápidos (como se observa en las dos pruebas anteriores). No ocurre lo mismo en el Palancia, siendo las pozas los mesohábitats más heterogéneos. Por último, para todo el conjunto de clases Río-Mesohábitat, las más homogéneas son las corrientes, tablas y rápidos del Villahermosa (VI-C, VI-T y VI-R), seguidas muy de cerca de las tablas y corrientes del 
Ebrón (EB-T y EB-C). Sin embargo, las pozas de los ríos Vallanca (VA-P) y Palancia (PA$P$ ) presentan valores $\bar{W}$ i mayores que $\bar{B}$, y por lo tanto, las pozas de estos dos ríos son las clases que presentan mayor variabilidad frente a la media de todas las demás.

\section{Asociación entre las unidades hidromorfológicas}

Este análisis ha permitido detectar patrones de comportamiento similar de los hábitats según las distintas características estudiadas. En la representación MDS (figura 3.2) no se observa claramente ninguna agrupación entre las clases de Río, Mesohábitat y Río-Mesohábitat (sólo EB-T/EB-P y VI-C/VI-T en ríos y VI-R/VA-R y VA$\mathrm{P} / \mathrm{PA}-\mathrm{P}$ en mesohábitats). Sólo las dos clases más homogéneas del dendrograma RíoMesohábitat, VI-C y VI-T (corrientes y tablas del Villahermosa), se agrupan en el extremo izquierdo superior mientras que las dos más variables, VA-P y PA-P (pozas de Vallanca y Palancia), en el extremo derecho inferior. Esto indica que estas clases serán similares en cuanto a las variables medidas y por lo tanto se parecerán más morfológicamente. En general, las corrientes y los rápidos de los diferentes ríos (mesohábitats rápidos) forman un grupo más compacto frente a las pozas y tablas (mesohábitats lentos). Además, existe la tendencia a que los mesohábitats rápidos se distribuyan en el umbral de los valores positivos del eje de ordenadas, mientras que los mesohábitats lentos por los valores negativos (excepto el VI-T que tiene valores positivos). 


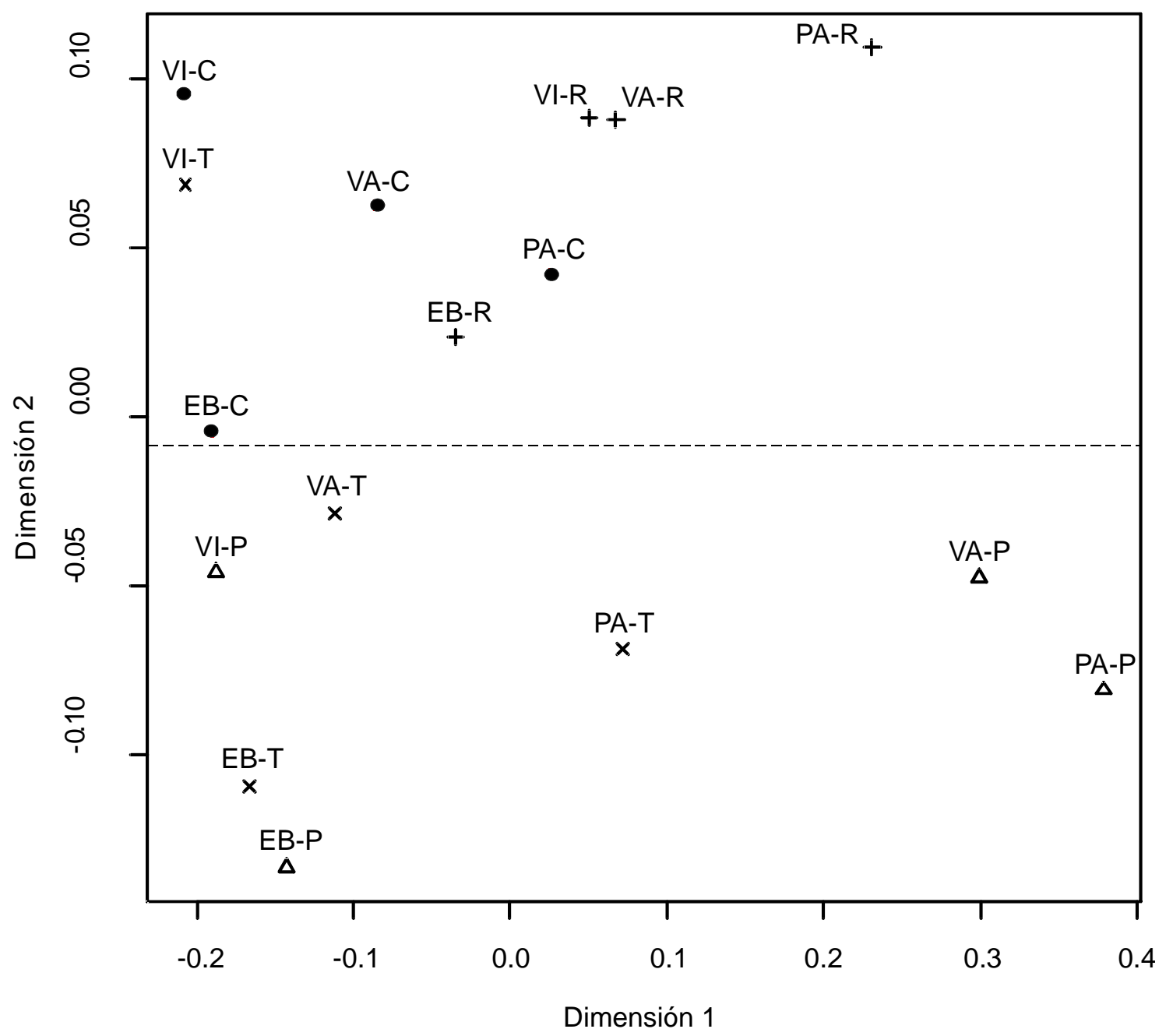

Figura 3.2. Escalado multidimensional métrico (MDS) de las distancias medias para los mesohábitats en los distintos ríos. Las abreviaturas están descritas en la tabla 3.1.

\section{Caracterización de las clases con mayor variabilidad}

En las pozas de los ríos Vallanca y Palancia se observó mayor variabilidad que en el resto de las clases (figura 3.1), y además, se comportaban de manera muy similar (figura 3.2), por lo que se aplicó en estas pozas la estrategia descrita en Lebart et al. (1995). Se observa que tanto las pozas del río Vallanca como las del Palancia se pueden agrupar en cuatro grupos diferenciados mediante el proceso de aglomeración conjunto de los métodos de Ward y k-medias (figura 3.3 a, b). Alrededor del primer grupo (conglomerado 1) del Vallanca (figura 3.3 a) se agrupan 36 pozas, 19 en el segundo, 36 en el tercero y 21 en el cuarto. Del mismo modo, el primer grupo del Palancia (figura 3.3 b) está formado por 12 pozas, 52 en el segundo, 15 en el tercero y 19 en el cuarto. Por otro lado, el plano factorial del río Vallanca recoge el $62 \%$ de la variabilidad frente el $60 \%$ del Palancia (figura $3.3 \mathrm{a}, \mathrm{b}$ ). 

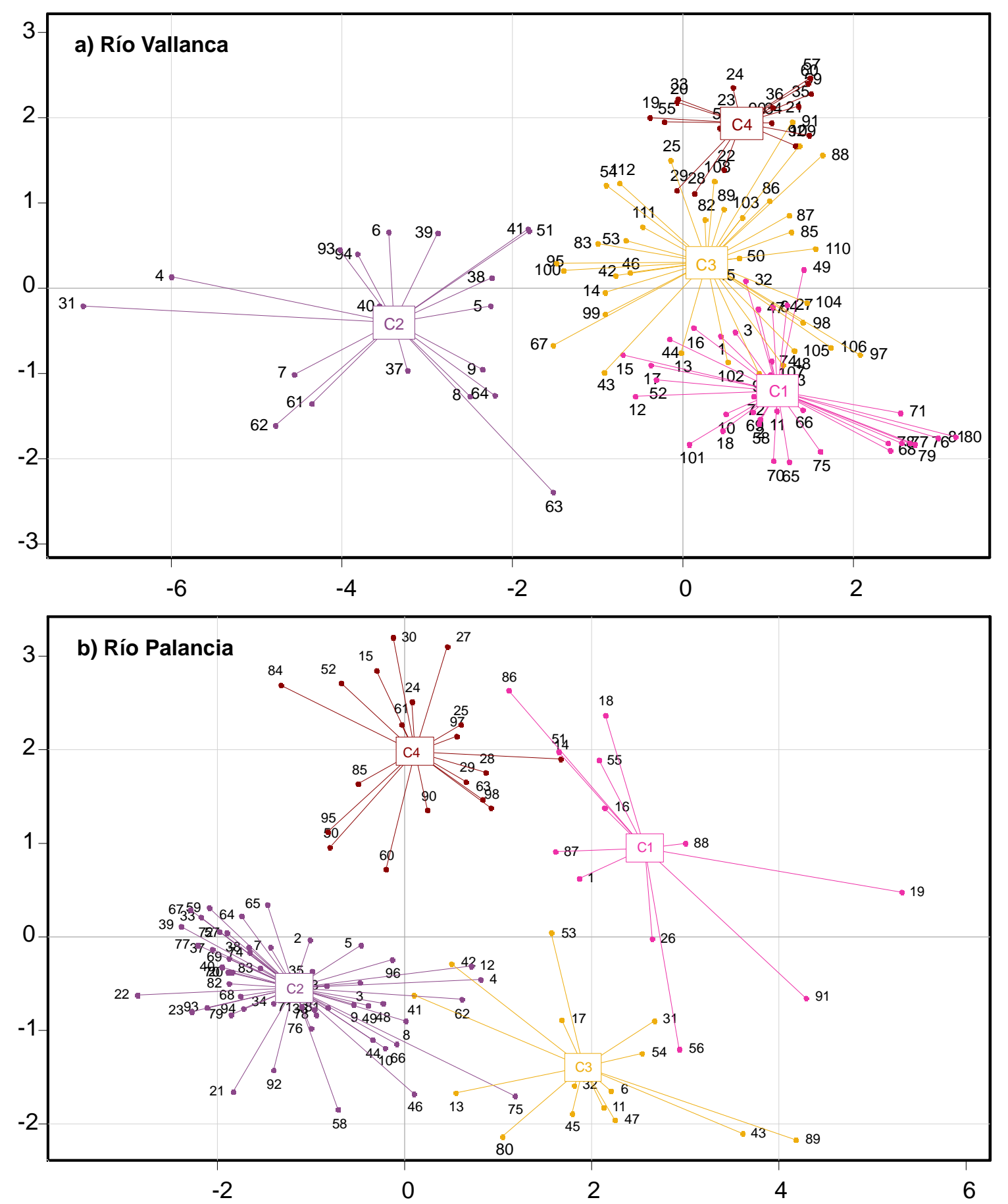

Figura 3.3. Plano factorial en el que muestra como se agrupan las pozas con respecto a los centros de los conglomerados $\mathrm{C} 1, \mathrm{C} 2, \mathrm{C} 3, \mathrm{C} 4$ en (a) el río Vallanca y en (b) el río Palancia.

Dichos grupos se han comparado entre sí mediante el test paramétrico robusto ANOVA. En aquellas variables en las que se detectó diferencias significativas entre sus medias $(p<0.005)$ se aplicó un análisis post hoc. Además, se han realizado gráficos box-plot que permiten observar la variabilidad física de los clusters. Estadísticamente, 
las medias de las ocho características analizadas en los cuatro grupos de pozas del río Vallanca (figura 3.4) fueron diferentes $(p<0.005)$. A continuación, el análisis post hoc detectó las diferencias entre pares de grupos de pozas $(p<0.05)$. El primer grupo de pozas tiene mayor porcentaje de sustrato grueso. Las pozas del segundo son las más grandes al tener significativamente las mayores longitudes, anchuras, profundidades (media y máxima) y volúmenes. Además, las pozas del cuarto grupo tienen mayor porcentaje de sustrato medio.
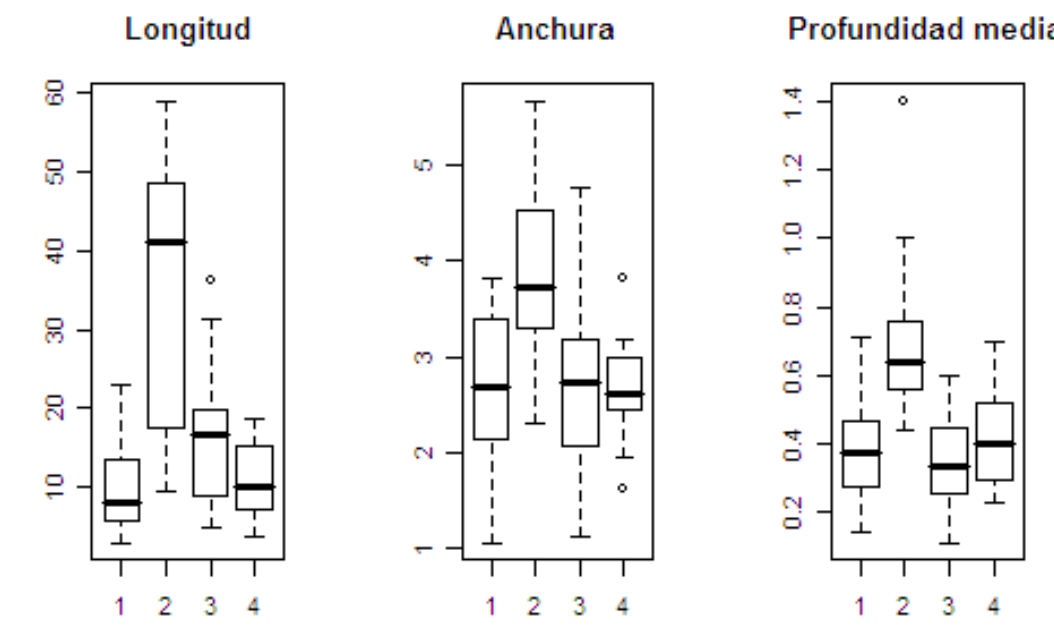

Profundidad máxima
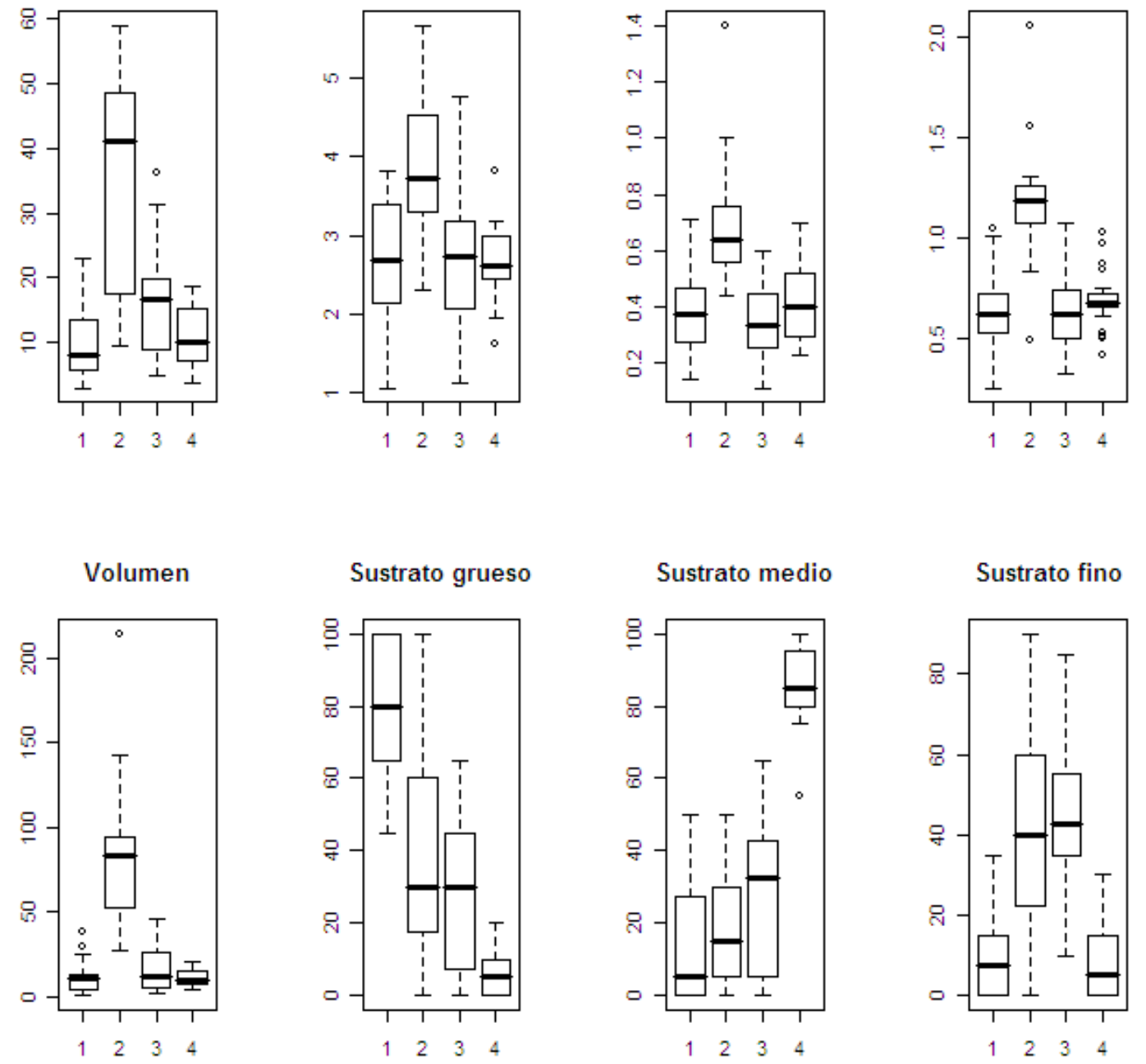

Sustrato grueso

Sustrato medio

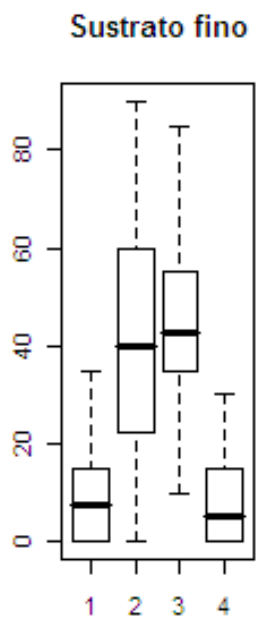

Figura 3.4. Gráficos box-plot de las pozas medidas en el río Vallanca $(N=112)$ para cada variable de mesohábitat según los cuatro conglomerados formados mediante el proceso de conglomeración de Lebart et al. (1995).

Por otro lado, en el río Palancia (figura 3.5), las medias de las características analizadas fueron diferentes en los cuatro grupos de pozas $(p<0.005)$, excepto para 
la anchura que no se detectaron diferencias significativas entre las cuatro medias. Además, el análisis post hoc de las variables detectó diferencias entre pares de grupos $(p<0.05)$. Las pozas del primer grupo son más largas, las del segundo tiene mayores porcentajes de sustrato grueso y las pozas del tercero tienen mayor profundidad máxima y mayor porcentaje de sustrato fino.
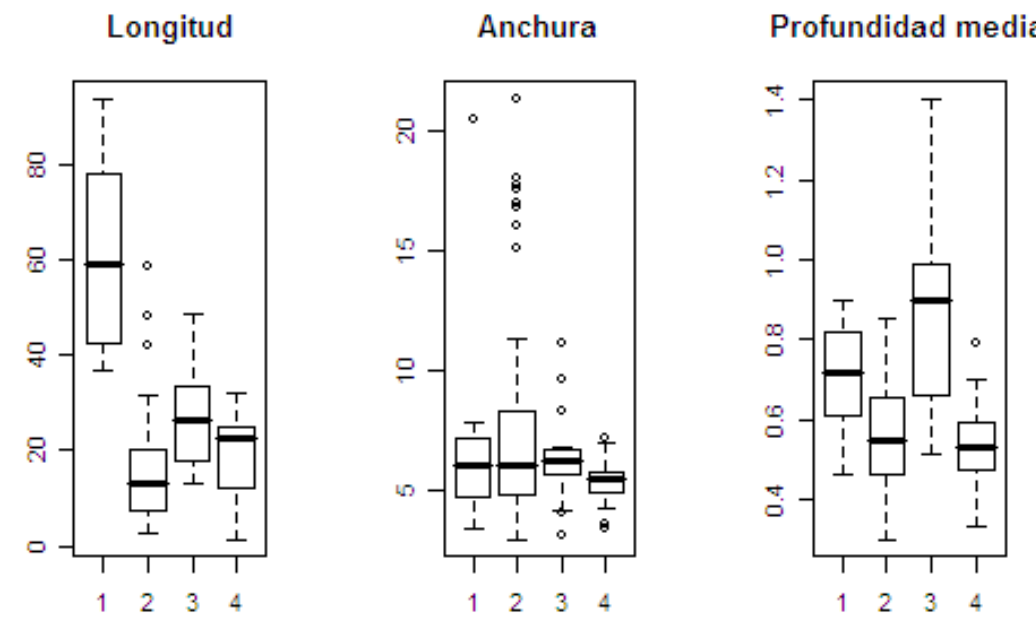

Profundidad máxima

Volumen

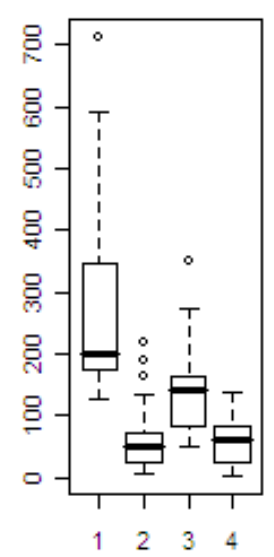

Sustrato grueso

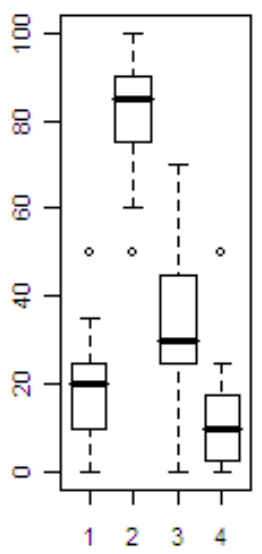

Sustrato medio

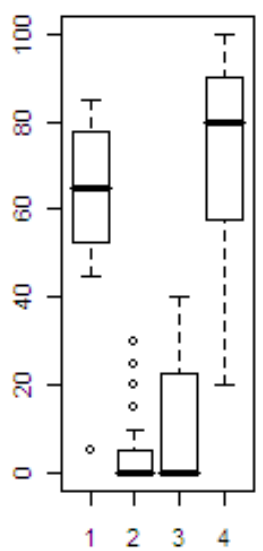

Sustrato fino

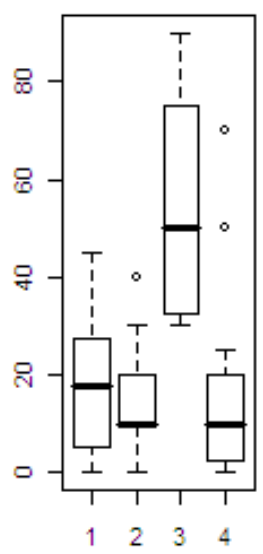

Figura 3.5. Gráficos box-plot de las pozas medidas en el río Palancia $(N=98)$ para cada variable de mesohábitat según los cuatro conglomerados formados mediante el proceso de conglomeración de Lebart et al. (1995).

\section{DISCUSIÓN}

El objetivo de este artículo era cuantificar la variación espacial de los diferentes tipos de hábitat según los diferentes atributos físicos que lo componen contestando a la 
pregunta de que si había más variabilidad física de los mesohábitat entre ríos o dentro de cada río según sus tipos mesohábitats. La respuesta es que los ríos Ebrón y Villahermosa son morfológicamente más homogéneos que Vallanca y Palancia; dado que el área de la cuenca en los puntos de estudio es mayor en los 2 primeros ríos (con 250 y $268 \mathrm{~km}^{2}$ respectivamente), podemos decir que el caudal se supone mayor en dichos ríos, produciéndose de forma natural una mayor tendencia a la homogeneidad de los hábitats.

Las corrientes y tablas son más homogéneas que pozas y rápidos, y consecuentemente, las pozas de los ríos Vallanca y Palancia son las más variables (figura 3.1). Esto también podría deberse a que los caudales medios que circulan por el Ebrón y Villahermosa son mayores que los de Vallanca y Palancia.

A nivel general, no hay muchos estudios que hayan incorporado análisis de la variabilidad espacial ocasionada en las unidades hidromorfológicas, y sus efectos sobre el diseño y análisis de programas de muestreo y experimentos de campo (Cooper et al., 1997). A pesar de que quedan por solucionar algunas cuestiones metodológicas y teóricas en el campo de los protocolos de identificación y la transferibilidad entre ríos (Clifford et al., 2006), los estudios sugieren que las características de los mesohábitat tienen significación ecológica por lo que la mejora futura del concepto y su enfoque se plantea necesaria (Harvey y Clifford, 2009).

La utilización de índices sencillos para observar la variación de los valores de la muestra, como es la media y la desviación estándar, deberían usarse con precaución porque distintas combinaciones de los valores pueden dar el mismo resultado. Estos índices suelen variar con el tamaño de las muestras o con número de registros en la muestra, y por consecuencia, afecta a la comparación entre los distintos estudios, sistemas o clasificaciones (Cooper et al., 1997). Tal es así, que al comparar los atributos físicos de las diferentes unidades hidromorfológicas en estos cuatro ríos no encontramos diferencias significativas entre las profundidades medias y los volúmenes, sin embargo, el río Vallanca está formado por pequeños hábitats, los del Ebrón son largos y profundos, los del Villahermosa son largos pero anchos y de escasa profundidad y los hábitats del Palancia suele ser los más profundos (tabla 3.2).

Por eso, muchos investigadores y gestores medioambientales han usado métodos más robustos como las distancias entre parejas de individuos de la matriz de proximidad para medir la similitud (o disimilitud) de los objetos estudiados (Wolda, 1981; Van Sickle y Hughes, 2000; Snelder et al., 2005). En este sentido, el test propuesto por Van Sickle (1997) ha resultado ser válido y robusto para evaluar la 
fortaleza y la utilidad de las clasificaciones. Su uso ha sido aplicado recientemente con gran énfasis en la ecología fluvial, permitiendo comparar los distintos sistemas de clasificación propuestos, como por ejemplo, la clasificación del hábitat por medio de las características físicas de los ríos (Snelder et al., 2005), el uso conjunto de los factores físicos con la comunidad de macroinvertebrados (Van Sickle y Hughes, 2000; Ilmonen et al., 2009), o bien, utilizando las características físicas y la comunidad de peces (Brenden et al., 2008). Si comparamos estas clasificaciones con nuestra propuesta de clasificación, ésta ha sido bastante más simple y con una fortaleza más pobre. No obstante, la utilización del dendrograma de similaridad nos ha permitido comparar visualmente el compactamiento y aislamiento de las clases establecidas $a$ priori, detectando aquellas clases con mayor variabilidad.

También el análisis MDS nos ha permitido observar las relaciones espaciales entre los diferentes ríos y mesohábitats. Los mesohábitats rápidos (corrientes y rápidos) tienden a agruparse más compactamente en la parte superior del eje de ordenadas, mientras que los mesohábitats lentos (pozas y tablas) están menos agrupados y casi todos en la parte inferior (figura 3.2). Esta técnica estadística también se ha usado frecuentemente en la clasificación de distintos cursos fluviales (Snelder et al., 2004; Brenden et al., 2008).

Todos estos resultados sugieren que se pueden agrupar los mesohábitats rápidos y los lentos en ríos de ambiente mediterráneo y que las pozas aportan la mayor variabilidad en la clasificación. Buffington y Montgomery (1999) apuntaban que los mesohábitats lentos (pozas y tablas) y rápidos (corrientes y rápidos) son espacialmente los más heterogéneos de todos los biotopos establecidos en las distintas clasificaciones. Vadas y Orth (1998) utilizaron una clasificación de siete tipos de mesohábitats para demostrar que la mayor variabilidad la aportan las variables relacionadas con la rugosidad del lecho, como el sustrato y la cobertura, frente a las variables hidráulicas. En este sentido, Jowett (1993) sugirió una clasificación sencilla de 3 tipos de mesohábitats (pool, riffle, run). Según él, estos mesohábitats son relativamente fáciles de distinguir visualmente, pero que, a diferencia de los que ocurre en los ríos mediterráneos, son los hábitats rápidos los más variables y donde se cometen más equivocaciones a la hora de clasificarlos correctamente. Sugiere además, que la formación de los hábitats se debió al amplio rango de las condiciones físicas locales del agua circulante, siendo la velocidad y la profundidad las variables más influyentes. Del mismo modo que en esta tesis, Harvey y Clifford (2009) demostraron que las pozas -a diferencia de tablas y rápidos- son hidráulicamente 
más complejas y tienen mayor heterogeneidad espacial, debido a las grandes variaciones de profundidad y a su estructura de flujo.

Por último, usando la propuesta de Lebart et al. (1995) han sido detectadas distintos patrones de pozas en los ríos Vallanca y Palancia (figura 3.3). En cada uno de estos dos ríos, las pozas se han agrupado en cuatro grupos. Esto sugiere que el biotopo poza podría clasificarse en varios subtipos. Nosotros hemos adaptado el sistema de clasificación utilizado por Dolloff et al. (1993). Ellos utilizaron un sistema de clasificación de hábitat simple, reconociendo al menos seis tipos de hábitat. En esta tesis, se ha utilizado un sistema sencillo con cuatro tipos de hábitat (pues el resto de tipos apenas estaban representados), sin embargo, según sus atributos físicos, esta clasificación no nos ha permitido agrupar las pozas de forma estable. El muestreo realizado ha resultado más rápido que si hubiéramos utilizado muchos más tipos de hábitats (véase las clasificaciones de Hawkins et al., 1993; Flosi y Reynolds, 1994) y es relativamente ambiguo en comparación con clasificaciones de hábitats más detalladas (Roper y Scarnecchia, 1995). Por poner un ejemplo, Hawkins et al., 1993 propuso un sistema jerárquico de clasificación con dieciocho biotopos diferentes, de los cuales once estaban establecidas como aguas lentas o pozas.

El uso de metodologías de muestreo ya establecidas, permite obtener de manera rápida y sencilla la caracterización física del hábitat. A menudo, estas técnicas ha sido desarrolladas y testadas en cursos fluviales donde las condiciones hidrogeomorfológicas difieren mucho a los ambientes mediterráneos. La metodología desarrollada en este estudio ha permitido observar la variabilidad espacio-temporal del hábitat de manera rápida y eficaz, destacando, según sus atributos, las fortalezas y debilidades de la clasificación utilizada. Como conclusión final, resultaría positivo en futuras clasificaciones establecer una subdivisión en los mesohábitats con mayor profundidad, dividiendo las pozas en varios tipos, como han propuesto otros investigadores, pero de igual modo es importante evaluar dichas clasificaciones en nuevos y específicos estudios para ríos de régimen mediterráneo. Este estudio presenta una aplicación directa para los estudios hidromorfológicos e hidrobiológicos en ríos trucheros o ríos de montaña de la Península Ibérica, así como para la aplicación de metodologías innovadoras para el estudio de caudales ambientales a distintas escalas, en países dentro y fuera del ámbito mediterráneo. 


\section{BIBLIOGRAFÍA}

Beisel J.N, P. Usseglio-Polatera, S. Thomas y J.C Moreteau. 1998. Stream community structure in relation to spatial variation: the influence of mesohabitat characteristics. Hydrobiologia 389: 73-88.

Bisson, P.A., J.L. Nielsen, R.A. Palmason y L.E. Grove. 1982. A system of naming habitat types in small streams, with examples of habitat utilization by salmonids during low streamflow. Pages 62-73 en N.B. Armantrout (Ed.). Acquisition and utilization of aquatic habitat inventory information. Symposium proceeding, Portland, Oregon, USA.

Bisson, P.A., J.M. Buffington y D.R. Montgomery. 2006. Valley segment, stream reaches, and channel units. Pages 23-49 en F.R. Hauer y G. A. Lamberti (Eds.). Methods in stream ecology. Academic Press, San Diego, California, USA.

Brenden, T.O., L. Wang y P.W. Seelbach. 2008. A river valley segment classification of Michigan streams based on fish and physical attributes. Transactions of the American Fisheries Society 137: 1621-1636.

Brown, A.V. y P.P. Brussock. 1991. Comparisons of benthic invertebrate between riffles and pools. Hydrobiologia 220: 99-108.

Buffington, J.M., y D.R. Montgomery. 1999. Effects of hydraulic roughness on surface textures of gravel-bed rivers. Water Resources Research 35: 3507-3522.

CEN (Comité Européen de Normalisation). 2004. Water quality -Guidance standard for assessing the hydromorphological features of rivers. Final draft prEN 14614, European Standard. $21 \mathrm{pp}$.

Clifford N.J., O. Harmar, G. Harvey y G.E. Petts. 2006. Physical habitat, ecohydraulics and river design: a review and case study re-evaluation of some popular concepts and methods. Aquatic Conservation: Marine and Freshwater Ecosystems 16: 389-408.

Cooper, S.D., L. Barmuta, O. Sarnelle, K. Kratz y S. Diehl. 1997. Quantifying spatial heterogeneity in streams. Journal of the North American Benthological Society 16: 174188.

Digby, P.G.N. y R.A. Kempton. 1987. Multivariate analysis of ecological communities. Chapman and Hall, London, UK.

Dolloff, C.A., D.G. Hankin y G.H. Reeves. 1993. Basinwide estimation of habitat and fish populations in streams. U.S. Department of Agriculture. Forest Service. Southeastern Forest Experiment Station, 25 pp. 
Erös, T. y G.D. Grossman. 2005. Effects of within-patch habitat structure and variation on fish assemblage characteristics in the Bernecei stream, Hungary. Ecology of Freshwater Fish 14: 256-266.

European Commission. 2000. Directive 2000/60/EC of the European parliament of the council of 23 October 2000 establishing a framework for Community action in the field of water policy. Official Journal of the European Communities L327: 1-72.

Flosi, G., y F.L. Reynolds. 1994. California salmonid stream habitat restoration manual. 2nd ed. Pacific Lumber Company, Scotia, California.

Frissell, C.A., W.J. Liss, C.E. Warren y M.D. Hurley. 1986. A hierarchical fremework for stream habitat classification: Viewing streams in a watershed context. Environmental Management 10: 199-214.

García Pérez, A. 2005. Métodos avanzados de estadística aplicada. Métodos robustos y de remuestreo. Universidad Nacional de Educación a Distancia, UNED, Madrid. 255 pp.

González del Tánago, M y D. García de Jalón. 2006. Propuesta de caracterización jerárquica de los ríos españoles para su clasificación según la Directiva Marco de la Unión Europea. Limnetica 25: 693-712.

Goslee, S.C. y D.L. Urban. 2007. The ecodist package for dissimilarity-based analysis of ecological data. Journal of Statistical Software 22: 1-19.

Hankin, D.G. y G.H. Reeves. 1988. Estimating total fish abundance and total habitat area in small streams based on visual estimation methods. Canadian Journal of Fisheries and Aquatic Sciences 45: 834-844.

Harvey, G.L. y N.J. Clifford. 2009. Microscale hydrodynamics and coherent flow structures in rivers: implications for the characterization of physical habitat. River Research and Applications 25: 160-180.

Hawkins, C.P., J.L. Kershner, P.A. Bisson, M.D. Bryant, L.M. Decker, S.V. Gregory, D.A. McCullough, C.K. Overton, G.H. Reever, R.J. Steedman y M.K. Young. 1993. A hierarchical approach to classifying stream habitat features. Fisheries 18: 3-12.

Hawkins, C.P., R.H. Norris, J. Gerritsen, R.M. Hughes, S.K. Jackson, R.K. Johnson y R.J. Stevenson. 2000. Evaluation of the use of landscape classifications for the prediction of freshwater biota: synthesis and recommendations. Journal of the North American Benthological Society. 19: 541-556.

Hayes, D., E. Baker, R. Bednarz, D. Borgeson, Jr. J. Braunscheidel, J. Breck, M. Bremigan, A. Harrington, R. Hay, R. Lockwood, A. Nuhfer, J. Schneider, P. Seelbach, J. Waybrant y T. 
Zorn. 2003. Developing a standardized sampling program: the Michigan experience. Fisheries 28: 18-25.

Ilmonen, J., L. Paasivirta, R. Virtanen y T. Muotka. 2009. Regional and local drivers of macroinvertebrate assemblages in boreal springs. Journal of Biogeography 36: 822-834

Jowett, I.G. 1993. A method for objetively identifying pool, run, and riffle habitats from physical measurements. New Zeland Journal of Marine and Freshwater Research 27: 241248.

Lawa. 2000. Gewässerstrukturgütebewertung in der Bundesrepublik Deutschlan. Verfahren für kleine und mittelgroße Fließgewässer, Berlin.

Lebart, L., A. Morineau y M. Piron. 1995. Statisitique exploratoire multidimensionnelle. Dunod, Paris.

Modde, T., R.C. Ford y M.G. Parsons. 1991. Use of a habitat-based stream classification system for categorizing trout biomass. North American Journal of Fisheries Management 11: $305-311$.

Parasiewicz, P. 2001. MesoHABSIM: a concept for application of instream flow models in river restoration planning. Fisheries 26: 6-13.

Pardo, C.E. y P.C. Del Campo. 2007. Combinación de métodos factoriales y de análisis de conglomerados en R. Revista Colombiana de Estadística 30: 231-245.

Pardo, I., M. Álvarez, J. Casas, J. L. Moreno, S. Vivas, N. Bonada, J. Alba-Tercedor, P. JáimezCuéllar, G. Moyá, N. Prat, S. Robles, M. L. Suárez, M. Toro y M.R. Vidal-Abarca. 2002. El hábitat de los ríos mediterráneos. Diseño de un índice de diversidad de hábitat. Limnetica 21:115-133.

Pardo, I. y P.D. Armitage. 1997. Species assemblages as descriptors of mesohabitats. Hydrobiologia 344: 111-128.

Parsons, M., M.C. Thoms y R.H. Norris. 2003. Scales of macroinvertebrate distribution in relation to the hierarchical organization of river systems. Journal of the North American Benthological Society 22: 105-122.

Platts, W.S., W.F. Megahan y G.W. Minshall. 1983. Methods for evaluating stream riparian, and biotic conditions. USDA Forest Service. General Tech. Report. INT-138. 70 pp.

Poff, N.L. 1997. Landscape filters and species traits: towards mechanistic understanding and prediction in stream ecology. Journal of the North American Benthological Society 16: 391-409. 
Raven, P.J., P. Fox, M. Everard, N.T.H. Holmes y F.H. Dawson. 1997. River Habitat Survey: a new system for classifying rivers according to their habitat quality. En: Freshwater quality: Defining the indefinable? P. J. Boon \& D. L. Howell (eds.): 215-234. The Stationery Office, Edinburgh.

R Development Core Team (2008). R: A language and environment for statistical computing. $\mathrm{R}$ Foundation for Statistical Computing, Vienna, Austria. ISBN 3-900051-07-0, URL http://www.R-project.org.

REFCOND. 2003. Guidance on establishing reference conditions and ecological status class boundaries for inland surface waters. EU Common Implementation Strategy for the Water Framework Directive. 86 pp.

Roper, B.B. y D.L. Scarnecchia. 1995. Observer variability in classifying habitat types in stream surveys. North American Journal of Fisheries Management 15:49-53.

Schwartz, J.S. y E.E. Herricks. 2008. Fish use of ecohydraulic-based mesohabitat units in a low-gradient Illinois stream: implications for stream restoration. Aquatic Conservation: Marine and Freshwater Ecosystems 18: 852-866.

Seelbach, P.W., M.J. Wiley, M.E. Baker y K.E. Wehrly. 2006. Initial classification of river valley segments across Michigan's Lower Peninsula. Pages 25-48 in R.M. Hughes, L. Wang and P.W. Seelbach, editors. Landscape influences on stream habitats and biological assemblages. American Fisheries Society, Symposium 48, Bethesda, Maryland.

Snelder, T.H., F. Cattanéo, A.M. Suren y B.J.F. Biggs. 2005. Is the river environment classification an improved landscape-scale classification of rivers? Journal of the North American Benthological Society 23: 580-598.

Snelder, T.H., R. Woods y B.J.F. Biggs. 2005. Improved ecohydrological classification of rivers. River Research and Applications 21: 609-628.

Sowa, S.P., D.D. Diamond, R. Abbitt, G. Annis, T. Gordon, M. E. Morey, G. R. Sorensen y D. True. 2005. A gap analysis for riverine ecosystems of Missouri. USGS National Gap Analysis Program, Final Report, Reston, Virginia.

Stoddard, J.L., D.V. Peck, S.G. Paulsen, J. Van Sickle, C.P. Hawkins, A.T. Herlihy, R.M. Hughes, P.R. Kaufmann, D.P. Larsen, G. Lomnicky, A.R. Olsen, S.A. Peterson, P.L. Ringold y T. R. Whittier. 2005. An ecological assessment of western streams and rivers. U.S. Environmental Protection Agency, EPA 620/R-05/005, Washington, D.C.

Tickner, D., P.D. Armitage, M.A. Bickerton y K.A. Hall. 2000. Assessing stream quality using information on mesohabitat distribution and character. Aquatic Conservation: Marine and Freshwater Ecosystems 10: 179-196. 
Thomson, J.R., M.P. Taylor y G.J. Brierley. 2004. Are river styles ecologically meaningful? A test of the ecological significance of a geomorphic river characterization scheme. Aquatic Conservation: Marine and Freshwater Ecosystems 14: 25-48.

Tonn, W.M. 1990. Climate change and fish communities: a conceptual framework. Transactions of the American Fisheries Society 119: 337-352.

Vadas, R.L. y D.J. Orth. 1998. Use of physical variables to discriminate visually determined mesohabitat types in North American stream. River 6: 143-159.

Van Sickle, J. 1997. Using mean similarity dendrograms to evaluate classifications. Journal of Agricultural, Biological and Environmental Statistics 2: 370-388.

Van Sickle, J. y R.M. Hughes. 2000. Classification strengths of ecoregions, catchments, and geographic clusters for aquatic vertebrates in Oregon. Journal of the North American Benthological Society 19: 370-384.

Wang, L., P.W. Seelbach y R.M. Hughes. 2006. Introduction to landscape influences on stream habitats and biological assemblages. American Fisheries Society Symposium 48: 123.

Wolda, H. 1981. Similarity indices, simple size and diversity. Oecologia 50: 296-302. 


\section{CAPÍTULO 4}

\section{CRECIMIENTO, ABUNDANCIA Y PRODUCCIÓN DE LA TRUCHA COMÚN EN RÍOS MEDITERRÁNEOS; REVISIÓN Y COMPARACIÓN CON OTRAS}

POBLACIONES

\section{Resumen}

Se han estudiado las poblaciones españolas de trucha común en cuatro ríos que vierten al mar Mediterráneo durante cuatro años (2003-2006). Se calcularon en distintas unidades hidromorfológicas, las longitudes, el peso y la tasa de crecimiento anual por clases de edad. También se calcularon las medias de las abundancias (densidad y biomasa), la producción y la tasa de renovación P/B. Se utilizaron métodos robustos en la estimación de las variables, empleándose como parámetro de localización el estimador de Huber, Tn, y como parámetro de escala la Desviación Absoluta Mediana Estandarizada, NMAD. El crecimiento en longitud de las truchas es grande $(72-95 \mathrm{~mm}$ en la edad 0+, 146-178 mm en la edad 1+, 206-241 $\mathrm{mm}$ en la edad 2+, 213-315 mm en la edad 3+). Hay considerable variación en la densidad y biomasa media de los ríos, con valores comprendidos entre 250-3247 truchas $\cdot$ ha $^{-1}$ y 20-119 $\mathrm{Kg} \cdot \mathrm{ha}^{-1}$, respectivamente. La producción anual es baja con un rango comprendido entre los 4-17 kg.ha $a^{-1} \cdot a_{n} o^{-1}$, con valores muy bajos de la tasa de renovación anual (0.08-0.25). El crecimiento, las abundancias y las producciones se han comparado y discutido en relación con otras poblaciones trucheras en ríos de Europa y América.

Palabras clave: Salmo trutta, trucha común, dinámica poblacional, ríos mediterráneos, Península Ibérica. 


\section{INTRODUCCIÓN}

Uno de los peces continentales ampliamente distribuida por el mundo es la trucha común (Salmo trutta). Ésta es originaria de Europa, norte de África y oeste de Asia aunque en los últimos años ha sido introducida en al menos 24 países fuera de Europa (Elliott, 1994). La razón de su amplia distribución geográfica es la gran plasticidad que tiene para adaptarse a los diferentes ambientes donde habita, además del gran interés que suscita debido a su gran valor social y económico. Por lo tanto, la especie varia en tamaño, tasas de crecimiento, nichos de alimentación y usos del hábitat a través de los distintos cursos de agua donde vive (Klemetsen et al., 2003).

En los últimos 30 años las poblaciones de trucha común han sido objeto de numerosos estudios en distintas partes del mundo, abarcando multitud de condiciones. En Europa, la mayoría de los trabajos sobre las poblaciones de trucha común han sido publicados en países del norte, como por ejemplo, Noruega (Hesthagen et al., 2004), Suecia (Nordwall et al., 2001), Irlanda (Annoni et al., 1997), Francia (Baglinière et al., 1989) y Gran Bretaña (Elliott, 1994). En la Península Ibérica los estudios más significativos han sido realizados en ríos del centro y el norte de España, por ejemplo en el río Jarama (Lobón-Cerviá y Penczak, 1984), en el río Chabatchos (Lobón-Cerviá, 2003), en el río Tormes (Alonso-González et al., 2004) y en los ríos tributarios del Tajo y Duero (Almodóvar et al., 2006).

En los últimos años, los avanzados estudios genéticos sugieren una gran diversidad evolutiva de la trucha común en los países mediterráneos del sur de Europa (GarcíaMarín et al., 1999; Machordom et al., 2000). Sólo en la Península Ibérica, Machordom et al. (2000) establecieron cinco linajes distintos según la distribución haploide y la biogeografía Ibérica. Nuestro estudio está encuadrado en poblaciones filogeográficas del tipo mediterráneo, residentes dentro de un área de distribución geográfica muy pequeña. Además de su limitada distribución, y al igual que otras poblaciones del sur de Europa, están afectadas por la destrucción de sus hábitats, la polución, la introducción de especies exóticas, sobrepesca y la introducción de genes de otras truchas extranjeras como resultado de una reintroducción artificial (Almodóvar et al., 2006; Ferreira et al., 2007; Sánchez-Montoya et al., 2009). Si a esto le añadimos que los ríos mediterráneos están influenciados por la torrencialidad de sus regímenes de caudales y por las fuertes fluctuaciones de temperatura (García de Jalón, 1992), podemos decir que la conservación de la especie pasa por una adecuada gestión de 
sus poblaciones, basada en el estudio de su ecología y el detallado conocimiento sobre los factores y mecanismos que controlan la dinámica poblacional.

El primer paso para el entendimiento de su ecología es la cuantificación de los parámetros poblacionales como por ejemplo el crecimiento, las abundancias y la producción de las poblaciones salvajes de trucha.

El presente estudio pretende (1) establecer los rangos del crecimiento, las densidades y biomasas y las producciones de cuatro poblaciones mediterráneas de trucha común, así como (2) comparar dichas poblaciones de ríos mediterráneos del este de la península con otras poblaciones del mundo.

\section{MÉTODOS}

\section{Adquisición de datos en campo}

Todas las muestras de trucha común $(N=1188)$ se recogieron en los meses de Julio y Agosto entre los años 2003 y 2006. Se establecieron cuatro estaciones de muestreo en cada río (en total 16 estaciones en 4 ríos). En todos los años de muestreo los cuatro ríos permanecieron vedados a la pesca deportiva. Todos los muestreos fueron realizados con caudal base y se destaca el hecho de que en los dos últimos años de estudio (2005 y 2006) hubo una fuerte sequía que hizo que los tramos más altos de los ríos Vallanca y Villahermosa se secaran, perdiéndose tres de las dieciséis estaciones establecidas.

Se empleó un equipo de pesca eléctrica en la captura de los peces. Después de cerrar el área con redes, correspondiendo cada una a un único mesohábitat o unidad hidromorfológica, se realizaron como mínimo tres pasadas sin reemplazamiento de las truchas en cada estación de muestreo. A todos los peces extraídos se les midió la longitud furcal ( $L f, \pm 1 \mathrm{~mm}$ ) y su peso ( $W, \pm 1 \mathrm{~g}$ ). A la mayoría de los individuos de más de un año de edad se les extrajeron escamas para su posterior análisis. Las edades fueron establecida en el laboratorio mediante el análisis de las frecuencias de longitudes y verificadas mediante la lectura de las escamas de la muestra de peces. Durante los cuatro años de muestreo sólo se capturaron tres truchas de más de cinco años de edad, una en el río Ebrón con $420 \mathrm{~mm}$ de longitud, otra en el río Palancia con $402 \mathrm{~mm}$ y otra en el río Villahermosa con $384 \mathrm{~mm}$. 
La tasa de crecimiento anual en peso $\mathrm{G}_{\mathrm{W}}\left(\mathrm{g} \cdot \mathrm{año} \mathrm{o}^{-1}\right)$ se calculó mediante la ecuación $\mathrm{GW}$ $=\left(\ln W_{2}-\ln W_{1}\right) /\left(t_{2}-t_{1}\right)$, donde $W_{2}$ y $W_{1}$ (en gramos) es el peso medio de la trucha de cada clase de edad en los años $t_{2}$ y $t_{1}$. La densidad de truchas ( $D$, truchas $\cdot$ ha $^{-1}$ ) fue estimada para cada muestra aplicando el método de máxima verosimilitud ponderada de Carle y Strub (1978). La biomasa (B, $\mathrm{kg} \cdot \mathrm{ha}^{-1}$ ) fue calculada como el producto del peso medio por la densidad poblacional (García de Jalón et al., 1993). La producción anual $\left(P, \mathrm{~kg} \cdot \mathrm{ha}^{-1} \cdot \mathrm{año}^{-1}\right)$ fue evaluada mediante el método algebraico de Ricker (1946) a través del producto de la biomasa media $\left(B_{m}\right)$ y la tasa de crecimiento anual $(G w)$, siendo $B_{m}=B_{0}\left(e^{G w-Z}-1\right) /(G w-Z)$ donde $B_{0}$ es la biomasa inicial, $G w$ la tasa de crecimiento anual y $\mathrm{Z}$ la tasa de mortalidad $\left(\mathrm{N}_{2}=\mathrm{N}_{1} \cdot \mathrm{e}^{-\mathrm{zt}}\right)$. Por último, se calculó la tasa de renovación anual $\mathrm{P} / \mathrm{B}$ definido como el cociente entre la producción anual y la biomasa.

\section{Análisis de los datos}

Las edades fueron establecida en el laboratorio mediante el método de Petersen o análisis de las frecuencias de longitudes y verificadas mediante la lectura de las escamas, para cada río y para cada año. Las edades fueron designadas siguiendo la terminología estándar; la trucha común en el primer verano de vida fue nombrada como 0+, el segundo año, con la formación en invierno del primer annuli, como 1+ y así sucesivamente.

Una vez asignados la edad de cada individuo, se calculó la longitud, el peso y el crecimiento medio en cada río y para cada clase de edad, sin embargo la densidad, la biomasa, la producción y la tasa de renovación fue calculada globalmente para cada río y cada año. En todas las medias de estos índices se utilizó como parámetro de localización el estimador de Huber, Tn, y como parámetro de escala la Desviación Absoluta Mediana Estandarizada, NMAD (García Pérez, 2005). En los ríos trucheros, es conocida la considerable variabilidad que pueden presentar los parámetros (p.e. Newman y Waters, 1989); por ello todos los parámetros calculados fueron comparados entre ríos mediante el test paramétrico ANOVA de Welch. Para la observación de posibles semejanzas en el crecimiento entre ríos se solicitó a éste test la comparación múltiple por parejas por el método generalizado de Yuen, para poder determinar que medias difieren (análisis post hoc) con un nivel de significación $\alpha=$ 0.01. El programa estadístico utilizado fue el $\mathrm{R}$ ( $R$ Development Core Team, 2008). 


\section{RESULTADOS}

\section{Asignación de edad}

La determinación de la edad de las truchas se hizo mediante el análisis de los histogramas de frecuencia y la lectura de escamas. De esta manera se transformaron las distintas clases modales a clases de edad, estableciendo así la edad para cada individuo. Las figuras 4.1, 4.2, 4.3 y 4.4 muestran los histogramas de frecuencias de longitud furcal ( $\mathrm{mm}$ ) de los ríos Ebrón, Vallanca, Palancia y Villahermosa, respectivamente. A nivel general, en todos los ríos se observa que los histogramas del 2005 son mejores que para el resto de los años. Mejor en cuanto a que hay un aumento de las capturas de la clase $0+$, mejorando el alevinaje, y las campanas de Gauss de las distintas clases de edad se observan mejor.
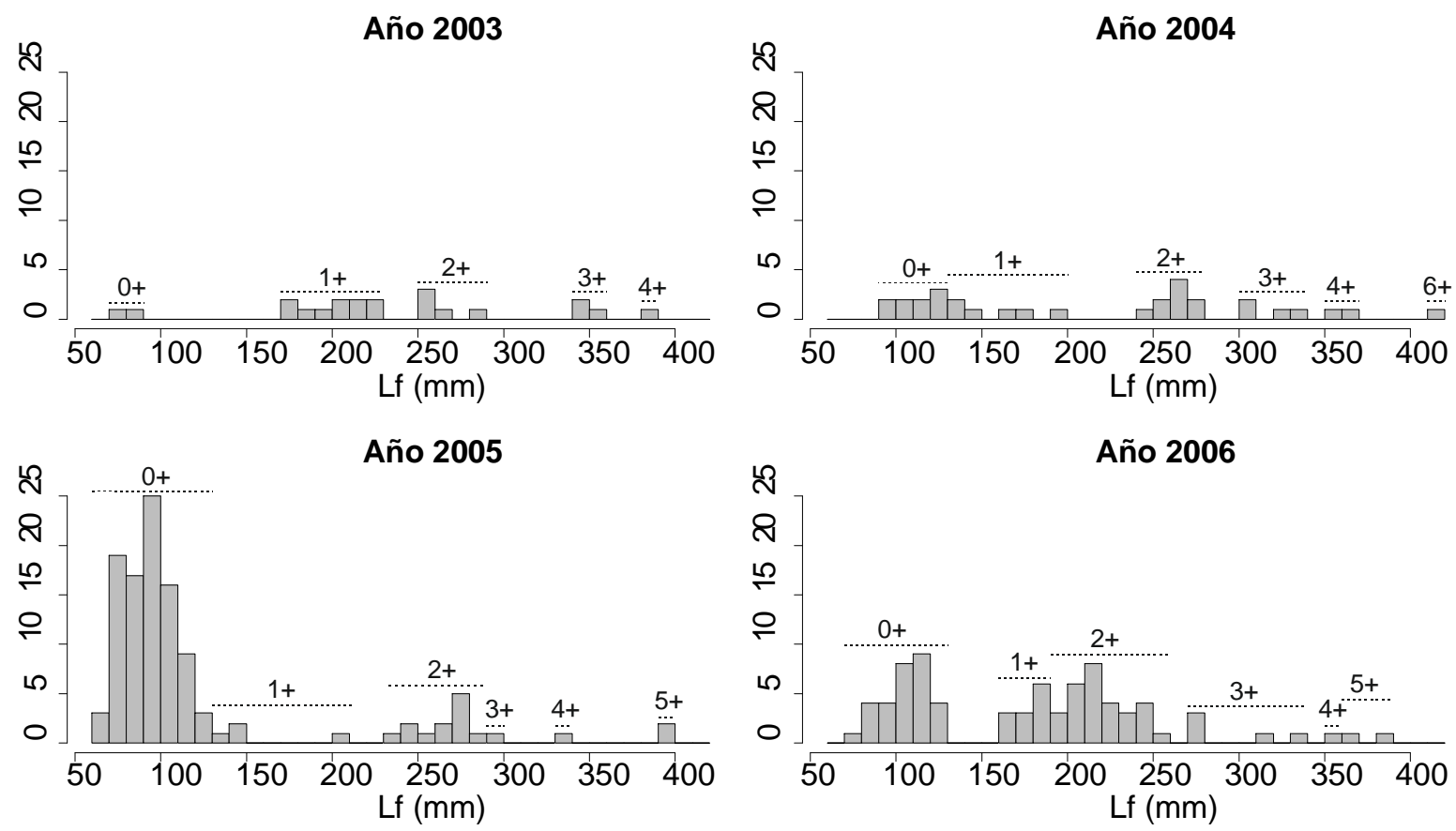

Figura 4.1. Histogramas de frecuencias del río Ebrón para los años 2003, 2004, 2005 y 2006. Lf, longitud furcal. 

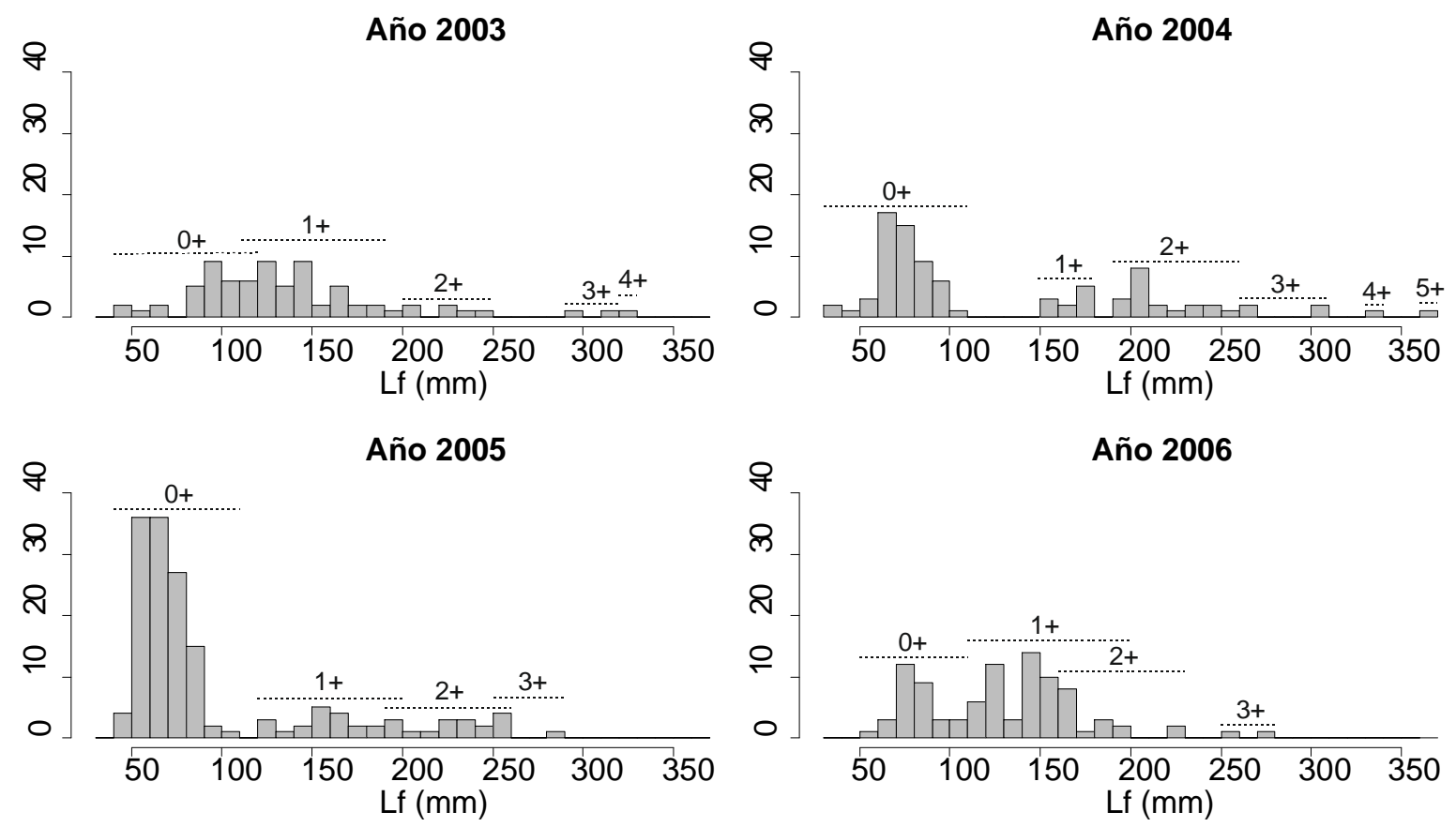

Figura 4.2. Histogramas de frecuencias del río Vallanca para los años 2003, 2004, 2005 y 2006. Lf, longitud furcal.
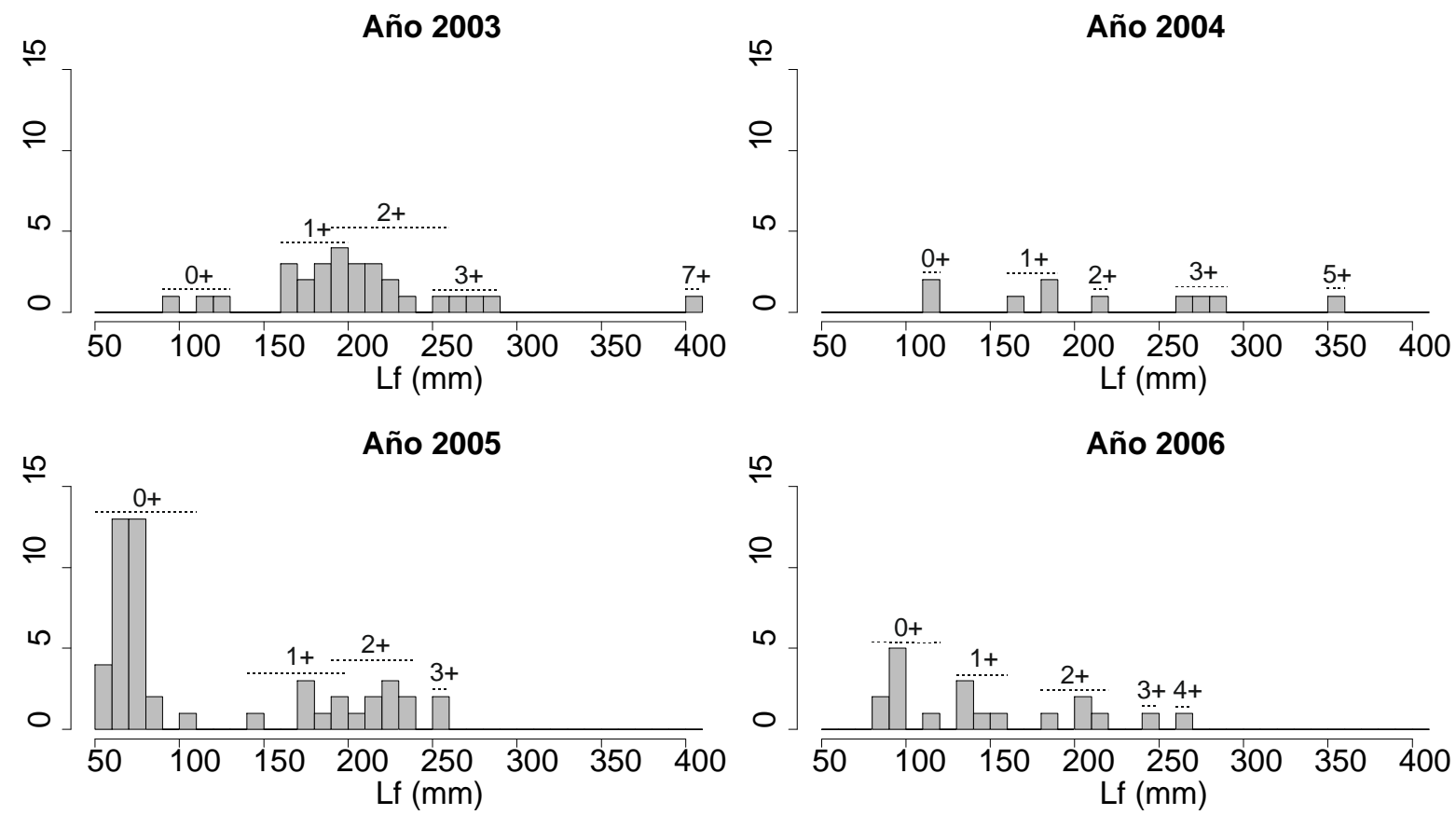

Figura 4.3. Histogramas de frecuencias del río Palancia para los años 2003, 2004, 2005 y 2006. Lf, longitud furcal. 

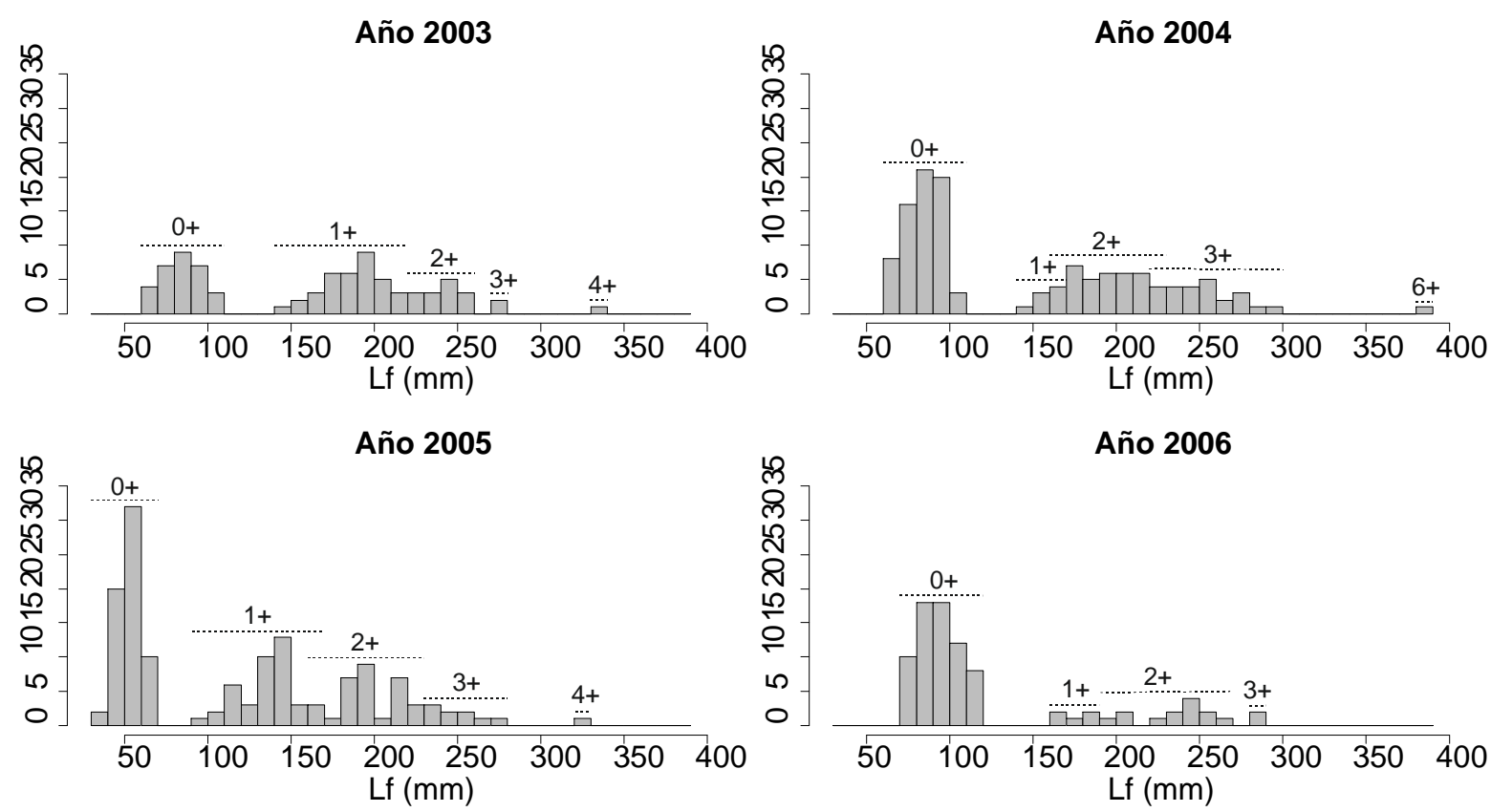

Figura 4.4. Histogramas de frecuencias del río Villahermosa para los años 2003, 2004, 2005 y 2006. Lf, longitud furcal.

\section{Crecimiento}

La tabla 4.1 muestra el sumario de la longitud media, peso medio y el crecimiento de la trucha común para las distintas clases de edad en los ríos Ebrón, Vallanca, Palancia y Villahermosa. La longitud y el peso de la trucha común estaban comprendidos entre 72-315 mm y 5-350 g, respectivamente. Se observó una alta variabilidad espacial entre las distintas poblaciones, siendo las truchas dominantes en longitud y peso medio, en cada clase de edad, las del río Ebrón (figura 4.5). Por ejemplo, la longitud media de los alevines (0+) en el Ebrón fue de $95 \mathrm{~mm}$ seguida del Villahermosa con 78 $\mathrm{mm}$, Palancia con $76 \mathrm{~mm}$ y Vallanca con $72 \mathrm{~mm}$. Además, las truchas del Ebrón subieron de peso notablemente a partir del segundo año, con un incremento casi del doble que en los demás ríos, con medias de $350 \mathrm{~g}$ en el tercer año (tabla 4.1). La comparación mostró diferencias significativas, entre los cuatro ríos, para las medias de la longitud y del peso $(p<0.01)$. Los alevines $(0+)$ y los adultos $(2+$ y $3+)$ del río Ebrón fueron significativamente $(p<0.01)$ más largos que los del Palancia, Villahermosa y Vallanca así más como pesados para las clases $0+$ y $2+$. Por el contrario, los juveniles (1+) de los ríos Ebrón, Palancia y Villahermosa fueron significativamente más largos y pesados que los del río Vallanca $(p<0.01)$. 
Tabla 4.1. Descriptores estadísticos $(T n \pm N M A D)$ de la trucha común en los ríos Ebrón, Palancia, Vallanca y Villahermosa relativos a la longitud furcal $\left(L_{f}, m m\right)$, peso $(W, g)$ y tasa anual de crecimiento $\left(G_{w}, g \cdot a n ̃ o-1\right)$.

\begin{tabular}{cccccc}
\hline Río & Edad & $\mathbf{N}$ & $\mathbf{L}_{\mathbf{f}}(\mathbf{m m})$ & $\mathbf{W}(\mathbf{g})$ & $\mathbf{G}_{\mathbf{w}}\left(\mathbf{g} \cdot \mathbf{a n ̃} \mathbf{o}^{-\mathbf{1}}\right)$ \\
\hline \multirow{4}{*}{ Ebrón } & $0+$ & 132 & $95.27 \pm 17.79$ & $10.89 \pm 5.93$ & $1.52 \pm 1.10$ \\
& $1+$ & 33 & $178.00 \pm 23.72$ & $66.19 \pm 29.65$ & $1.03 \pm 0.61$ \\
& $2+$ & 56 & $240.77 \pm 36.32$ & $169.25 \pm 81.54$ & $0.87 \pm 0.26$ \\
Vallanca & $3+$ & 11 & $315.01 \pm 29.65$ & $350.27 \pm 155.67$ & $0.47 \pm 0.12$ \\
& $0+$ & 235 & $71.74 \pm 16.31$ & $4.62 \pm 2.97$ & $2.02 \pm 0.82$ \\
& $1+$ & 119 & $146.29 \pm 22.24$ & $35.87 \pm 16.31$ & $0.90 \pm 0.28$ \\
Palancia & $2+$ & 47 & $214.03 \pm 25.20$ & $117.94 \pm 43.00$ & $0.71 \pm 0.55$ \\
& $3+$ & 10 & $268.15 \pm 14.08$ & $195.97 \pm 22.98$ & $0.72 \pm 0.59$ \\
& $0+$ & 46 & $76.09 \pm 18.53$ & $5.58 \pm 2.97$ & $1.39 \pm 0.28$ \\
& $1+$ & 24 & $170.39 \pm 20.76$ & $64.42 \pm 19.27$ & $0.84 \pm 0.39$ \\
Villahermosa & $2+$ & 26 & $213.38 \pm 14.08$ & $121.51 \pm 30.39$ & $0.64 \pm 0.31$ \\
& $3+$ & 10 & $265.89 \pm 10.38$ & $223.88 \pm 28.17$ & \\
& $0+$ & 228 & $77.51 \pm 20.76$ & $5.64 \pm 4.38$ & $2.14 \pm 0.50$ \\
& $1+$ & 89 & $161.11 \pm 34.10$ & $56.96 \pm 34.10$ & $0.85 \pm 0.36$ \\
& $2+$ & 87 & $206.37 \pm 25.20$ & $105.67 \pm 36.32$ & $0.59 \pm 0.10$ \\
& $3+$ & 35 & $252.82 \pm 25.20$ & $172.89 \pm 32.62$ & $0.55 \pm 0.20$ \\
\hline
\end{tabular}

Por otro lado, la tasa de crecimiento anual en peso $\left(G_{W}\right)$ decreció al aumentar el tamaño del pez (figura 4.5). El crecimiento fue alto a la edad 0+, los crecimientos de los ríos Villahermosa $\left(2.14 \mathrm{~g} \cdot \mathrm{año}^{-1}\right)$ y Vallanca $\left(2.02 \mathrm{~g} \cdot \mathrm{año}{ }^{-1}\right)$ fueron más grandes que los del río Ebrón (1.52 g·año ${ }^{-1}$ ) y Palancia (1.39 g·año ${ }^{-1}$ ), aunque el test ANOVA no observó diferencias significativas. El crecimiento en los dos primeros descendió bruscamente en el primer año de edad con $0.85 \mathrm{~g} \cdot \mathrm{año}{ }^{-1}$ en el Villahermosa y 0.90 g·año ${ }^{-1}$ en el Vallanca, equiparándose al de los otros dos ríos. En el segundo año de edad se estabilizó el crecimiento de los ríos Vallanca, Palencia y Villahermosa mientras que descendió bruscamente en el río Ebrón. En la edad 3+ tampoco se encontró diferencia significativa en el crecimiento. 

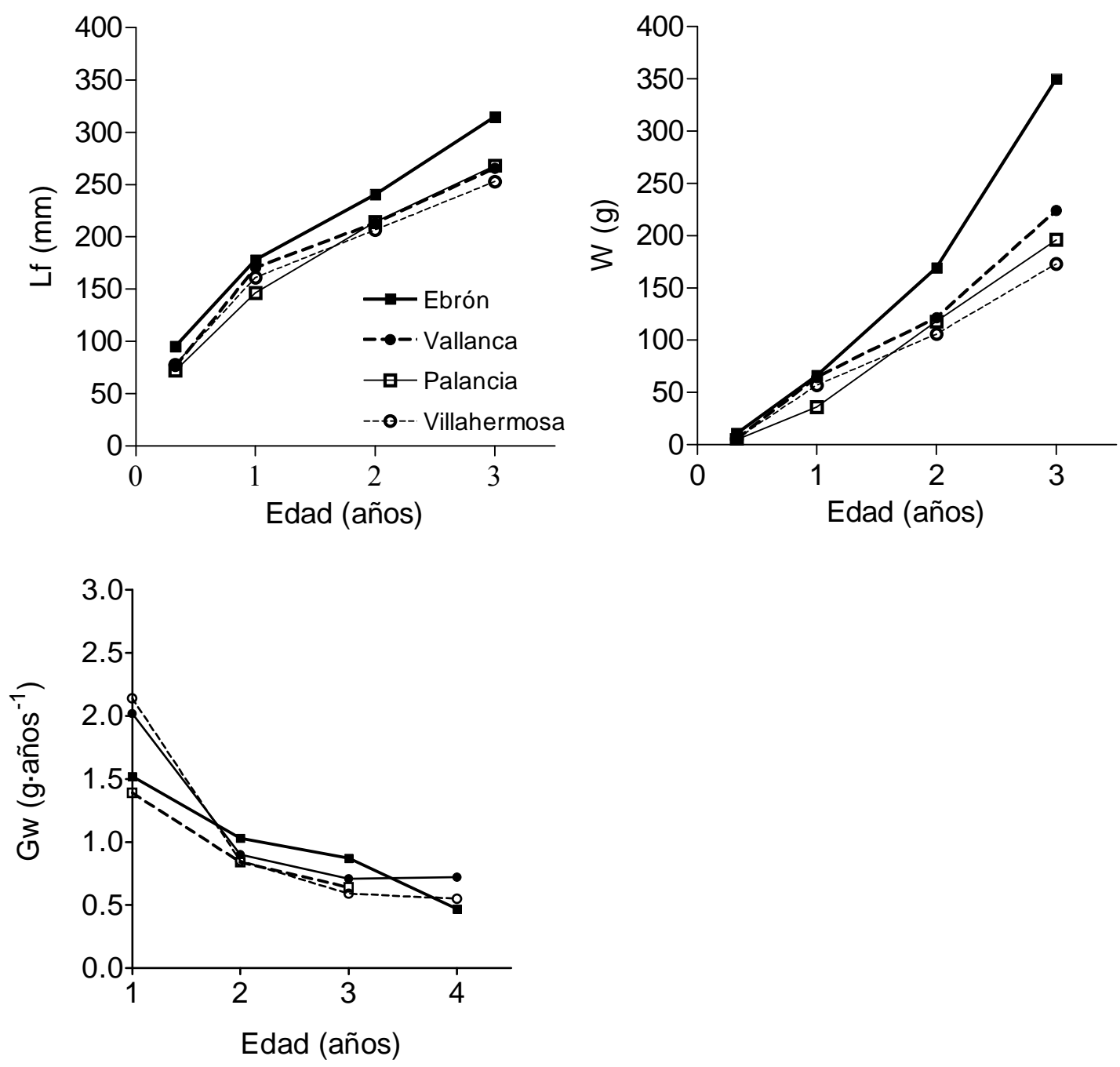

Figura 4.5. Tendencia de la trucha común en los ríos Ebrón, Palancia, Vallanca y Villahermosa relativos a la longitud furcal $\left(L_{f}, m m\right)$, peso $(W, g)$ y tasa anual de crecimiento $\left(G_{w}, g \cdot a n ̃ o o^{-1}\right)$.

\section{Densidad y biomasa}

En la tabla 4.2 se observa que el río Vallanca tenía la mayor densidad con 3247 truchas $\cdot \mathrm{ha}^{-1}$, seguidos del Villahermosa con 1009 truchas.ha ${ }^{-1}$ y que los ríos Ebrón y Palancia sustentaban bastantes menos truchas con 371 truchas $^{-1} a^{-1}$ y 250 truchas.ha ${ }^{-}$ 1 , respectivamente. No obstante, el test ANOVA no encontró ninguna diferencia significativa entre las densidades de los cuatro ríos. En todos los ríos, las mayores densidades la aportaban la clase de edad 0+ (figura 4.6), seguidas de la clase de edad $2+$ (excepto en el río Vallanca donde es en la clase de edad 1+). En términos de biomasa, también en el río Vallanca se encontraban las mayores biomasas relativas con una media de $119.2 \mathrm{~kg} \cdot h a^{-1}$. Mucho más bajas fueron las observadas en el Villahermosa $\left(40.3 \mathrm{~kg} \cdot \mathrm{ha}^{-1}\right)$, Ebrón $\left(31.2 \mathrm{~kg} \cdot \mathrm{ha}^{-1}\right)$ y Palancia $\left(19.9 \mathrm{~kg} \cdot \mathrm{ha}{ }^{-1}\right)$. Tampoco en 
la biomasa se encontró ninguna diferencia significativa entre los cuatro ríos. La clase de edad que aportaba la biomasa mayor es la 2+, excepto en el río Ebrón donde se da en la clase de edad 4+ (figura 4.6).

\section{Producción}

Los valores de la producción anual de los ríos estudiados fueron bajos. No se encontró ninguna diferencia significativa entre la producción en los cuatro ríos debido a la variabilidad de los datos (tabla 4.2). Sin embargo, el río Vallanca presentaba un valor medio de $17.3 \mathrm{~kg} \cdot \mathrm{ha}^{-1} \cdot \mathrm{año}^{-1}$, mucho mayor que el resto de ríos que tienen un rango entre 3.6 y $9.3 \mathrm{~kg} \cdot \mathrm{ha}^{-1} \cdot \mathrm{anno}^{-1}$. Por último, la tasa de renovación anual $\mathrm{P} / \mathrm{B}$ era muy pequeña, con valores que oscilan entre los 0.25 del río Palancia y los 0.08 del río Villahermosa, en donde tampoco se detectó ninguna diferencia significativa. Las mayores producciones se dan en la clase de edad 1+, excepto en el río Vallanca donde se da con en la clase de edad 3+ con gran diferencia.

Tabla 4.2. Descriptores estadísticos ( $T n \pm N M A D)$ de la trucha común en los ríos Ebrón, Palancia, Vallanca y Villahermosa relativos a la media total de densidad (D, truchas $\left.\cdot h a^{-1}\right)$, biomasa $\left(\mathrm{B}, \mathrm{kg} \cdot \mathrm{ha}{ }^{-1}\right)$, producción anual $\left(\mathrm{P}, \mathrm{kg} \cdot h \mathrm{a}^{-1} \cdot \mathrm{año}^{-1}\right)$ y tasa de renovación $(\mathrm{P} / \mathrm{B})$.

\begin{tabular}{ccccc}
\hline Río & D & B & P & P/B \\
\hline Ebrón & $371 \pm 261$ & $31.2 \pm 24.9$ & $9.3 \pm 9.3$ & $0.18 \pm 0.13$ \\
Palancia & $250 \pm 99$ & $19.9 \pm 10.1$ & $5.6 \pm 3.1$ & $0.25 \pm 0.14$ \\
Vallanca & $3247 \pm 2595$ & $119.2 \pm 84.7$ & $17.3 \pm 11.7$ & $0.17 \pm 0.09$ \\
Villahermosa & $1009 \pm 729$ & $40.3 \pm 30.4$ & $3.6 \pm 1.8$ & $0.08 \pm 0.07$ \\
\hline
\end{tabular}



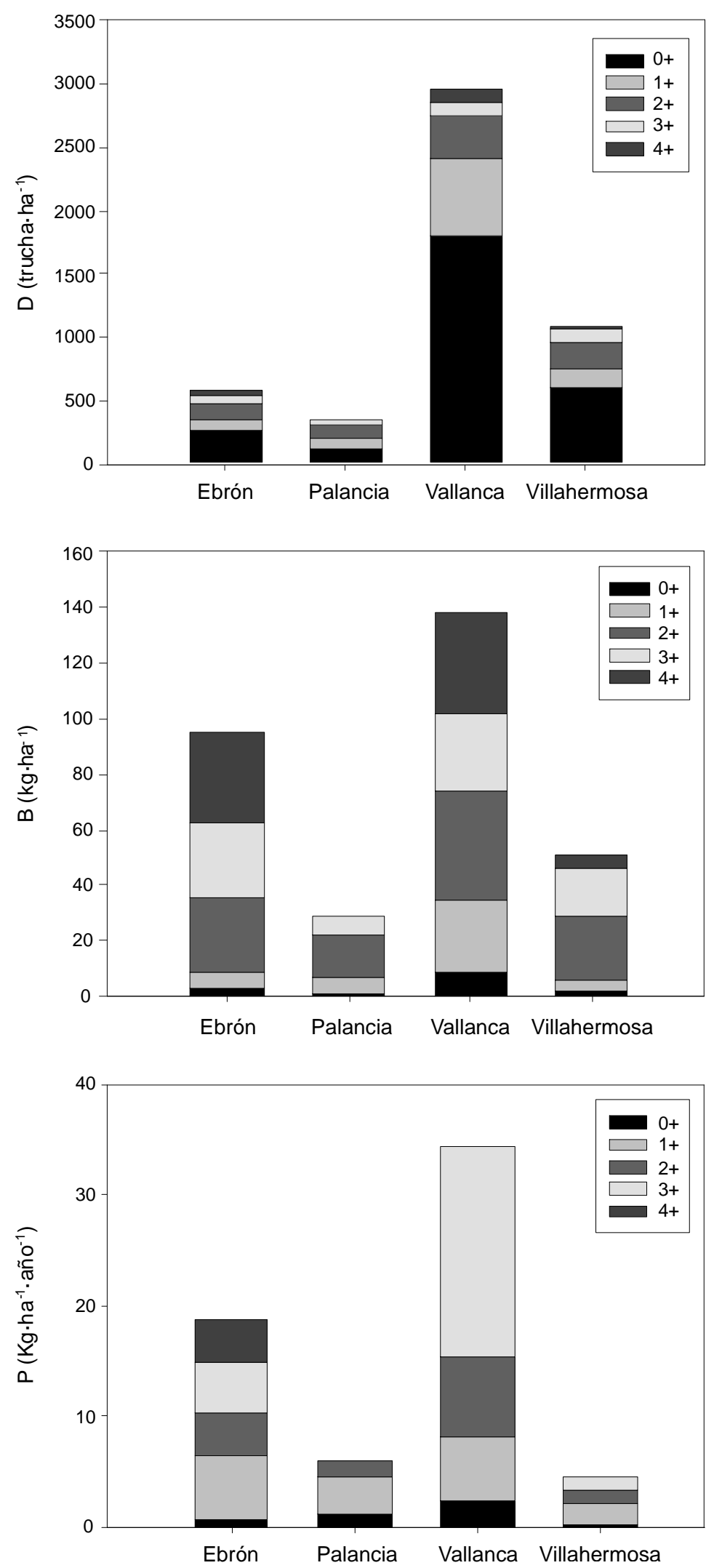

Figura 4.6. Densidad $\left(D\right.$, truchas $\left.\cdot \mathrm{ha}^{-1}\right)$, biomasa $\left(B, \mathrm{~kg} \cdot \mathrm{ha}^{-1}\right)$ y producción anual $\left(P, \mathrm{~kg} \cdot \mathrm{ha}{ }^{-1} \cdot \mathrm{año}^{-}\right.$ $\left.{ }^{1}\right)$, por grupos de edad, de la trucha común en los ríos Ebrón, Palancia, Vallanca y Villahermosa. 


\section{DISCUSIÓN}

Se ha observado una gran variabilidad en los resultados durante los cuatro años de estudio. Tal es así que, debido a la amplia varianza que muestran los valores de cada río, no se ha detectado diferencias significativas en la tasa de crecimiento anual, densidades, biomasas, producción anual y tasa de renovación. Los resultados de otras poblaciones también sugieren que la alta variabilidad en los parámetros poblacionales es común para esta especie (Newman y Waters, 1989; Elliott, 1994; Lobón-Cerviá, 2003).

\section{Crecimiento}

Los resultados indican que la longitud media por edad de las poblaciones mediterráneas de trucha común en la época de crecimiento, pueden ser, en general, mayores que las poblaciones de otras zonas de Europa (anexo 4.1). En ríos Noruegos, la longitud media de la trucha en su tercer año de edad no supera los $190 \mathrm{~mm}$ (Hesthagen et al., 2004), con valores similares en ríos irlandeses (Kelly-Quinn y Bracken, 1988; Lobón- Cerviá y Fitzmaurice, 1988) y suecos (Nordwall et al., 2001). Estos autores esbozan como principales causas para el lento crecimiento la limitación del hábitat, el origen ácido de las rocas de cabecera y la estacionalidad severa de estas latitudes, con una baja temperatura en invierno como factor controlador del crecimiento. Por el contrario, en las Islas Británicas; Williams y Harcup (1986) en ríos galeses, Egglishaw y Shackley (1977) en ríos escoceses y Elliott (1994) al suroeste de Inglaterra, observaron de forma separada una alta variabilidad entre años, con valores considerablemente menores que los considerados en este capítulo. Estos dos últimos autores encontraron rangos de longitudes furcales similares comprendidos entre 57-68 mm (0+ años), 112-121 mm (1+) y 156-166 mm (2+). Elliott (1994) apunta como posibles razones en la variación de las tallas de los peces adultos, los requerimientos metabólicos de las truchas y el incremento del coste energético en la defensa de sus territorios. También, las tallas de las truchas en ríos de Polonia y de Bulgaria fueron pequeñas (Penczak et al., 1986; Jankov, 1986). En Francia, Baglinière et al. (1989) analizaron dos tributarios del río Scorff, encontrando un alta variabilidad, con rangos comprendidos entre 68-89 mm para truchas de 0+ años de edad y 111$163 \mathrm{~mm}$ para truchas de $1+$ que se asemejan parcialmente a nuestros resultados.

Las poblaciones ibéricas de trucha común revisadas en la literatura se encuadran en el norte y centro de la península. En el norte, Braña et al. (1992) encontraron un 
crecimiento lento en las poblaciones de truchas similar a los países del norte de Europa, con valores comprendidos entre los 82-107 mm en la edad 1+, 116-175 mm en la edad 2+ y 145-197 mm en la edad 3+. Por otro lado, Parra et al. (2009) encontraron mucha variabilidad en la talla en los peces de ríos del norte de la Península Ibérica, en un estudio largo que abarcaba 13 ríos, con rangos de 57-101 $\mathrm{mm}$ en la edad 0+, 112-176 mm en la edad 1+, 156-248 mm en la edad 2+ y 194-291 $\mathrm{mm}$ en la edad 3+. En este estudio se observa una relación negativa entre la longitud furcal y la altitud, lo que podría relacionarse con cambios en los factores ambientales asociada a la altitud como la temperatura, la anchura y profundidad del río, la concentración de nutrientes o abundancia de alimento y la disponibilidad de hábitat para individuos grandes. En el centro de la península Ibérica, Lobón-Cerviá y Penczak (1984) establecieron en el río Jarama tallas del rango de 73-77 mm en la edad 1+, 150-160 mm en la edad 2+ y 227-230 mm a la edad de 3+, siendo muy inferiores a las obtenidas en nuestros resultados. Por el contrario, Alonso-González et al. (2004) trabajaron con poblaciones de truchas del río Tormes y obtuvieron longitudes medias más próximas a las nuestras, con $61 \mathrm{~mm}$ a la edad de $0+, 153 \mathrm{~mm}$ a la edad de $1+\mathrm{y}$ $209 \mathrm{~mm}$ a la edad de 2+. Estos últimos encontraron relaciones positivas entre las longitudes a las edades $0+$ y $1+$ y los caudales medios en el periodo de incubación de los huevos y en el periodo de emergencia del alevín, respectivamente. Además asociaron los caudales bajos del periodo de incubación con el aumento de temperatura de las aguas y los caudales bajos del periodo de emergencia con la explosión demográfica de los macroinvertebrados. Observando la literatura citada se ve que hay un patrón latitudinal en el tamaño del pez de modo que las truchas de las regiones del norte de Europa alcanzan menor longitud (por clase de edad) que las del sur. Esta relación podría estar asociada al incremento de la temperatura del agua y la productividad en las regiones del sur de Europa. En estas regiones es donde hay más frecuentemente temperaturas óptimas para el crecimiento, entre 13-18 으 según Elliott y Hurley (2000). Al igual que indican Parra et al. (2009), las poblaciones de Salmo trutta ibéricas, no siguen la regla de Bergmann (Belk y Houston, 2002), la cual sostiene que para animales endotérmicos, el tamaño del cuerpo incrementa cuando incrementa la latitud (o cuando decrece la temperatura).

\section{Densidad y biomasa}

Entre las densidades y biomasas medias en los cuatro ríos mediterráneos hay un amplio rango de valores, sin embargo, estas estimaciones están comprendidas dentro 
de los rangos que otros autores han registrado para esta especie en otras partes del mundo (anexo 4.2). Los valores más altos se han encontrado en ríos de Bulgaria y Gales con valores muy altos comprendidos entre 7475-31113 truchas.ha ${ }^{-1}$ (Jankov, 1986) y 3600-11148 truchas $\cdot$ ha $^{-1}$ (Williams y Harcup, 1986), respectivamente. Tanto Lobón-Cerviá y Fitzmaurice (1988) como Kelly-Quinn y Bracken (1988) también mostraban valores extremos en ríos irlandeses con 22088 y 10800 truchas.ha $^{-1}$ respectivamente, aunque el rango normal de este último este comprendido entre 2300-8900 truchas $\cdot$ ha $^{-1}$. Los ríos Vallanca y Villahermosa (con mayores densidades) estarían dentro del rango de valores medios de los ríos de Noruega (700-3490 truchas.ha ${ }^{-1}$ en Bergheim y Hesthagen, 1990) y estadounidenses de Minnesota (18673258 truchas.ha $^{-1}$ en Newman y Waters, 1989; 1024 truchas.ha $^{-1}$ en Waters et al., 1990 y 347-8096 truchas.ha ${ }^{-1}$ en Kwak y Waters, 1997). Por el contrario, las densidades de los ríos Ebrón y Palancia (con menores densidades) estarían por debajo de los ríos de Dinamarca (98-771 truchas $\cdot \mathrm{ha}^{-1}$ en Rasmussen, 1986). Esta alta variabilidad es observada en los ríos polacos con densidades altas (5067-9066 truchas.ha ${ }^{-1}$ en Mortensen y Penczak, 1988), medias (21-2333 truchas.ha $^{-1}$ en Debowski, 1991) y bajas (8-207 truchas.ha ${ }^{-1}$ en Penczak et al., 1986). Algunos autores han observado que la densidad máxima puede estar limitada por la disponibilidad del hábitat (Newman y Waters, 1989; Armstrong et al., 2003), lo que podría forzar la migración de peces jóvenes hacia hábitat más idóneos con menor densidad de truchas.

En la Península Ibérica, también podemos encontrar una gran variabilidad en las abundancias de trucha común. En Portugal, Formigo y Penczak (1999) en el río Âncora calcularon un máximo de 11327 truchas $\cdot$ ha $^{-1}$ frente a Valente (1990) que dio un mínimo de 200 truchas.ha $^{-1}$ en el río Estoräos, ambos ríos al norte de Portugal. En España, Lobón-Cerviá et al. (1986) también encontró en el centro de la Península una alta variabilidad con valores comprendidos entre 18 y 3903 truchas.ha $^{-1}$ en el río Jarama. Por otro lado, Almodóvar et al. (2006) en doce ríos tributarios del Tajo y Duero constataron densidades comprendidas entre 1957 y 5866 truchas $^{-1} \mathrm{ha}^{-1}$ donde sólo podrían enmarcarse nuestros resultados del río Vallanca. En este último estudio no se encontró ninguna relación entre la densidad y el contenido de nutrientes en el agua, la abundancia de alimento y la temperatura del agua. Alonso-González et al. (2004) calcularon en el río Tormes una media de 2600 truchas.ha $^{-1}$ frente a LobónCerviá y Penczak (1984) que observaron en el río Jarama densidades comprendidas entre 211-960 truchas $\cdot \mathrm{ha}^{-1}$. Como se observa, la alta variabilidad en las densidades de trucha común incluso en regiones muy cercanas, como ocurre con nuestros resultados, podría estar explicada por factores medioambientales como son las 
características físicas del hábitat, la temperatura del agua y los mecanismos densodependientes o los procesos hidrológicos (Elliott, 1994; Cattanéo et al., 2002; Armstrong et al., 2003). De hecho, Alonso-González et al. (2008) encontraron una fuerte correlación negativa entre la duración de los periodos de crecida y las densidades de reclutamiento de los alevines, de forma que periodos prolongados de caudales altos durante la incubación de los huevos de trucha, disminuye el reclutamiento de los juveniles.

También el rango de biomasa en distintas poblaciones salvajes del mundo es muy variable. En nuestro estudio, la mayor biomasa la presenta el río Vallanca con 119 $\mathrm{kg} \cdot \mathrm{ha}^{-1}$ frente a los otros tres ríos que están alrededor de los $30 \mathrm{~kg} \cdot \mathrm{ha}^{-1}$. Tanto KellyQuinn y Bracken (1988) y Lobón-Cerviá y Fitzmaurice (1988) en Irlanda, Williams y Harcup (1986) en Gales, como Formigo y Penczak (1999) en Portugal mostraban un rango de biomasas muy parecidas (aunque sus densidades máximas disten mucho de las españolas). Del mismo modo, Newman y Waters (1989) y Scarnecchia y Bergersen (1987) muestran en ríos norteamericanos biomasas parecidas a las del Vallanca aunque Kwak y Waters (1997) estimaron en ríos de Minnesota (EE.UU) una biomasa mayor con $355 \mathrm{~kg} \cdot \mathrm{ha}^{-1}$. Scarnecchia y Bergersen (1987) encontraron una relación significativa con la dureza de las aguas. Por el contrario, las biomasas más bajas las encontramos en Noruega (15-83 kg.ha ${ }^{-1}$ en Bergheim y Hesthagen, 1990), Dinamarca (23-33 kg.ha ${ }^{-1}$ en Rasmussen, 1986), Polonia (1-50 kg.ha ${ }^{-1}$ en Penczak et al., 1986; 10 $\mathrm{kg} \cdot \mathrm{ha}{ }^{-1}$ en Mortensen y Penczak, 1988; $1-98 \mathrm{~kg} \cdot \mathrm{ha}^{-1}$ en Debowski, 1991) y en Bulgaria (1-45 kg.ha-1 en Penczak et al., 1985; 27-98 kg.ha ${ }^{-1}$ en Jankov, 1986).

La Península Ibérica presenta una alta versatilidad en las estimaciones sobre biomasas. Como ejemplo podemos citar al trabajo realizado por Lobón-Cerviá et al. (1986) en tributarios del río Duero, en el centro de la Península, con valores que oscilan de 1 hasta $302 \mathrm{~kg} \cdot \mathrm{ha}^{-1}$. Por otro lado, en el río Jarama Lobón-Cerviá y Penczak (1984) observaron un rango menor que nuestros resultados, con valores de 4-12 $\mathrm{kg} \cdot h a^{-1}$; sin embargo Lobón-Cerviá (2003) menciona un rango mayor en el río Chabatchos (60-83 kg.ha $\left.{ }^{-1}\right)$ que los encontrados en el río Ebrón, Palancia y Villahermosa pero menor que en el Vallanca. Almodóvar et al. (2006) indicaron también un mayor rango, con $57-240 \mathrm{~kg} \cdot \mathrm{ha}^{-1}$ en los ríos tributarios del Duero y Tajo. Estos últimos autores encontraron una relación positiva con la concentración de nutrientes inorgánicos ya que hay más abundancia de alimento. No obstante, como ocurría en las densidades, hay otros factores físicos que pueden estar influenciando a la biomasa total como la altitud, la pendiente, el caudal medio anual, la abundancia 
de macroinvertebrados, la diversidad de especies, la anchura del cauce o el porcentaje de sustrato grueso (Annoni et al., 1997; Alcaraz-Hernández, et al., 2007).

\section{Producción}

Mann y Penczak (1986) tras consultar 38 publicaciones obtuvieron un rango de producción para la trucha común de 1 a $547 \mathrm{~kg} \cdot \mathrm{ha}^{-1} \cdot \mathrm{año}^{-1}$, sugiriendo como valor máximo de $300 \mathrm{~kg} \cdot \mathrm{ha}^{-1} \cdot$ año $^{-1}$. Waters (1992) se sumó a estos postulados y sugirió que con valor entre $100-300 \mathrm{~kg} \cdot \mathrm{ha}^{-1} \cdot \mathrm{año}^{-1}$ la productividad de un río es alta.

Según dicho criterio, si observamos la literatura comprobaremos que la mayoría de los ríos trucheros presentan valores de productividad medios o altos (anexo 4.2). En Estados Unidos se ha observado un rango de $34-258 \mathrm{~kg} \cdot \mathrm{ha}^{-1} \cdot \mathrm{año}^{-1}$ (Scarnecchia y Bergersen, 1987; Newman y Waters, 1989; Waters et al., 1990; Kwak y Waters, 1997). Al igual que pasaba en la densidad y la biomasa, Scarnecchia y Bergersen (1987) relaciona la productividad con la dureza de las aguas.

En Europa la situación es muy parecida, con un rango de $30-234 \mathrm{~kg} \cdot \mathrm{ha}^{-1} \cdot \mathrm{año}{ }^{-1}$ (Almodóvar et al., 2006). Elliott (1994) en un estudio en Inglaterra demostró la alta variabilidad de las producciones a lo largo de 25 años, y daba una media de 240 $\mathrm{kg} \cdot \mathrm{ha}^{-1} \cdot \mathrm{año} \mathrm{o}^{-1}$ y un rango de $89-339 \mathrm{~kg} \cdot \mathrm{ha}^{-1} \cdot \mathrm{año}^{-1}$. Este autor comenta que las menores producciones están asociadas a periodos de sequía, ya que se reduce el caudal del río disminuyendo el área disponible para los peces y la disponibilidad de alimento, y además aumenta la temperatura del agua.

Por lo tanto, si comparamos los resultados medios de los ríos mediterráneos de este estudio (con un rango de 4-17 $\mathrm{kg} \cdot \mathrm{ha}^{-1} \cdot \mathrm{año}^{-1}$ ), la productividad de nuestros ríos es muy baja. Un ejemplo similar con valores bajos comparables a los ríos mediterráneos son los calculados en Gales (1-52 kg·ha ${ }^{-1} \cdot$ año $^{-1}$ en Williams y Harcup, 1986), Dinamarca (14-30 kg·ha ${ }^{-1} \cdot$ año $^{-1}$ en Rasmussen, 1986), Bulgaria (1-63 kg.ha ${ }^{-1} \cdot$ año $^{-1}$ en Penczak et al., 1985) y Polonia (2-56 kg.ha ${ }^{-1} \cdot$ año $^{-1}$ en Penczak et al., 1986; $37 \mathrm{~kg} \cdot \mathrm{ha}^{-1} \cdot \mathrm{año}^{-1}$ en Mortensen y Penczak, 1988). Los rangos de la producción de trucha común en la Península Ibérica fueron los siguientes, $1-462 \mathrm{~kg} \cdot \mathrm{ha}^{-1} \cdot \mathrm{año}^{-1}$ en ríos tributarios del

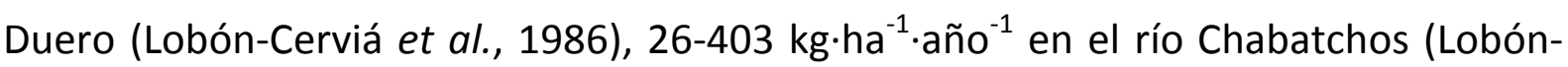
Cerviá, 2003), 47-182 kg·ha ${ }^{-1} \cdot$ año $^{-1}$ en las cuencas del Duero y Tajo (Almodóvar et al., 2006), $10-135 \mathrm{~kg} \cdot \mathrm{ha}^{-1} \cdot \mathrm{año}^{-1}$ en la cuenca del Lima (Valente, 1990) y 12-111 kg.ha${ }^{1}$-año ${ }^{-1}$ en la cuenca del Âncora (Formigo y Penczak, 1999). Sólo la producción de truchas en el río Jarama es comparable a las nuestras ( $8 \mathrm{~kg} \cdot \mathrm{ha}^{-1} \cdot a n ̃ o^{-1}$, Lobón-Cerviá y 
Penczak, 1984), aunque en este río la trucha no es la especie dominante y la producción de trucha fue sólo un $2-4 \%$ de la producción piscícola total.

Las estimaciones más elevadas en las producciones trucheras sugieren una relación de la producción con la fertilidad del agua, que están relacionadas con el origen geológico de las rocas (Mann y Penczak, 1986; Kwak y Waters, 1997). En este sentido, Almodóvar et al. (2006) señalan que los ríos ibéricos tienen mayor productividad de truchas en ríos de aguas duras que en blandas, siendo su naturaleza química uno de los factores que más afectan a los rangos nativos de la especie. Por el contrario y en contrastada opinión, hay autores que sostienen la hipótesis de que las bajas productividades son debidas principalmente a las bajas densidades y al pobre reclutamiento de sus poblaciones (Lobón-Cerviá y Penczak, 1984; Lobón-Cerviá, 2003). Todos los muestreos del presente estudio están realizados sobre lechos calcáreos, por lo que se plantea la hipótesis de que la baja productividad obtenida en estos ríos puede ser explicada por otros factores de origen biótico o abiótico.

Finalmente, la tasa anual $\mathrm{P} / \mathrm{B}$ para la trucha común en estas poblaciones mediterráneas son las más bajas dadas en la literatura para distintas partes del mundo. Nuestros ríos presentan un rango entre 0.08 y 0.25 . Elliott (1994) durante 25 años obtuvo tasas $\mathrm{P} / \mathrm{B}$ altos con valores comprendidos entre los 2.28-4.02. Lo más frecuente es observar tasas de renovación comprendidas entre 0.70-1.75, tanto en la Península Ibérica (Lobón-Cerviá y Penczak, 1984; Lobón-Cerviá et al., 1986; Formigo y Penczak, 1999; Almodóvar et al., 2006) como en otras zonas de Europa y América (Penczak et al., 1985; Penczak et al., 1986; Jankov, 1986; Williams y Harcup, 1986; Newman y Waters, 1989; Waters et al., 1990; Debowski, 1991; Kwak y Waters, 1997). Sólo Lobón-Cerviá y Fitzmaurice (1988) obtuvieron valores más altos con rangos comprendidos entre 1.40 y 3.00. Por otro lado, Scarnecchia y Bergersen (1987) obtuvieron valores más bajos al resto de los autores con 0.34-0.41. Una simple explicación es que los ríos mediterráneos del levante albergan poblaciones de trucha muy jóvenes con pobre reclutamiento, y además la probabilidad de que un individuo llegue a 4 años es muy baja.

Por lo tanto y a modo de conclusión, nuestra investigación en edad, crecimiento, abundancias y producción de cuatro poblaciones de trucha común, en ríos mediterráneos, se suma a los muchos estudios realizados a la especie. Nuestra revisión literaria ha permitido observar los patrones de crecimiento en diversas regiones geográficas donde la especie es nativa o ha sido introducida, así como plantear futuras líneas de investigación para las poblaciones mediterráneas (referidas 
al final de esta tesis). Una adecuada evaluación de la dinámica poblacional es esencial para el entendimiento de los factores que regulan y limitan las poblaciones y para una adecuada gestión. Resumiendo, al comparar las poblaciones mediterráneas de trucha común con el resto de lugares, se observó que éstas tienen un crecimiento alto, tanto en longitud como en peso, con adecuadas densidades y biomasas pero con una producción muy baja. Según la literatura estudiada, el origen de esta atípica situación habría que buscarlo en los factores biológicos y en las características medioambientales. No obstante se podría decir que los parámetros poblacionales se ajustan a la teoría de las poblaciones periféricas, que describe cómo estas poblaciones son más variables ya que el desarrollo de la especie está condicionado por los rangos periféricos del hábitat, principalmente como resultado de la mayor variabilidad de los factores abióticos, por lo que predominan los efectos de los procesos denso-independientes. Por el contrario otras poblaciones "centrales" con rangos más idóneos del hábitat, pueden estar reguladas principalmente por procesos denso-dependientes (Nicola et al., 2008; Nicola et al., 2009).

\section{BIBLIOGRAFÍA}

Alcaraz-Hernández, J.D., F. Martínez-Capel, M. Peredo y A.B. Hernández-Mascarell. 2007. Relaciones entre densidades y biomasas de Salmo trutta fario y mediciones del mesohábitat en tramos trucheros de la Comunidad Valenciana. Limnetica 26 (1): 159-167.

Almodóvar, A., G.G. Nicola y B. Elvira. 2006. Spatial variation in brown trout production: the role of environmental factors. Transactions of the American Fisheries Society 135: 13481360.

Alonso-González, C., D. García de Jalón, J. Gortázar y D. Baeza Sanz. 2004. Abiotic control of brown trout (Salmo trutta L.) population dynamics by highly variable stream flow regimes in a central Iberian mountain basin. In: D. García de Jalón \& P. Vizcaino (eds.). Procs. $5^{\text {th }}$ Int. Symp. on Ecohydraulics. Aquatic Habitats: Analysis \& Restoration Vol. 2: 1198-1206. Madrid.

Alonso-González, C., J. Gortázar, D. Baeza Sanz y D. García de Jalón. 2008. Dam function rules based on brown trout flow requirements: design of environmental flow regimes in regulated streams. Hydrobiologia 609: 253-262.

Annoni, P., I. Saccardo, G. Gentili y L. Guzzi. 1997. A multivariate model to relate hydrological, chemical and biological parameters to salmonid biomass in Italian Alpine rivers. Fisheries Management and Ecology 4: 439-452. 
Armstrong J.D., P.S. Kemp, G.J.A. Kennedy, M. Ladle y N.J. Milner. 2003. Habitat requirements of Atlantic salmon and brown trout in rivers and streams. Fisheries Research 62: 143-170.

Baglinière, J.L., G. Maisse, P.Y. Lebail y A. Nihouarn. 1989. Population dynamics of brown trout, Salmo trutta L., in a tributary in Brittany (France): spawning and juveniles. Journal of Fish Biology 34: 97-110.

Belk, M.C. y D.D. Houston. 2002. Bergmann's rule in ectotherms: a test using freshwater fishes. The American Naturalist 160: 803-808.

Bergheim, A. y T. Hesthagen. 1990. Production of juvenile Atlantic salmon, Salmo salar L., and brown trout, Salmo trutta L., within different sections of a small enriched Norwegian river. Journal of Fish Biology 36: 545-562.

Braña, F., A.G. Nicieza y M.M. Toledo. 1992. Effects of angling on population structure of brown trout, Salmo trutta L., in mountain streams of northern Spain. Hydrobiologia 237: 61-66.

Carle, F.L. y M.R. Strub. 1978. A new method for estimating population size from renoval data. Biometrics 34: 621-380.

Cattanéo, F., N. Lamouroux, P. Breil y H. Capra. 2002. The influence of hydrological and biotic processes on brown trout (Salmo trutta) population dynamics. Canadian Journal of Fisheries and Aquatic Sciences 59: 12-22.

Debowski, P. 1991. Production of brown trout (Salmo trutta m. fario L.) in two tributaries of the Pasleka river. Polskie Archiwum Hydrobiologii 38: 283-294.

Egglishaw, H.J. y P.E. Shackley. 1977. Growth, survival and production of juvenile salmon and trout in a Scottish stream, 1966-1975. Journal of Fish Biology 11: 647-672.

Elliott, J.M. 1994. Quantitative ecology and the brown trout. Oxford: Oxford University Press. $286 \mathrm{pp}$.

Elliott, J.M. y M.A. Hurley. 2000. Daily energy intake and growth of piscivorous brown trout, Salmo trutta. Freshwater Biology 44: 237-245.

Ferreira, T., J. Oliveira, N. Carola, A. De Sostoa, F. Casals, R. Cortes, A. Economou, S. Zogaris, D. García de Jalón, M. Ilhéu, F. Martínez-Capel, D. Pont, C. Rogers y J. Prenda. 2007. Ecological traits of fish assemblages from Mediterranean Europe and their responses to human disturbance. Fisheries Management and Ecology 14: 473-481.

Formigo, N. y T. Penczak. 1999. Fish stocks of the Âncora River, northern Portugal: production. Fisheries Reserch 40: 91-96. 
García de Jalón, D. 1992. Dinámica de las poblaciones piscícolas en los ríos de montaña Ibéricos. Ecología 6: 281-296.

García de Jalón, D., M. Mayo, F. Hervella, E. Barceló y C. Fernández. 1993. Principios y técnicas de gestión de la pesca en aguas continentales. Ed. Mundi-Prensa. Madrid.

García Pérez, A. 2005. Métodos avanzados de estadística aplicada. Métodos robustos y de remuestreo. Universidad Nacional de Educación a Distancia, UNED, Madrid. 255 pp.

García-Marín, J.L., F.M. Utter y C. Pla. 1999. Postglacial colonization of brown trout in Europe based on distribution of allozyme variants. Heredity 82: 46-56.

Hesthagen, T., O. Hegge, J. Skurdal y B.K. Dervo. 2004. Age and growth of Siberian sculpin (Cottus poecilopus) and young brown trout (Salmo trutta) in a subalpine Norwegian river. Hydrobiologia 521: 107-115.

Jankov, J.I. 1986. The production of the brown trout (Salmo trutta fario L.) in the Rilska river, Bulgaria. Polskie Archiwum Hydrobiologii 33: 455-462.

Kelly-Quinn, M. y J.J. Bracken. 1988. Brown trout, Salmo trutta L., production in an Irish coastal stream. Aquaculture and Fisheries Management 19: 69-95.

Klemetsen, A., P.A. Amundsen, J.B.Dempson, B.Jonsson, N. Jonsson, M.F.O'Connell y E. Mortensen. 2003. Atlantic salmon Salmo salar L., brown trout Salmo trutta L., and Arctic charr Salvelinus alpinus (L.): a review of aspects of aspects of their life histories. Ecology of Freshwater Fish 12: 1-59.

Kwak, T.J. y T.F. Waters. 1997. Trout production dynamics and water quality in Minnesota streams. Transactions of the American Fisheries Society 126: 35-48.

Lobón-Cerciá, J. 2003. Spatiotemporal dynamics of brown trout production in a Cantabrian stream: effects of density and habitat quality. Transactions of the American Fisheries Society 132: 621-637.

Lobón-Cerviá, J. y P. Fitzmaurice. 1988. Stock assessment, production rates and food consumption in four constrasting Irish populations of brown trout (Salmo trutta L.). Polskie Archiwum Hydrobiologii 35: 497-513.

Lobón-Cerviá, J. y T. Penczak. 1984. Fish production in the Jarama River, Central Spain. Holarctic Ecology 7: 128-137.

Lobón-Cerviá, J., A. De Sostoa y C. Montañez. 1986. Fish production and its relation with the community structure in an aquifer-fed stream of Old Castile (Spain). Polskie Archiwum Hydrobiologii 33: 333-343. 
Machordom, A., J. Suárez, A. Almodóvar y J.M. Bautista. 2000. Mitochondrial haplotype variation and phylogeography of Iberian brown trout populations. Molecular Ecology 9: 1325-1338.

Mann, R.H.K. y T. Penczak. 1986. Fish production in rivers: a review. Polskie Archiwum Hydrobiologii 33: 233-247.

Mortensen, E. y T. Penczak. 1988. Populations, growth, biomasa and production of fish in a small stream in north-west Poland. Ekologia Polska 36: 445-458.

Newman, R.M. y T.F. Waters. 1989. Differences in brown trout (Salmo trutta) production among contiguous sections of an entire stream. Canadian Journal of Fisheries and Aquatic Sciences 46: 203-213.

Nicola, G.G., A. Almodóvar y B. Elvira. 2009. Influence of hydrologic attributes on brown trout recruitment in low-latitude range margins. Oecologia 160: 515-524.

Nicola, G.G., A. Almodóvar, B. Jonsson y B. Elvira. 2008. Recruitment variability of resident brown trout in peripheral populations from southern Europe. Freshwater Biology 53: 2364-2374.

Nordwall, F., I. Näslund y E. Degerman. 2001. Intercohort competition effects on survival, movement, and growth of brown trout (Salmo trutta) in Swedish streams. Canadian Journal of Fisheries and Aquatic Sciences 58: 2298-2308.

Parra, I., A. Almodóvar, G.G. Nicola y B. Elvira. 2009. Latitudinal and altitudinal growth patterns of brown trout Salmo trutta at different spatial scales. Journal of Fish Biology 74: 2355-2373.

Penczak, T., J. Jankov, TS.J. Dikov y M. Zalewnki. 1985. Fish production in the Mesta River, Rila mountain, Samokov, Bulgaria. Fisheries Research 3: 201-221.

Penczak, T., J. Lobón-Cerviá, K. O’Hara y H. Jakubowski. 1986. Production and food consumption by fish populations in the Pilawa and Dobrzyca rivers, north Poland. Polskie Archiwum Hydrobiologii 33: 345-372.

R Development Core Team (2008). R: A language and environment for statistical computing. $\mathrm{R}$ Foundation for Statistical Computing, Vienna, Austria. ISBN 3-900051-07-0, URL http://www.R-project.org.

Rasmussen, G. 1986. Influence of trout farm discharge on the production of two populations of stream-dwelling brown trout Salmo trutta (L.) and rainbow trout Salmo gairdneri (Rich.). Polskie Archiwum Hydrobiologii 33: 433-453. 
Ricker, W.E. 1946. Production and utilization of fish populations. Ecological Monographs 16: 374-391.

Sánchez-Montoya, M.M., M.R. Vidal-Abarca, T. Puntí, J.M. Poquet, N. Prat, M. Rieradevall, J. Alba-Tercedor, C. Zamora-Muñoz, M. Toro, S. Robles, M. Álvarez y M.L. Suárez. 2009. Defining criteria to select reference sites in Mediterranean streams. Hydrobiologia 619: 39-54.

Scarnecchia, D.L. y E.P. Bergersen. 1987. Trout production and standing crop in colorado's small streams, as related to environmental features. North American Journal of Fisheries Management 7: 315-330.

Valente, A.C.N. 1990. Trout populations in the Lima Basin, North Portugal. In: W.L.T. van Densen, B. Steinmetz y R.H. Hughes (Eds). Management of freshwater fisheries. Proceeding of a symposium organized by the European Inland Fisheries Advisory Commission, Göteborg Sweden. Pudoc. Wageningen, 437-446.

Waters, T.F. 1992. Annual production, production/biomass ratio, and the ecotrophic coefficient for management of trout in streams. North American Journal of Fisheries Management 12: 34-39.

Waters, T.F., M.T. Doherty y C.C Krueger. 1990. Annual production and production: biomass ratios for three species of stream trout in lake Superior tributaries. Transactions of the American Fisheries Society 119: 470-474.

Williams, R. y M.F. Harcup. 1986. Fish production in some river Ebbw tributaries. Polskie Archiwum Hydrobiologii 33: 319-332. 


\section{ANEXOS}

Anexo 4.1. Sumario de las longitudes furcales $\left(L_{f}, \mathrm{~mm}\right)$ según clases de edad encontrada en la literatura científica para poblaciones de Salmo trutta en diferentes países. El paréntesis que hay en los valores del número de ríos indica los diferentes tramos muestreados en los correspondientes ríos.

\begin{tabular}{ccccccc}
\hline País & Número de ríos & $\mathbf{L}_{\mathbf{f}} \mathbf{0 +}$ año & $\mathbf{L}_{\mathbf{f}} \mathbf{1 +}$ año & $\mathbf{L}_{\mathbf{f}} \mathbf{2 +}$ & $\mathbf{L}_{\mathbf{f}} \mathbf{3 +}$ año & Referencias \\
\hline Noruega & $1(2)$ & $35-43$ & $76-78$ & $111-124$ & $143-153$ & Hesthagen et al., 2004 \\
Suecia & 6 & - & $94-112$ & $127-135$ & $147-153$ & Nordwall et al., 2001 \\
Inglaterra & 1 & $57-68$ & $112-121$ & $144-166$ & - & Elliott, 1994 \\
Escocia & 1 & $57-68$ & $112-121$ & $156-165$ & - & Egglishaw y Shackley, 1977 \\
Gales & $4(7)$ & - & $67-82$ & $99-113$ & $118-144$ & Williams y Harcup, 1986 \\
Irlanda & $1(5)$ & - & $55-76$ & $114-130$ & $152-175$ & Kelly-Quinn y Bracken, 1988 \\
Irlanda & $4(13)$ & - & $49-73$ & $102-146$ & $177-190$ & Lobón-Cerviá y Fitzmaurice, 1988 \\
Polonia & $2(8)$ & - & 88 & 189 & 318 & Penczak et al., 1986 \\
Bulgaria & $1(3)$ & - & $84-101$ & $114-149$ & $164-199$ & Jankov, 1986 \\
Francia & $1(4)$ & $68-89$ & $111-163$ & - & - & Bleginière et al., 1989 \\
España & $1(2)$ & - & $73-77$ & $150-160$ & $227-230$ & Lobón-Cerviá y Penczak, 1984 \\
España & $3(7)$ & - & $82-107$ & $116-175$ & $145-197$ & Braña et al., 1992 \\
España & $1(14)$ & 61 & 153 & 209 & - & Alonso-González et al., 2004 \\
España & $13(16)$ & $57-101$ & $112-176$ & $156-248$ & $194-291$ & Parra et al., 2009 \\
\hline
\end{tabular}


Anexo 4.2. Sumario de las densidades $\left(D\right.$, truchas $\left.\cdot h a^{-1}\right)$, biomasas $\left(B, \mathrm{~kg} \cdot \mathrm{ha}^{-1}\right)$, producción $\left(P, \mathrm{~kg} \cdot \mathrm{ha} \mathrm{a}^{-1} \cdot \mathrm{año}^{-1}\right)$ y tasa de renovación $(\mathrm{P} / \mathrm{B})$ encontrada en la literatura científica para poblaciones de Salmo trutta en diferentes países. El paréntesis que hay en los valores del número de ríos indica los diferentes tramos muestreados en los correspondientes ríos.

\begin{tabular}{ccccccc}
\hline País & Número de ríos & $\mathbf{D}$ & $\mathbf{B}$ & $\mathbf{P}$ & $\mathbf{P} / \mathbf{B}$ & Referencias \\
\hline Colorado & 2 & - & $101-176$ & $34-83$ & $0.34-0.68$ & Scarnecchia y Bergersen, 1987 \\
Minnesota & $1(8)$ & $1867-3258$ & $86-165$ & $73-258$ & $0.90-1.49$ & Newman y Waters, 1989 \\
Minnesota & $1(2)$ & 1024 & 47 & 43 & 0.90 & Waters et al., 1990 \\
Minnesota & 8 & $343-8096$ & $32-355$ & $37-252$ & $0.64-1.40$ & Kwak y Waters, 1997 \\
Inglaterra & 1 & - & - & $89-339$ & & Elliott, 1994 \\
Gales & $5(8)$ & $3600-11148$ & $32-166$ & $1-52$ & $0.72-1.20$ & Williams y Harcup, 1986 \\
Irlanda & $1(5)$ & $2300-10800$ & $40-205$ & $38-150$ & $0.95-1.15$ & Kelly-Quinn y Bracken, 1988 \\
Irlanda & $4(13)$ & $2194-22088$ & $5-167$ & $14-291$ & $1.40-3.00$ & Lobón-Cerviá y Fitzmaurice, 1988 \\
Dinamarca & $1(3)$ & $98-771$ & $23-33$ & $14-30$ & $0.42-1.02$ & Rasmussen, 1986 \\
Polonia & $2(8)$ & $8-207$ & $1-50$ & $2-56$ & 1.73 & Penczak et al., 1986 \\
Polonia & $2(7)$ & $21-2333$ & $1-98$ & $71-145$ & $1.23-1.61$ & Debowski, 1991 \\
Polonia & 1 & $5067-9066$ & 10 & 37 & - & Mortensen y Penczak, 1988 \\
Bulgaria & $1(4)$ & $13-3180$ & $1-45$ & $1-63$ & 1.34 & Penczak et al., 1985 \\
Bulgaria & $1(3)$ & $7475-31113$ & $27-98$ & $48-160$ & $1.62-1.75$ & Jankov, 1986 \\
Portugal & $5(7)$ & $200-4100$ & - & $10-135$ & - & Valente, 1990 \\
Portugal & $1(5)$ & $1330-11327$ & $12-112$ & $12-111$ & $1.09-1.31$ & Formigo y Penczak, 1999 \\
España & $1(2)$ & $211-960$ & $4-12$ & 8 & 1.56 & Lobón-Cerviá y Penczak, 1984 \\
España & $4(9)$ & $18-3903$ & $1-302$ & $1-462$ & 1.70 & Lobón-Cerviá et al., 1986 \\
España & $1(4)$ & - & $60-83$ & $26-403$ & - & Lobón-Cerviá, 2003 \\
España & $1(14)$ & 2600 & - & - & - & Alonso-González et al., 2004 \\
España & $10(20)$ & $1567-5866$ & $57-239$ & $47-182$ & $1.01-1.56$ & Almodóvar et al., 2006 \\
\hline
\end{tabular}




\section{CAPÍTULO 5}

\section{MODELOS DE CRECIMIENTO Y RELACIONES DE}

\section{DENSO-DEPENDENCIA DE LA TRUCHA COMÚN EN RÍOS MEDITERRÁNEOS}

\section{Resumen}

La regulación de una población es el proceso por el cual la población muestra una tendencia a volver a su equilibrio. Así pues, resulta importante identificar los mecanismos que caracterizan la denso-dependencia, esenciales para tal regulación, y el entendimiento de los factores que regulan a una población pueden ayudar tanto a mejorar la gestión de la especie como a proteger los ríos donde habita. El objetivo de este capítulo ha sido estudiar el crecimiento de la trucha común y su relación con la densidad. La relación longitud-peso y los modelos de crecimiento teórico de Von Bertalanffy nos permitieron observar la alta variabilidad que presentaba el crecimiento según los distintos años y según los diferentes ríos valencianos en donde se estudió la especie. La modelación del crecimiento somático con respecto a sus densidades nos ha permitido encontrar una relación negativa de denso-dependencia de las clases $0+$ y $1+$ en el río Vallanca y de la clase 1+ en el río Palancia. Finalmente, las consecuencias de la regulación denso-dependiente fueron discutidas.

Palabras clave: Trucha común, crecimiento, modelos de Von Bertalanffy, densodependencia. 


\section{INTRODUCCIÓN}

La regulación de una población es el proceso por el cual la población muestra una tendencia a volver a su equilibrio. Ésta es fundamental para la ecología y otros campos relacionados como la conservación y la gestión de las especies. Mucha atención se han puesto a los mecanismos de retroalimentación que caracterizan la denso-dependencia ya que éstos son esenciales para tal regulación (Ratikainen et al., 2007). Tanto es así que la identificación de las respuestas compensatorias a los cambios en la densidad de la población es de vital importancia para la comprensión de la demografía y la dinámica en la estructura de la población (Grant y Imre, 2005; Vincenzi et al., 2007). Un mecanismo de la regulación de la población es la dependencia de la densidad con la tasa de crecimiento individual, ya que ésta se relaciona con la supervivencia y la fecundidad al mantener una relación positiva con el tamaño del cuerpo del pez (Jenkins et al., 1999). Por ello, el estudio del crecimiento de la trucha común se considera esencial para conocer la biología de la población en relación al medio en el que vive. Por lo tanto, es elemental conocer la estructura de la población según las edades, sus crecimientos y su densidad poblacional.

A través del tiempo, la dinámica de la población esta impulsada por una combinación de procesos exógenos y endógenos, dependiendo principalmente de las etapas de vida de los peces y de las condiciones ambientales (Elliott, 1994; Lobón-Cerviá, 2007). En la literatura científica los procesos relacionados con la densidad de los peces están bien documentados, aunque todavía están en debate. Por un lado, se han estudiado las relaciones denso-independientes (procesos exógenos) de la trucha común. En este sentido, la influencia hidrológica sobre las clases de edad con altos o bajos periodos de caudales pueden afectar a las densidades de la especie, especialmente a los alevines durante época de incubación o emergencia de las larvas (Cattanéo et al., 2002; Alonso-González et al., 2008; Lobón-Cerviá, 2007), al reclutamiento (LobónCerviá y Rincón, 2004; Lobón-Cerviá, 2007) y a las clases adultas (Lobón-Cerviá, 2004). También se ha averiguado que ciertos modelos de índices de calidad de hábitat para salmones en Canadá, los cuales definen la calidad del hábitat para la especie a partir de las propiedades físicas, explican una pequeña proporción de la variación de las densidades juveniles (Hedger et al., 2004). Aunque recientemente, se ha detectado una relación significativa entre la tasa de ocupación del hábitat (trucha.WUA $\mathrm{m}^{-2}$, siendo WUA el hábitat potencial útil, o HPU, de la especie en un tramo de río) y el crecimiento de la trucha común (Parra el al., 2010). 
Por otro lado, las relaciones denso-dependientes (procesos endógenos) pueden actuar en varios estados del ciclo de vida de las truchas. Como ejemplos, la densidad se ha relacionado con la reproducción (Wootton, 1998), el reclutamiento (Simonović y Nikolić. 2007; Nicola et al., 2008), la mortalidad (Elliott, 1994) y la emigración (Rose et al., 2001). Sin embargo, no están del todo claras las relaciones de densodependencia con el crecimiento. Normalmente, el crecimiento somático se incrementa cuando hay bajas densidades, lo que puede estar influenciando tanto a la mortalidad como a la fecundidad (Jenkins et al., 1999). No obstante, Imre et al. (2005) y Grant e Imre (2005) puntualizan que el crecimiento de los salmones a la edad de 0+ es denso-dependiente sólo cuando existen bajas densidades (es decir, crecen más con densidades más bajas), mientras que la emigración y el aumento de mortalidad son mecanismos regulados por altas densidades. Por el contrario, Elliott (1994) indicó que el crecimiento individual de cada trucha se ve poco afectado por la densidad de la población, mientras que Lobón-Cerviá y Rincón (2004) concluyeron que hay poca o ninguna evidencia de la regulación denso-dependiente en la trucha común.

En este sentido, este capítulo ahonda en distintos aspectos del crecimiento de la trucha común en diferentes ríos mediterráneos y durante distintos años de muestreo. Por lo tanto, los objetivos primarios del capítulo fueron (1) estudiar el crecimiento somático de las distintas poblaciones y (2) explorar las posibles relaciones de denso-dependencia en función del crecimiento de las truchas.

\section{MÉTODOS}

\section{Adquisición de datos en campo}

Las capturas de trucha común se realizaron en los meses de Julio y Agosto entre los años 2003 y 2006. En el primer año se establecieron dos estaciones de muestreo por río (en total 8 estaciones) y en los restantes años cuatro (16 estaciones). En los años de muestreo los cuatro ríos permanecieron vedados a la pesca deportiva. Todos los muestreos fueron realizados con caudal base y se destaca el hecho de que en los dos últimos años de estudio (2005 y 2006) hubo una fuerte sequía que hizo que los tramos más altos de los ríos Vallanca y Villahermosa se secaran, perdiéndose tres de las dieciséis estaciones establecidas.

Se empleó un equipo de pesca eléctrica en la captura de los peces. Después de cerrar el área con redes, acotando un único mesohábitat, se realizaron como mínimo en 
cada estación de muestreo tres pasadas sin reemplazamiento de las capturas. A todos los peces extraídos se les midió la longitud furcal ( $L f, \pm 1 \mathrm{~mm}$ ) y su peso $(\mathrm{W}, \pm 1$ g). A la mayoría de los individuos de más de un año de edad se les extrajeron escamas para su posterior análisis. Los peces capturados fueron retornados vivos cerca del punto de captura.

\section{Análisis de los datos}

Para el estudio del crecimiento de las poblaciones, se calculó inicialmente la relación longitud-peso, mediante la transformación logarítmica de la ecuación de Ricker, Log $(W)=\log a+b \log (L f)$, obteniendo las constantes $a$ y $b$ del modelo $(p<0.001)$. La constante $b$ (pendiente de la recta) permitió conocer si la población presenta un crecimiento isométrico $(b=3)$ o alométrico $(b \neq 3)$. Además, se empleó el análisis de la varianza (ANOVA) para comparar los modelos de longitud-peso según los años de muestreo de cada río.

Por otro lado, también se calcularon los modelos de crecimiento Von Bertalanffy según la parametrización de Beverton-Holt, para cada río y para cada año:

$$
L(x)=L \infty\left[1-e^{-k(x-x 0)}\right]
$$

donde $x$ es la edad (en años), $L_{\infty}$ es la máxima longitud $(\mathrm{mm}), k$ es el coeficiente de crecimiento $\left(a n ̃ o s^{-1}\right.$ ) de la edad sobre la longitud y $x_{0}$ es la edad en la que la longitud se iguala a 0 . Los parámetros de crecimiento del modelo Von Bertalanffy fueron ajustados usando regresiones no lineales $(p<0.05)$. También se empleó el análisis de la varianza (ANOVA) para comparar los modelos según los años de muestreo de cada río. Todos los análisis fueron realizados mediante el uso del programa estadístico $\mathrm{R}(R$ Development Core Team, 2008), utilizando el paquete FSA programado por D.H. Ogle (www.ncfaculty.net/dogle/fishR).

Para cada tramo y para cada año, se estimó la correlación de Pearson entre las longitudes medias de la trucha común alevín y juvenil $(0+$ y $1+)$ y las adultas $(2+$ y $3+)$ para los ríos Ebrón, Vallanca, Palancia y Villahermosa y una combinación de todos los ríos. Finalmente, se estudió la relación de denso-dependencia de la longitud con la densidad. Para ello, se calculó para cada tramo y cada año, la densidad de truchas (D, truchas $\left.\cdot \mathrm{ha}^{-1}\right)$, aplicando el método de máxima verosimilitud ponderada de Carle y Strub (1978). Posteriormente, se calculó la regresión (logarítmica) entre la longitud media de cada clase de edad y su densidad en cada tramo, año y río. 


\section{RESULTADOS}

La relación longitud-peso, calculada para cada año y para cada río, puede verse en la tabla 5.1, que incluye las constantes de cada modelo. Se observa un buen ajuste en todos los modelos con coeficientes de regresión siempre superiores al 96\% ( $p<$ 0.001). En todos los ríos se observa que tanto la constante a como la $b$ son mayores en el año 2006. Además, hay valores de b cercanos a 3 en el Vallanca (2005 y 2006) y Villahermosa (2003), por lo que las poblaciones de truchas de esos ríos y en esos años tendrán un crecimiento isométrico. La constante b del Ebrón y del Vallanca aumenta con el paso de los años. Por el contrario, el río Palancia presenta un valor cercano a 3 en el año 2003 pero disminuye al siguiente año para ir creciendo progresivamente hasta el 2006, donde alcanza un valor máximo de 3.42. Finalmente la constante b del Villahermosa es mayor en los años 2003 y 2006 que en los años centrales. Estas diferencias fueron poco importantes, ya que los ANOVAS sugieren que no hubo diferencias significativas $(p<0.005)$ entre los modelos longitud-peso de cada río si los comparamos entre años.

Tabla 5.1. Constantes a y b del modelo de crecimiento de Ricker de los ríos Ebrón, Vallanca, Palancia y Villahermosa de cada año de muestreo. $N$ es el tamaño de la muestra y $R^{2}$ es el coeficiente de regresión del modelo $(p<0.001)$.

\begin{tabular}{cccccc}
\hline Río & Año & $\mathbf{N}$ & $\mathbf{a}$ & $\mathbf{b}$ & $\mathbf{R}^{\mathbf{2}}$ \\
\hline \multirow{3}{*}{ Ebrón } & 2003 & 21 & -10.443 & 2.837 & 0.994 \\
& 2004 & 31 & -10.548 & 2.859 & 0.992 \\
& 2005 & 112 & -11.143 & 2.975 & 0.980 \\
Vallanca & 2006 & 79 & -12.495 & 3.194 & 0.991 \\
& 2003 & 75 & -10.734 & 2.884 & 0.980 \\
& 2004 & 89 & -10.859 & 2.904 & 0.984 \\
& 2005 & 158 & -11.629 & 3.061 & 0.976 \\
Palancia & 2006 & 95 & -11.982 & 3.080 & 0.984 \\
& 2003 & 29 & -10.888 & 2.928 & 0.992 \\
& 2004 & 10 & -10.614 & 2.873 & 0.989 \\
& 2005 & 50 & -10.777 & 2.903 & 0.981 \\
& 2006 & 19 & -13.619 & 3.417 & 0.987 \\
\hline \multirow{5}{*}{ Villahermosa } & 2003 & 82 & -11.309 & 3.003 & 0.977 \\
& 2004 & 131 & -11.088 & 2.956 & 0.989 \\
& 2005 & 143 & -10.888 & 2.897 & 0.971 \\
& 2006 & 86 & -13.306 & 3.349 & 0.969 \\
\hline
\end{tabular}


Los parámetros de la curva de crecimiento de Von Bertalanffy por río y año están en la tabla 5.2. Los valores del parámetro $x_{0}$ siempre fueron significativos $(p<0.05)$. Igual pasa con todos los valores de los parámetros de la curva de crecimiento de los ríos Ebrón y Villahermosa. Por el contrario, parámetros con valores no significativos se encuentran en el río Vallanca ( $L_{\infty}$ en el 2006 y $k$ en el 2003 y 2006) y en el Palancia ( $k$ en el 2004). Si comparamos por años la longitud máxima asintótica de cada río (tabla 5.2, figura 5.1), sorprende los valores altos de algunos años, como por ejemplo, en el río Ebrón (año 2006), en el Vallanca (año 2006) y en el Villahermosa (año 2004). Además, se comprobó en cada río mediante ANOVA que hay diferencias significativas entre los modelos de crecimiento de Von Bertalanffy excepto para los años 20032004 del Ebrón $(p<0.05)$ y 2003-2006 del Palancia $(p<0.05)$. Por otro lado, se juntaron en cada río los datos de todos los años de muestreo, siendo significativos ( $p$ $<0.05$ ) todos sus parámetros. Para los cuatro años de muestreo, la longitud asintótica mayor fue la del río Ebrón, seguidas de Vallanca, Palancia y Villahermosa.

Tabla 5.2. Parámetros de las curvas de crecimiento de Von Bertalanffy por año de muestreo para los ríos Ebrón, Vallanca, Palancia y Villahermosa $(p<0.05)$ y para el conjunto de todos los años. $L_{\infty}$; longitud máxima $(\mathrm{mm}), k$; coeficiente de crecimiento de la edad sobre la longitud $\left(a n ̃ o^{-1}\right)$ y $x_{0}$; edad (años) en la que la longitud se iguala a 0.

\begin{tabular}{ccccc}
\hline Río & Año & $\mathrm{L}_{\infty}$ & $\mathbf{x}_{\mathbf{0}}$ & $\mathbf{k}$ \\
\hline \multirow{5}{*}{ Ebrón } & 2003 & 473.34 & -0.58 & 0.34 \\
& 2004 & 639.86 & -1.00 & 0.17 \\
& 2005 & 509.25 & -0.80 & 0.25 \\
& 2006 & 1156.76 & -1.58 & $0.06^{*}$ \\
Vallanca & $2003-2006$ & 628.87 & -1.01 & 0.16 \\
& 2003 & 826.56 & -1.37 & $0.08^{\text {n.s. }}$ \\
& 2004 & 602.13 & -0.81 & 0.16 \\
& 2005 & 372.50 & -0.54 & 0.36 \\
Palancia & 2006 & $4361.00^{\text {n.s. }}$ & -1.36 & $0.01^{\text {n.s. }}$ \\
& $2003-2006$ & 609.03 & -0.84 & 0.15 \\
& 2003 & 681.87 & -1.91 & 0.10 \\
& 2005 & 729.29 & -1.78 & $0.10^{\text {n.s. }}$ \\
& $2003-2006$ & 276.34 & -0.42 & 0.67 \\
& 2003 & 493.47 & -1.40 & $0.15^{*}$ \\
& 2004 & 1154.96 & -1.34 & 0.06 \\
& 2005 & 472.45 & -0.54 & 0.21 \\
& 2006 & 431.19 & -0.90 & 0.27 \\
& $2003-2006$ & 391.92 & -0.79 & 0.28 \\
\hline \multirow{5}{*}{ Villahermosa } & & & &
\end{tabular}

Nota: ${ }^{*} p<0.1,{ }^{\text {n.s. }} p>0.1$. 

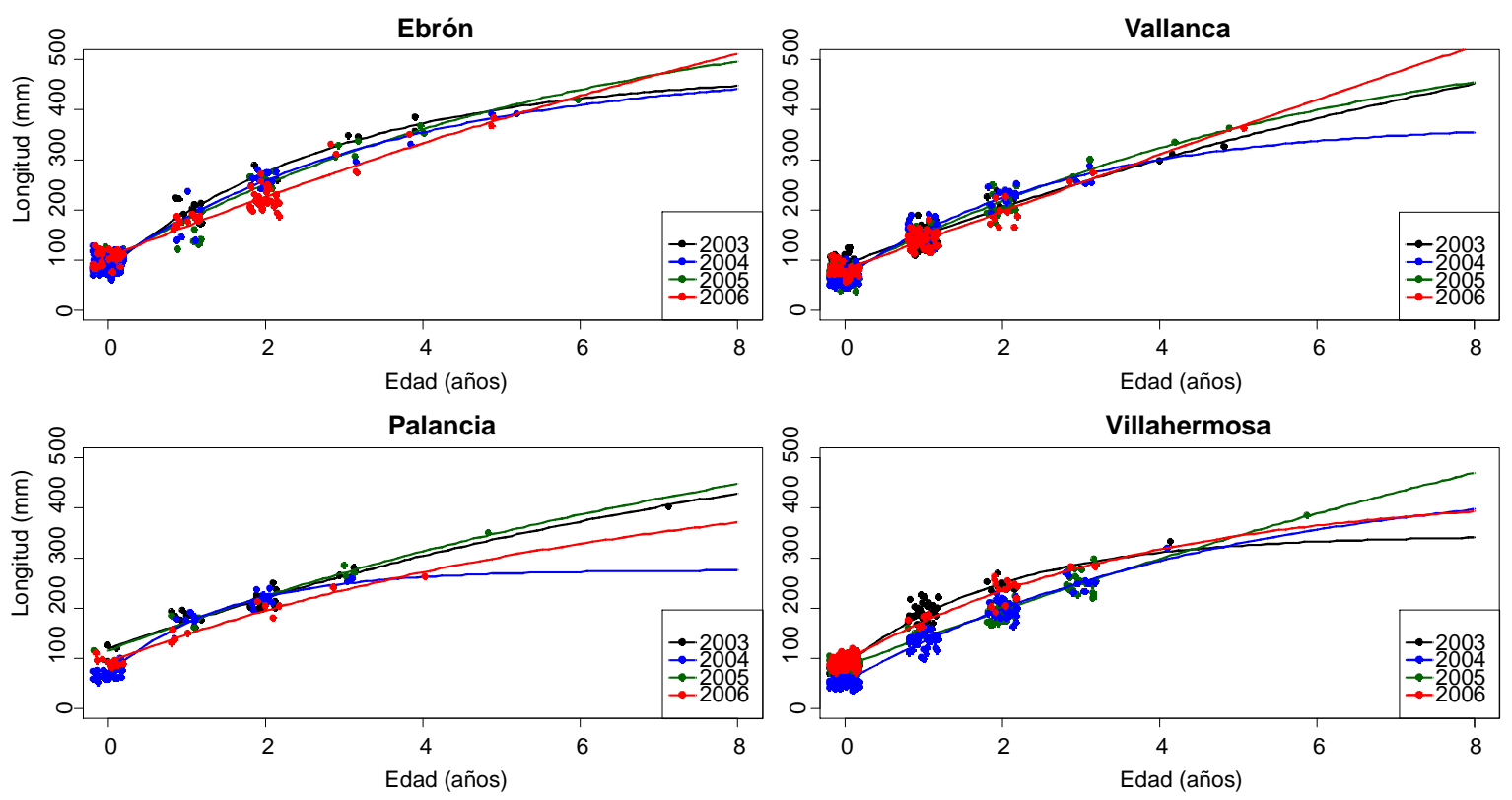

Figura 5.1. Comparación de las curvas de crecimiento de Von Bertalanffy según los años de muestreo en los ríos Ebrón, Vallanca, Palancia y Villahermosa.

Por otro lado, no se observó ninguna correlación significativa entre la longitud de la trucha alevín $(0+)$ o juvenil (1+) con las adultas $(2+$ y 3+) en los ríos Ebrón y Vallanca (Tabla 5.3), probablemente debido al bajo número de la muestra. En el río Villahermosa, la longitud a la edad de $0+$ fue positivamente correlacionada con la longitud a la edad 1+. De igual forma, en los ríos Palancia y Villahermosa la longitud a la edad 1+ fue correlacionada con la de 2+. Para el conjunto de datos de todos los ríos, se obtuvo una correlación significativa entre las longitudes a la edad $0+\operatorname{con} 2+y$ $3+y$ entre las longitudes de $1+$ con $2+$. 
Tabla 5.3. Correlación de Pearson entre la longitud furcal media de la trucha común a las edades de $0+$ y $1+$ con la longitud a las edades 1+, 2+ y 3+ para los ríos Ebrón, Vallanca, Palancia y Villahermosa y una combinación de todos los ríos. El tamaño de la muestra esta indicado entre paréntesis.

\begin{tabular}{cccccc}
\hline Edades & Ebrón & Vallanca & Palancia & Villahermos & Combinado \\
\hline $0+\rightarrow 1+$ & $-0.53(8)^{\text {n.s. }}$ & $-0.40(13)^{\text {n.s. }}$ & $0.07(7)^{\text {n.s. }}$ & $0.71(8)^{*}$ & $0.10(36)^{\text {n.s. }}$ \\
$0+\rightarrow 2+$ & $-0.23(7)^{\text {n.s. }}$ & $0.18(13)^{\text {n.s. }}$ & $-0.35(4)^{\text {n.s. }}$ & $0.52(9)^{\text {n.s. }}$ & $0.43(33)^{\text {n }}$ \\
$0+\rightarrow 3+$ & $-0.63(6)^{\text {n.s. }}$ & $0.48(7)^{\text {n.s. }}$ & $0.61(5)^{\text {n.s. }}$ & $0.51(8)^{\text {n.s. }}$ & $0.44(26)^{*}$ \\
$1+\rightarrow 2+$ & $-0.23(7)^{\text {n.s. }}$ & $0.14(13)^{\text {n.s. }}$ & $0.95(5)^{*}$ & $0.73(7)^{* *}$ & $0.33(32)^{* *}$ \\
$1+\rightarrow 3+$ & $0.46(5)^{\text {n.s. }}$ & $0.54(7)^{\text {n.s. }}$ & $0.23(6)^{\text {n.s. }}$ & $0.65(6)^{\text {n.s. }}$ & $0.34(24)^{\text {n.s. }}$ \\
\hline
\end{tabular}

Nota: ${ }^{* *} p<0.1,{ }^{*} p<0.05,{ }^{\text {n.s. }} p>0.1$.

A continuación se presentan las regresiones entre la longitud media y la densidad de cada tramo y para las distintas clases de edad (figuras 5.2 y 5.3). Para cada edad, los modelos logarítmicos negativos denso-dependientes dieron un mejor ajuste que los modelos lineales. Todas las curvas logarítmicas negativas explicaron una pequeñísima porción de variabilidad del ajuste entre la longitud y la densidad en todas las clases de edad, con los coeficientes de variación regresión inferiores a 0.10, excepto para las clases de edad $0+$ y $1+$ del río Vallanca, con coeficientes de regresión de 0.73 y 0.67 respectivamente (figura 5.2), y para 0+ del río Palancia, con un coeficiente de 0.45 (figura 5.3). 
Río Vallanca (0+)

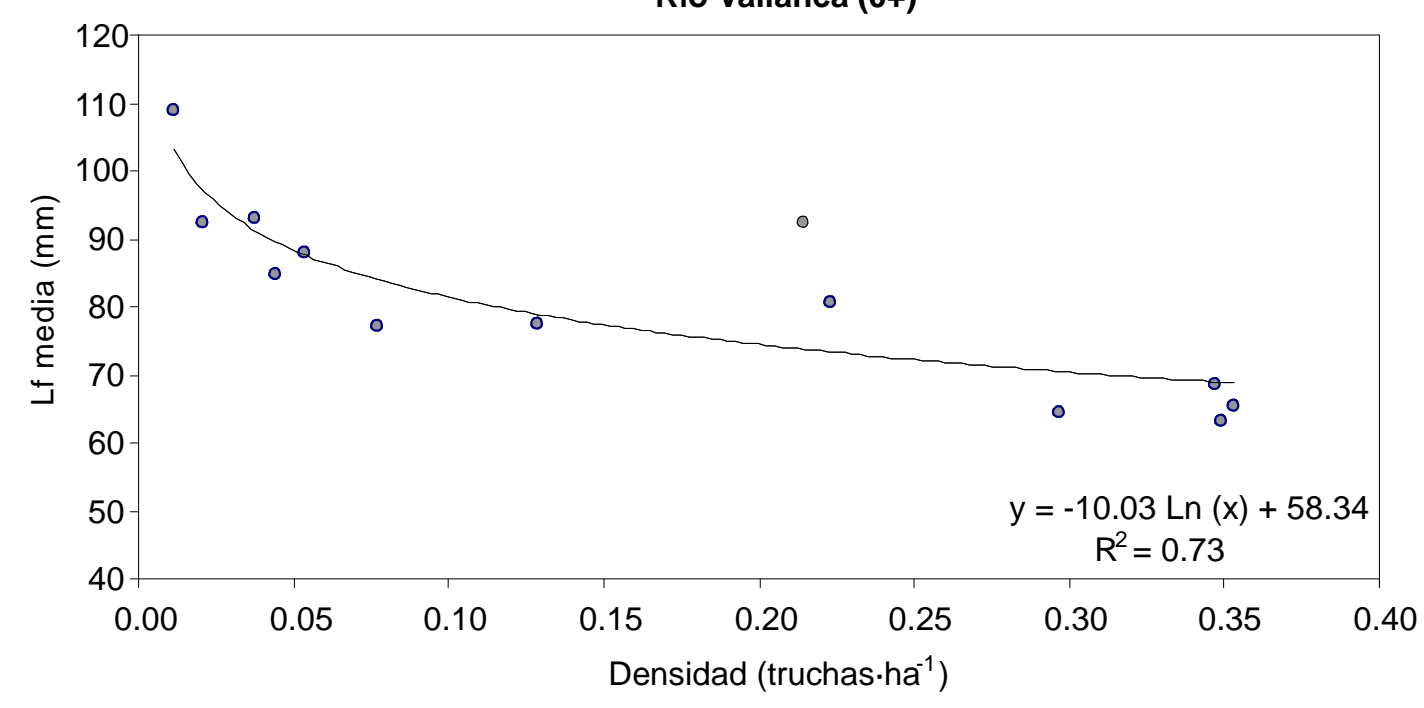

Río Vallanca (1+)

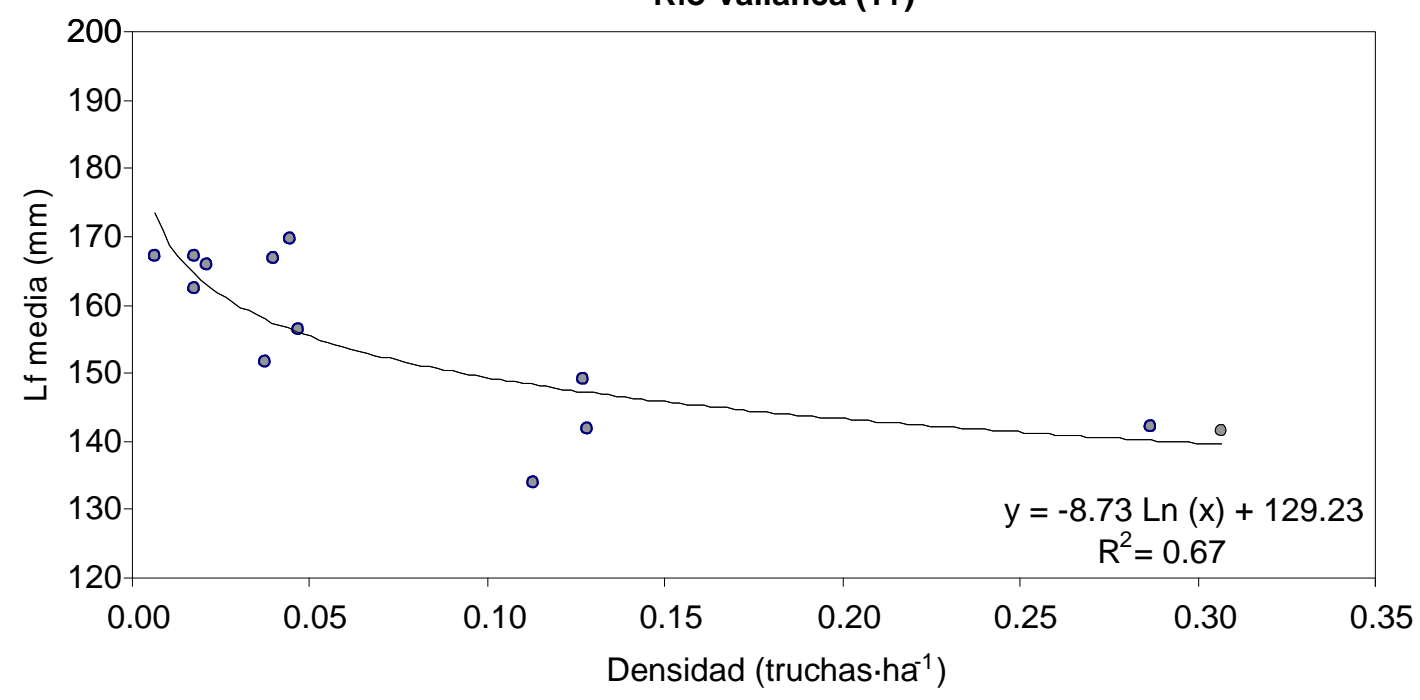

Figura 5.2. Curva logarítmica entre la longitud furcal media (Lf) y la densidad de la clase de edad $0+(N=13)$ y $1+(N=13)$ del río Vallanca. 


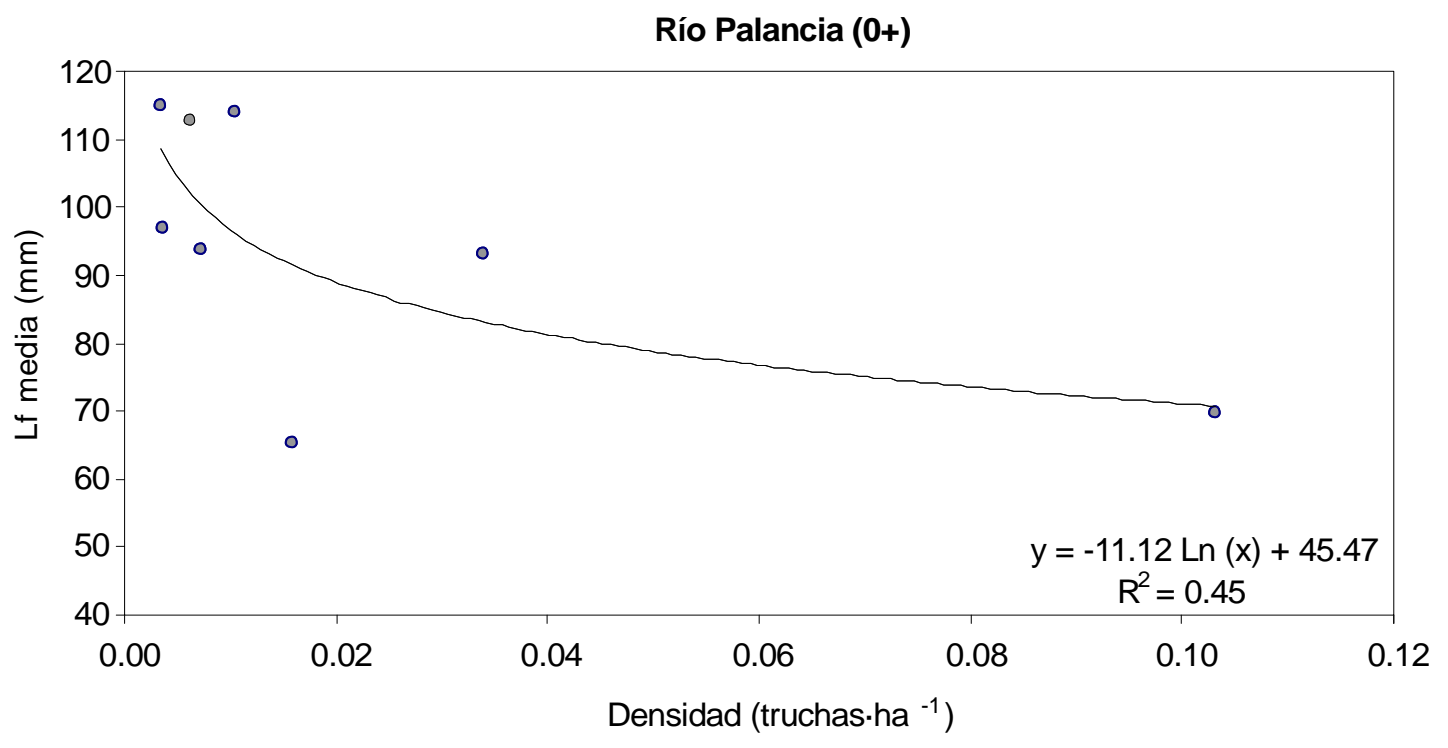

Figura 5.3. Curva logarítmica entre la longitud furcal media (Lf) y la densidad de la clase de edad $0+$ del río Palancia $(N=8)$.

\section{DISCUSIÓN}

Distintos estudios en diferentes peces y ambientes permiten asegurar que los valores de la constante alométrica $b$ en condiciones naturales oscilan entre 2.5 y 4 , siendo en muy raras ocasiones igual a 3 (Granado-Lorencio, 2002). Para la trucha común, Elliott (1994) encontró valores inferiores a 2.8 en todas las clases de edad, excepto para los alevines con tallas menores a $40 \mathrm{~mm}$ donde la constante fue de 3.5. En este estudio, se han observado valores de la constante $b$ que oscilan mucho entre años y ríos, con valores comprendidos entre 2.84 en el río Ebrón y 3.42 en el Palancia (Tabla 5.1). En los ríos Ebrón, Vallanca y Palancia aumentan los coeficientes de alometría conforme avanzan los años de muestreo, mientras que en el Villahermosa disminuyen, excepto en el último año de muestreo, en donde aumenta notablemente. Además, es en este último año de muestreo de cada río donde se alcanzan los valores del coeficiente más altos, todos ellos superiores a 3. Simonović y Nikolić (2007) sugieren que un aumento del coeficiente $b$ nos indicaría que hay un mayor crecimiento en peso en esos años, lo que podría acelerar la maduración sexual de las truchas y afectar posteriormente tanto a la dinámica poblacional como a las densidades.

Para la trucha común, la tasa del crecimiento anual en peso, Gw, disminuyó conforme avanzaba la edad (capítulo 4), por lo que se considera apropiado el cálculo de las curvas de crecimiento teórico de Von Bertalanffy. Estas curvas fueron calibradas según edad y longitud de la trucha (Tabla 5.2), observándose una gran variabilidad 
entre años y entre ríos. Sólo en los ríos Vallanca y Palancia se observaron parámetros de la curva estadísticamente no significativos. Estos sesgos podrían deberse a que no se han incluido en el modelo teórico de Von Bertalanffy un número similar de peces en cada clase de edad (Guy y Brown, 2007). También, al juntar todos los años de muestreo nos permitió calcular las longitudes asintóticas hipotéticas de los ríos de estudio, siendo la mayor la del río Ebrón, seguidas del Vallanca, Palancia y Villahermosa. Además, las diferencias encontradas entre ríos y años deben ser interpretadas con precaución, no sólo por tratarse de diferentes poblaciones sino porque el crecimiento individual de cada pez está fuertemente influenciado por factores ambientales como la temperatura, el alimento y la velocidad del agua (Vincenzi et al., 2007). Otros autores también han estimado los parámetros de los modelos de crecimiento longitudinal de Von Bertalanffy para la trucha en la Península Ibérica con valores muy dispares. García de Jalón et al. (1986) para ríos pirenaicos observó valores de $L_{\infty}$ comprendidos entre 321,583 y $374 \mathrm{~mm}$ y un valor $\mathrm{K}$ de 0.36 , 0.15 y 0.23 años $^{-1}$ (río Gállego, diferenciando los mesohábitas rápidos de los lentos y río Escarra, respectivamente). Igualmente, Lobón-Cerviá et al. (1986) encontró en el río Duero valores de $L_{\infty}$ de $659 \mathrm{~mm}$ y de $k$ de 0.18 años $^{-1}$. La cantidad de variación observada en los patrones de crecimiento de la trucha parece ser una adaptación fenotípica a las condiciones ecológicas locales, como demuestra el experimento de Mann et al. (1983).

Por otro lado, no se encontraron correlaciones significativas entre las longitudes de las diferentes clases de edad de ningún río, excepto para las clases $0+$ y $1+$ del Villahermosa y entre $1+$ y $2+$ del Villahermosa y Palancia (tabla 5.3). Probablemente esto se deba al bajo tamaño muestral, como indica el hecho de que cuando al combinar los datos de todos los ríos se hallan correlaciones entre las tallas de las truchas inmaduras con las adultas $(0+$ con $2+$ y $3+$, y $1+$ con $2+)$. Tampoco se observó ninguna relación entre las longitudes de trucha de cada clase de edad y su densidad en los ríos mediterráneos, excepto para 0+ y 1+ del río Vallanca (figura 5.2) y 1+ del río Palancia (figura 5.3), en donde se encontró una relación negativa no linear. Algunos experimentos de campo con poblaciones de trucha muestran que el crecimiento de los juveniles puede verse afectado negativamente por el aumento de la densidad (Jenkins et al., 1999; Bohlin et al., 2002; Sundström et al., 2004), aunque Lobón-Cerviá (2005) encontró relaciones denso-dependientes con el crecimiento a cualquier edad. Zorn y Nuhfer (2007) encontraron un efecto negativo en la longitud con las densidades de la trucha y sugirieron que el número de adultas pueden limitar la densidad de $0+$. 
Elliott (1994) sugiere que los cambios en la densidad de la trucha común podrían deberse a los factores denso-dependientes en áreas favorables con altas densidades y a los factores denso-independientes en áreas desfavorables con bajas densidades. De ser así, bastaría con controlar los factores ambientales (caudales, temperatura del agua, alimento...) en poblaciones con bajas densidades para gestionar adecuadamente las poblaciones de trucha. Sin embargo, Lobón-Cerviá $(2007,2009)$ encontró que bajas densidades de trucha juvenil pueden afectar en sus crecimientos pero no en su mortalidad, en contraste con las altas densidades, donde puede operar tanto en el crecimiento como en la mortalidad. Por otro lado, Nicola et al. (2008) encontró que entre el 30 y el $50 \%$ de la variabilidad en la densidad de alevines en septiembre fue explicada por la variación en la densidad inicial de huevos. De los cuatro ríos de estudio, el Vallanca es el que presenta las densidades más altas y el Palancia las más bajas (capítulo 4). Sin embargo, el río Palancia cuenta con una población de trucha arco-iris bien estructurada de mayor densidad, ocupando el mismo nicho ecológico que la trucha común autóctona (Alcaraz-Hernández y Martínez-Capel, 2004). Por lo tanto, a las densidades de la trucha común habría que sumarle las de la trucha arco-iris. Distintos factores pueden explicar el efecto de la densidad. La trucha común debe de competir por recursos limitados siendo territorial, por lo menos en verano con caudales bajos, por lo tanto las truchas inmaduras ( $\leq 1$ año) deben de competir tanto por el espacio como por el alimento. Las altas densidades requieren el invertir más energía y tiempo en las interacciones competitivas que las bajas, disminuyendo el crecimiento individual (Deverill et al., 1999).

Finalmente, otros factores exógenos se han relacionado con las densidades de las truchas inmaduras, principalmente los caudales de avenida, aunque este supuesto no se ha comprobado en este estudio por falta de las series de caudales, constituyendo una de las líneas futuras de investigación de esta tesis doctoral. En este sentido, Cattanéo et al. (2002) y Lobón-Cerviá (2007) encontró que los altos caudales en el periodo de emergencia de las larvas reducen las densidades de 0+. Lobón-Cerviá (2003, 2007) observó que al aumentar los caudales medios de marzo, el reclutamiento aumentaba linealmente. También Zorn y Nuhfer (2007) observaron un efecto negativo sobre los alevines con la magnitud de los caudales punta en primavera, y también detectaron que las concentraciones de fósforo del agua tienen un efecto positivo sobre ésta clase de edad. Alonso-González et al. (2008) en la península ibérica, hallaron una correlación entre el caudal medio anual y la densidad de $0+$ en verano. En este estudio, es precisamente en los ríos Vallanca y Palancia (donde se han detectado relaciones denso-dependientes), en donde menos caudal 
medio circula al año, frente a los ríos Ebrón y Villahermosa que son más caudalosos (capítulo 2).

Los análisis nos han permitido analizar los crecimientos en distintos años y ríos, y como se comportan ante la densidad de la trucha común. Sólo en dos ríos se ha obtenido una relación de dependencia entre la longitud individual de las clases no adultas y su densidad ( $0+$ y $1+$ en el Vallanca y $1+$ en el Palancia). Para ambos ríos, estos resultados sugieren que las truchas inmaduras podrían estar reguladas por diferentes mecanismos denso-dependientes. Los mecanismos denso-independientes vinculados a los caudales no han podido ser explorados por falta de estaciones de aforo en los ríos de estudio. Estos mecanismos son relevantes para la gestión poblacional de la trucha ya que limita los factores que causan fluctuaciones en las poblaciones, siendo más fácil detectar los mecanismos necesarios para la persistencia de la especie a largo plazo. Por lo tanto, los resultados no son definitivos ya que, según la bibliografía, diferentes factores no estudiados podrían afectar a las densidades de ríos mediterráneos, crucial para la regulación de la dinámica poblacional. Sería necesario contar con un plan de monitorización de la especie duradero en el tiempo con el fin de poder observar y documentar estos procesos en un periodo de tiempo más largo.

\section{BIBLIOGRAFÍA}

Alcaraz-Hernández, J.D. y F. Martínez-Capel. 2004. Estudio del estado de conservación de las poblaciones de trucha común en la Comunidad Valenciana. Informe metodológico. Grupo de Evaluación de Impacto Ambiental. Universidad Politécnica de Valencia. 119 pp.

Alonso-González, C., J. Gortázar, D. Baeza Sanz y D. García de Jalón. 2008. Dam function rules based on brown trout flow requirements: design of environmental flow regimes in regulated streams. Hydrobiologia 609: 253-262.

Bohlin, T., L.F. Sundström, J.I. Johnsson, J. Höjesjö y J. Pettersson. 2002. Density-dependent growth in brown trout: effects of introducing wild and hatchery fish. Journal of Animal Ecology 71: 683-692.

Carle, F.L. y M.R. Strub. 1978. A new method for estimating population size from renoval data. Biometrics 34: 621-380.

Cattanéo, F., N. Lamouroux, P. Breil y H. Capra. 2002. The influence of hydrological and biotic processes on brown trout (Salmo trutta) population dynamics. Canadian Journal of Fisheries and Aquatic Sciences 59: 12-22. 
Deverill, J.I., C.E. Adams y C.W. Bean. 1999. Prior residence, aggression and territory acquisition in hatchery-reared and wild brown trout. Journal of Fish Biology 55: 868-875.

Elliott, J.M. 1994. Quantitative ecology and the brown trout. Oxford: Oxford University Press. $286 \mathrm{pp}$.

García de Jalón, D., E. Tolosana-Esteban y F. Rodríguez-Alcalde. (1986). Estimación de algunos parámetros poblacionales de la trucha común (Salmo trutta fario) en los ríos pirenaicos. Boletín de la Estación Central de Ecología 29: 51-58.

Granado-Lorencio, C. 2002. Ecología de peces. Secretariado de Publicaciones, Universidad de Sevilla, Sevilla, 353 pp.

Grant, J.W.A. y I. Imre. 2005. Patterns of density-dependent growth in juvenile streamdwelling salmonids. Journal of Fish Biology 67: 100-110.

Guy, C.S y M.L. Brown, editores. 2007. Análisis and interpretation of freshwater fisheries data. American Fisheries Society, Bethesda, Maryland, EE.UU. 961 pp.

Hedger, R.D., J.J. Dodson, N.E. Bergeron y F. Caron. 2004. Quantifying the effectiveness of regional habitat quality index models for predicting densities of juvenile Atlantic salmon (Salmo salar L.). Ecology of Freshwater Fish 13: 266-275.

Imre, I., J.W.A. Grant y R.A. Cunjak. 2005. Density-dependent growth of young-of-the-year Atlantic salmon Salmo salar in Catamaran Brook, New Brunswick. Journal of Animal Ecology 74: 508-516.

Jenkins, T.M., S. Diehl, K.W. Kratz y S.D. Cooper. 1999. Effects of population density on individual growth of brown trout in streams. Ecology 80: 941-956.

Lobón-Cerciá, J. 2003. Spatiotemporal dynamics of brown trout production in a Cantabrian stream: effects of density and habitat quality. Transactions of the American Fisheries Society 132: 621-637.

Lobón-Cerviá, J. 2004. Discharge-dependent covariation patterns in the population dynamics of brown trout (Salmo trutta) within a Cantabrian river drainage. Canadian Journal of Fisheries and Aquatic Sciences 61: 1929-1939.

Lobón-Cerviá, J. 2005. Spatial and temporal variation in the influence of density dependence on growth of stream-living brown trout (Salmo trutta). Canadian Journal of Fisheries and Aquatic Sciences 62: 1231-1242.

Lobón-Cerviá, J. 2007. Numerical changes in stream-resident brown trout (Salmo trutta): uncovering the roles of density-dependent and density-independent factors across space and time. Canadian Journal of Fisheries and Aquatic Sciences 64: 1429-1447.

Lobón-Cerviá, J. 2009. Recluitment as a driver of production dynamics in stream-resident brown trout (Salmo trutta). Freshwater Biology 54: 1692-1704. 
Lobón-Cerviá, J. y P.A. Rincón. 2004. Environmental determinants of recluitment and their influence on the population dynamics of stream-living brown trout Salmo trutta. Oikos 105: 641-646.

Lobón-Cerviá, J., C. Montañes y A. De Sosota. 1986. Reproductive ecology and growth of a population of brown trout (Salmo trutta L.) in a aquifer-fed stream of Old Castile (Spain). Hydrobiologia 135: 81-94.

Mann, R.H.K., C.A. Mills y D.T. Crisp. 1983. Geographical variation in the life history tactics of some species of freshwater fish. En Miller, J.T. (ed.). Fish reproduction. Academic Press, London, 171-186.

Nicola, G.G., A. Almodóvar, B. Jonsson y B. Elvira. 2008. Recruitment variability of resident brown trout in peripheral populations from southern Europe. Freshwater Biology 53: 2364-2374.

Parra, I., A. Almodóvar, D. Ayllón, G.G. Nicola y B. Elvira. 2010. Ontogenetic variation in density-dependent growth of brown trout through habitat competition. Freshwater Biology. Doi: 10.1111/j.1365-2427.2010.02520.x.

R Development Core Team (2008). R: A language and environment for statistical computing. $R$ Foundation for Statistical Computing, Vienna, Austria. ISBN 3-900051-07-0, URL http://www.R-project.org.

Ratikainen, I.I., J.A. Gill, T.G. Gunnarsson, W.J. Sutherland y H. Kokko. 2008. When density dependence is not instantaneous: theoretical developments and management implications. Ecology Letters 11: 184-198.

Rose, K.A., J.H. Cowan, K.O. Winemiller, R.A. Myers y R. Hilborn. 2001. Compensatory density dependence in fish populations: importance, controversy understanding and prognosis. Fish and Fisheries 2: 293-327.

Simonović, P.D. y V.P. Nikolić. 2007. Density-dependence of growth characteristics and maturation in stream-dwelling resident brown trout, Salmo trutta, in Serbia. Fisheries Management and Ecology 14: 1-6.

Sundström, L.F., T. Bohlin y J.I. Johnsson. 2004. Density-dependent growth in hatcheryreared brown trout released into a natural stream. Journal of Fish Biology 65: 1385-1391.

Vicenzi, S., A.J. Crivelli, D. Jesensek, J.F. Rubin y G.A. De Leo. 2007. Density-dependent individual growth of marble trout (Salmo marmoratus) in the Soca and Idrijca river basins, Slovenia. Hydrobiologia 58: 57-68.

Wootton, R.J. 1998. Ecology of teleost fishes. Chapman and Hall, London, UK. 392 pp.

Zorn T.G. y A.J. Nuhfer. 2007. Influences on brown and brook trout population dynamics in a Michigan river. Transactions of the American Fisheries Society 136: 691-705. 


\section{CAPÍTULO 6}

\section{RELACIONES CUALITATIVAS ENTRE DENSIDADES DE TRUCHA COMÚN Y LAS CARACTERÍSTICAS FÍSICAS DEL HÁBITAT. ANÁLISIS POR RÍOS}

\section{Resumen}

Las densidades de trucha común son controladas por factores denso-independientes, cuya relevancia y jerarquía en la mayoría de los casos son desconocidas por los gestores medioambientales. La estratificación de los muestreos según tipos de mesohábitats nos ha permitido estudiar qué características físicas del mesohábitat tienen más relevancia en la variación de la densidad, tanto para la trucha inmadura como la adulta, en cada uno de los cuatro ríos de estudio (Ebrón, Vallanca, Palancia y Villahermosa) durante los meses de verano. Para ello se realizaron en cada río un análisis de correspondencia simple $(C A)$ y se comprobaron las correlaciones por rangos de Spearman entre las densidades y las características físicas del hábitat. Los resultados fueron plasmados en mapas bidimensionales que muestran las distintas relaciones entre las variables. La proporción de varianza explicada por estos mapas varía aproximadamente entre el $51 \%$ y el $61 \%$. Se observa, gracias a las correlaciones de Spearman, que todas las variables del hábitat, salvo el sustrato fino, han sido correlacionadas significativamente con la densidad de trucha en algunos de los mapas del Ebrón, Vallanca y Villahermosa. No obstante, en cada río son diferentes las variables físicas correlacionadas con la densidad, excepto para la trucha adulta de los ríos Vallanca y Villahermosa ya que en ambos casos existe una correlación positiva con la profundidad y el volumen. Por el contrario, no se observó ninguna relación entre las densidades de trucha común y las variables físicas del río Palancia. Por lo tanto, los resultados reflejan la alta variabilidad local de cada uno de los ríos de estudio. Por otro lado, el estudio ha permitido observar una relación densodependiente entre la densidad de trucha inmadura y adulta sólo en el río Vallanca.

Palabras clave: Salmo trutta, trucha común, hábitat físico, mesohábitat, análisis de correspondencias, ríos mediterráneos. 


\section{INTRODUCCIÓN}

El hábitat fluvial es el lugar donde los peces viven y se desarrollan a lo largo de su vida. El uso actual del hábitat acuático por los peces es la manifestación de la multitud de preferencias y limitaciones de la especie donde se incluye la optimización del área de alimentación y freza, la interacción pasada y presente con otras especies y las limitaciones ontogénicas (Roper et al., 1994). Por otro lado, la evaluación del hábitat acuático es una disciplina abordada desde multitud de diferentes enfoques como lo demuestran tanto el elevado número de protocolos o índices de caracterización como por el uso de distintas variables de estudio en los muestreos. Algunas de sus características pueden servir para predecir la abundancia de peces mientras que otras no tienen apenas significación en diversos estudios. Cuando las características del hábitat tienen este poder predictivo, será razonable pensar que el hábitat está actuando como un factor limitador y que la abundancia de peces está limitada por factores particulares del hábitat. Se debería prestar especial atención a identificar estas características físicas que limitan a las poblaciones (García de Jalón et al., 1996). En los últimos tiempos, los modelos han sido incorporados paulatinamente por los investigadores medioambientales para evaluar la relación que existe entre las abundancias de peces y las características del hábitat, como pone de manifiesto las revisiones efectuadas en EE.UU por Fausch et al. (1988) y en Europa por Barnard y Wyatt (1995). En ellas, la mayor parte de las variables del hábitat fueron tomadas directamente de los tramos de estudio o sacadas de mapas topográficos, empleándose técnicas estadísticas multivariantes en la creación de los modelos.

No obstante, con la gestación y desarrollo en las últimas décadas de la teoría jerárquica multiescalar (Frissell et al., 1986), se han desarrollado diferente métodos de muestreo que se adaptan a esta conceptualización del hábitat de los ríos, seguidas a la vez del uso de nuevas herramientas estadísticas. Hay experiencias que demuestran la distribución y competencia de diferentes especies de salmónidos a lo largo de la cuenca y del segmento fluvial (Burnett, 2001; Argent et al., 2003), o el uso de las truchas según los biotopos o mesohábitats del río (Baran et al., 1997; Inoue y Nakano, 1999) o también el uso y la preferencia de estas por distintas características del microhábitat (Strakosh et al., 2003; Al-Chokhachy y Budy, 2007). En este sentido, también se han desarrollado estudios en la Península Ibérica a nivel de cuenca y microhábitat, donde se indagan sobre las particularidades que sufren las especies que viven en ríos influenciados por el clima mediterráneo, donde los fuertes periodos de lluvias torrenciales y sequías y la alta variación intra-anual e inter-anual de sus caudales es una constante (Gasith y Resh, 1999). Ejemplos a nivel de cuenca o 
segmentos fluviales lo encontramos en ríos portugueses (Godinho et al., 2000; Filipe et al., 2002; Magalhães et al., 2002) y más recientemente a nivel de microhábitat en ríos centrales españoles (Ayllón et al., 2009; Martínez-Capel et al., 2009), pero sorprende el hecho de que no se ha realizado ningún estudio sobre la influencia de los hábitats en las abundancias de peces en ríos mediterráneos.

Hankin (1984) recomendaba que las secciones de muestreo del hábitat se realizaran de forma equivalente e independientemente en estratos construidos a partir de los distintos tipos naturales de los hábitats de un río dentro de cada cuenca, para cometer menor error en la estimación del número de salmones. Bisson et al. (2006) argumentaban varias razones para clasificar los biotopos del hábitat entre ellas la descripción exacta de los ríos y de sus unidades hidromorfológicas, como un primer paso en la descripción de los requerimientos ecológicos de los organismos durante su vida, así como para describir los procesos que influyen en su abundancia y distribución (Schlosser, 1987).

Nuestro estudio está realizado en cuatro ríos mediterráneos, en donde se estimaron las densidades de trucha común y se caracterizó el hábitat mediante los atributos físicos de las distintos mesohábitats o unidades hidromorfológicas. Nuestra investigación pretende contestar a las siguientes preguntas (1) ¿existe alguna relación entre las características físicas de los hábitats y las densidades de trucha para cada uno de los ríos estudiados? y si es así (2) ¿qué características son las más destacables?

\section{MÉTODOS}

\section{Adquisición de datos en campo}

Todos los muestreos se realizaron en los meses de junio, julio y agosto desde el año 2003 hasta el 2006, ambos inclusive, cuando el caudal de los ríos era bajo. Basados en las características físicas generales (p.e. profundidad y velocidad del agua), el hábitat se dividió en distintos biotopos (mesohábitat o unidades hidromorfológicas). La tipificación y caracterización de los distintos mesohábitat se realizó siguiendo los criterios generales de la técnica "Basinwide Visual Estimation Technique - BVET" (Hankin y Reeves, 1988; Dolloff et al., 1993). En los análisis estadísticos sólo se utilizaron cuatro tipos de mesohábitats; pozas, tablas, corrientes y rápidos. El número de step (o escalones) y tramos secos fueron inferiores al 3\% de la longitud total de los tramos. Además, otras unidades hidromorfológicas como las cascadas no fueron 
detectadas a lo largo del estudio. La clasificación visual se ejecutó siguiendo los siguientes criterios de muestreo:

- Pozas, con profundidades mayores de $0.6 \mathrm{~m}$ (producidas generalmente por erosiones locales), velocidades inferiores a la media del tramo y pendientes muy bajas.

- Tablas, con profundidades menores de $0.6 \mathrm{~m}$, velocidades similares a la media el tramo y sin turbulencias apreciables y con secciones trasversales aproximadamente simétricas.

- Corrientes, con aguas poco profundas con rizaduras superficiales, velocidades del agua inferiores a $0.4 \mathrm{~m} \cdot \mathrm{s}^{-1}$ y secciones trasversales aproximadamente simétricas, con un calado de magnitud similar al sustrato superficial.

- Rápidos, con aguas someras con velocidades mayores que la media del tramo, con abundantes turbulencias superficiales, elementos de sustrato grueso que sobresalen del agua y predominio del flujo supercrítico.

A continuación, se caracterizó cada mesohábitat mediante la medición de sus características físicas: longitud del mesohábitat $(L, m)$, anchura media del cauce $(A$, $\mathrm{m}$ ) tomada como media de tres puntos que corresponden a $1 / 4,1 / 2, y 3 / 4$ de la longitud total de la unidad hidromorfológica, profundidad media (Pmed, m) tomada como promedio de nueve puntos correspondientes a la medida tomada en $1 / 4,1 / 2, y 3 / 4$ en cada transecto donde se midió la anchura y, por último, profundidad máxima (Pmáx, $\mathrm{m})$. La longitud, anchura y profundidad media determinan la dimensión de la columna de agua y el predominio de las velocidades del agua. Con estos tres parámetros se calculó el volumen $\left(\mathrm{V}, \mathrm{m}^{3}\right)$. Además, para estudiar la heterogeneidad y complejidad del hábitat se estimó visualmente el porcentaje de sustrato (\%) de los materiales gruesos ( $\mathrm{Sg}$, con partículas mayores de $256 \mathrm{~mm}$ de diámetro), los materiales medios (Sm, 2-256 mm) y los materiales finos ( $\mathrm{Sf},<2 \mathrm{~mm}$ ), el sombreado del cauce (Som, \%), el recubrimiento de finos del lecho ( $R f, \%)$ y la densidad de madera (Dmad, troncos $\cdot \mathrm{m}^{-2}$ ). Igualmente, se estimó la distancia relativa entre rápidos (DRR, $\mathrm{m}$ ), calculada como la media de las distancias que hay entre el final de un mesohábitat rápido hasta el inicio del siguiente en un tramo de estudio de 300 metros. Este índice refleja la capacidad del río para aportar alimento a las truchas. Por último, se estimó el índice de refugio (IR) propuesto por García de Jalón y Schmidt (1995) como:

$$
I R=C e+\frac{C s b+C s t+C v s+C p}{4}
$$


Este índice esta desarrollado conjuntamente por aquellos parámetros más importantes para el refugio de los peces siendo Ce el refugio debido a cornisas, cuevas y bancos, Csb el debido al sombreado, Cst el debido al tipo de sustrato, Cvs el debido a la vegetación sumergida y $\mathrm{Cp}$ el debido a la profundidad de la columna de agua. Este índice valoró independientemente cada tipo de refugio entre una escala de grados de seis puntos que va de 0 (no proporciona refugio) a 5 (disponibilidad máxima) según las recomendaciones que se describen en la tabla 6.1.

Tabla 6.1. Valoración numérica de la capacidad de refugio mediante los coeficientes de orilla (Ce), de sombra (Csb), de sustrato (Cst), de vegetación sumergida (Cvs) y de profundidad (Cp).

\begin{tabular}{ccccccc}
\hline VALORES & $\mathbf{0}$ & $\mathbf{1}$ & $\mathbf{2}$ & $\mathbf{3}$ & $\mathbf{4}$ & $\mathbf{5}$ \\
\hline Ce & Ausencia & $\begin{array}{c}\text { Cornisa } \\
\text { aérea }\end{array}$ & $\begin{array}{c}\text { Cornisa } \\
\text { sumergida }\end{array}$ & $\begin{array}{c}\text { Cornisa } \\
\text { sumergida } \\
\text { profunda }\end{array}$ & $\begin{array}{c}\text { Raíces } \\
\text { riparias }\end{array}$ & $\begin{array}{c}\text { Cornisa } \\
\text { profunda } \\
\text { y raíces }\end{array}$ \\
Csb & $0 \%$ & $<10 \%$ & $10-25 \%$ & $25-50 \%$ & $50-75 \%$ & $>75 \%$ \\
Cst & $\begin{array}{c}\text { Roca } \\
\text { madre }\end{array}$ & $\begin{array}{c}\text { Limos y } \\
\text { arenas }\end{array}$ & $\begin{array}{c}\text { Gravas y } \\
\text { gravillas }\end{array}$ & $\begin{array}{c}\text { Cantos } \\
\text { rodados }\end{array}$ & Bloques & $\begin{array}{c}\text { Roca } \\
\text { madre } \\
\text { fisurada }\end{array}$ \\
Cvs & Ninguna & $<1 \%$ & $1-5 \%$ & $5-15 \%$ & $15-30 \%$ & $>30 \%$ \\
$\begin{array}{c}\text { Cp } \\
\text { Agua clara/ } \\
\text { turbia }\end{array}$ & $<15 \mathrm{~cm}$ & $15-50 \mathrm{~cm}$ & $50-80 \mathrm{~cm}$ & $\begin{array}{c}80-100 / \\
15-50 \mathrm{~cm}\end{array}$ & $\begin{array}{c}100-150 / \\
50-80 \mathrm{~cm}\end{array}$ & $>150 /$ \\
\hline
\end{tabular}

Por otro lado, los peces fueron muestreados mediante pesca eléctrica en cada mesohábitat. El tamaño de las poblaciones de peces fue estimado por capturas sucesivas, realizando como mínimo tres pasadas sin reemplazamiento, y a un esfuerzo constante, siempre con los mesohábitats cerrados con redes. Todos los peces fueron colocados en neveras con agua continuamente oxigenada para su datación y devueltos posteriormente al río cerca del lugar donde se capturaron. $A$ todos los peces extraídos se les midió la longitud furcal $( \pm 1 \mathrm{~mm})$ y su peso $( \pm 1 \mathrm{~g})$. A la mayoría de los individuos de más de un año de edad se les extrajeron escamas para su posterior análisis. Las edades fueron establecida en el laboratorio mediante el análisis de las frecuencias de longitudes y verificadas mediante la lectura de las escamas de la muestra de peces. La densidad de truchas (truchas $\cdot \mathrm{m}^{-2}$ ) fue estimada en cada muestra y para cada edad (Cowx, 1983), aplicándose el método de máxima verosimilitud ponderada de Carle y Strub (1978). Para la realización de este estudio 
se establecieron dos categorías de densidad; inmadura (Dinma, < 2 año) y adulta (Dadul, $\geq 2$ año).

\section{Análisis de los datos}

Se realizaron distintos análisis de correspondencia simple $(C A)$ con el fin de encontrar posibles asociaciones entre las características hidromorfológicas de los mesohábitats y las densidades de trucha común. Se utilizó $C A$ debido a que el número de individuos de la muestra disminuyó al aumentar la estratificación del estudio, haciendo inviable el uso de otras técnicas estadísticas cuantitativas que requieren mayor tamaño muestral, a una escala de trabajo de río. Las variables incluidas en los análisis fueron: longitud, anchura, profundidad media y máxima, volumen, proporción de sustrato grueso, medio y fino, distancia relativa entre rápidos, índice de refugio y densidad de trucha inmadura y adulta. La densidad de madera, el porcentaje de recubrimiento de finos y el porcentaje de sombreado no se incluyeron en el CA porque durante los análisis exploratorios preliminares, la aportación a la inercia en cada una de las dimensiones fue muy baja. Se realizó un $C A$ por cada río, sumando un total de cuatro.

Para este fin, se convirtieron todas las variables continuas en categóricas. Para ello, se transformaron los datos siguiendo la propuesta desarrollada por Greenacre (2008). Para ello, inicialmente, se recodificaron los valores de cada variable para obtener una escala de rangos o grados; después se ordenaron los datos continuos de cada variable de forma decreciente, para posteriormente asignarle (dentro de un rango de valores) un valor discreto ordinal. Este rango es único y varía según el número de individuos que interviene en el análisis. Por ejemplo, en los mesohábitat del río Ebrón, el rango osciló entre 1 y 28 y se procedió de la siguiente forma: al valor continuo más bajo se le asignó el valor más bajo del rango para progresivamente, conforme se acrecentaban los valores continuos, se le iban asignando valores discretos más altos. Se dio la posibilidad de encontrarse datos continuos con el mismo valor, en tal caso, se le asignó un único valor discreto ordinal a cada dato, siendo éste el valor medio de sus rangos.

A continuación, una vez obtenidas las variables categóricas, se llevó a cabo el doblado de las variables. El doblado es un procedimiento que se utiliza habitualmente en $C A$ para datos procedentes de grados. Para ello se redefinió la escala de grados obtenida mediante un par de escalas complementarias, una con valores positivos y otra con valores negativos, con el fin de obtener un gradiente explicativo entre los dos polos. Greenacre (2008) recomienda que antes de llevar a cabo el doblado hay que empezar 
con el extremo inferior de la escala de grados igualado a cero y que los valores altos correspondan a valores altos de la escala de grados. Por lo tanto, esta nueva escala estaría definida por el polo negativo, que se obtiene al restarle 1 a todos los valores de la serie (igualando el valor mínimo a 0 ) y el polo positivo, que se obtiene restando a toda la serie su mayor valor. Además, se aplicó el test de independencia de caracteres Chi-cuadrado para comprobar el supuesto de homogeneidad entre las variables. Para ello, se estableció como hipótesis nula la independencia entre las variables $(p>0.005)$.

Por último, los resultados se mostraron en mapas bidimensionales asimétricos representando los perfiles de las variables en coordenadas principales, con el único fin de conseguir una adecuada interpretación, debido a que las distancias de los mapas asimétricos son aproximadamente distancias Chi-cuadrado (Greenacre, 2008). A los ejes de los mapas se le añadió el porcentaje de inercia de cada dimensión. Además, se aplicó el test de correlación de rangos de Spearman $(p<0.05)$ entre pares de variables para comprobar estadísticamente la relación de cercanía que muestran los mapas entre las densidades y las características del hábitat. Todos los análisis fueron realizados mediante el programa estadístico de libre acceso $\mathrm{R}(R$ Development Core Team, 2008), utilizando el paquete ca programado por Nenadic y Greenacre (2007).

\section{RESULTADOS}

Los tests Chi-cuadrado de todos los ríos fueron significativos, obteniéndose $p$-valores muy pequeños $(p<0.005)$, por lo que hizo que se rechazara la hipótesis nula de independencia entre variables. Así pues, en todos los ríos se pudo aplicar el análisis de correspondencias. 
Tabla 6.2. Correlaciones de Spearman entre las densidades y las características físicas del hábitat de los ríos Ebrón, Vallanca, Palancia y Villahermosa. $N$, número de la muestra; Dinma, densidad de trucha inmadura; Dadul, densidad de trucha adulta; L, longitud; $A$, anchura; Pmed, profundidad media; Pmáx, profundidad máxima; $V$, volumen; Sg, porcentaje de sustrato grueso; Sm, porcentaje de sustrato medio; Sf, porcentaje de sustrato fino; IR, índice de refugio; DRR, distancia relativa entre rápidos. $\left(^{*}\right)$ Nivel de significación $p<0.05$.

\begin{tabular}{ccccccccc}
\hline & \multicolumn{2}{c}{$\begin{array}{c}\text { EBRÓN } \\
(\boldsymbol{N}=\mathbf{2 8})\end{array}$} & \multicolumn{2}{c}{$\begin{array}{c}\text { VALLANCA } \\
(\boldsymbol{N}=\mathbf{2 6})\end{array}$} & \multicolumn{2}{c}{$\begin{array}{c}\text { PALANCIA } \\
(\boldsymbol{N}=\mathbf{2 1})\end{array}$} & \multicolumn{2}{c}{$\begin{array}{c}\text { VILAHERMOSA } \\
(\boldsymbol{N}=\mathbf{1 8})\end{array}$} \\
& Dinma & Dadul & Dinma & Dadul & Dinma & Dadul & Dinma & Dadul \\
\hline Dinma & - & 0.276 & - & $0.396^{*}$ & - & 0.114 & - & 0.070 \\
L & 0.016 & 0.048 & $0.409^{*}$ & 0.318 & 0.013 & 0.340 & 0.029 & 0.182 \\
A & 0.053 & $0.415^{*}$ & 0.170 & 0.227 & 0.047 & 0.086 & -0.276 & -0.022 \\
Pmed & -0.148 & 0.291 & 0.047 & $0.653^{*}$ & -0.235 & -0.004 & -0.323 & $0.711^{*}$ \\
Pmáx & -0.210 & 0.267 & 0.233 & $0.726^{*}$ & -0.115 & 0.272 & -0.407 & 0.388 \\
V & -0.020 & $0.412^{*}$ & 0.124 & $0.543^{*}$ & -0.154 & 0.184 & -0.314 & $0.479 *$ \\
Sg & 0.254 & 0.252 & 0.084 & -0.133 & -0.070 & -0.099 & $-0.551^{*}$ & -0.067 \\
Sm & $-0.400^{*}$ & -0.058 & 0.052 & 0.021 & 0.314 & 0.104 & 0.339 & 0.295 \\
Sf & 0.298 & 0.140 & -0.259 & 0.059 & -0.325 & -0.176 & 0.089 & -0.401 \\
IR & -0.234 & 0.183 & -0.052 & $0.594^{*}$ & 0.322 & 0.081 & -0.091 & 0.413 \\
DRR & 0.041 & $-0.386^{*}$ & -0.182 & -0.285 & 0.006 & 0.087 & 0.175 & 0.175 \\
\hline
\end{tabular}

\section{Rio Ebrón}

El mapa bidimensional recogió aproximadamente el $51 \%$ de la inercia total de los datos de las variables (figura 6.1). El eje formado por la densidad de inmaduras es casi perpendicular al eje formado por los adultos, lo que indica una relación nula entre ambas variables. Por otro lado, la densidad de trucha inmadura está alineada con el porcentaje del sustrato medio, existiendo una relación negativa estadísticamente significativa (tabla 6.2). Además, la trucha adulta está alineada positivamente con la anchura del cauce y negativamente con la distancia entre rápidos, como lo reflejan las correlaciones de Spearman (tabla 6.2). 


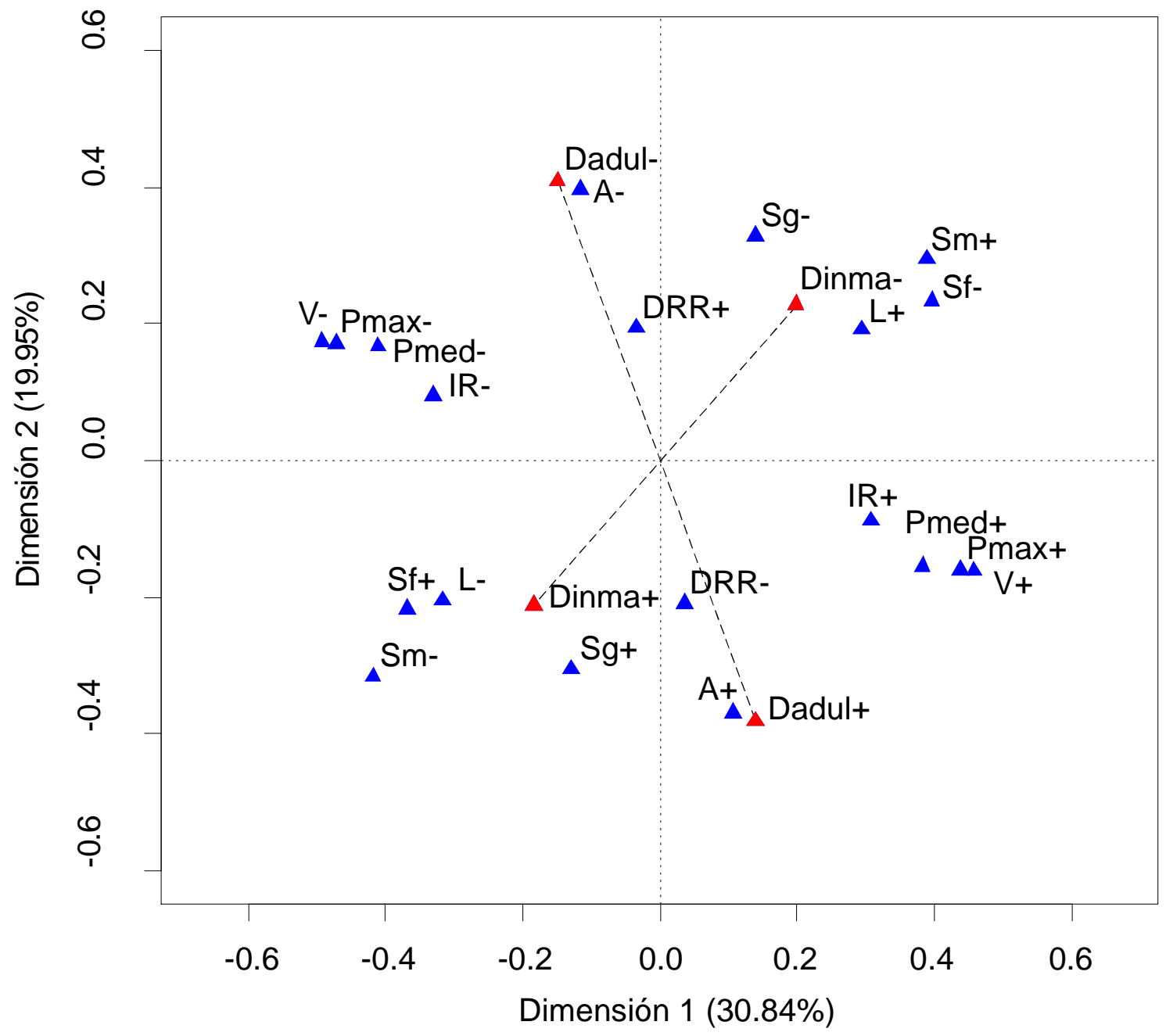

Figura 6.1. Análisis categórico de las características hidromorfológicas del hábitat ( $\Delta$ ) y de las densidades $(\boldsymbol{\Delta})$ en el río Ebrón. Las abreviaciones están descritas en la tabla 6.2.

\section{Rio Vallanca}

El mapa recoge aproximadamente el $61 \%$ de la inercia de los datos de las variables (figura 6.2). Como se observa en el mapa, existe una correlación positiva entre la densidad de trucha adulta y la inmadura y entre la densidad de trucha adulta y el índice de refugio (tabla 6.2). Además, se han detectado otras variables del hábitat físico fuertemente correlacionadas con las densidades (tabla 6.2) y cuya aproximación no se ve reflejada en el mapa. Estas son; la trucha inmadura con la longitud y la adulta con la profundidad media y máxima y el volumen. Esto se debe a que los mapas bidimensionales no recogen toda la variabilidad de los datos, por lo que habría que combinar otros planos con otras dimensiones para su observación. 


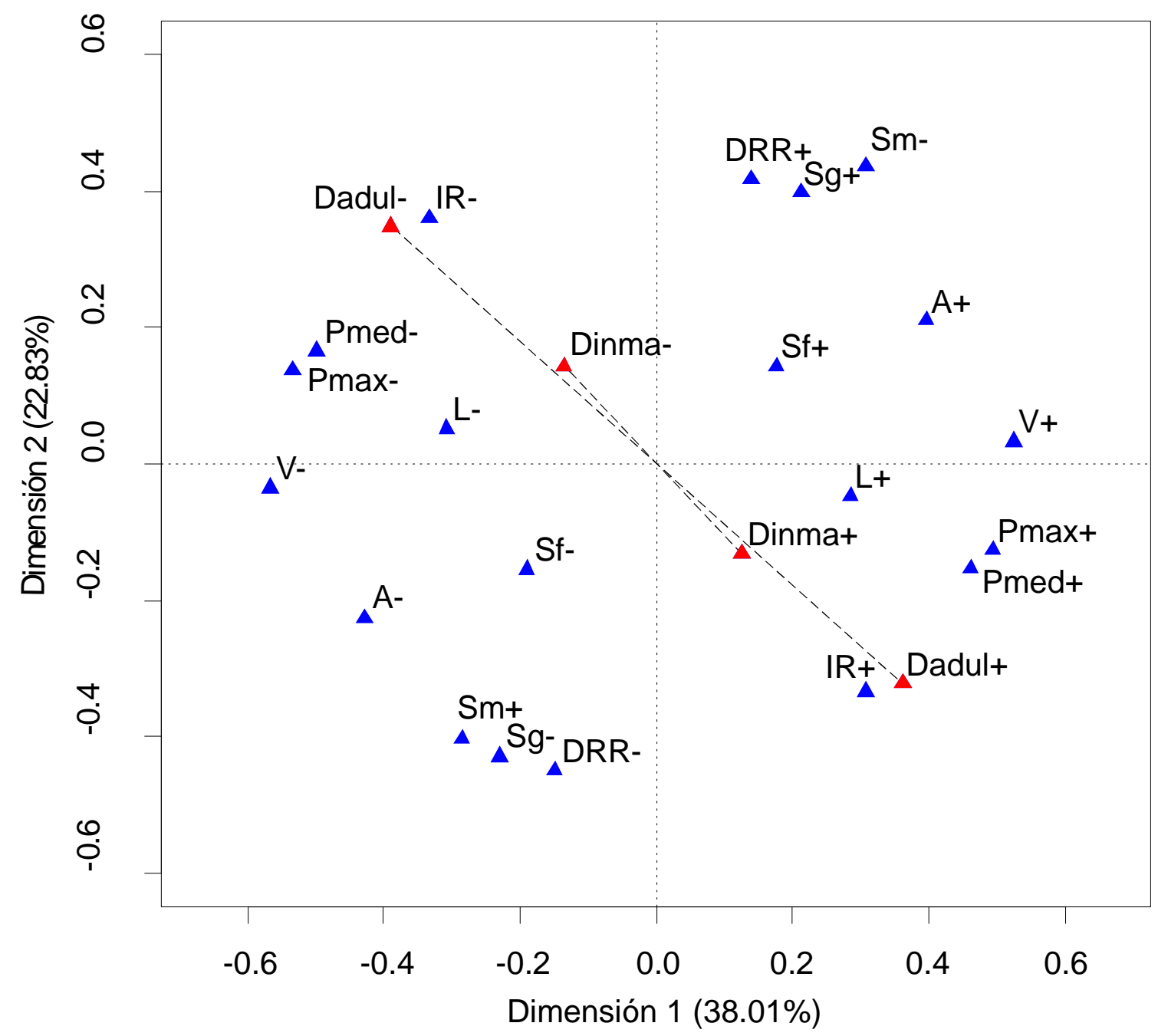

Figura 6.2. Análisis categórico de las características hidromorfológicas del hábitat ( $\Delta$ ) y de las densidades $(\boldsymbol{\Delta})$ en el río Vallanca. Las abreviaciones están descritas en la tabla 6.2.

\section{Rio Palancia}

Los datos del río Palancia aglutinan aproximadamente un 53\% de inercia total en dos dimensiones (figura 6.3). Como ocurría en el río Ebrón, el eje formado por la densidad de adultos es casi perpendicular al eje formado por los inmaduros, lo que indica una relación nula entre ambas variables. Además, ni la densidad de trucha inmadura ni la de adulta están correlacionadas con ninguna de las variables física del mesohábitat (tabla 6.2). 


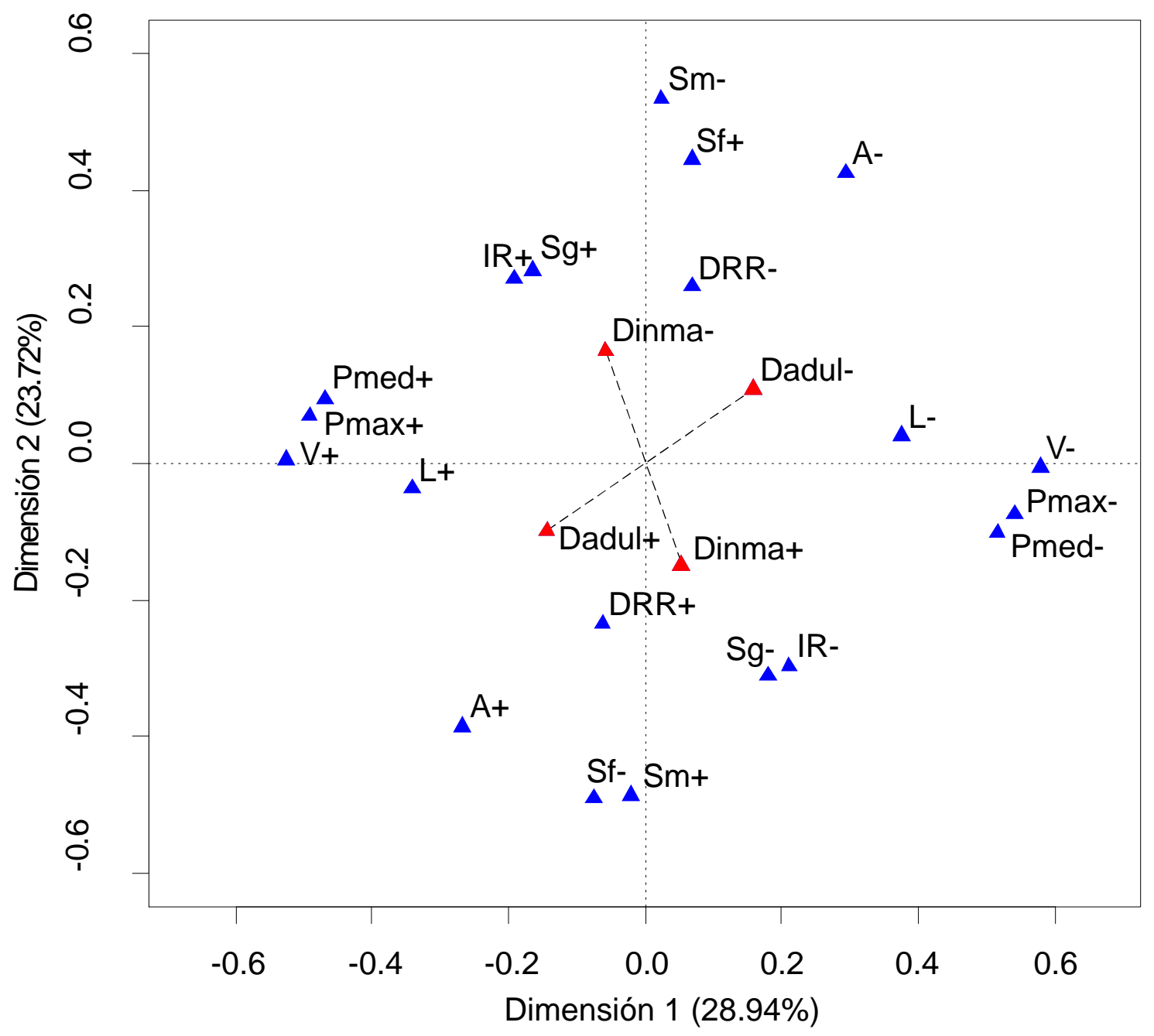

Figura 6.3. Análisis categórico de las características hidromorfológicas del hábitat $(\Delta)$ y de las densidades $(\boldsymbol{\Delta})$ en el río Palancia. Las abreviaciones están descritas en la tabla 6.2.

\section{Rio Villahermosa}

De manera aproximada, la inercia de los dos mapas bidimensionales son del $51 \%$ (figura 6.4). El gradiente de la densidad de trucha inmadura es perpendicular al de la adulta por lo que no existe relación entre ambas variables. No obstante, la densidad de trucha inmadura está negativamente correlacionada con el sustrato grueso frente a la adulta que está positivamente correlacionada con la profundidad media y el volumen (tabla 6.2, figura 6.4). 


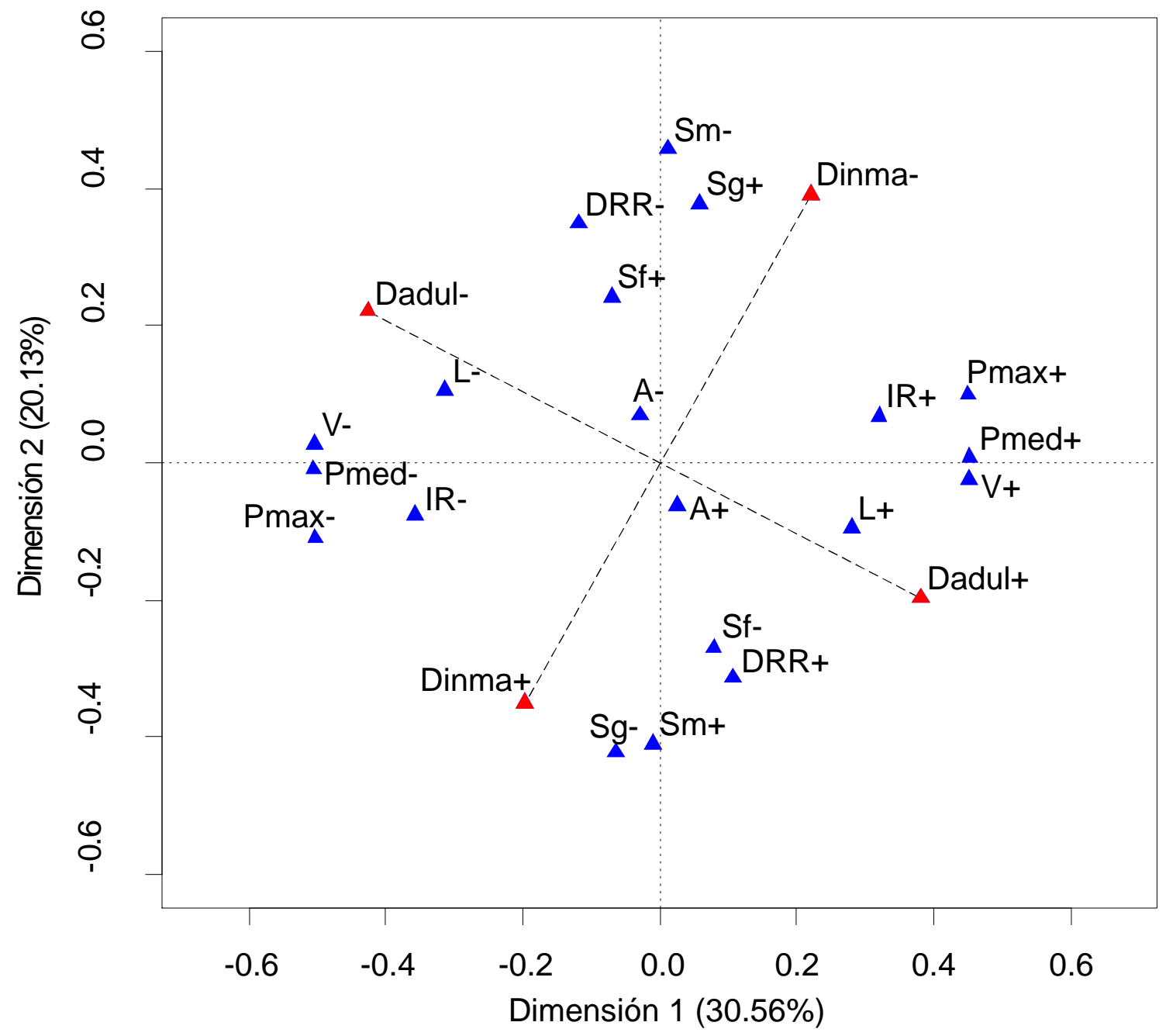

Figura 6.4. Análisis categórico de las características hidromorfológicas del hábitat ( $\Delta$ ) y de las densidades $(\boldsymbol{\Delta})$ en el río Villahermosa. Las abreviaciones están descritas en la tabla 6.2.

\section{DISCUSIÓN}

El hábitat es el que mejor determina la variación espacial en la abundancia y distribución de muchas poblaciones de truchas (Milner et al., 2003). Este estudio se suma a otros en donde se ahonda en la variabilidad medioambiental y subraya su importancia a través de la fluctuación de la densidad de peces con la revisión de algunas de las características del hábitat (Baran et al., 1997; Jutila et al., 1999; Johansen et al., 2005). Nuestros resultados recogen un cierto porcentaje de explicación (entre el 51 y el 61\%), no elevado pero aceptable en los cuatro mapas bidimensionales de datos categóricos, uno por cada río. De las diez variables del hábitat que inicialmente se consideraron, nueve han sido correlacionadas significativamente en algún caso con la densidad de trucha en tres de los cuatros ríos. 
El porcentaje de sustrato fino fue la única variable que no se correlacionó en ningún río con ninguna densidad. La longitud siempre fue correlacionada positivamente con la densidad de trucha inmadura, así como la anchura, la profundidad media y máxima, el volumen y el índice de refugio mantuvieron siempre una correlación positiva con la adulta. Por el contrario, el porcentaje de sustrato grueso y medio estaban correlacionado negativamente con la densidad de trucha inmadura, mientras que la distancia relativa entre rápidos con la adulta. Tradicionalmente, la profundidad y velocidad del agua, el tamaño de partícula del sustrato y el refugio han sido las variables abióticas medidas más frecuentemente (Heggenes et al., 1999).

Además, no se observó ninguna correlación en el río Palancia entre las densidades de trucha común y las variables físicas de sus hábitats. Esto sugiere que los factores denso-independientes sólo tienen gran relevancia en tres de los cuatro ríos. Las condiciones físicas de los hábitats del río Palancia son óptimas (capítulo 3 de este estudio), ya que sus mesohábitats presentan mayor variabilidad que en el resto de los ríos y por lo tanto aumenta las alternativas de elección del espacio para la especie. No obstante, las densidades y biomasas de la trucha común del río Palancia son las más bajas de los cuatro ríos de estudio (capítulo 4). Una causa parcialmente explicatoria podría ser que las densidades de la trucha común no están reguladas por factores abióticos y si por mecanismos denso-dependientes, concretamente la clase $0+$ (ver capítulo 5). Además, podría estar dándose competencia interespecífica entre trucha común y arco-iris, ya que en este río, las poblaciones de arco-iris están bien establecidas, siendo las densidades y biomasas mayores que las de la común (AlcarazHernández y Martínez-Capel, 2004a).

Por otro lado, en el río Ebrón y Villahermosa, la densidad de trucha inmadura ha sido correlacionada negativamente con el porcentaje de sustrato medio y grueso, respectivamente. Algunos estudios no encuentran relación significativa entre tamaño de trucha y uso del sustrato (Maki-Petays et al., 1997), aunque otros demuestran como la trucha ocupa lugares con grandes cantidades de sustrato medio (8-128 mm de diámetro) (Eklöv et al., 1999). En general, la trucha adulta es menos abundante en hábitats donde predomina sustrato fino en el fondo del cauce, prefiriendo instalarse en sustratos más gruesos (Heggenes et al., 1999). Bardonnet y Heland (1994) realizaron distintas experiencias en canales artificiales asegurando que los alevines de trucha común prefieren sustratos entre 10-90 mm de diámetro. La aparente razón para elegir este sustrato fue que es mayor la disponibilidad de refugio en los espacios entre partículas gruesas, y que las bajas velocidades aportan micronichos en los que se incrementa la eficiencia bioenergética. Según estos autores, la causa de este fenómeno se debe a que partículas de mayor tamaño aumentan la abundancia y 
diversidad de la fauna invertebrada al incrementarse la porosidad del sustrato (Maridet et al., 1992) y crean micronichos con velocidades del agua más bajas en donde las truchas adultas pueden conservar su energía mientras visualiza los macroinvertebrados a la deriva al igual que obtienen espacios intersticiales para ocultarse de los predadores (Bardonnet y Heland, 1994), desplazando a las truchas de menor edad hacia hábitats de menor idoneidad.

De la misma manera, la trucha inmadura siempre se correlacionó positivamente con la longitud en el río Vallanca. Es en este río, donde circulan los caudales de agua más bajos, donde sus mesohábitats son los más pequeños y sus hábitats lentos recogen mayor variabilidad hidromorfológica (capítulo 3). Además, existe una relación significativa entre la densidad de truchas adultas e inmadura en el río Vallanca al estar positivamente correlacionadas ambas variables, lo que indica la ausencia segregación espacial entre los individuos de los diferentes mesohábitats (lentos y rápidos). No obstante, la talla y el peso de los alevines es más pequeña que en los ríos Ebrón y Villahermosa (capítulo 4) y se ha observado una relación de dependencia entre las longitudes de las clases inmaduras y su densidad (capítulo 5), lo que indicaría la posible competencia intraespecífica entre clases de edad por el alimento. Por lo tanto, como se comentaba en el párrafo anterior, la correlación positiva de la trucha inmadura con la longitud podría deberse a la disponibilidad de alimento lo que obligaría a la trucha inmadura a desplazarse a hábitats con mayor espacio y de peor calidad bioenergética. En este mismo sentido, Jutila et al. (1999) demostró como los alevines de trucha ( $\leq 1$ año) utilizan las pozas pero en ausencia de grandes truchas. Por el contrario, Baran et al. (1997) encontraron un gradiente entre las unidades hidromorfológicas y las clases de edad de la trucha según las características físicas de profundidad, velocidad y refugio, encontrando densidades muy bajas en los hábitat profundos de ríos pirenaicos franceses.

Por otro lado, la trucha adulta también se correlacionó positivamente con la anchura en los mesohábitats del río Ebrón. Esta última variable ha sido importante en otros estudios para explicar la distribución global de los peces y su estratificación por clases (Sheldon y Meffe, 1995; Godinho et al., 2000). En el norte de la Península Ibérica, Reyes-Gavilán et al. (1995) encontraron una correlación negativa entre la densidad de truchas y la anchura del cauce alegando que ésta producía un efecto dispersante en la densidad del tramo. En nuestro estudio, el Ebrón es el cauce que menor número de mesohábitats lentos tiene por metros lineales de río (Alcaraz-Hernández y Martínez-Capel, 2004b). El comportamiento más frecuente observado en la literatura científica es que los alevines de trucha utilizan mesohábitats someros, hasta que alcanzan cierto tamaño y entonces se desplazan hacia los hábitats más profundos. 
Esto se puede observa con las truchas adultas de los ríos Vallanca y Villahermosa, ya que prefieren mesohábitats de mayor profundidad y volumen. Una explicación para este comportamiento podría ser la competición intraespecífica o la territorialidad (Elliott, 1990; Elso y Giller, 2001) y el riesgo de predación (Greenberg et al., 1997). La idea de reducir el gasto de energía o maximizar la energía obtenida usando los mesohábitat lentos también ha sido sugerida (Bridcut y Giller, 1993).

A raíz de lo expuesto anteriormente, es lógico pensar que en ríos pequeños como el Ebrón, donde hay carencias estructurales de profundidad en sus cauces, la densidad de trucha aumente en las unidades hidromorfológicas más anchas, ya que estas se desplazan según sus requerimientos del hábitat ocupando todo el territorio. En este sentido, Young (1994) sugirió que el área de campeo que utiliza la trucha abarca más de un mesohábitat. Además, la trucha del río Ebrón está correlacionada negativamente con la distancia relativa entre rápidos y por lo tanto con la mayor superficie y longitud total de pozas.

Por último, el índice de refugio esta correlacionado positivamente con el número de trucha adulta en los hábitats del río Vallanca. Este índice agrupa las variables más importantes que dan mayor cobertura a las poblaciones de truchas; sombreado, cornisas, dominancia del tipo de sustrato, vegetación sumergida y profundidad (García de Jalón y Schmidt, 1995). Las áreas de refugio han sido consideradas como un factor importante en la selección del nicho espacial por la trucha, apoyando la idea de que su uso indica la preferencia de estos peces por hábitats energéticamente más favorables (Rincón y Lobón-Cerviá, 1993; Maki-Petays et al., 1997), así como dar protección a las truchas frente a caudales rápidos, altas temperaturas y predación (García de Jalón et al., 1996). De esta forma, Hermansen y Krog (1984) encontró una correlación significativa entre las densidades de trucha y las cornisas y macrófitas sumergidas en ríos Daneses. Por el contrario, García de Jalón et al. (1996) señalaron que las turbulencias, la profundidad, la superficie de las rocas y las macrófitas sumergidas proporcionaban la mejor cobertura a las truchas de los ríos ibéricos del Pirineo, siendo escasa la cobertura proporcionada por el sombreado de la vegetación de ribera. Además apuntaba que la capacidad de refugio para los peces adultos está limitada por la profundidad del agua.

A nivel global, como se deriva de los párrafos anteriormente, parece que la trucha común de los río mediterráneos hacen uso del hábitat según su disponibilidad, por lo que coincidiremos con Baran et al. (1997) al afirmar que el uso de los peces sobre los hábitats depende de dos factores biológicos: el requerimiento del pez sobre el hábitat (que depende del tamaño del pez y de su actividad) y la competencia 
intraespecífica. Como se ha observado en este estudio, la combinación de estas dos características en las poblaciones de trucha causa un uso concreto de los individuos sobre su medioambiente. Este estudio nos ha permitido obtener modelos que reflejan la variabilidad local de cada río en la disponibilidad y el uso del hábitat por parte de las truchas.

\section{BIBLIOGRAFÍA}

Alcaraz-Hernández, J.D. y F. Martínez-Capel. 2004a. Estudio del estado de conservación de las poblaciones de trucha común en la Comunidad Valenciana. Informe metodológico. Grupo de Evaluación de Impacto Ambiental. Universidad Politécnica de Valencia. 119 pp.

Alcaraz-Hernández, J.D. y F. Martínez-Capel. 2004b. Estudio del hábitat físico para las poblaciones de trucha común y arco iris en la Comunidad Valenciana. Informe metodológico. Grupo de Evaluación de Impacto Ambiental. Universidad Politécnica de Valencia. 119 pp.

Al-Chokhachy, R. y P. Budy. 2007. Summer microhabitat use of fluvial bull trout in eastern Oregon streams. North American Journal of Fisheries Management 227: 1068-1081.

Argent, D.G., J.A. Bishop, J.R. Stauffer, R.F. Carline y W.L. Myers. 2003. Predicting freshwater fish distributions using landscape-level variables. Fisheries Research 60: 17-32.

Ayllón, D., A. Almodóvar, G.G. Nicola y B. Elvira. 2009. Interactive effects of cover and hydraulics on brown trout habitat selection patterns. River Research and Aplications 25: 1051-1065.

Baran, P., M. Delacoste y J.M. Lascaux. 1997. Variability of mesohabitat used by brown trout populations in the French central Pyrenees. Transactions of the American Fisheries Society 126: 747-757.

Bardonnet, A. y M. Heland. 1994. The influence of potential predation on the habitat preferenda of emerging brown trout. Journal of Fish Biology 45: 131-142.

Barnard, S. y R.J. Wyatt. 1995. An analysis of predictive models for stream salmonid populations. Bulletin Français de la Pêche et de la Pisciculture 337/338/339: 365-373.

Bisson, P.A., J.M. Buffington y D.R. Montgomery. 2006. Valley segment, stream reaches, and channel units. Pages 23-49 in F.R. Hauer y G. A. Lamberti, editors. Methods in stream ecology. Academic Press, San Diego, California, USA.

Bridcut, E.E. y P.S. Giller. 1993. Diet variability in relation to season and habitat utilisation in brown trout, Salmo trutta L. in a southern Irish stream. Canadian Special Publications of Fisheries and Aquatic Sciences 118: 17-24. 
Burnett, K.M. 2001. Relationships among juvenile anadromous salmonids, their freshwater hábitat, and landscape characteristics over multiple years and spatial scales in the Elk river, Oregon. PdD dissertation, Oregon State University, Corvallis, Oregon. 71 pp.

Carle, F.L. y M.R. Strub. 1978. A new method for estimating population size from removal data. Biometrics 34: 621-380.

Cowx, I.G. 1983. Review of the methods for estimating fish population size from removal data. Biometrics 34: 621-830.

Dolloff, C.A., D.G. Hankin y G.H. Reeves. 1993. Basinwide estimation of habitat and fish populations in streams. U.S. Department of Agriculture. Forest Service. Southeastern Forest Experiment Station, 25 pp.

Eklöv, A.G., L.A. Greenberg, C. Brönmark, P. Larsson y O. Berglund. 1999. Influence of water quality, habitat and species richness on brown trout population. Journal of Fish Biology 54: 33-43.

Elso, J.I. y P.S. Giller. 2001. Physical characteristics influencing the utilization of pools by brown trout in an afforested catchment in Southern Ireland. Journal of Fish Biology 58: 201-221.

Elliott, J.M. 1990. Mechanisms responsible for population regulation in young migratory trout, Salmo trutta. III. The role of territorial behaviour. Journal of Animal Ecology 59: 803-818.

Fausch, K.D., C.L. Hawkes y M.G. Parsons. 1988. Models that predict standing crop of stream fish from habitat variables: 1950-85. Gen. Tech Rep. PNW-GTR-213. Portland, OR: U.S. Department of Agriculture, Forest Service, Pacific Northwest Research Station. 52 pp.

Filipe, A.P., I.G. Cowx y M.J. Collares-Pereira. 2002. Spatial modelling of freshwater fish in semi-arid river systems: a tool for conservation. River Research and Applications 18: 123136.

Frissell, C.A., W.J. Liss, C.E. Warren y M.D. Hurley. 1986. A hierarchical framework for stream habitat classification: viewing streams in a watershed context. Environmental Management 10: 199-214.

García de Jalón, D. y G. Schmidt. 1995. Manual práctico para la gestión sostenible de la pesca fluvial. Asociación para el estudio y mejora de los salmónidos. Madrid, 169 pp.

García de Jalón, D., M. Mayo y M.C. Molles. 1996. Characterization of Spanish pyrenean stream habitat: relationships between fish communities and their habitat. Regulated Rivers: Research and Management 12: 305-316.

Gasith, A. y V.H. Resh. 1999. Streams in Mediterranean climate regions: abiotic influences and biotic responses to predictable seasonal events. Annual Review of Ecology and Systematics 30: 51-81. 
Godinho, F.N., M.T. Ferreira y J.M. Santos. 2000. Variation in fish community composition along an Iberian river basin from low to high discharge: relative contributions of environmental and temporal variables. Ecology of Freshwater Fish 9: 22-29.

Greenacre, M. 2008. La práctica del análisis de correspondencias. Fundación BBVA. 375pp.

Greenberg, L.A., E. Bergman y A.G. Eklöv. 1997. Effects of predation and intraespecific interactions on habitat use and foraging by brown trout in artificial streams. Ecology of Freshwater Fish 6: 16-26.

Hankin, D.G. 1984. Multistage sampling designs in fisheries research: applications in small streams. Canadian Journal of Fisheries and Aquatic Sciences 41: 1575-1591.

Hankin, D.G. y G.H. Reeves. 1988. Estimating total fish abundance and total habitat area in small streams based on visual estimation methods. Canadian Journal of Fisheries and Aquatic Sciences 45: 834-844.

Heggenes, J., J.L. Baglinière y R.A. Cunjak. 1999. Spatial niche variability for young Atlantic salmon (Salmo salar) and brown trout (S. trutta) in heterogeneous streams. Ecology of Freshwater Fish 8: 1-21.

Hermansen, H. y C. Krog. 1984. Influence of physical factors on density of stocked brown trout (Salmo trutta fario L.) in a Danish lowland stream. Fisheries Management 15: 107-115.

Inoue, M. y S. Nakano. 1999. Habitat structure along channel-unit sequences for juvenile salmon: a subunit-based analysis of in-stream landscapes. Freshwater Biology 42: 597608.

Johansen, M., J.M. Elliott y A. Klemetsen. 2005. A comparative study of juvenile salmon density in 20 streams throughout a very large river system in northern Norway. Ecology of Freshwater Fish 14: 96-110.

Jutila, E., A. Ahvonen y M. Laamanen. 1999. Influence of environmental factors on the density and biomass of stocked brown trout, Salmo trutta L., parr in brooks affected by intensive forestry. Fisheries Management and Ecology 6: 195-205.

Magalhães, M.F., D.C. Batalha y M.J. Collares-Pereira. 2002. Gradients in stream fish assemblages across a Mediterranean landscape: contributions of environmental factors and spatial structure. Freshwater Biology 47: 1015-1031.

Maki-Petays, A., T. Muotka, A. Huusko, P. Tikkanen y P. Kreivi. 1997. Seasonal changes in habitat use and preference by juvenile brown trout, Salmo trutta, in a northern boreal river. Canadian Journal of Fisheries and Aquatic Sciences 54: 520-530.

Maridet, L., J.B. Masson y M. Philippe. 1992. Vertical distribution of fauna in the bed sediment of three running water sites: influence of physical and thropic factors. Regulated Rivers 7: 45-55.

Martínez-Capel, F., D. García de Jalón, D. Werenitzky, D. Baeza y M. Rodilla-Alamá. 2009. Microhabitat use by three endemic Iberian cyprinids in Mediterranean rivers (Tagus River Basin, Spain). Fisheries Management and Ecology 16: 52-60. 
Milner, N.J., J.M. Elliott, J.D. Armstrong, R. Gardiner, J.S. Welton y M. Ladle. 2003. The natural control of salmon and trout populations in streams. Fisheries Research 62: 111125.

Nenadic, O. y M. Greenacre. 2007. Correspondence Analysis in R, with Two- and Threedimensional Graphics: The ca Package. Journal of Statistical Software 20 (3): 1-13.

R Development Core Team (2008). R: A language and environment for statistical computing. $\mathrm{R}$ Foundation for Statistical Computing, Vienna, Austria. ISBN 3-900051-07-0, URL http://www.R-project.org.

Reyes-Gavilán, F.G., R. Garrido, A.G. Nicieza, M.M. Toledo y F. Braña. 1995. Variability in growth, density and age structure of brown trout populations under contrasting environmental and managerial conditions. En: D.M. Harper y A.J.D. Ferguson (eds) The Ecological Basis for River Management. 389-406.

Rincón, P.A. y J. Lobón-Cerviá. 1993. Microhabitat use by stream-resident brown trout: bioenergetic consequences. Transactions of American Fisheries Society 122: 575-587.

Roper, B.B., D.L. Scarnecchia y T.J. La Marr. 1994. Summer distribution of and habitat use by chinook salmon and steelhead within a major basin of the south Umpqua river, Oregon. Transactions of the American Fisheries Society 123: 298-308.

Schlosser, I.J. 1987. A conceptual framework for fish communities in small warmwater streams. Pages 17-24 en W. J. Matthews y D.C. Heins (Eds.). Community and Evolutionary Ecology of North American Stream Fishes. University of Oklahoma Press, Norman, USA.

Sheldon, A.L. y G.K. Meffe. 1995. Path analysis of collective properties and habitat relationships of fish assemblages in coastal plain streams. Canadian Journal of Fisheries and Aquatic Sciences 52: 23-33.

Strakosh, T.R., R.M. Neumann y R.A. Jacobson. 2003. Development and assessment of habitat suitability criteria for adult brown trout in southern New England rivers. Ecology of Freshwater Fish 12: 265-274.

Young, M.K. 1994. Mobility of brown trout in south-central Wyoming streams. Canadian Journal of Zoology 72: 2078-2083. 


\section{CAPÍTULO 7}

\section{ANÁLISIS DE LA DENSIDAD DE TRUCHA COMÚN SEGÚN MESOHÁBITATS MEDIANTE MODELOS ADITIVOS GENERALIZADOS}

\section{Resumen}

Algunos ríos de cabecera de la Comunidad Valenciana (S.E. de España) se caracterizan por mantener poblaciones silvestres de trucha común (Salmo trutta), de gran importancia ecológica por su linaje mediterráneo, estando adaptadas ecológicamente a un área de distribución muy pequeña, con las condiciones ambientales propias de los ríos mediterráneos. Por ello, el mantenimiento del hábitat es fundamental para su conservación. El objetivo de este trabajo fue estudiar las relaciones existentes entre las densidades de truchas adultas e inmaduras y las variables del hábitat en dos biotopos diferentes; primero para los mesohábitats lentos (pozas y tablas) y segundo para los mesohábitats rápidos (corrientes y rápidos). Para ello, se ha calculado, entre los años 2003-2006, las densidades de trucha inmadura ( $<2$ años) y adulta ( $\geq 2$ años) en cada una de las estaciones de muestreo, mediante el método de capturas sucesivas sin reposición en tramos cerrados. Paralelamente, se ha caracterizado el hábitat siguiendo los criterios establecidos por la técnica BVET (Basinwide Visual Estimation Technique), registrando la longitud, anchura, profundidad media y máxima, volumen, porcentaje de sombreado, porcentaje de recubrimientos de finos, porcentaje de sustrato, índice de refugio y distancia relativa entre rápidos. Mediante Modelos Aditivos Generalizados (GAM) se han evaluado el grado de relación entre las poblaciones de trucha y sus mesohábitats. Los resultados obtenidos nos muestran un alto grado de asociación entre la densidad de trucha adulta e inmadura y algunas de las principales características de los mesohábitats lentos y rápidos. Además, se observó por un lado, que la trucha inmadura disminuye de acuerdo al volumen en los dos tipos establecidos de mesohábitats y por otro, la adulta en los mesohábitats lentos se relaciona con la profundidad máxima y la distancia relativa entre rápidos, mientras que en los rápidos se relaciona con el índice de refugio. Estas cuatro variables predictivas podrían ser indicadoras de la territorialidad de la especie por la disponibilidad de alimento y refugio. 
Palabras clave: Densidad, Salmo trutta, trucha común, mesohábitat, modelos aditivos generalizados, GAM, ríos mediterráneos.

\section{INTRODUCCIÓN}

En la Península Ibérica, en pequeños ríos de cabecera del área circum-mediterránea todavía residen poblaciones nativas de trucha común (Salmo trutta). Estas poblaciones se están reduciendo, siendo las causas principales de su retroceso la destrucción de sus hábitats, la polución de sus aguas y la competición inter-específica de especies exóticas (Almodóvar et al., 2004). Su importancia ecológica reside en la adaptación ecológica de la especie a las condiciones mediterráneas, caracterizadas por intermitentes periodos de lluvia torrencial y sequías, y una alta variación intra-anual e inter-anual de sus caudales (Gasith y Resh, 1999). Son en éstas regiones de régimen semiárido, donde hay una marcada estacionalidad en los eventos climáticos con sequías naturales durante largos periodos de tiempo en los meses de verano (Baeza et al., 2005), y donde hay una escasez de información sobre los patrones de selección del hábitat de los peces y a su vez los factores limitantes que afectan a su distribución y abundancia (Alcaraz-Hernández et al., 2007).

De hecho, los hábitats de los ríos están caracterizados por distintos procesos fluviales que forman y mantienen patrones medioambientales heterogéneos en los cauces de los ríos (Carling, 1992; Hildrew y Giller, 1994; Inoue y Nakano, 1999). Se entiende por hábitat al rango de factores físicos y químicos que afectan a los animales a lo largo de su ciclo vital. En muchas ocasiones, estos factores actúan de inmediato alrededor del animal, sin embargo, en otros casos, hay otros muchos procesos que se dan a distintas escalas espacio-temporales que también pueden actuar sobre ellos (Armstrong et al., 1999).

En las últimas décadas se ha despertado el interés en el análisis de la relación entre las especies y sus hábitats, extendiéndose los estudios de selección de hábitat a la realización de modelos que predicen la distribución y abundancia de las especies, como por ejemplo, la influencia que ejerce la heterogeneidad espacio-temporal de las estructuras del hábitat sobre la distribución y abundancia en los peces (Fausch et al., 1988; Barnard y Wyatt, 1995; Lobón-Cerviá, 2007). La mayoría de estos modelos han sido creados por medio de regresiones lineales múltiples. Gran parte de ellos se recogen en las revisiones realizadas por Fausch et al. (1988) para distintas poblaciones de peces en ríos de Norte América y por Barnard y Wyatt (1995) para el 
norte de Europa. Estos autores concluyen que las características físicas del hábitat deberían ser las primeras variables que se incluyan en una evaluación de densoindependencia de las poblaciones de peces.

Sin embargo, estos modelos están limitados debido a que asumen unas premisas que no se suelen dar en la naturaleza. Se destaca, entre las principales suposiciones; (1) se asume que los errores se distribuyen idéntica e independientemente, esto incluye la suposición de que la varianza de la variable respuesta es constante a través de las observaciones (homocedasticidad), (2) los modelos siguen una distribución normal Gaussiana y (3) la función de la regresión es lineal en las predicciones (AhmadiNedushan et al., 2006). No obstante, recientemente se han desarrollado una gran variedad de técnicas de modelado que han superado estas limitaciones. Entre ellos destacan los Modelos Aditivos Generalizados (GAM) por usarse con éxito en estudios ecológicos debido a la disponibilidad para dar con los diferentes tipos de distribución que caracterizan los datos ecológicos (Guisan et al., 2002). Estos son extensiones no paramétricas de los modelos lineales que permiten un modelado flexible de los datos, tanto de manera lineal, o mediante complejas respuestas aditivas, o como la combinación de ambas formas en el mismo modelo (Marmion et al., 2009).

En este sentido, este estudio examina mediante GAM las características físicas del hábitat a nivel de mesohábitat en cuatro ríos de montaña y cómo éstas influyen sobre las abundancias de las poblaciones autóctonas de trucha común. Concretamente intentamos contestar a las siguientes cuestiones: (1) ¿̇e puede obtener modelos multivariantes no lineales significativos de abundancia de trucha común, en función de las variables físicas a escala de mesohábitat? (2) ¿se observa algún patrón entre las distintas variables físicas de los distintos tipos de mesohábitat?

\section{MÉTODOS}

\section{Adquisición de datos en campo}

Todos los muestreos se realizaron durante los meses de verano entre los años 2003 y 2006. En cada uno de los cuatro ríos se seleccionaron cuatro tramos de estudio de más de $300 \mathrm{~m}$. Esta longitud se estableció considerando los estudios de Leopold et al. (1964), y Meador et al. (1993) que estimaron que el espaciamiento natural de rápidos y remansos es alrededor de 6 veces la anchura del cauce. Durante los dos últimos años hubo una fuerte sequía que hizo que los tramos más altos de los ríos Vallanca y 
Villahermosa se secaran (perdiéndose seis unidades de muestreo). Además, en el tramo más alto del río Palancia no se capturó ninguna trucha común.

Por otro lado, se caracterizó el hábitat mediante sus atributos físicos utilizando la técnica de muestreo rápido BVET (Basinwide Visual Estimation Technique). Ésta consiste en estratificar visualmente el cauce según los distintos biotopos (unidades hidromorfológicas o mesohábitats), registrándose en cada uno de ellos las diferentes características hidromorfológicas (Hankin y Reeves, 1988; Dolloff et al., 1993). Para este estudio se simplificó la metodología agrupando las unidades hidromorfológicas en sólo 2 tipos; (1) lentos que incluían todas las pozas (profundidades mayores de 0.6 $\mathrm{m}$, velocidades inferiores a la media del tramo y pendientes muy bajas, donde suele presentarse algún tipo de erosión local) y las tablas (profundidades menores de 0.6 $\mathrm{m}$, lecho aproximadamente llano, agua sin rizaduras superficiales ni turbulencias apreciables, velocidades similares a la media el tramo, y secciones trasversales aproximadamente simétricas), (2) rápidos que incluyen las corrientes (aguas poco profundas con rizaduras superficiales, velocidades del agua inferiores a $0.4 \mathrm{~m} \cdot \mathrm{s}^{-1} \mathrm{y}$ secciones trasversales aproximadamente simétricas, con un calado de magnitud similar al sustrato superficial) y los rápidos (aguas someras con velocidades mayores que la media del tramo, con abundantes turbulencias superficiales, elementos de sustrato que sobresalen del agua y predominio del flujo supercrítico).

A continuación, se midieron las siguientes variables en cada mesohábitat: longitud del mesohábitat $(L, m)$, anchura media del cauce $(A, m)$ tomada como media de tres puntos que corresponden a $1 / 4,1 / 2, y 3 / 4$ de la longitud total de la unidad hidromorfológica, profundidad media (Pmed, $\mathrm{m}$ ) tomada como promedio de nueve puntos correspondientes a la medida tomada en $1 / 4,1 / 2, y 3 / 4$ en cada transecto donde se midió la anchura $y$, por último, profundidad máxima (Pmáx, $m$ ). Con estos parámetros se calculó el volumen $\left(\mathrm{V}, \mathrm{m}^{3}\right)$ como el producto de la longitud del mesohábitat, su anchura y su profundidad media. Además se estimó visualmente el sombreado del cauce (Som, \%), el recubrimiento de finos (Rf, \%) y el sustrato (\%). Los tipos de sustrato (según la clasificación simplificada de la American Geophysical Union) considerados fueron: roca madre (roca continua), grandes bloques (> 1024 $\mathrm{mm}$ de diámetro), bolos $(256-1024 \mathrm{~mm})$, cantos $(64-256 \mathrm{~mm})$, gravas $(8-64 \mathrm{~mm})$, gravillas $(2-8 \mathrm{~mm})$, arenas $(62 \mu \mathrm{m}-2 \mathrm{~mm})$, limos $(4-62 \mu \mathrm{m})$ y arcillas $(<4 \mu \mathrm{m})$. Para simplificar el análisis de dichos tipos, se agruparon en sustrato grueso ( $\mathrm{Sg}$, roca madre, grandes bolos y bolos), sustrato medio ( $\mathrm{Sm}$, cantos rodados, gravas y gravillas) y sustrato fino ( $\mathrm{Sf}$, arenas, limos y arcillas). Por último se calculó la distancia relativa entre rápidos (DRR, $\mathrm{m}$ ), como la media de las distancias que hay entre el final de un mesohábitat rápido hasta el inicio del siguiente en un tramo de estudio; esta 
última variable es indicadora tanto de las longitudes representativas de hábitats lentos, como de las distancias entre los grupos de hábitats no lentos, por lo que puede asociarse o relacionarse con ambos grupos de mesohábitats. Igualmente, se estimó el índice de refugio (IR) propuesto por García de Jalón y Schmidt (1995) como:

$$
I R=C e+\frac{C s b+C s t+C v s+C p}{4}
$$

Siendo Ce el refugio debido a cornisas, cuevas y bancos, Csb el debido al sombreado, Cst el debido al tipo de sustrato, Cvs el debido a la vegetación sumergida y Cp el debido a la profundidad de la columna de agua. Este índice valoró independientemente cada tipo de refugio entre una escala de grados de seis puntos que va de 0 (no proporciona refugio) a 5 (disponibilidad máxima) según las recomendaciones que se describen en la tabla 7.1.

Tabla 7.1. Valoración numérica de la capacidad de refugio mediante los coeficientes de orilla (Ce), de sombra (Csb), de sustrato (Cst), de vegetación sumergida (Cvs) y de profundidad (Cp).

\begin{tabular}{ccccccc}
\hline VALORES & $\mathbf{0}$ & $\mathbf{1}$ & $\mathbf{2}$ & $\mathbf{3}$ & $\mathbf{4}$ & $\mathbf{5}$ \\
\hline Ce & Ausencia & $\begin{array}{c}\text { Cornisa } \\
\text { aérea }\end{array}$ & $\begin{array}{c}\text { Cornisa } \\
\text { sumergida }\end{array}$ & $\begin{array}{c}\text { Cornisa } \\
\text { sumergida } \\
\text { profunda }\end{array}$ & $\begin{array}{c}\text { Raíces } \\
\text { riparias }\end{array}$ & $\begin{array}{c}\text { Cornisa } \\
\text { profunda } \\
\text { y raíces }\end{array}$ \\
Csb & $0 \%$ & $<10 \%$ & $10-25 \%$ & $25-50 \%$ & $50-75 \%$ & $>75 \%$ \\
Cst & $\begin{array}{c}\text { Roca } \\
\text { madre }\end{array}$ & $\begin{array}{c}\text { Limos y } \\
\text { arenas }\end{array}$ & $\begin{array}{c}\text { Gravas y } \\
\text { gravillas }\end{array}$ & $\begin{array}{c}\text { Cantos } \\
\text { rodados }\end{array}$ & Bloques & $\begin{array}{c}\text { Roca } \\
\text { madre } \\
\text { fisurada }\end{array}$ \\
Cvs & Ninguna & $<1 \%$ & $1-5 \%$ & $5-15 \%$ & $15-30 \%$ & $>30 \%$ \\
$\begin{array}{c}\text { Cp } \\
\begin{array}{c}\text { Agua clara/ } \\
\text { turbia }\end{array}\end{array}$ & $<15 \mathrm{~cm}$ & $15-50 \mathrm{~cm}$ & $50-80 \mathrm{~cm}$ & $\begin{array}{c}80-100 / \\
15-50 \mathrm{~cm}\end{array}$ & $\begin{array}{c}100-150 / \\
50-80 \mathrm{~cm}\end{array}$ & $>150 /$ \\
\hline
\end{tabular}

Para finalizar, para estudiar la población de truchas en cada tramo se realizaron capturas mediante el método de pesca eléctrica en dos mesohábitats distintos: uno lento (pozas y tablas) y uno rápido (corrientes y rápidos). El equipo consistió en un generador eléctrico de $950 \mathrm{~W}$, conectado a un transformador-rectificador para aportar corriente continua y seleccionar el voltaje más adecuado. En cada estación de muestreo se realizaron como mínimo tres pasadas sin reemplazamiento, colocándose 
redes al principio y al final de cada tramo. Los peces extraídos se colocaron en neveras con agua continuamente oxigenada para la adecuada recuperación de éstos antes de medirlos y ser soltados de nuevo en el río cerca del punto de captura. Las truchas fueron medidas (longitud furcal, $\pm 1 \mathrm{~mm}$ ) y pesados ( $\pm 1 \mathrm{~g}$ ) y a la mayoría de los individuos de más de un año de edad se les extrajeron escamas para la posterior verificación de las clases de edad-longitud junto al análisis del histograma de frecuencias de longitudes. Finalmente, se calcularon la densidad de trucha inmadura (Dinma, $<2$ años) y adulta (Dadul, $\geq 2$ años) aplicando el método de máxima verosimilitud ponderada de Carle y Strub (1978).

\section{Análisis de los datos}

Se utilizaron Modelos Aditivos Generalizados (GAM) para determinar el efecto de las variables físicas del hábitat sobre las densidades de trucha, tanto adulta como inmadura, para dos casos diferentes; (1) para los mesohábitats lentos y (2) para los mesohábitats rápidos. La función básica de los GAM es:

$$
E(y)=b_{0}+s_{1}\left(x_{1}\right)+s_{2}\left(x_{2}\right)+s_{3}\left(x_{3}\right)+\ldots
$$

donde $y$ es la variable respuesta, $b_{0}$ el parámetro constante del modelo y $s_{1}, s_{2}, s_{3}$ las funciones de suavizado de las variables predictivas $x_{1}, x_{2}$ y $x_{3}$ (Wood, 2001).

Los GAM son una generalización no paramétrica de los Modelos Lineales Generalizados $(G L M)$, los cuales son a la vez, una generalización de la regresión lineal múltiple. Los GAM permiten un análisis flexible de los datos donde las únicas suposiciones son que las variables del modelo son aditivas y que sus datos son suavizados mediante el ajuste de la curva de distribución mediante distintas funciones (Ahmadi-Nedushan et al., 2006). Estos métodos admiten la incorporación de términos no paramétricos en el modelo, lo que permite una mejor exploración de la forma de las relaciones entre variables y evita tener que presuponerlas por medio de la trasformación de los datos para ajustarlos a una distribución estadística paramétrica. La trasformación no paramétrica se consigue mediante una función que suaviza la variable predictiva. La cantidad de suavizado puede ser controlada especificando los grados de libertad de la función suavizadora. En este estudio se uso la regresión spline penalizada para la elección de los grados de libertad de la función de suavizado (Wood y Augustin, 2002). Wood (2006) realiza una descripción detallada 
de cómo las funciones de suavizado pueden expresarse como combinaciones lineales de las funciones básicas y las ventajas a la hora de usar las regresiones spline penalizadas en la construcción de los modelos GAM.

Para cada modelo, el nivel de significación de cada variable predictiva se estimó en 0.05 , excluyéndose del modelo las variables con una significación mayor. No obstante, también se tuvo en cuenta los coeficientes de determinación $R^{2}$ y los estadístico GCV (Valoración Cruzada Generalizada) y AIC (Criterio de Información de Akaike) como criterios para selección del mejor subconjunto de variables predictivas (Wood, 2006).

A diferencia de GLM que pueden expresarse más fácilmente en forma de una ecuación, la interpretación de los modelos GAM requiere la representación gráfica de las variables del modelo, debido al ajuste de los datos por medio de la función de suavizado, por lo que se presentan los gráficos de todas las variables predictivas de todos los modelos. Todos los análisis fueron realizados mediante la utilización del programa estadístico de libre acceso $\mathrm{R}$ ( $R$ Development Core Team, 2008), utilizando el paquete $m g c v$ programado por Wood (2001).

\section{RESULTADOS}

\section{Análisis de los mesohábitats lentos}

El modelo de la densidad de trucha inmadura en los mesohábitats lentos recogió aproximadamente el $62 \%$ de la variabilidad de los datos de dos variables, volumen y sustrato fino (tabla 7.2). Ambas variables fueron significativas dentro del modelo, ajustándose las curvas de suavizado del volumen y del sustrato fino con aproximadamente 2 y 7 grados de libertad, respectivamente (figura 7.1). 
Tabla 7.2. Resultados del modelo de densidad de trucha inmadura en mesohábitats lentos ( $N$ $=42$ ). Edf, grados de libertad efectivos; $s$, función de suavizado; $R^{2}$, coeficiente de determinación; $G C V$, valoración cruzada generalizada; $A I C$, criterio de Información de Akaike; $\mathrm{V}$, volumen; Sf, sustrato fino.

\begin{tabular}{ccc}
\hline Valores paramétricos & Coeficiente estimado & p-valor \\
Intercepción & 0.127 & $<0.001$ \\
Valores de suavizado & Edf & p-valor \\
S (V) & 1.844 & 0.002 \\
S (Sf) & 6.819 & 0.003 \\
Valores del modelo & & \\
$\mathrm{R}^{2}=61.9 \%$ & $\mathrm{GCV}=0.018$ & $\mathrm{AIC}=-50.896$ \\
\hline
\end{tabular}
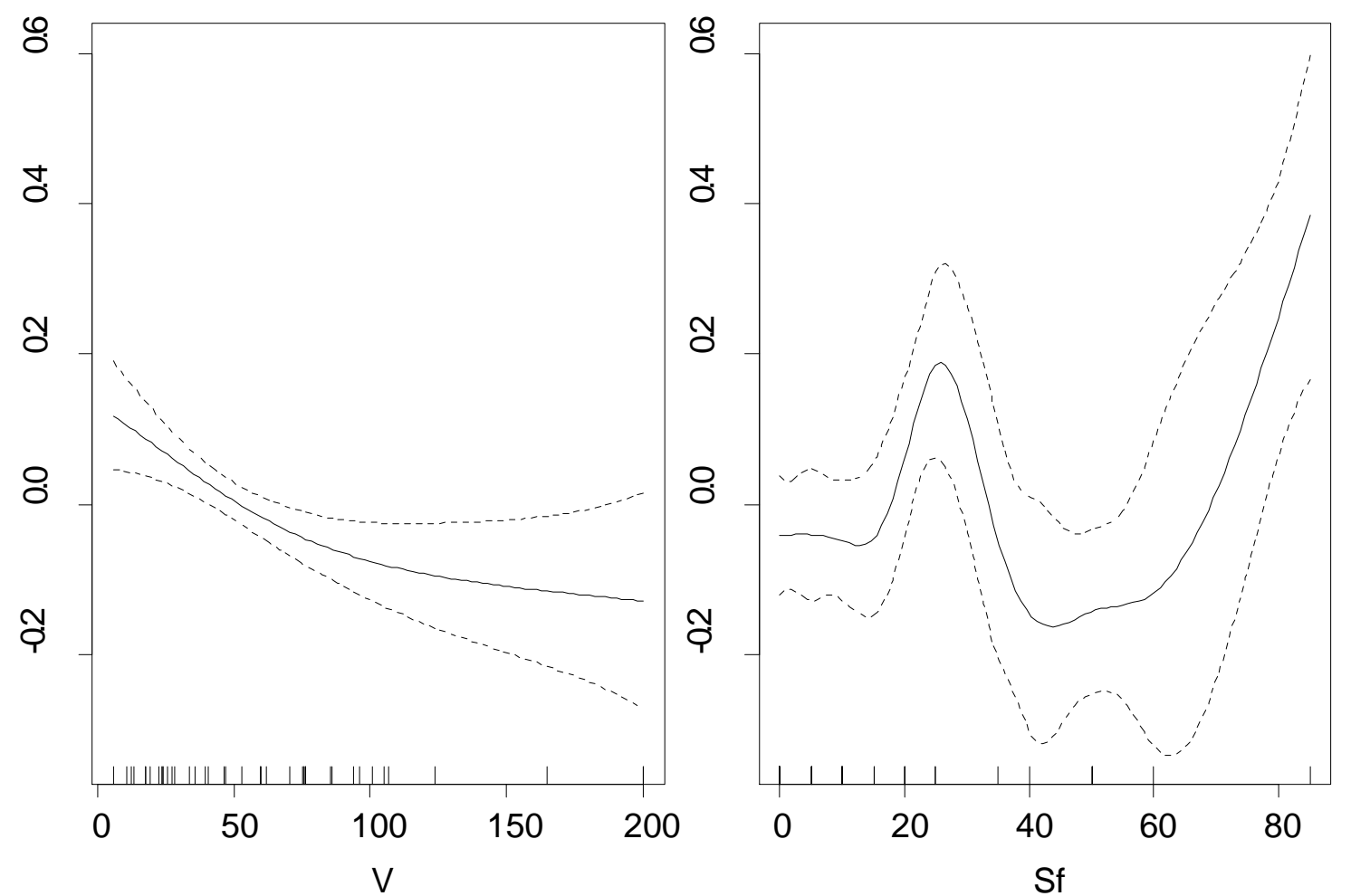

Figura 7.1. Estimación no paramétrica de las variables volumen (V) y sustrato fino (Sf), para densidad de trucha inmadura, en mesohábitats lentos $(N=42)$. Los valores del eje " $\mathrm{y}$ " corresponden al predictor linear, interpretado como probabilidad de presencia de la especie. Se usó un suavizado spline penalizado con intervalo de confianza al 95\%.

Por el contrario, el mejor modelo de densidad de trucha adulta en los mesohábitats lentos aglutinó tan sólo el $42 \%$ de la variabilidad de los datos, siendo éste el valor más bajo de los cuatro modelos. Las dos variables que entraron en el modelo fueron profundidad máxima y distancia relativa entre rápidos (tabla 7.3). Ambas variables fueron significativas dentro del modelo, ajustándose las curvas de suavizado de ambas variables con 1 y 2 grados de libertad, respectivamente (figura 7.2). 
Tabla 7.3. Resultados del modelo de densidad de trucha adulta en mesohábitats lentos $(N=$ 42). Edf, grados de libertad efectivos; $s$, función de suavizado; $R^{2}$, coeficiente de determinación; GCV, valoración cruzada generalizada; $A I C$, criterio de Información de Akaike; Pmáx, profundidad máxima; DRR, distancia relativa entre rápidos.

\begin{tabular}{ccc}
\hline Valores paramétricos & Coeficiente estimado & p-valor \\
Intercepción & 0.044 & $<0.001$ \\
Valores de suavizado & Edf & p-valor \\
S (Pmáx) & 1.000 & 0.026 \\
S (DRR) & 2.218 & 0.001 \\
Valores del modelo & & \\
$\mathrm{R}^{2}=41.7 \%$ & $\mathrm{GCV}=0.001$ & $\mathrm{AIC}=-154.538$ \\
\hline
\end{tabular}
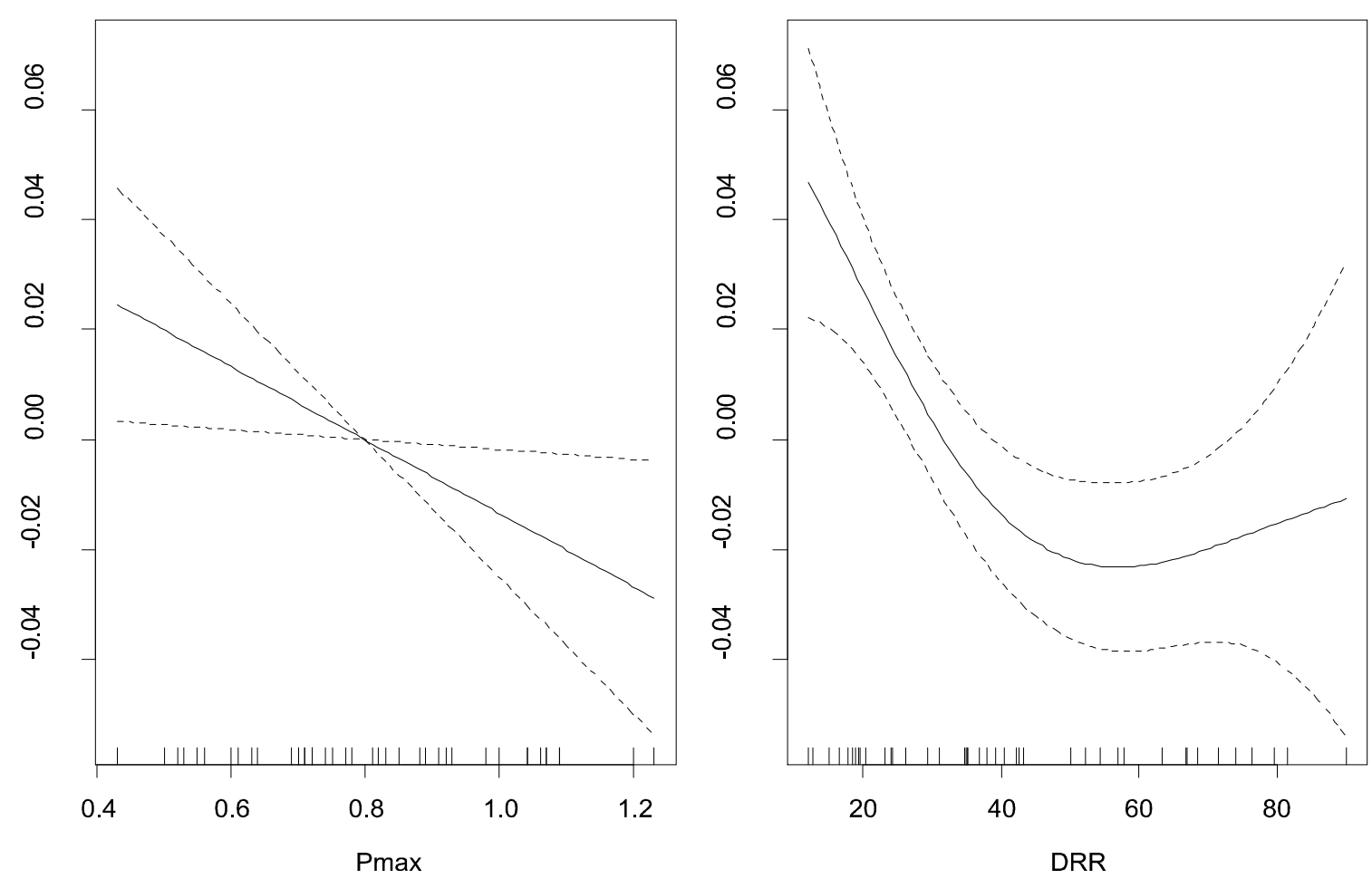

Figura 7.2. Estimación no paramétrica de las variables profundidad máxima (Pmáx) y distancia relativa entre rápidos (DRR), para la densidad de trucha adulta, en mesohábitats lentos $(N=42)$. Los valores del eje " $y$ " corresponden al predictor linear, que se interpreta como la probabilidad de presencia de la especie. Se usó un suavizado spline penalizado con intervalo de confianza al 95\%.

\section{Análisis de los mesohábitats rápidos}

El modelo de densidad de trucha inmadura en los mesohábitats rápidos ha recogido aproximadamente el 39\% de la variabilidad de los datos de dos variables, el volumen y el sustrato grueso (tabla 7.4). Todas las variables muestran una significación adecuada dentro del modelo. Además, se han utilizado aproximadamente 3 y 2 grados de libertad en la función de suavizado (figura 7.3). 
Tabla 7.4. Resultados del modelo de densidad de trucha inmadura en mesohábitats rápidos $(N=39)$. Edf, grados de libertad efectivos; $s$, función de suavizado; $R^{2}$, coeficiente de determinación; GCV, valoración cruzada generalizada; $A I C$, criterio de Información de Akaike; $\mathrm{V}$, volumen; $\mathrm{Sg}$, sustrato grueso.

\begin{tabular}{ccc}
\hline Valores paramétricos & Coeficiente estimado & p-valor \\
Intercepción & 0.118 & $<0.001$ \\
Valores de suavizado & Edf & p-valor \\
S (V) & 2.804 & 0.048 \\
s (Sg) & 2.131 & 0.038 \\
\hline Valores del modelo & & \\
$\mathrm{R}^{2}=39.0 \%$ & $\mathrm{GCV}=0.017$ & $\mathrm{AIC}=-46.913$ \\
\hline
\end{tabular}
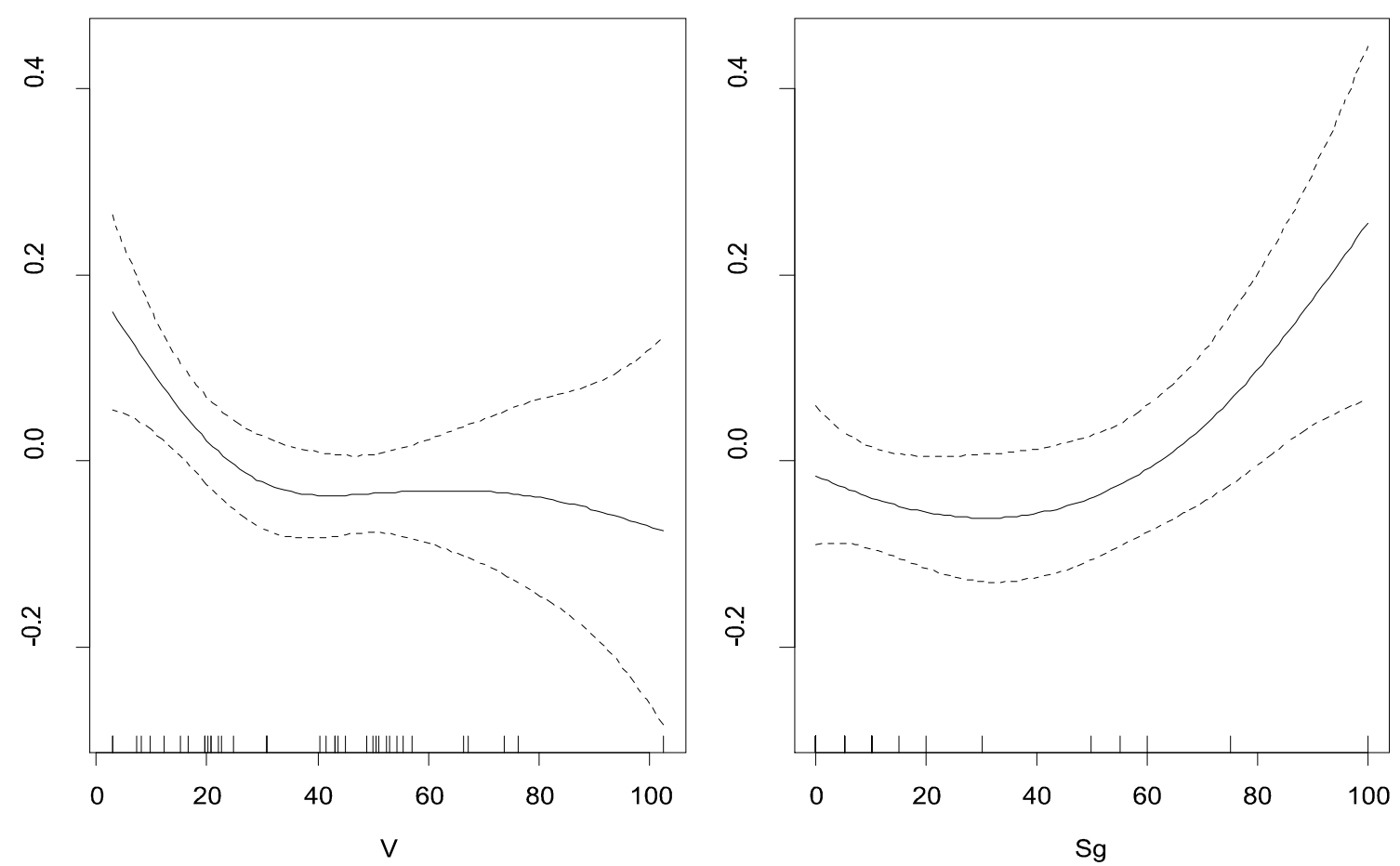

Figura 7.3. Estimación no paramétrica de las variables volumen (V) y sustrato grueso (Sg), para la densidad de trucha inmadura, en mesohábitats rápidos $(N=39)$. Los valores del eje " $y$ " corresponden al predictor linear, que se interpreta como la probabilidad de presencia de la especie. Se usó un suavizado spline penalizado con intervalo de confianza al 95\%.

Por último, el modelo de densidad de trucha adulta en mesohábitats rápidos, incorporó tres variables, la longitud, la anchura y el índice de refugio. El modelo recoge el $82 \%$ de la variabilidad de los datos, siendo éste el valor más alto obtenido de los cuatro modelos (tabla 7.5). Los grados de libertad utilizados en la función de suavizado son aproximadamente de 7,6 y 3, respectivamente (figura 7.4).

Tabla 7.5. Resultados del modelo de densidad de trucha adulta en mesohábitats rápidos ( $N=$ 39). Edf, grados de libertad efectivos; $s$, función de suavizado; $R^{2}$, coeficiente de 
determinación; $G C V$, valoración cruzada generalizada; $A I C$, criterio de Información de Akaike; $L$, longitud; $A$, anchura; IR, índice de refugio.

\begin{tabular}{ccc}
\hline Valores paramétricos & Coeficiente estimado & p-valor \\
Intercepción & 0.066 & $<0.001$ \\
Valores de suavizado & Edf & p-valor \\
S (L) & 7.074 & 0.001 \\
S (A) & 5.776 & 0.003 \\
S (IR) & 3.411 & 0.001 \\
Valores del modelo & & \\
$\mathrm{R}^{2}=82.4 \%$ & $\mathrm{GCV}<0.001$ & $\mathrm{AIC}=-212.620$ \\
\hline
\end{tabular}
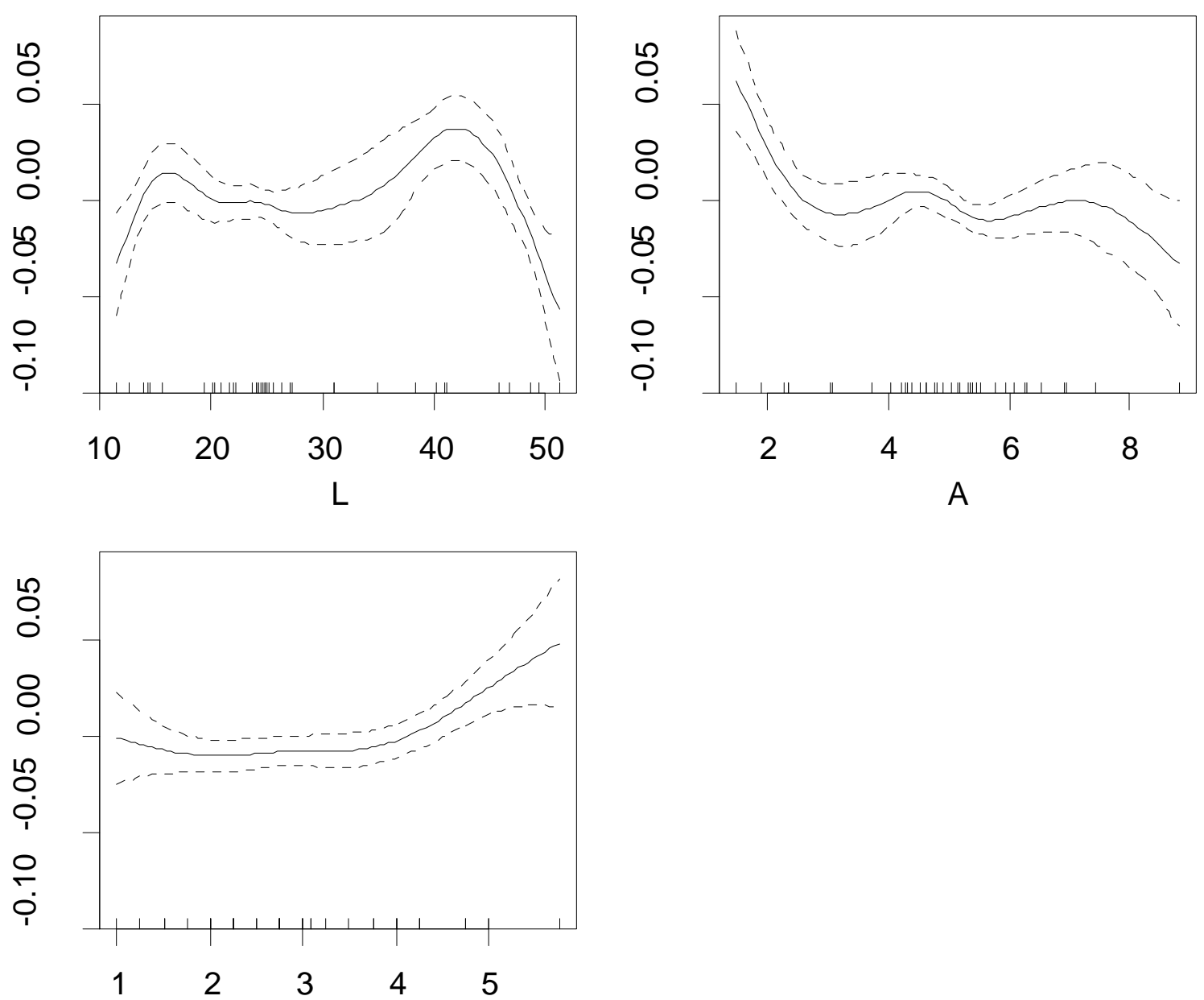

IR

Figura 7.4. Estimación no paramétrica de las variables longitud (L), anchura $(A)$ e índice de refugio $(I R)$, para la densidad de trucha adulta, en mesohábitats rápidos $(N=39)$. Los valores del eje " $y$ " corresponden al predictor linear, que se interpreta como la probabilidad de presencia de la especie. Se usó un suavizado spline penalizado con intervalo de confianza al $95 \%$. 


\section{DISCUSIÓN}

La construcción de modelos por parte de los investigadores se debe a que, gracias a la obtención de las variables predictivas más significativas, se revelan los mecanismos fundamentales que controlan la abundancia en los peces, favoreciendo el entendimiento teórico entre la relación de la población y el hábitat del río (Fausch et al., 1988). Armstrong et al. (1999) revisaron diferentes estudios sobre la gestión de los salmones a distintas escalas de trabajo y llegaron a la conclusión de que no es posible generalizar cómo el hábitat limita a los peces, pero para cada población se debería identificar independientemente los factores que limitan la producción. No obstante, simples trabajos han demostrado experimentalmente que modelos lineales no proporcionan adecuadas descripciones en el comportamiento de la comunidad de peces, siendo más apropiado la utilización de otros sistemas más complejos (Hulot et al., 2000). En este sentido, Armstrong et al. (2003) apuntaban que las relaciones entre el hábitat y los peces son extremadamente complejas y dinámicas y que debe tenerse precaución si se aplican modelos para predecir los efectos de alteraciones específicas en las características del hábitat en planes de restauración de los ríos. En este sentido, los GAM son herramientas útiles para detectar estos factores limitantes ya que no dependen de que sus variables tengan una relación linear (Marmion et al., 2009). Además, estos modelos ya han sido aplicados con éxito en ecología debido a la adaptación de los datos ecológicos a los diferentes tipos de distribución (Guisan et al., 2002), como por ejemplo en ecología fluvial (Lehman, 1998; Milner et al., 2001) o en la predicción del hábitat de los peces (Knapp y Preisler, 1999; Jowett y Davey, 2007).

En este sentido, Alcaraz-Hernández et al. (2007) calcularon, para los mismos ríos del presente estudio y sólo para un año de muestreo, un modelo lineal de densidad total con las variables físicas. En dicho modelo la variabilidad de las variables predictivas recogida por el modelo fue del $45 \%$, no recogiendo así la variabilidad temporal de las poblaciones de trucha. Los nuevos modelos GAM recogen un porcentaje de explicación igual o mayor para cuatro años de muestreo y estratificado en dos escenarios diferentes y en dos clases de edad. Para los mesohábitats lentos, el coeficiente de determinación para la densidad de trucha inmadura y adulta fue del $62 \%$ y $42 \%$, respectivamente, mientras que para los rápidos fue de $39 \%$ y $82 \%$. Además, los dos modelos de trucha inmadura presentaron valores AIC más altos que sus homólogos los adultos. No obstante, a causa de la imposibilidad de controlar la falta de aleatoriedad de los datos obtenidos debido al número insuficiente de años de seguimiento, los modelos generados se han empleado tan sólo para identificar la 
posible relación de las densidades con determinadas características físicas del mesohábitat.

Armstrong et al. (1999) sugieren que el enfoque jerárquico (p.e. tipos de mesohábitats) para modelar la influencia del hábitat en la abundancia de las truchas puede ser un camino útil en la identificación de factores limitantes. A nivel de mesohábitat, Erös y Grossman (2005) obtuvieron un gradiente significativo en los patrones del hábitat en donde la estructura de la comunidad de peces se relacionaba con el mosaico corriente-poza aunque con influencia de la variabilidad ambiental a gran escala (p.e. riadas). Por el contrario, Prenda et al. (1997) en ríos mediterráneos no observaron una separación entre la asociación del hábitat corriente-poza, aunque si demostró una asociación de especies generalistas de peces en el gradiente continuo del hábitat. En este sentido, la mayoría de las variables físicas estudiadas en este estudio se correlacionaron con la densidad, en alguno de los modelos. En concreto ocho de las doce variables del mesohábitat que inicialmente se consideraron. La profundidad media, el porcentaje de sustrato medio, sombreado y recubrimientos de finos fueron las únicas variables que no se correlacionaron con ninguna densidad.

En principio, debido a la variabilidad recogida por los modelos y al alto número de factores físicos utilizados como variables predictivas, concordaría con la hipótesis que plantean Nicola et al. (2009) para poblaciones marginales de trucha común, como es la mediterránea que habita en el perímetro de su distribución global. Como ocurre en este estudio, las densidades de la población son bajas y estarán reguladas mayoritariamente por procesos abióticos denso-independientes frente a las poblaciones centrales de Europa que gozarían de altas densidades y estarán reguladas por procesos bióticos denso-dependientes (Guo et al., 2005). No obstante, a pesar de la fuerte variabilidad temporal de los caudales en los ríos mediterráneos, puede que la realización del muestreo en los meses de verano y durante un periodo de cuatro años hizo que se obtuviera un pequeño tamaño muestral para cada río y para cada mesohábitat, considerándose una deficiencia potencial del estudio. Esto fue una limitación económica que puede contribuir a un incremento en la proporción de la variación inexplicada de los datos, debilitando la explicación de los modelos entre la abundancia de truchas y las variables físicas del hábitat, tanto de los mesohábitats lentos como de los rápidos.

No obstante, en este estudio el volumen siempre fue correlacionado negativamente con la densidad de trucha inmadura, tanto para los mesohábitats lentos como para los rápidos. El volumen es una variable compuesta que recoge la variabilidad de tres 
variables; la longitud, la anchura y la profundidad media. Keeley y Grant (1995) observaron que la selección del hábitat que realizaban los salmones (Salmo salar) se debía al tamaño del pez y a sus requerimientos espaciales de volumen. En este mismo sentido, Elso y Giller (2001) observaron que la utilización de la trucha está fuertemente relacionada con el tamaño de las pozas especialmente en verano y otoño, soportando las pozas largas más densidades que las pequeñas. Por lo tanto, las truchas inmaduras se refugiarían en pequeños volúmenes de agua donde la trucha adulta no llega o le supone un riesgo acercarse. Acorde a ésto, nuestro estudio demuestra que el número de trucha inmadura decrece conforme el volumen del hábitat aumenta.

Sin embargo, se ha observado una diferencia entre el modelo de trucha inmadura de los mesohábitats lentos respecto a los rápidos. En el primero, la densidad tiende a disminuir al aumentar el volumen y a aumentar con el porcentaje de sustrato fino; sin embargo en el segundo la tendencia del volumen se mantiene pero aumenta la densidad con el porcentaje de sustrato grueso. Ya se ha descrito extensamente la relación que existe entre las truchas y los distintos tipos de sustrato, en el capítulo 6 de esta tesis. En principio parece contradictorio que las poblaciones de trucha inmadura elijan sustratos tan dispares dependiendo del mesohábitat en el que se encuentren. En los análisis categóricos mostrados anteriormente en esta tesis (capítulo 6), se detectó en general que el porcentaje de sustrato grueso y medio estaba correlacionado negativamente con la densidad de trucha inmadura, lo que contradice el modelo de los rápidos, mientras que coincide con el de los lentos. Por lo general, los estudios indican que la trucha prefiere hábitats con abundante sustrato medio y grueso (Eklöv et al., 1999; Heggenes et al., 1999), de modo que estos resultados podrían estar indicando que el método de muestreo no ha sido capaz de discernir adecuadamente la selección de sustratos (debido al trabajo en escala de mesohábitat, donde cada tipo contiene un sustrato diverso), o también para este caso particular, puede que estas relaciones sólo estén mostrando la mayor disponibilidad natural de estos tipos de sustrato en los distintos hábitats (finos en hábitats lentos, más gruesos en los rápidos), sin una relación significativa general entre los alevines y el sustrato. Por otra parte, esta aparente contradicción podría indicar que el sustrato sea una variable secundaria en la abundancia de la trucha, salvo su correlación con otras variables como el calado y la velocidad del flujo, de modo que son otras variables físicas las que son la clave de los modelos. En otras especies de peces, de la familia de los ciprínidos, esto se ha detectado para el sustrato en ciertos análisis estadísticos, aunque las variables físicas fueron medidas a 
escala de microhábitats (Prenda, 1993; Grossman y De Sostoa, 1994a y b; Martínez Capel, 2000).

Por otro lado, existe una correlación negativa significativa entre la profundidad máxima y la densidad de trucha adulta en los mesohábitats lentos. Heggenes et al. (1999) aseguraron que la profundidad es la variable más importante del hábitat en pequeños ríos para la trucha común, especialmente durante periodos bajos de caudal. Concretamente, Jutila et al. (1999) estudiaron la densidad y biomasa de trucha alevín (edad $\leq 1$ año), obteniendo una correlación negativa con la profundidad; en su caso, plantearon la hipótesis de que se debía al hecho de que la mitad de los arroyos estudiados habían sido dragados. Nosotros pensamos que se debe a que en las regiones semiáridas la disponibilidad de aguas profundas está muy limitada, particularmente en ríos pequeños, por lo que una buena proporción de la población se ve desplazada por competencia con los peces de mayor tamaño y por la presencia de peces predadores, a otras zonas más someras de menor idoneidad para los peces. Es decir que, debido al fuerte estiaje en verano de los ríos mediterráneos, con caudal mínimo, las grandes truchas compiten por las zonas más profundas, relegando a las truchas más jóvenes a zonas más someras. En este sentido, MakiPetays et al. (1997) observaron que la relación entre grandes peces y profundidad del hábitat en general se cumple en ciertos ríos salmonícolas, pero que también hay movimientos hacia microhábitats pocos profundos en verano e invierno, dependiendo de la disponibilidad del recurso. Por lo tanto, estas teorías quedan reforzadas con los modelos obtenidos en los ríos mediterráneos, ya que son las truchas de mayor tamaño ( $y$ asociadas a una menor densidad) las que ocupan los mesohábitats más profundos.

También la distancia relativa entre rápidos también es la otra variable que influye sobre la densidad de trucha adulta en mesohábitats lentos mediante una relación negativa. Esta distancia está relacionada indirectamente con la cantidad de alimento para los peces. Se sabe que la diversidad de macroinvertebrados es mayor en los rápidos que en los lentos y por lo tanto mayor su densidad y biomasa (Brown y Brussock, 1991). Bridcut y Giller (1993) relacionaron la capacidad que tienen los mesohábitats rápidos para aportar a los lentos macroinvertebrados acuáticos (en forma de deriva) con los movimientos migratorios de la trucha de las pozas a los rápidos en verano. En este sentido, Jowett (1995) encontró una relación positiva entre abundancias de trucha y biomasa de invertebrados bentónicos en ríos de Nueva Zelanda, y García de Jalón et al. (1996) encontraron una correlación significativa entre la producción total de trucha y biomasa de macroinvertebrados en ríos del pirineo 
español. Baran et al. (1997) relacionaban positivamente el porcentaje de rápidos en el tramo de estudio con la densidad de trucha adulta en mesohábitats profundos.

Por último, hay una tendencia de que las densidades de trucha adulta se relacionan negativamente con la longitud y anchura de sus mesohábitats rápidos y positivamente con el índice de refugio. Las relaciones de estas tres variables con las densidades ya han sido descritas ampliamente en el capítulo 6 de esta tesis. Sin embargo, es destacable el uso del refugio por las truchas adultas en mesohábitats rápidos. Esto apoya la hipótesis de que el refugio ayuda a la trucha adulta en la explotación de los recursos alimenticios, en los hábitats donde el balance energético es desfavorable (Rincón y Lobón-Cerviá, 1993; Maki-Petays et al., 1997).

Respecto al estudio en su conjunto, podemos decir que es uno de los primeros de Europa ubicados sobre ríos de cabecera mediterráneos y con trucha común como especie dominante. Además, la escala de estudio a nivel de los mesohábitats se considera relevante para establecer las relaciones entre los peces y las características físicas del hábitat (Bisson et al., 2006). Los GAM indicaron que tanto las densidades de truchas inmaduras como adultas estuvieron significativamente relacionadas con muchos de los factores ambientales en los dos casos estudiados, los mesohábitats lentos y los rápidos, recogiéndose una alta variabilidad de los datos en los modelos de densidad de trucha inmadura en hábitats lentos y densidad adulta en hábitats rápidos. Sin embargo, la baja explicación en los otros, pueden indicar que el método aplicado en la estratificación del hábitat (su escala) no es el más adecuado para ciertas variables, o también que la diversidad de datos entre ríos es muy elevada para realizar estos modelos. Los modelos significativos han aportado finalmente una información que puede ser útil para la gestión y conservación de la trucha común, y en el diseño de medidas de conservación y restauración de estos ríos por los gestores medioambientales.

\section{BIBLIOGRAFÍA}

Ahmadi-Nedushan, B., A. St-Hilaire, M. Bérubé. E. Robichaud, N. Thiémonge y B. Bobée. 2006. A review of statistical methods for the evaluation of aquatic habitat suitability for instream flowassessment. River Research and Applications 22; 503-523.

Alcaraz-Hernández, J.D., F. Martínez-Capel, M. Peredo y A.B. Hernández-Mascarell. 2007. Relaciones entre densidades y biomasas de Salmo trutta fario y mediciones del mesohábitats en tramos trucheros de la Comunidad Valenciana. Limnetica 26: 159-167. 
Almodóvar, A. y G.G. Nicola. 2004. Angling impact on conservation of Spanish streamdwelling brown trout Salmo trutta. Fisheries Management and Ecology 11: 173-182.

Armstrong J.D., P.S. Kemp, G.J.A. Kennedy, M. Ladle y N.J. Milner. 2003. Habitat requirements of Atlantic salmon and brown trout in rivers and streams. Fisheries Research 62: 143-170.

Armstrong, J.D., J.W.A. Grant, H.L. Forsgren, K.D. Fausch, R.M. DeGraaf, I.A. Fleming, T.D. Prowse y I.J. Schlosser. 1999. The application of science to the management of Atlantic salmon: integration across scales. Canadian Journal of Fisheries and Aquatic Sciences 55: 303-311.

Baeza Sanz, D., D. García de Jalón, B. Gutiérrez Teira y P. Vizcaíno. 2005. Basin influence on natural variability of rivers in semi-arid environments. The International Journal of River Basin Management 3: 247-259.

Baran, P., M. Delacoste y J.M. Lascaux. 1997. Variability of mesohabitat used by brown trout populations in the French central Pyrenees. Transactions of the American Fisheries Society 126: 747-757.

Barnard, S. y R.J. Wyatt. 1995. An analysis of predictive models for stream salmonid populations. Bulletin Français de la Pêche et de la Pisciculture 337/338/339: 365-373.

Bisson, P.A., J.M. Buffington y D.R. Montgomery. 2006. Valley segment, stream reaches, and channel units. Pages 23-49 in F.R. Hauer y G. A. Lamberti, editors. Methods in stream ecology. Academic Press, San Diego, California, USA.

Bridcut, E.E. y P.S. Giller. 1993. Diet variability in relation to season and habitat utilisation in brown trout, Salmo trutta L. in a southern Irish stream. Canadian Special Publications of Fisheries and Aquatic Sciences 118: 17-24.

Brown, A.V. y P.P. Brussock. 1991. Comparisons of benthic invertebrates between riffles and pools. Hydrobiologia 220: 99-108.

Carle, F.L. y M.R. Strub. 1978. A new method for estimating population size from removal data. Biometrics 34: 621-380.

Carling, P.A. 1992. In-stream hydraulics and sediment transport. The Rivers Handbook 1: Hydrology and Ecological Principles (eds P.Calow y G.E. Petts). Blackwell Scientific Publications, Oxford. 101-125.

Dolloff, C.A., Hankin, D.G. y Reeves, G.H. 1993. Basinwide estimation of habitat and fish populations in streams. U.S. Department of Agriculture. Forest Service. Southeastern Forest Experiment Station, 25 pp. 
Eklöv, A.G., L.A. Greenberg, C. Brönmark, P. Larsson y O. Berglund. 1999. Influence of water quality, habitat and species richness on brown trout population. Journal of Fish Biology 54: 33-43.

Elso, J.I. y P.S. Giller. 2001. Physical characteristics influencing the utilization of pools by brown trout in an afforested catchment in Southern Ireland. Journal of Fish Biology 58: 201-221.

Erös, T. y G.D. Grossman. 2005. Effects of within-patch habitat structure and variation on fish assemblage characteristics in the Bernecei stream, Hungary. Ecology of Freshwater Fish 14: 256-266.

Fausch, K.D., C.L. Hawkes y M.G. Parsons. 1988. Models that predict standing crop of stream fish from habitat variables: 1950-85. Gen. Tech Rep. PNW-GTR-213. Portland, OR: U.S. Department of Agriculture, Forest Service, Pacific Northwest Research Station. 52 pp.

García de Jalón, D. y G. Schmidt. 1995. Manual práctico para la gestión sostenible de la pesca fluvial. Asociación para el estudio y mejora de los salmónidos. Madrid, 169 pp.

García de Jalón, D., M. Mayo y M.C. Molles. 1996. Characterization of Spanish pyrenean stream habitat: relationships between fish communities and their habitat. Regulated Rivers: Research and Management 12: 305-316.

Gasith, A. y V.H. Resh. 1999. Streams in Mediterranean climate regions: abiotic influences and biotic responses to predictable seasonal events. Annual Review of Ecology and Systematics 30: 51-81.

Grossman, G.D. y A. De Sostoa. 1994a. Microhabitat use by fishes in the lower rio Matarraña, Spain: 1984-1987. Ecology of Freshwater Fish 3: 123-136.

Grossman, G.D. y A. De Sostoa. 1994b. Microhabitat use by fishes in the upper rio Matarraña, Spain: 1984-1987. Ecology of Freshwater Fish 3: 141-152.

Guisan, A., T.C. Edwards y T. Hastie. 2002. Generalized linear and generalized additive models in studies of species distributions: setting the scene. Ecological Modelling 157: 89100.

Guo, Q., M. Taper, M. Schoenberger y J. Brandle. 2005. Spatial-temporal population dynamics across species range: from centre to margin. Oikos 108: 47-57.

Hankin, D.G. y G.H. Reeves. 1988. Estimating total fish abundance and total habitat area in small streams based on visual estimation methods. Canadian Journal of Fisheries and Aquatic Sciences 45: 834-844. 
Heggenes, J., J.L. Baglinière y R.A. Cunjak. 1999. Spatial niche variability for young Atlantic salmon (Salmo salar) and brown trout (S. trutta) in heterogeneous streams. Ecology of Freshwater Fish 8: 1-21.

Hildrew, A.G. y P.S. Giller. 1994. Patchiness, species interactions and disturbance in the stream benthos. Aquatic Ecology: Scale, Pattern and Process (eds P.S. Giller, A.G. Hildrew and D.G. Raffaelli). Blackwell Scientific Publications, Oxford. 21-62.

Hulot, F.D., G. Lacroix y L.M. Lercher-Moutoue.2000. Functional diversity governs ecosystem response to nutrient enrichment. Nature 405: 340-344.

Inoue, M. y S. Nakano. 1999. Habitat structure along channel-unit sequences for juvenile salmon: a subunit-based analysis of in-stream landscapes. Freshwater Biology 42: 597608.

Jowett, I.G. 1995. Spatial and temporal variability of brown trout abundance: a test of regression models. Rivers 5: 1-12.

Jowett, I.G. y A.J.H. Davey. 2007. A comparison of composite habitat suitability indices and Generalized Additive Models of invertebrate abundance and fish presence-habitat availability. Transactions of the American Fisheries Society 136: 428-444.

Jutila, E., A. Ahvonen y M. Laamanen. 1999. Influence of environmental factors on the density and biomass of stocked brown trout, Salmo trutta L., parr in brooks affected by intensive forestry. Fisheries Management and Ecology 6: 195-205.

Keeley, E.R. y J.W.A. Grant. 1995. Allometric and environmental correlates of territory size in juvenile Atlantic salmon (Salmo salar). Canadian Journal of Fisheries and Aquatic Sciences 52: 186-196.

Knapp, R.A. y H.K. Preisler. 1999. It is possible to predict habitat use by spawning salmonids? A test using California golden trout (Oncorhynchus mykiss aguabonita). Canadian Journal of Fish and Aquatic Sciences 56: 1576-1584.

Lehman, A. 1998. GIS modelling of submerged macrophyte distribution using Generalized Additive Models. Plant Ecology 139: 113-124.

Leopold, L.B., Wolman, M.G. y Miller, J.P. 1964. Fluvial Processes in Geomorphology. Freeman Co. San Francisco. 522 pp.

Lobón-Cerviá, J. 2007. Numerical changes in stream-resident brown trout (Salmo trutta): uncovering the roles of density-dependent and density-independent factors across space and time. Canadian Journal of Fisheries and Aquatic Sciences 64: 1429-1447. 
Maki-Petays, A., T. Muotka, A. Huusko, P. Tikkanen y P. Kreivi. 1997. Seasonal changes in habitat use and preference by juvenile brown trout, Salmo trutta, in a northern boreal river. Canadian Journal of Fisheries and Aquatic Sciences 54: 520-530.

Marmion, M., M. Luoto, R.K. Heikkinen y W. Thuiller. 2009. The performance of state-of-theart modelling techniques depends on geographical distribution of species. Ecological Modelling 220: 3512-3520.

Martínez-Capel, F. 2000. Preferencias de microhábitat de Barbus bocagei, Chondrostoma polylepis y Leuciscus pyrenaicus en la cuenca del río Tajo. PhD Thesis. Madrid: Universidad Politécnica de Madrid. 337 pp.

Meador, M.R., T.F. Cuffney y M.E. Gurtz. 1993. Methods for sampling fish communities as part of the National Water-Quality Assessment Program. U.S. Geological Survey Open-File Report 93-104.Raleigh, USA. 40 pp.

Milner, A.M., J.E. Brittain, E. Castella y G.E. Petts. 2001. Trends of macroinvertebrate community structure in glacier-fed rivers in relation to environmental conditions: a synthesis. Freshwater Biology 46: 1833-1847.

Nicola, G.G., A. Almodóvar y B. Elvira. 2009. Influence of hydrologic attributes on brown trout recruitment in low-latitude range margins. Oecologia 160: 515-524.

Prenda, J. 1993. Uso del hábitat en algunas poblaciones de animales acuáticos de un río del sur de España. Influencia de las interacciones bióticas. Tesis Doctoral. Universidad de Sevilla.

Prenda, J., P.D. Armitage y A. Grayston. 1997. Habitat use by the fish assemblages of two chalk streams. Journal of Fish Biology 51: 64-79.

R Development Core Team (2008). R: A language and environment for statistical computing. $R$ Foundation for Statistical Computing, Vienna, Austria. ISBN 3-900051-07-0, URL http://www.R-project.org.

Rincón, P.A. y J. Lobón-Cerviá. 1993. Microhabitat use by stream-resident brown trout: bioenergetic consequences. Transactions of American Fisheries Society 122: 575-587.

Wood, S.N. 2001. Mgcv: GAMs and Generalized Ridge Regression for R. R news 1-2: 20-25.

Wood, S.N. 2006. Generalized Additive Models: An Introduction with R. Chapman and Hall/CRC press: Boca Raton, FL. 392 pp.

Word, S.N. y N.H. Augustin. 2002. GAMs with integrated model selection using penalized regression splines and applications to environmental modelling. Ecological Modelling 157: 157-177. 


\section{CAPÍTULO 8}

\section{IDONEIDAD DEL HÁBITAT DE LA TRUCHA COMÚN MEDIANTE ANÁLISIS DE LÓGICA DIFUSA EN RIOS MEDITERRÁNEOS ESPAÑOLES ${ }^{1}$}

\section{Resumen}

En los últimos años, se ha reconocido que los modelos difusos se aproximan adecuadamente a los modelos de distribución de especies, debido a su transparencia y a su capacidad para incorporar la teoría del gradiente ecológico. En concreto, por la similitud que hay entre la superposición de los límites en las clases de un modelo difuso con las transiciones de las diferentes condiciones ambientales. Sin embargo, una limitación importante para desarrollar estos modelos es la necesidad de expertos con el conocimiento ecológico adecuado. Por otra parte, ha sido muy controvertida la consistencia de las preferencias ecológicas de algunas especies de peces entre diferentes ríos. Recientes investigaciones han demostrado que los modelos de lógica difusa puede solucionar este "cuello de botella" gracias a la adquisición de estos conocimientos, siendo este estudio una contribución adicional. El objetivo fue realizar un modelo de la idoneidad del hábitat de la trucha común (Salmo trutta) basándose en el análisis de datos con los modelos de lógica difusa y compararlos con una técnica de modelado comúnmente aplicada, Random Forests. Se aplicó un algoritmo heurístico de "Nearest Ascent Hill-Climbing" en la optimización de las reglas difusas y de Random Forests, analizando las preferencias ecológicas de la trucha común en 93 mesohábitats. No se observaron diferencias significativas en la representación de los modelos entre el modelo óptimo difuso y el modelo Random Forests, y ambas aproximaciones seleccionaron la anchura del río, el índice de refugio y la velocidad de flujo como las variables más importantes para describir la idoneidad del hábitat de la

\footnotetext{
${ }^{1}$ A.M. Mouton, J.D. Alcaraz-Hernández, B. De Baets, P.L.M. Goethals, F. Martínez-Capel. 2011. Data-driven fuzzy habitat suitability models for brown trout in Spanish Mediterranean rivers. Artículo publicado en la revista Environmental Modelling \& Software 26: 615-622.
} 
trucha común. Además, los modelos difusos combinan la relevancia ecológica con una aceptable interpretabilidad, mientras que fue limitada la trasparencia de los modelos Random Forests. Este capítulo muestra que los modelos difusos pueden ser una aproximación válida para modelar la distribución de especies y que su representación es comparable al estado del arte de las técnicas de modelado como Random Forests. Los modelos difusos podrían ser por lo tanto una herramienta de soporte en la evaluación de decisiones en la gestión de los ríos y aumentar la comunicación las partes interesadas.

Palabras clave: Modelos difusos, peces, trucha común, ríos mediterráneos, idoneidad del hábitat, aprendizaje automático, conocimiento ecológico, Random Forests.

\section{INTRODUCCIÓN}

Durante las últimas décadas, la distribución de la trucha común (Salmo trutta) en la región valenciana (al S.E. de España) ha disminuido sustancialmente debido, entre otras cosas, a la alteración de sus ríos por actividades humanas (Alcaraz-Hernández et al., 2007). Algunas de las perturbaciones observadas son la regulación del caudal del cauce, la pérdida de hábitat, la contaminación de los ríos, la excesiva pesca, la introducción tanto de especies exóticas como de genes exóticos de truchas, como consecuencia de reintroducciones artificiales (Almodóvar et al., 2006; SánchezMontoya et al., 2009). Así pues, son necesarias diferentes medidas de restauración en los ríos para alcanzar los objetivos fijados por la Directiva Marco del Agua. Sin embargo, la asignación eficiente de estos esfuerzos a pequeña escala requiere un análisis exhaustivo de su posible impacto en la ecología del río. Dado que los modelos de distribución de especies permiten este análisis y, en particular, la identificación de los "cuellos de botella" en una cuenca hidrográfica, estos modelos pueden ser una herramienta valiosa para la gestión integrada de los ríos (Mouton et al., 2007).

Debido a su transparencia y facilidad de uso, los modelos difusos (en inglés, modelos fuzzy) se han aplicado ampliamente en el modelado de distribución de especies. Estos modelos toman en cuenta la incertidumbre inherente de las variables ecológicas y permiten expresar de una manera transparente, las relaciones no lineales entre las variables ecológicas. Los modelos difusos utilizan descripciones lingüísticas tales como "bajo", "moderado" o "alto" para la cuantificación de las variables y utilizan los conocimientos de expertos en ecología para transformar estas descripciones a un marco matemático donde realizar el análisis de los datos (Kampichler et al., 2000). En 
concreto, el conocimiento del experto se incluye en la regla difusa del "si-entonces", es decir, "SI la velocidad del flujo es alta y la profundidad es baja, ENTONCES la idoneidad del hábitat es alta para los peces reófilos". Los modelos difusos usan conjuntos difusos para aplicar la definición en la incertidumbre de los valores lingüísticos "alta", "baja" y "alta" a las variables lingüísticas "velocidad", "profundidad" e "idoneidad del hábitat". Debido a que los límites de dos conjuntos difusos se solapan, un objeto (p.e. un valor real) podría pertenecer parcialmente a dos conjuntos consecutivos y por lo tanto, una descripción lingüística imprecisa puede ser incorporada a los modelos como "la profundidad es bastante baja, pero tiende a ser moderada". Esta enfoque contrasta marcadamente con la teoría clásica de conjuntos, donde un objeto en su totalidad pertenece a un sólo conjunto.

Durante el proceso de modelado, los modelos difusos de distribución de especies permiten la incorporación de aspectos ecológicos, tales como la teoría del gradiente ecológico. Esto convierte al modelado difuso en una técnica adecuada para el estudio de la distribución de especies ya que este enfoque puede reflejar problemas ecológicos y sus características específicas (Adriaenssens et al., 2004; Mouton et al., 2007). Sin embargo, el principal "cuello de botella" en la aplicación de la lógica difusa es la necesidad de un experto en el conocimiento ecológico. No sólo es porque el experto tenga que identificar los problemas más importantes, a menudo de forma difícil y tediosa, sino porque hay autores que dudan de su consistencia. No obstante, en recientes investigaciones se ha demostrado que se puede resolver el "cuello de botella" del conocimiento de los expertos al complementarse los sistemas difusos con técnicas de análisis de datos (Znidarsic et al., 2006). Por ejemplo, la inducción de reglas bases a los modelos difusos mediante la búsqueda de algoritmos heurísticos es a menudo usada en el ámbito del aprendizaje de éstas reglas (Hüllermeier, 2005; Mouton et al., 2008). Por lo tanto, ambas técnicas, el análisis de datos y el conocimiento de los expertos, deberían de ser usadas para desarrollar modelos más fiables de distribución de especies. En concreto, si hay datos disponibles, la técnica de análisis de datos podrían aplicarse para proporcionar un modelo preliminar para el experto, quien finalmente podría ajustar o aceptar el modelo (Mouton et al., 2008).

Este trabajo tiene como objetivo el subrayar la importancia de ambos enfoques para el desarrollo de los modelos de distribución de especies. La primera hipótesis testada fue que las reglas difusas de optimización podrían desarrollar un modelo de distribución de especies fiable y ecológicamente relevante para la trucha común en la región Mediterránea. Se comparó la realización y selección de variables con el análisis de los datos mediante la optimización de reglas difusas y de reglas Random Forests, ambas técnicas aplicadas ampliamente en la clasificación de los datos. Basándonos en 
investigaciones previas, se evaluó la relevancia ecológica de los modelos desarrollados y se discutió su aplicabilidad. Los resultados en este trabajo enfatizan en la fuerte cooperación entre el experto ecológico y el proceso de análisis de datos ya que puede contribuir al desarrollo fiable y bien fundado de modelos de distribución de especies.

\section{MÉTODOS}

\section{Adquisición de datos en campo}

Hay sólo cuatro ríos en la Comunidad Valenciana (al S.E. de España) donde las poblaciones de trucha común son importantes para los pescadores, los ríos Ebrón, Vallanca, Palancia y Villahermosa. Durante los años 2003 al 2006, en el mes de Julio se muestrearon 42 corrientes y 51 pozas y se midieron las características físicas de sus hábitats. Además, durante el día, las truchas inmaduras y de más edad fueron capturadas sin reemplazamiento en estos mesohábitats por medio de pesca eléctrica.

La idoneidad del hábitat fue cuantificada para la densidad de trucha y se basó en las medidas tomadas en los muestreos de los mesohábitats. Las variables del hábitat fueron medidas en tramos de 300 metros centrados alrededor de los mesohábitats donde se realizó la pesca eléctrica. Algunos autores han recomendado tramos con longitudes similares de muestreo (Leopold et al., 1964; Meador et al., 1993). Cada mesohábitat fue caracterizado siguiendo los criterios de la técnica "Basinwide Visual Estimation Technique - BVET" para ríos de salmónidos (Hankin y Reeves, 1988; Dolloff et al., 1993). La anchura $(\mathrm{m})$ fue medida en cada mesohábitat como media de tres puntos diferentes que corresponden a $1 / 4,1 / 2, y 3 / 4$ de la longitud total, la profundidad media $(\mathrm{m})$ tomada como promedio de nueve puntos correspondientes a la medida tomada en $1 / 4,1 / 2, y 3 / 4$ en cada transecto donde se midió la anchura y la velocidad fue clasificada como baja o alta en pozas o corrientes, respectivamente. El porcentaje de sustrato fue estimado visualmente según su tamaño de partícula mediante la modificación de la escala dada en la American Geophysical Union. El porcentaje de sustrato fue convertido a un simple índice (S) mediante el ponderado de porcentajes de cada tipo de sustrato (Jowett et al., 1991). Para permitir que se considere la categoría de gravilla (2-8 $\mathrm{mm}$ ), fueron ligeramente modificados de la forma original los valores de los pesos usados en el código de sustrato, propuestos en la metodología IFIM (Instream Flow Incremental Methodology, Bovee, 1982): S $=0.08 x$ 
roca madre $+0.07 \times$ bolos $+0.06 \times$ canto rodado $+0.05 \times$ grava $+0.04 \times$ gravilla +0.03 $x$ arena.

Finalmente, fue estimado el índice de refugio (IR) propuesto por García de Jalón y Schmidt (1995) como:

$$
I R=C e+\frac{C s b+C s t+C v s+C p}{4}
$$

Siendo Ce el refugio debido a cornisas, cuevas y bancos, Csb el debido al sombreado, Cst el debido al tipo de sustrato, Cvs el debido a la vegetación sumergida y Cp el debido a la profundidad de la columna de agua. Este índice valoró independientemente cada tipo de refugio entre una escala de grados de seis puntos que va de 0 (no proporciona refugio) a 5 (disponibilidad máxima) según las recomendaciones que se describen en la tabla 8.1.

Tabla 8.1. Valoración numérica de la capacidad de refugio mediante los coeficientes de orilla (Ce), de sombra (Csb), de sustrato (Cst), de vegetación sumergida (Cvs) y de profundidad (Cp).

\begin{tabular}{ccccccc}
\hline VALORES & $\mathbf{0}$ & $\mathbf{1}$ & $\mathbf{2}$ & $\mathbf{3}$ & $\mathbf{4}$ & $\mathbf{5}$ \\
\hline Ce & Ausencia & $\begin{array}{c}\text { Cornisa } \\
\text { aérea }\end{array}$ & $\begin{array}{c}\text { Cornisa } \\
\text { sumergida }\end{array}$ & $\begin{array}{c}\text { Cornisa } \\
\text { sumergida } \\
\text { profunda }\end{array}$ & $\begin{array}{c}\text { Raíces } \\
\text { riparias }\end{array}$ & $\begin{array}{c}\text { Cornisa } \\
\text { profunda } \\
\text { y raíces }\end{array}$ \\
Csb & $0 \%$ & $<10 \%$ & $10-25 \%$ & $25-50 \%$ & $50-75 \%$ & $>75 \%$ \\
Cst & $\begin{array}{c}\text { Roca } \\
\text { madre }\end{array}$ & $\begin{array}{c}\text { Limos y } \\
\text { arenas }\end{array}$ & $\begin{array}{c}\text { Gravas y } \\
\text { gravillas }\end{array}$ & $\begin{array}{c}\text { Cantos } \\
\text { rodados }\end{array}$ & Bloques & $\begin{array}{c}\text { Roca } \\
\text { madre } \\
\text { Cvs }\end{array}$ \\
Ninguna & $<1 \%$ & $1-5 \%$ & $5-15 \%$ & $15-30 \%$ & $>30 \%$ \\
$\begin{array}{c}\text { Cp } \\
\text { Agua clara/ } \\
\text { Turbia }\end{array}$ & $<15 \mathrm{~cm}$ & $15-50 \mathrm{~cm}$ & $50-80 \mathrm{~cm}$ & $\begin{array}{c}80-100 / \\
15-50 \mathrm{~cm}\end{array}$ & $\begin{array}{c}100-150 / \\
50-80 \mathrm{~cm}\end{array}$ & $>150 /$ \\
\hline
\end{tabular}

\section{Parámetros de optimización del conjunto difuso}

Se asignaron valores lingüísticos como "bajo", "moderado" y "alto" a la variable de salida (la calidad del hábitat) como a las cinco variables de entrada (profundidad, velocidad de flujo, anchura, sustrato e índice de refugio). Estos valores fueron definidos según los conjuntos difusos (Zadeh, 1965) y no según los conjuntos 
convencionales con límites "nítidos" (en adelante se llamarán conjuntos nítidos). Usamos estos conjuntos nítidos cuando decimos, por ejemplo, que las profundidades por debajo de $1.5 \mathrm{~m}$ se consideraran "bajas", profundidades entre 1.5 y $3 \mathrm{~m}$ "moderadas" y profundidades mayores de $3 \mathrm{~m}$ "altas". Por lo tanto, una determinada profundidad podría pertenecer o no a ese conjunto (con un grado de pertenencia de 1). Una función de pertenencia a un conjunto difuso particular, sin embargo, indica el grado en que un elemento pertenece a éste, con un rango de pertenencia que va de cero a uno. Por lo tanto, se solapan los límites de las funciones de pertenencia de los conjuntos difusos y la declaración lingüística "la profundidad es bastante moderada, pero tiende a ser alta" se puede traducir a una profundidad la cual tiene un grado de pertenencia de 0.4 al conjunto difuso "moderado" y de 0.6 al conjunto difuso "alto". En este estudio, todas las funciones de pertenencia tienen formas trapezoidales $y$ están definidas por cuatro parámetros $\left(a_{m}, b_{m}, c_{m}\right.$ y $\left.d_{m}\right)$ : el grado de pertenencia se incrementa linealmente entre $a_{m}$ y $b_{m}$ de 0 a 1 , es igual a 1 entre el $b_{m}$ y $c_{m}$ y disminuye linealmente entre $c_{m}$ y $d_{m}$ de 1 a 0 . Se obtiene una función de pertenencia triangular cuando $b_{m}$ se iguala a $c_{m}$ (Tabla 8.2).

Tabla 8.2. Variables de entrada del modelo de idoneidad del hábitat medida para cada tramo de río muestreado, con los valores lingüísticos asignados a cada variable y la descripción de los parámetros del conjunto difuso. Cada conjunto difuso está definido por cuatro parámetros $\left(a_{m}, b_{m}, c_{m}\right.$ y $\left.d_{m}\right)$ : el grado de pertenencia se incrementa linealmente entre $a_{m} y$ $b_{m}$ de 0 a 1 , es igual a 1 entre el $b_{m}$ y $c_{m}$ y disminuye linealmente entre $c_{m}$ y $d_{m}$ de 1 a 0 . Se obtiene una función de pertenencia triangular cuando $b_{m}$ se iguala a $c_{m}$.

\begin{tabular}{cccc}
\hline Variables & Unidades & Valor lingüístico & Parámetros del conjunto Fuzzy \\
\hline $\begin{array}{c}\text { Índice de } \\
\text { refugio }\end{array}$ & - & Bajo & $(0,0,2,3)$ \\
& & Moderado & $(2,3,4,6)$ \\
Profundidad & Alto & $(4,6,8,8)$ \\
& & Bajo & $(0.0,0.0,0.3,0.6)$ \\
Índice de & & Alto & $(0.3,0.6,0.8,0.8)$ \\
sustrato & - & Bajo & $(0.0,0.0,3.5,4.5)$ \\
Velocidad & & Moderado & $(3.5,4.5,6.0,7.0)$ \\
del flujo & - & Alto & $(6.0,7.0,8.0,8.0)$ \\
Anchura & \multirow{2}{*}{} & Bajo & $(0.0,0.0,0.4,0.6)$ \\
Idoneidad & - & Alto & $(0.4,0.6,1.0,1.0)$ \\
del hábitat & - & Bajo & $(0,0,4,6)$ \\
\end{tabular}


Los parámetros de las funciones de pertenencia que corresponden a las variables de entrada de los conjuntos difusos han sido a menudo descritas por los expertos en la materia (Mouton et al., 2007). Sin embargo, pueden estar mal calibradas las reglas que se aplican a este conjunto si un conjunto difuso de una variable de entrada contiene unos pocos casos de aprendizaje. Por lo tanto, antes de optimizar la regla base, se optimizan los conjuntos difusos creándose una distribución uniforme de las variables sobre éstos. La entropía de Shannon-Weaver (Shannon y Weaver, 1963) realiza esta uniformidad por lo que se aplica en la optimización de los parámetros, como se ha descrito en estudios anteriores (Mouton et al., 2009b; Mouton et al., 2009c). Los conjuntos difusos se convierten en nítidos cuando los límites de los puntos del correspondiente conjunto difuso tienen un grado de pertenencia de 0.5. Si no se obtuvo con el algoritmo un valor umbral mínimo de entropía de 0.85 para una determinada variable, la creación de los conjunto difuso fue mediante la clasificación de los datos de la variable y la localización de los límites superpuestos de los conjuntos difusos en regiones donde la pendiente de los datos clasificados cambiaban significativamente (Mouton et al., 2009b; Mouton et al., 2009c).

\section{Modelación y optimización de la regla difusa}

La regla base difusa relaciona las variables de entrada con la idoneidad del hábitat de la trucha común y consiste en una regla del tipo "si-entonces", como por ejemplo, "SI la profundidad ES moderada $Y$ la velocidad de flujo ES alta $Y$ el refugio ES alto, ENTONCES el hábitat ES idóneo". La parte del SI de la regla, el antecedente, describe en qué situación se aplica esta regla, mientras que la parte del ENTONCES, el consecuente, indica si el hábitat en esta situación es idóneo o no para la trucha común. Teniendo en cuenta los valores nítidos de las cuatro variables de entrada, la salida del modelo difuso se calculó según lo descrito por Van Broekhoven et al. (2006). Para cada caso, se calcularon los grados de pertenencia de los conjuntos difusos (tabla 8.2) de cada variable de entrada. El grado de cumplimiento de cada regla fue entonces calculado como el mínimo de los grados de pertenencia del antecedente. Por último, a cada valor lingüístico de salida se igualó al grado de cumplimiento máximo de todas las reglas con el valor de salida del consecuente considerado más bajo. El planteamiento fue similar al procedimiento de MamdaniAssilian (Assilian, 1974; Mamdani, 1974) en el que la salida difusa se trasforma en una nítida basadas en los conjuntos difusos de las variables de salida. Sin embargo, en este trabajo se aplicó un tipo diferente de modelo: un clasificador difuso (Van Broekhoven et al., 2006; Van Broekhoven et al., 2007). Se asignó el grado de 
cumplimiento más alto tanto a los valores de la variable de salida observados como a los modelados, lo que permitió la comparación entre la salida modelada con la salida observada y el cálculo de las medidas de pertenencia. En concreto, si un valor de idoneidad del hábitat tuvo una pertenencia de 0.6 al conjunto difuso "bajo" y de 0.4 al conjunto "moderado", entonces el valor asignado fue al conjunto "bajo".

Para generar un modelo fiable de idoneidad de hábitat, los consecuentes de las reglas difusas se optimizaron utilizando un algoritmo denominado "Nearest Ascent HillClimbing" (Michalewicz y Fogel, 2000). Comenzando con la fijación de los conjuntos difusos (tabla 8.2) y seleccionando aleatoriamente una regla base, se convirtió el consecuente de esa regla en el valor lingüístico de uno de sus conjuntos difusos vecinos (p.e. el reemplazamiento de "medio" por "bajo" o "alto") y se calculó el impacto del modelo representado. Si se incrementaba la representación del modelo, el algoritmo continuaba de nuevo ajustando la regla base, si no, continuaba con la original. Para observar la robustez de los resultados optimizados, los datos originales se doblaron tres veces de forma aleatoria y sin reemplazo.

Los modelos se entrenaron basándose en el coeficiente Kappa de Cohen (Cohen, 1960), con un rango que va de -1 a 1 , el cual se deriva de la matriz de confusión de la tabla cruzada de las observaciones y de la predicciones del modelo (Fielding y Bell, 1997). Esta medida fue seleccionada como criterio de entrenamiento de la representación porque con el entrenamiento basado en Kappa se obtuvo un buen resultado en un anterior estudio (Mouton et al., 2008). Cada iteración del entrenamiento se paró cuando se observó que no hubo un nuevo incremento en los índices del test de doblado de la representación. Cada iteración del entrenamiento fue repetido y cada nueva regla base obtenida fue comparada con la regla base obtenida en la interacción anterior. La similaridad entre dos reglas bases obtenidas indicó el porcentaje de los consecuentes que fueron diferentes. El entrenamiento continuó con otro nuevo doblamiento cuando se obtuvo cinco veces una regla base con la más alta representatividad en la prueba de doblamiento de los datos. El algoritmo de entrenamiento está descrito en detalle en Mouton et al. (2008). Sin embargo, no todas las variables de entrada estaban presentes en el área de estudio. Para saber que reglas fueron más relevantes, los conjuntos difusos se convirtieron en nítidos asumiendo que un determinado valor de entrada no pertenecía a un conjunto si su grado de pertenencia a ese conjunto era $<0.5$. A cada dato se le pudo asignar una condición ambiental, como consecuencia de la distribución de los datos sobre las condiciones ambientales del conjunto nítido descritas por las reglas (tabla 8.5). La distribución también dio una indicación sobre la utilidad de la regla base obtenida sobre el rango de condiciones ambientales que se encontraron en la región 
Valenciana. Todos los algoritmos difusos fueron programados en C\# por Ann Mouton (libremente disponibles bajo petición).

\section{Modelación con Random Forests}

En este estudio, se comparó la representación y la selección de variables para dos técnicas de análisis de datos, la optimización de la regla difusa y los Random Forests $(R F)$, ambas utilizadas ampliamente y basadas en reglas de aprendizaje (Breiman, 2001; Cutler et al., 2007; Peters et al., 2007). Esta comparación debería demostrar el valor de los modelos difusos en el modelado de la distribución de especies comparado al estado del arte en la técnica de modelación como Random Forests. La técnica de Random Forests genera aleatoriamente $k$ árboles de clasificación. A cada árbol se le añaden otros subconjuntos bootstrap mediante el entrenamiento de los datos del conjunto, y divide la mejor variable predictiva dividiendo cada nodo mediante un subconjunto de $m$ variables elegidas al azar. Tanto $k$ como $m$ son parámetros definidos por el usuario que debe ser optimizados para asegurar la convergencia de los modelos desarrollados (Peters et al., 2007).

Una importante característica de Random Forests es la disponibilidad de algunas mediciones para calcular la importancia de cada variable y para observar las observaciones anómalas. Además, este método puede trabajar con miles de variables de entrada, soportando eficientemente grandes bases de datos. Breiman (2001) muestra que la consistencia de Bayes se alcanza con una simple versión de $R F$ y reivindica que $R F$ raramente se sobreajusta. Diversos artículos muestran que $R F$ a menudo representa otro estado del arte en técnicas de modelado (Cutler et al., 2007; Pino-Mejías et al., 2010). Se implemento el algoritmo de RF en WEKA 3.6.1, testando diferentes combinaciones de parámetros como el número de árboles $(k)$ y el número de variables usadas para dividir los nodos $(m)$.

\section{Selección de variables}

Para reducir la complejidad del modelo, como de cálculo y de esfuerzo de monitoreo (D'heygere et al., 2003), las variables fueron seleccionadas como describe Mouton et al. (2009a). Esta selección se basó en la representación del modelo, cuantificada por un criterio de pertenencia tales como el porcentaje de casos clasificados correctamente (CCI) o Kappa (Fielding y Bell, 1997) y en el criterio de información de 
Akaike AIC (Akaike, 1974). Esta última medida cuantifica el balance entre el modelo representado y su complejidad y se calcula de la siguiente manera:

$$
\mathrm{AIC}=2 K+N \ln \left(\frac{R S S}{N}\right)
$$

Donde $K$ es el número de parámetros del modelo, $N$ el número total de datos y $R S S$ es la media cuadrada residual del modelo. Aunque esta medida asigna un peso arbitrario a las características de ambos modelo, indica la probabilidad de cómo un modelo genera predicciones sobreajustadas. El método de selección de variables fue una combinación de los procedimientos del paso adelante y paso atrás. La selección de variables por el paso adelante parte de un modelo que contiene una variable y luego se amplía éste mediante la adición una a una de otras variables. El método de selección por el paso atrás parte de un modelo que incluye todas las variables y luego las reduce una por una. En ambos casos, la contribución de cada variable es la diferencia entre la representatividad de los modelos con y sin esta variable. Si las variables de entrada no son independientes, la contribución de cada variable al modelo total representado por el paso adelante puede ser diferente que por el paso atrás. En concreto, el procedimiento paso adelante puede considerar diferentes correlaciones entre las variables que las correlaciones del paso atrás. Por lo tanto, el método de selección de variables aplicado fue una combinación de ambos procedimientos. Aunque esto es computacionalmente más costoso, este procedimiento considera todas las posibles correlaciones entre variables y por lo tanto genera resultados más consistentes y fiables.

\section{RESULTADOS}

El procedimiento de selección de variables indicó que la regla base óptima difusa, el modelo $A R V$, incluye tres variables como la anchura del río, el índice de refugio y la velocidad de flujo (figuras 8.1-8.4). La anchura del río fue la variable más importante que explica la idoneidad del hábitat de la trucha común, seguido del índice de refugio y de la velocidad de flujo. Si bien la anchura del río y el índice de refugio contribuyeron sustancialmente al modelo representado, la velocidad de flujo sólo mostró una contribución marginal. La inclusión del índice de sustrato en el modelo $A R V$ dio como resultado valores kappa más altos (modelos ARVS), pero no 
incrementó sustancialmente en los modelos los valores de la exactitud en la predicción $(C C I)$ y de ese modo conllevó al incremento de los valores AIC (tabla 8.3).

Tabla 8.3. Valores AIC de los cuatros modelos óptimos después de la adicción de variables al modelo inicial de una variable y basada en el modelado difuso y Random Forests. Los modelos incluyen las variables de entrada anchura (A), índice de refugio $(R)$, velocidad del flujo (V) e índice de sustrato (S).

\begin{tabular}{ccc}
\hline Modelo & Difuso & Random Forests \\
\hline A & $-82.36 \pm 13.41$ & $-88.04 \pm 14.34$ \\
AR & $-90.64 \pm 31.31$ & $-95.09 \pm 17.05$ \\
ARV & $-86.69 \pm 14.02$ & $-96.21 \pm 16.35$ \\
ARVS & $-39.5 \pm 20.62$ & $-90.32 \pm 15.19$ \\
\hline
\end{tabular}

Sin embargo, la similitud de los modelos representados que incluían la anchura con el índice de refugio o con el índice de sustrato (modelos $A R$ o $A S$ ) demuestra que el índice de sustrato puede utilizarse para dar una información adicional evaluable en las preferencias de la trucha por el hábitat. Además, las diferencias del índice Kappa no reflejaron la exactitud en la predicción entre el modelo $A R V$ y el modelo $A R V S$, pero los errores de omisión o de comisión de las observaciones, con elementos respectivos $(2,1)$ y $(1,2)$ de la matriz de confusión, se equilibraron más en los modelos $A R V$. Por el contrario, los modelos ARVS mostraron más errores por comisión que por omisión, además de observación de modelos significativamente sobrepronosticados (tabla 8.4). 


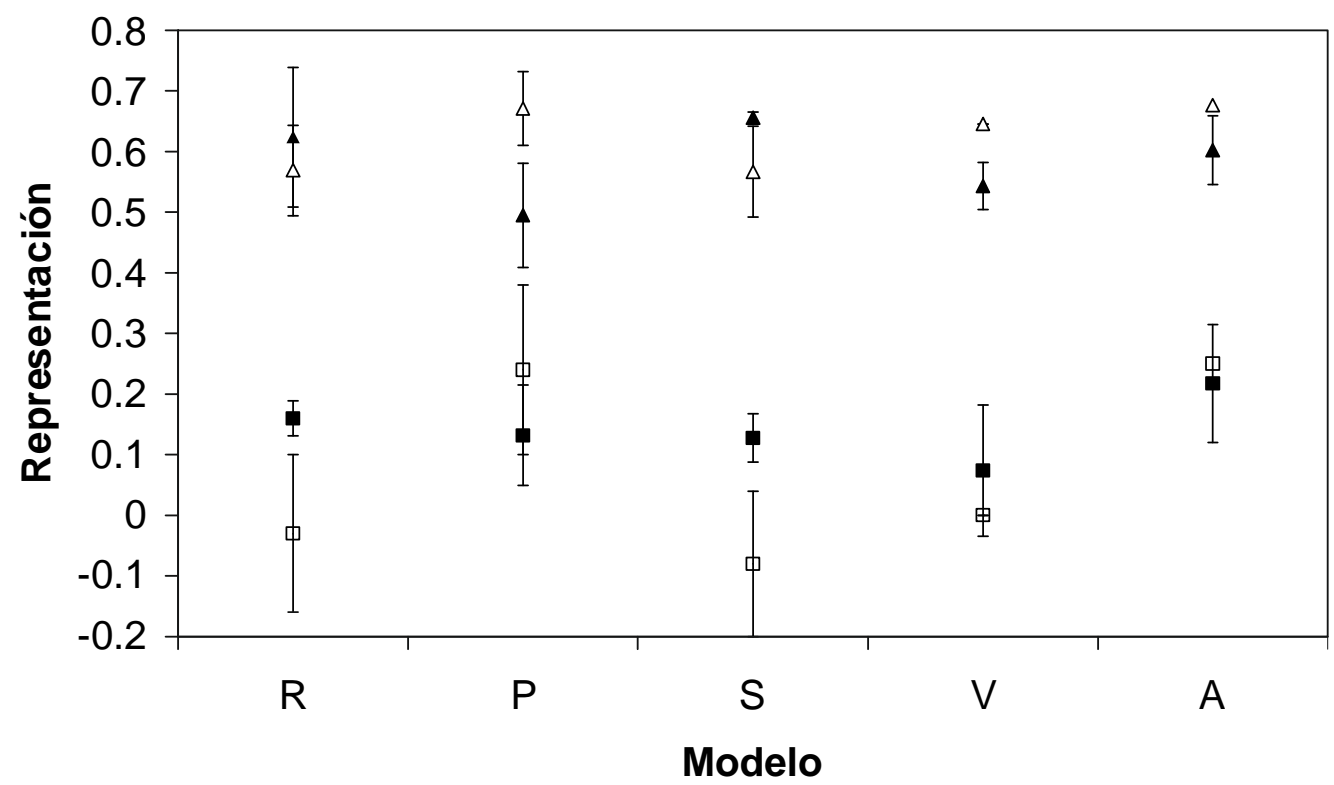

Figura 8.1. Representación de cinco modelos mediante reglas difusas de optimización (FRO, símbolo negro) y cinco modelos Random Forests ( $R F$, símbolo blanco) con una variable: anchura de río $(A)$, índice de refugio $(R)$, profundidad $(P)$, índice de sustrato $(S)$ o velocidad de flujo (V). Los modelos representados fueron cuantificados por el porcentaje de casos clasificados correctamente ( $C C l$, símbolo triangular) y Kappa ( $K$, símbolo cuadrado). Los valores de este criterio de representación fueron promediados sobre los tres doblamientos.

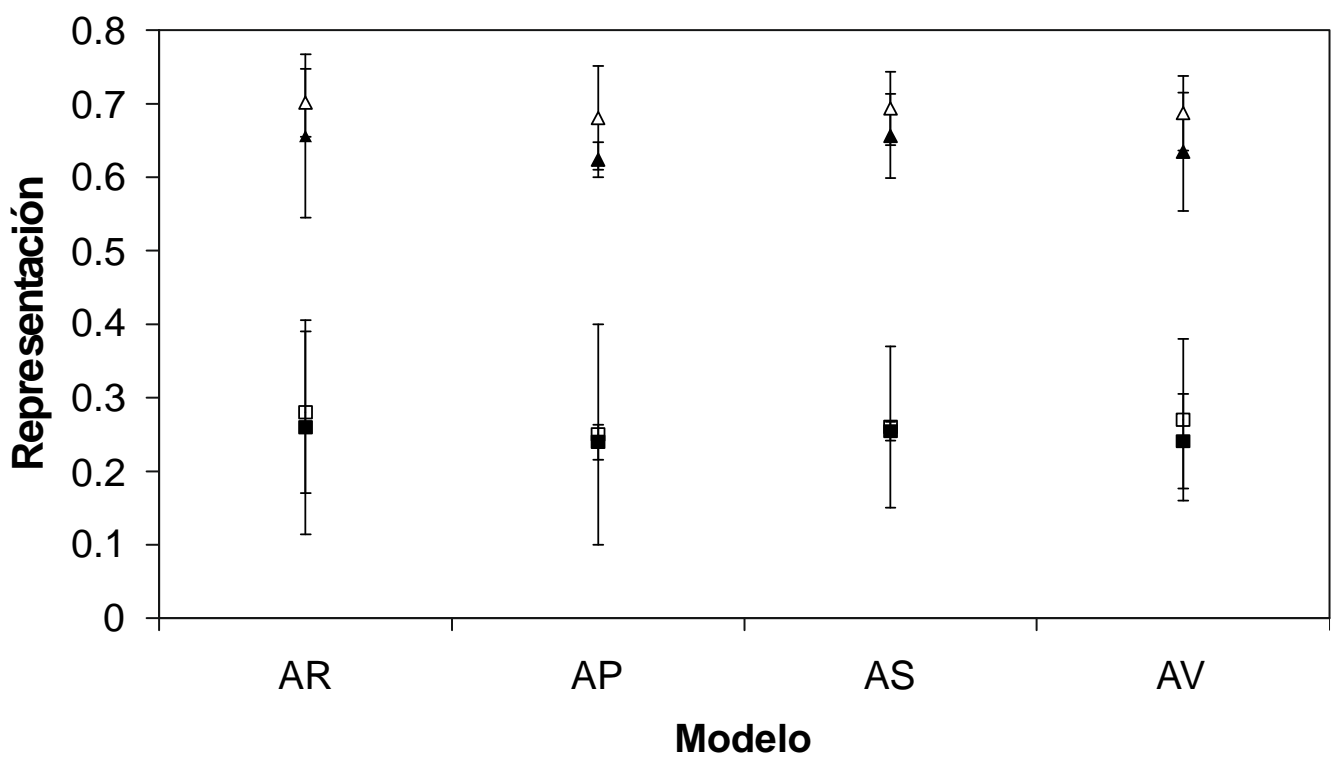

Figura 8.2. Representación de cuatro modelos mediante reglas difusas de optimización (FRO, símbolo negro) y cinco modelos Random Forests ( $R F$, símbolo blanco) que incorpora anchura del río $(A)$ y otras variables: índice de refugio $(R)$, profundidad $(P)$, índice de sustrato $(S)$ velocidad de flujo (V). Los modelos representados fueron cuantificados por el porcentaje de casos clasificados correctamente ( $C C l$, símbolo triangular) y Kappa ( $K$, símbolo cuadrado). Los valores de este criterio de representación fueron promediados sobre los tres doblamientos. 


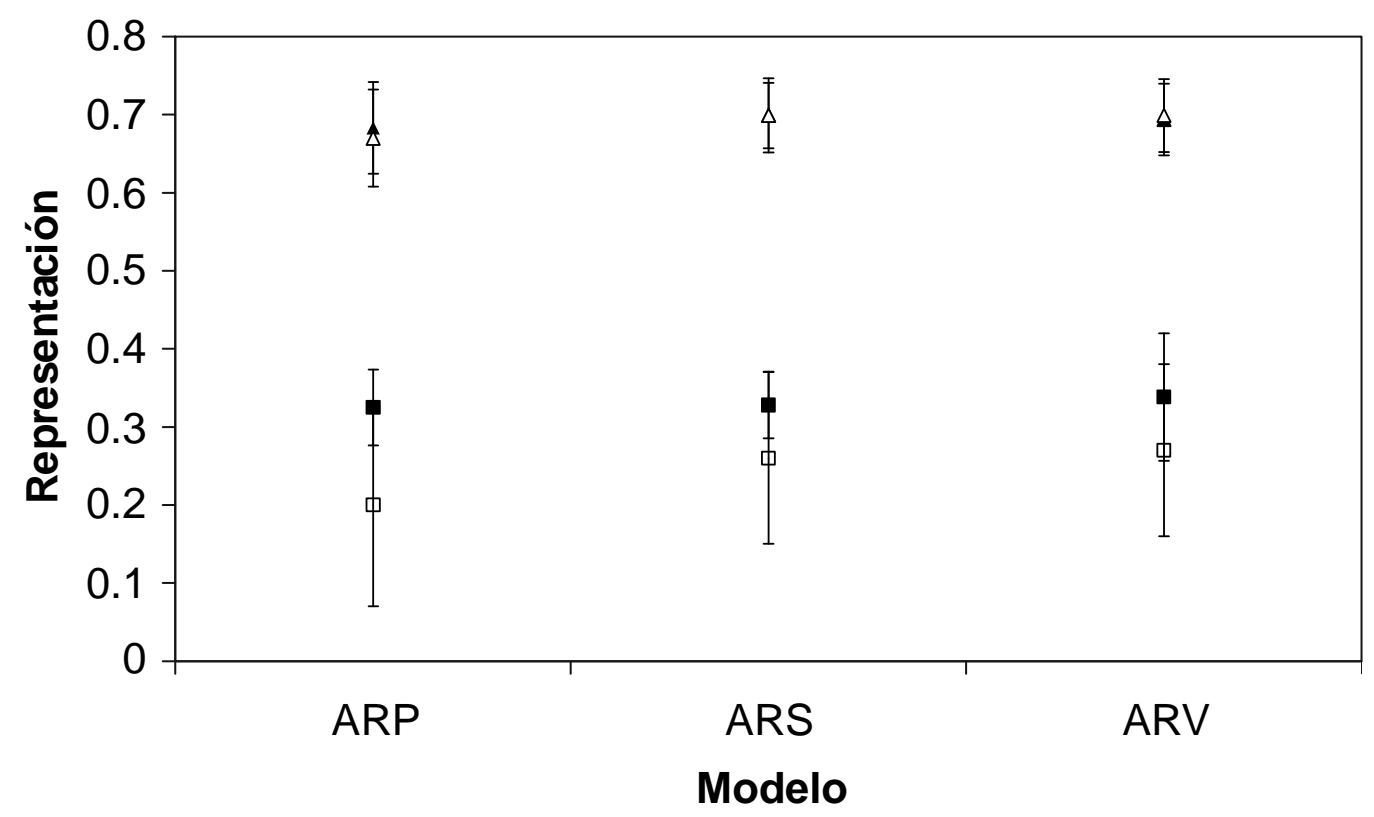

Figura 8.3. Representación de tres modelos mediante reglas difusas de optimización (FRO, símbolo negro) y cinco modelos Random Forests ( $R F$, símbolo blanco) que incorpora anchura del río (A), índice de refugio (R) y otras variables profundidad (P), índice de sustrato (S) o velocidad de flujo (V). Los modelos representados fueron cuantificados por el porcentaje de casos clasificados correctamente ( $\mathrm{CCl}$, símbolo triangular) y Kappa ( $K$, símbolo cuadrado). Los valores de este criterio de representación fueron promediados sobre los tres doblamientos.

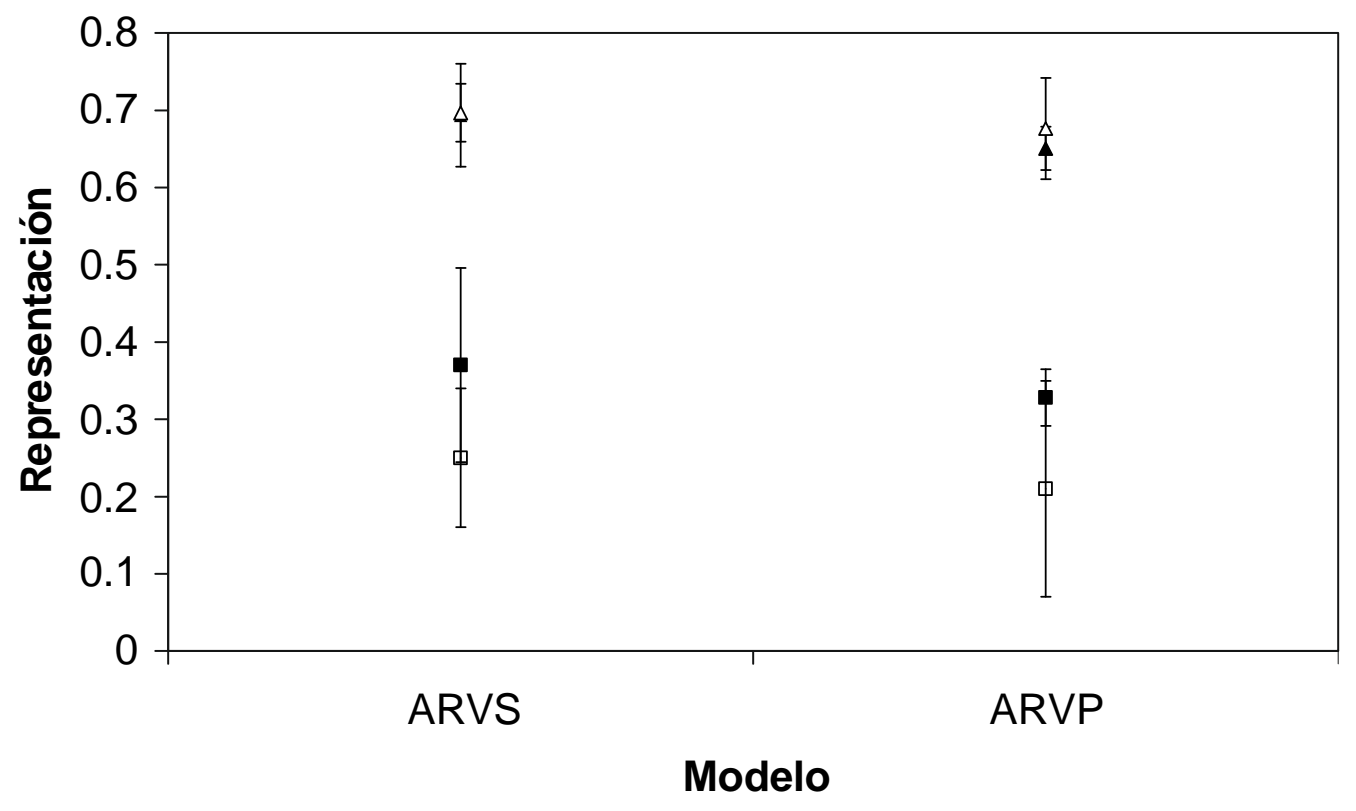

Figura 8.4. Representación de dos modelos mediante reglas difusas de optimización (FRO, símbolo negro) y cinco modelos Random Forests ( $R F$, símbolo blanco) que incorpora anchura del río (A), índice de refugio (R), velocidad de flujo (V) y otras variables como índice de sustrato (S) o profundidad (P). Los modelos representados fueron cuantificados por el porcentaje de casos clasificados correctamente ( $C C l$, símbolo triangular) y Kappa ( $K$, símbolo cuadrado). Los valores de este criterio de representación fueron promediados sobre los tres doblamientos. 
Tabla 8.4. Matrices de confusión de los diferentes modelos optimizados para la regla de optimización difua $(F R O)$ y los Random Forests $(R F)$. Todas las matrices se calcularon con el total de los datos. A, idoneidad del hábitat alta; $B$, idoneidad del hábitat baja; $A$, modelo basado en la anchura; $R$, índice de refugio; $V$, velocidad del flujo; $S$, índice de sustrato.

\begin{tabular}{|c|c|c|c|c|c|c|c|c|c|c|}
\hline & \multicolumn{8}{|c|}{ Pronosticada } \\
\hline & & & \multicolumn{2}{|c|}{ A } & \multicolumn{2}{|c|}{ AR } & \multicolumn{2}{|c|}{ ARV } & \multicolumn{2}{|c|}{ ARVS } \\
\hline & & & B & A & B & A & B & A & B & A \\
\hline \multirow{4}{*}{ 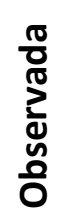 } & \multirow{2}{*}{ FRO } & B & $34 \pm 7$ & $27 \pm 3$ & $43 \pm 13$ & $18 \pm 12$ & $45 \pm 8$ & $16 \pm 4$ & $42 \pm 5$ & $20 \pm 4$ \\
\hline & & $A$ & $10 \pm 3$ & $22 \pm 2$ & $14 \pm 2$ & $18 \pm 5$ & $13 \pm 3$ & $20 \pm 5$ & $9 \pm 3$ & $23 \pm 2$ \\
\hline & \multirow{2}{*}{ RF } & $B$ & $48 \pm 6$ & $18 \pm 4$ & $54 \pm 4$ & $21 \pm 4$ & $54 \pm 4$ & $21 \pm 4$ & $54 \pm 4$ & $24 \pm 4$ \\
\hline & & $A$ & $12 \pm 6$ & $15 \pm 4$ & $6 \pm 4$ & $12 \pm 4$ & $6 \pm 4$ & $12 \pm 4$ & $6 \pm 4$ & $9 \pm 4$ \\
\hline
\end{tabular}

La selección de variables basada en Random Forests muestra que la anchura del río fue la variable más importante, seguidas del índice de refugio y la velocidad del flujo (figuras 8.1-8.4). Estos resultados concuerdan con el proceso de selección de variable en la optimización del modelo difuso. Por el contrario, el modelo óptimo Random Forests es el $A R$ y sólo incluye dos variables: anchura e índice de refugio (figura 8.2). La representación del modelo (figura 8.3) y la matriz de confusión (tabla 8.4) no mejoraron significativamente después de la incorporación de una nueva variable y la incorporación de la profundidad da como resultado un decrecimiento significativo del modelo representado (figura 8.3). Fueron testadas (resultados no mostrados en el capítulo) diferentes combinaciones del número de árboles ( $k$ ) y el número de variables usadas en la división de los nodos $(m)$ y los modelos mostraron una buena convergencia en los valores de $k$ y $m$ hacia 3 y 1000, respectivamente. No se observó una correlación significativa entre las variables anchura, velocidad e índice de refugio incluidos en la optimización de los modelos difusos y Random Forests (tabla 8.5). Por lo tanto, a la representación de modelos óptimos no debería afectarle los efectos de colinealidad.

Tabla 8.5. Matriz de correlación de las cinco variables de entrada. V, velocidad; $P$, profundidad del río; $A$, anchura del río; $S$, índice de sustrato; $\mathrm{R}$, índice de refugio.

\begin{tabular}{cccccc}
\hline & $\mathbf{V}$ & $\mathbf{P}$ & $\mathbf{A}$ & $\mathbf{S}$ & $\mathbf{R}$ \\
\hline $\mathbf{V}$ & 1 & & & & \\
$\mathbf{P}$ & -0.50502 & 1 & & & \\
$\mathbf{A}$ & -0.01607 & 0.28143 & 1 & & \\
$\mathbf{S}$ & 0.05979 & -0.01209 & 0.09860 & 1 & \\
$\mathbf{R}$ & -0.42378 & 0.33696 & -0.29623 & -0.17007 & 1 \\
\hline
\end{tabular}


Muchos de los modelos difusos optimizados mostraron valores Kappa mayores que los Random Forests, aunque los valores Kappa de los modelos de dos variables de RF fueron mayores que los difusos. Los valores $\mathrm{CCl}$ de muchos modelos RF fueron mayores que sus opuestos difusos, aunque se observaron valores $\mathrm{CCl}$ similares para los modelos con tres variables (figura 8.3). El modelo difuso óptimo (modelo ARV) muestra los valores Kappa y $\mathrm{CCl}$ más altos que el resto de modelos y su representación es mejor que el modelo $R F$ óptimo (modelo $A R$ ). Comparando la matriz de confusión de ambos modelos, se observa como el modelo $A R$ de $R F$ sobrepredice sustancialmente las observaciones, mientras que los errores de omisión y comisión del modelo difuso ARV fue más equilibrado (tabla 8.4).

La optimización de la regla base del modelo difuso ARV proporciona una interpretación fácil de las preferencias de la trucha común en la región Valenciana. La trucha común parece que prefiere tramos de ríos estrechos si la disponibilidad de refugio es moderada o alta. Si hay poca disponibilidad de refugio, ellas prefieren tramos más anchos con velocidades bajas. En general, la idoneidad del hábitat más alta de la trucha común fue pronosticada para tramos con refugio moderado o alto. Casi todas las condiciones medioambientales descritas por la regla base fueron representativas del conjunto de datos, aunque no se observó hábitats con anchura, índice de refugio y velocidad bajas o altas (tabla 8.6). Estos modelos de preferencia del hábitat están acordes con el uso de los hábitats visualizados en las figuras $8.5 \mathrm{a}, \mathrm{b}$, c. La regla base optimizada y los modelos $R F$ fueron aplicados a cuatro ríos diferentes mostrando similares matrices de confusión (tabla 8.7). 
Tabla 8.6. Regla difusa base del modelo difuso óptimo ( $A R V)$. La última columna muestra el número de reglas para alcanzar cada condición ambiental. $A$, alto; $M$, moderado; $B$, bajo.

\begin{tabular}{ccccc}
\hline Anchura & Refugio & Velocidad & $\begin{array}{c}\text { Idoneidad } \\
\text { del hábitat }\end{array}$ & $\begin{array}{c}\text { Número de } \\
\text { reglas }\end{array}$ \\
\hline B & B & B & A & 0 \\
B & B & A & B & 5 \\
A & B & B & A & 2 \\
A & B & A & B & 9 \\
B & M & B & A & 17 \\
B & M & A & A & 17 \\
A & M & B & B & 21 \\
A & M & A & B & 9 \\
B & A & B & A & 8 \\
B & A & A & A & 2 \\
A & A & B & B & 3 \\
A & A & A & B & 0 \\
\hline
\end{tabular}

Tabla 8.7. Matrices de confusión y exactitud predictiva $(C C I)$ de la óptima regla base difusa ( $F R O$; modelo $A R V$ ) y el óptimo modelo Random Forests (RF; modelo $A R$ ) aplicados a los cuatro ríos de estudio. ( $A$, alta idoneidad del hábitat; $B$, baja idoneidad del hábitat)

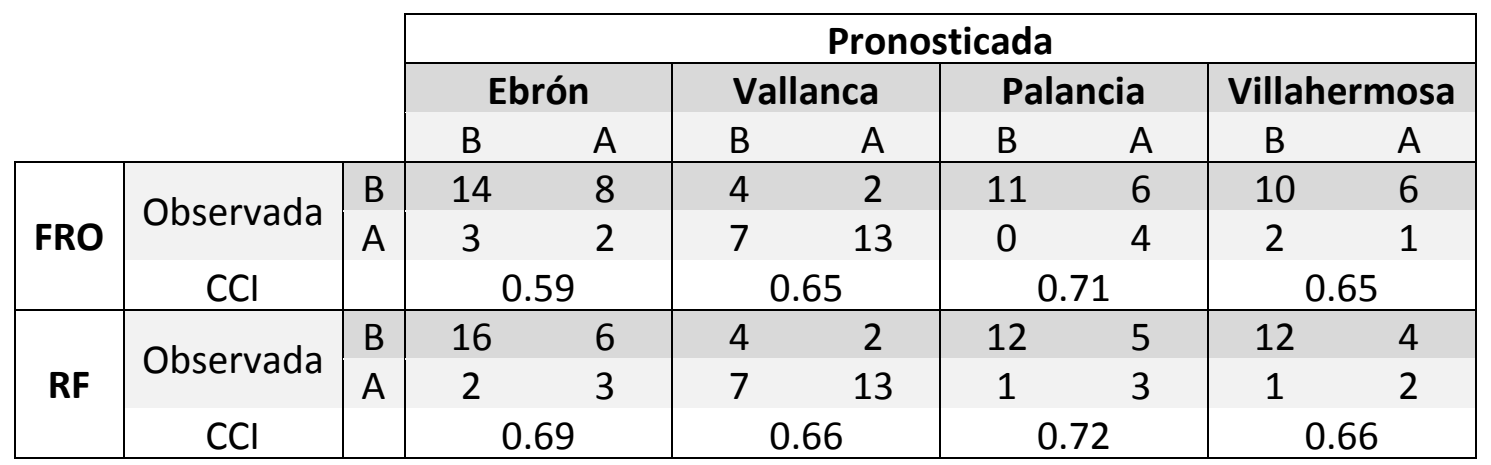



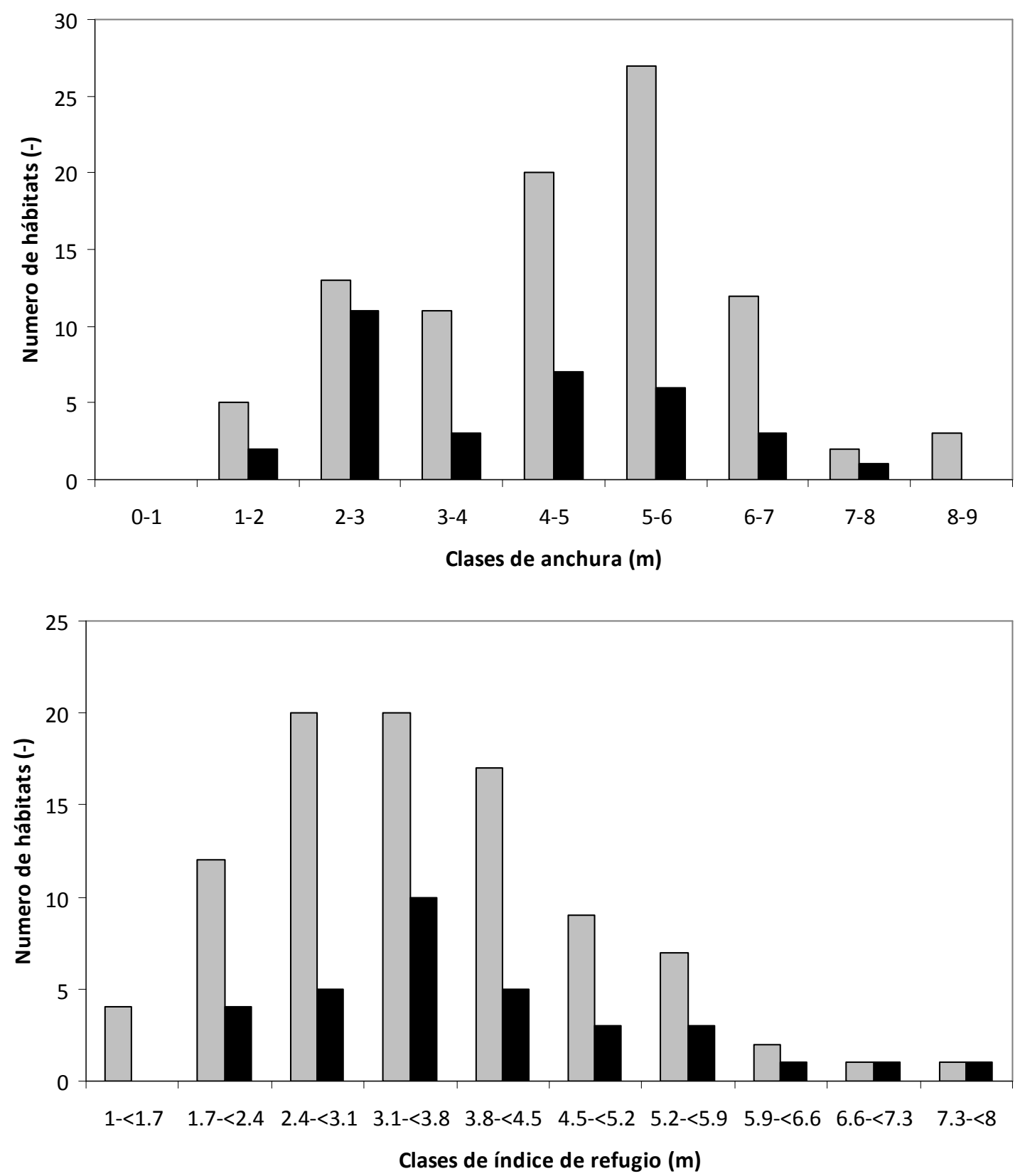

Figura 8.5a. Disponibilidad del hábitat (gris) y uso (negro) de la trucha común en el área de estudio cuantificada como número de disponibilidad y uso del hábitat. Los hábitats son caracterizados por cinco variables de entrada, en esta figura aparecen la anchura y el índice de refugio. 

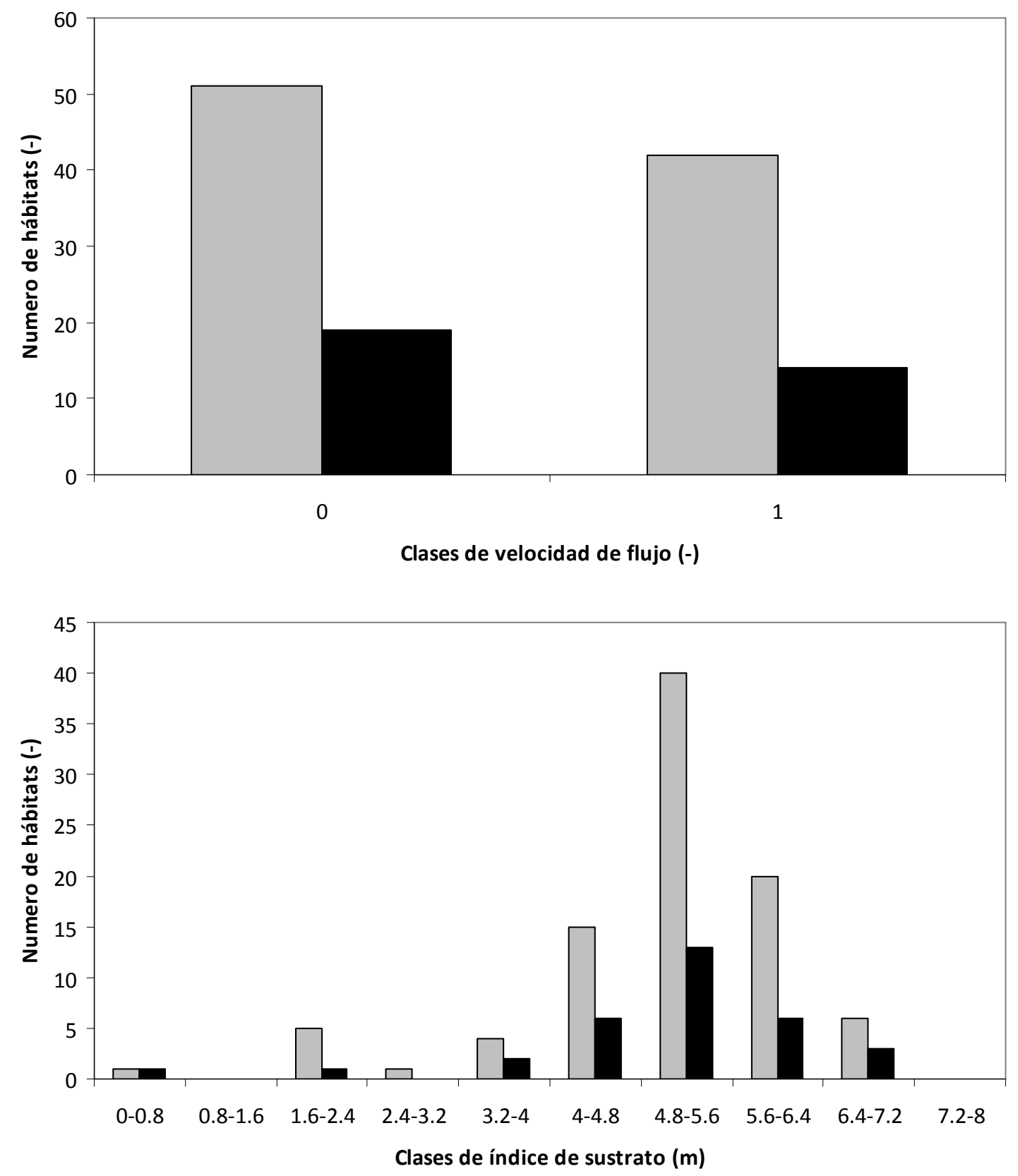

Figura 8.5b. Disponibilidad del hábitat (gris) y uso (negro) de la trucha común en el área de estudio cuantificada como número de disponibilidad y uso del hábitat. Los hábitats son caracterizados por cinco variables de entrada, en esta figura aparecen la velocidad y el índice de sustrato. 


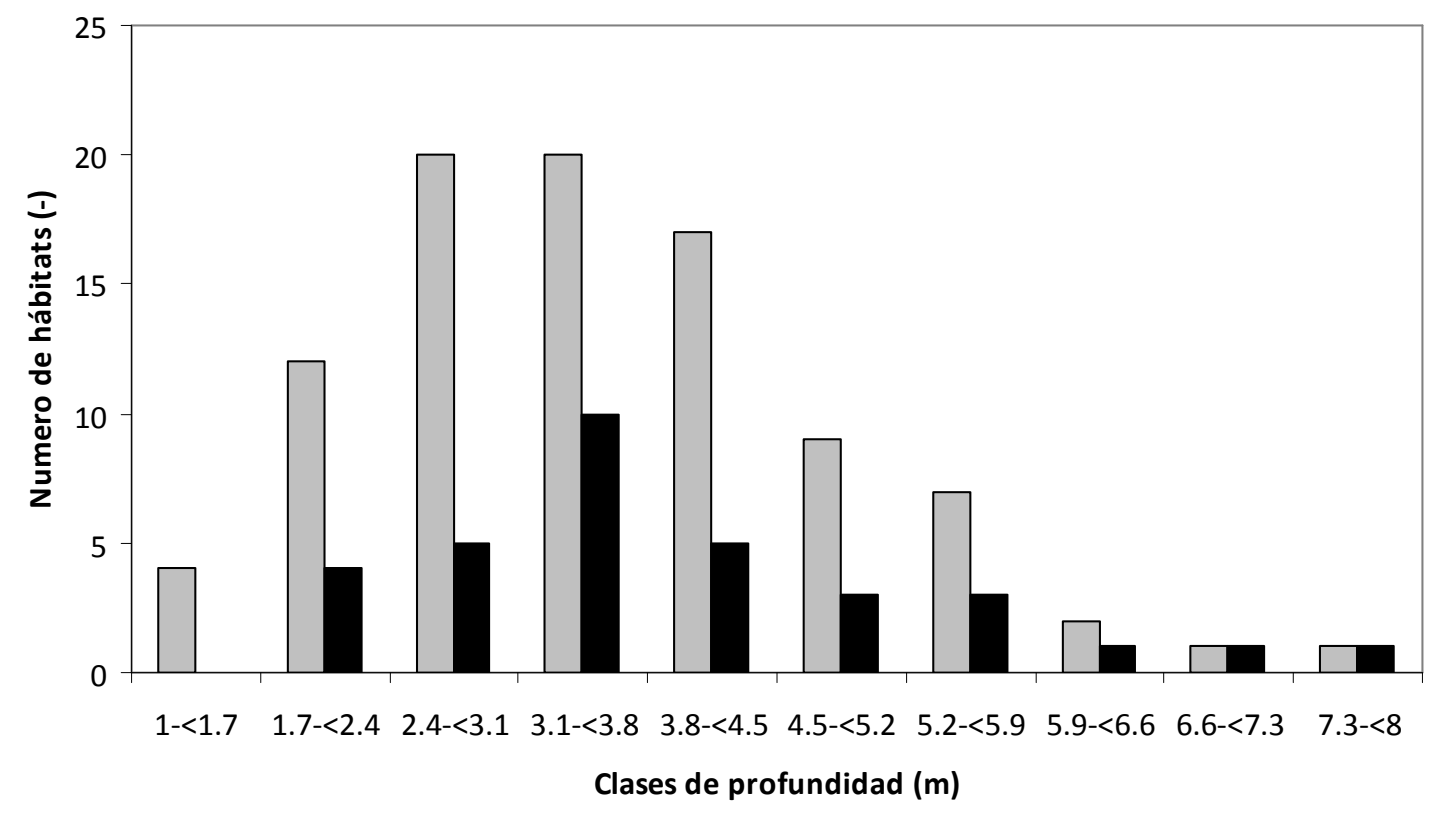

Figura 8.5c. Disponibilidad del hábitat (gris) y uso (negro) de la trucha común en el área de estudio cuantificada como número de disponibilidad y uso del hábitat. Los hábitats son caracterizados por cinco variables de entrada, en esta figura aparece la profundidad o calado.

\section{DISCUSIÓN}

El objetivo de este capítulo era desarrollar un análisis de los datos fiable de los modelos de distribución de la trucha común en la región mediterránea. Por lo tanto, se aplicaron y compararon la optimización de los modelos mediante dos técnicas de análisis de datos: la regla base de optimización difusa y Random Forests. La aproximación con reglas bases difusas han sido testadas y aplicadas para especies en distintas situaciones ecológicas, demostrando así su potencial para la modelación ecológica (Mouton et al., 2008; Mouton et al., 2009b; Mouton et al., 2009c). Este capítulo proporcionó una primera comparación de la aproximación difusa con los modelos Random Forests, técnica ampliamente aceptada y utilizada para la optimización de los datos (Breiman, 2001). Se seleccionó la técnica RF por haber sido aplicada exitosamente en ecología y por estar categorizada como una de las mejores técnicas disponibles para realizar modelos ecológicos. Por lo tanto, los resultados de este capítulo pueden indicar el potencial de la aproximación de las reglas bases difusas de optimización, comparadas con otras técnicas de análisis de los datos.

Ambas técnicas se compararon basándose en cuatro aspectos: la representación del modelo, la selección de las variables, la relevancia ecológica en la predicción del 
modelo y la transparencia del modelo. La representación del modelo optimizado difuso, el modelo $A R V$ parece que sobrepasa al modelo óptimo $R F$ (el modelo $A R$, figuras 8.1-8.4). Aunque se usaron más grados de libertad para el primer modelo, los modelos $R F$ que incluían más variables no se representaban mejor que los modelos difusos. No obstante, fueron relativamente pequeñas las diferencias entre los modelos representados con ambas técnicas, lo que concuerda con otros estudios comparativos de técnicas de análisis de datos (Elith et al., 2006). Además, los resultados también demuestran la necesidad de considerar diferentes criterios de representación a la hora de comparar modelos. En concreto, valores similares de $\mathrm{CCl}$ no implica necesariamente valores similares de Kappa, lo cual también se demostró en estudios previos (Mouton et al., 2008).

En el proceso de selección de las variables de ambos modelos, difusos y Random Forests, se seleccionó la anchura del río y el índice de refugio como las variables explicativas más importantes para la distribución de la trucha común en el área de estudio. Al aumentar a tres variables, ambas técnicas seleccionaron la velocidad de flujo como la tercera variable más importante. Puesto que, las desviaciones estándar de Kappa fueron más pequeñas para los modelos difusos que para los $R F$, los valores de Kappa de los diferentes modelos $R F$ muestran más superposición que los modelos difusos (figuras 8.1-8.4). Entonces, los modelos difusos se distinguieron de manera más exacta entre las diferentes variables. Por lo tanto, al añadir la velocidad al modelo $A R$ condujo a una mejora sustancial en la representación de los modelos difusos, pero no en la de los modelos $R F$.

Aunque la selección de variables en este capítulo estuvo basada en Kappa, se debería haber obtenido las mismas variables basadas en $\mathrm{CCl}$ en la optimización de los modelos RF. Por el contrario, los modelos difusos deberían seleccionar el índice de sustrato como la variable más importante según CCl. No obstante, la nueva combinación de variables revela que el modelo difuso $A R V$ tienen los valores más altos de Kappa y $\mathrm{CCl}$ (figuras 8.1-8.4). Estos resultados demuestran que para el proceso desarrollado no es necesariamente la representación el criterio más seguro en la exactitud de la predicción y enfatiza la necesidad de considerar diferentes criterios de representación.

En general, los modelos difusos pueden ser considerados ecológicamente relevantes concordes con las preferencias de hábitat de la trucha común como ya se describió en investigaciones previas (Elliott et al., 1992; Blaginiere y Maisse, 2002). En realidad, la trucha común se supone que prefiere un refugio intermedio o alto y relativamente baja velocidad de flujo si se dispone de limitación del refugio. La importancia de la 
anchura del río en el modelo difuso puede indicar que la trucha común prefiere los ríos de cabecera más estrechos en el área de estudio. La profundidad no fue seleccionada por los modelos aunque es considerada una variable importante en la distribución de la trucha común. Esto puede ser explicado por la correlación relativamente alta de la profundidad con otras variables. Los modelos del hábitat estándar como PHABSIM sólo dependen de variables hidráulicas como la profundidad y la velocidad (Bovee, 1982), pero la importancia del refugio en los modelos optimizados enfatizan la necesidad de considerar otras variables en los modelos de distribución de especies. La regla base optimizada (tabla 8.6) predice consistentemente la preferencia del hábitat de la trucha común en los cuatro ríos. Las pequeñas diferencias en la exactitud de las predicciones entre ríos pueden indicar que otras variables no incluidas en los modelos afectan a la distribución de la trucha común. Por lo tanto, nuevas investigaciones podrían proporcionar más detalle, aportando modelos más fiables. La necesidad de nuevos estudios en este lugar específico también se enfatiza por la ligera diferencia que hay en la preferencia del hábitat de la trucha común en otros modelos previos (Mouton et al., 2009c). No obstante, futuras investigaciones nos revelarán si los modelos desarrollados son aplicables a otros ríos de la región mediterránea.

La comparación de la matriz de confusión entre los modelos difusos y RF (tabla 8.4) indica que el modelo $R F$ optimizado $A R$ sobrepredice sustancialmente las observaciones, mientras que los errores de omisión y comisión del modelo difuso $A R V$ fueron más equilibrados. Investigaciones previas muestran desde un punto de vista ecológico, que los modelos que sobrepredicen las observaciones pueden no ser necesariamente irrelevantes ecológicamente (Mouton et al., 2009b). Concretamente, la subpredicción de las observaciones siempre supone un error en el modelo, mientras que la sobrepredicción puede deberse a un desequilibrio de colonización del hábitat en el área de estudio. Para este efecto, se han propuesto varias explicaciones como la barreras longitudinales del cauce que impiden la migración, la variación temporal de las poblaciones y los muestreos ineficientes (Mackenzie et al., 2003; Barry y Elith, 2006). En este punto, la elección del modelo óptimo dependerá de los objetivos del modelo y del dictamen experto del modelador. No obstante, la falta de trasparencia en los modelos $R F$ limita la interpretabilidad de sus aspectos ecológicos, en contraste con los modelos difusos.

Aunque tanto para la optimización de la regla difusa como para los $R F$ generan modelos ecológicos similares, los modelos difusos son con creces más transparentes que los $R F$. Generalmente, los modelos difusos pueden representarse como una combinación de reglas difusas y conjuntos difusos, mientras que los $R F$ consisten en 
un conjunto de arboles aleatorios. Ya que muchos de sus árboles difieren, la interpretabilidad de estos modelos es limitada. Por el contrario, los modelos difusos pueden ser fácilmente interpretados debido a las características lingüísticas de las reglas difusas. Este aspecto puede ser importante cuando los modelos óptimos deben de aplicarse en el contexto de gestión del río. Los modelos difusos son trasparentes para un amplio número de usuarios y por lo tanto puede estimular la comunicación entre los modeladores, los gestores y los usuarios de los ríos. Investigaciones previas han demostrado la aplicabilidad de los modelos difusos en este contexto (Chen y Mynett, 2003).

Este capítulo demuestra que la regla base de optimización difusa permite el desarrollo de modelos de distribución de la trucha común en la región mediterránea. Además, los modelos difusos son una alternativa evaluable para el estado del arte de otras técnicas de minería de datos (Data Mining), como son los Randoms Forests. Aunque ambas técnicas generan resultados similares, los modelos de lógica difusa pueden ser apropiados para situaciones donde la trasparencia e interpretatividad del resultado del modelo es importante. Por otra parte, la universalidad de la aproximación permite la fácil incorporación de otras especies o ecosistemas, mientras que la trasparencia facilita la comparación de diferentes modelos. Por lo tanto, la presente aproximación puede ser una prometedora herramienta para la restauración de ríos o en general la gestión ecológica.

\section{BIBLIOGRAFÍA}

Adriaenssens, V., B. De Baets, P.L.M. Goethals y N. De Pauw. 2004. Fuzzy rule-based models for decision support in ecosystem management. Science of the Total Environment 319: 112.

Akaike, H. 1974. A new look at statistical-model identification. IEEE Transactions on Automatic Control 19: 716-723.

Alcaraz-Hernández, J.D., F. Martínez-Capel, M. Peredo y A.B. Hernández-Mascarell. 2007. Relaciones entre densidades y biomasas de Salmo trutta fario y mediciones del mesohábitats en tramos trucheros de la Comunidad Valenciana. Limnetica 26: 159-167.

Almodóvar, A., G.G. Nicola y B. Elvira. 2006. Spatial variation in brown trout production: The role of environmental factors. Transactions of the American Fisheries Society 135: 13481360. 
Assilian, S. 1974. Artificial intelligence in the control of real dynamical systems. Ph. D. Thesis. London University, London, Great Britain.

Bagliniere, J.L. y G. Maisse. 2002. La biologie de la truite commune (Salmo trutta L.) dans la rivière Scorff, Bretagne: une synthèse des études de 1972 à 1997. INRA Productions Animales 15: 319-331.

Barry, S. y J. Elith. 2006. Error and uncertainty in habitat models. Journal of Applied Ecology 43: 413-423.

Bovee, K.D. 1982. A guide to stream habitat analysis using the Instream Flow Incremental Methodology. US Fish and Wildlife Service, Fort Collins, Colorado. 248 pp.

Breiman, L. 2001. Random forests. Machine Learning 45: 5-32.

Cohen, J. 1960. A coefficient of agreement for nominal scales. Educational and Psychological Measurement 20: 37-46.

Cutler, D.R., T.C. Edwards, K.H. Beard, A. Cutler y K.T. Hess. 2007. Random forests for classification in ecology. Ecology 88: 2783-2792.

Chen, Q.W. y A.E. Mynett. 2003. Integration of data mining techniques and heuristic knowledge in fuzzy logic modelling of eutrophication in Taihu Lake. Ecological Modelling 162: 55-67.

D'heygere, T., P.L.M. Goethals y N. De Pauw. 2003. Use of genetic algorithms to select input variables in decision tree models for the prediction of benthic macroinvertebrates. Ecological Modelling 160: 291-300.

Dolloff, C.A., D.G. Hankin y G.H. Reeves. 1993. Basinwide estimation of habitat and fish populations in streams. U.S. Department of Agriculture. Forest Service, Southeastern Forest Experiment Station. 25 pp.

Elith, J., C.H. Graham, R.P. Anderson, M. Dudik, S. Ferrier, A. Guisan, R.J. Hijmans, F. Huettmann, J.R. Leathwick, A. Lehmann, J. Li, L.G. Lohmann, B.A. Loiselle, G. Manion, C. Moritz, M. Nakamura, Y. Nakazawa, J.M. Overton, A.T. Peterson, S.J. Phillips, K. Richardson, R. Scachetti-Pereira, R.E. Schapire, J. Soberon, S. Williams, M.S. Wisz y N.E. Zimmermann. 2006. Novel methods improve prediction of species' distributions from occurrence data. Ecography 29: 313-329.

Elliott, J.M., D. Trevor Crisp, R.H.K. Mann, I. Pettman, A.D. Pickering, T.G. Pottinger y I.J. Winfield. 1992. Sea trout literature review and bibliography. NRA National Rivers Authority, Bristol. 141 pp.

Fielding, A.H. y J.F. Bell. 1997. A review of methods for the assessment of prediction errors in conservation presence/absence models. Environmental Conservation 24: 38-49. 
Garcia de Jalón, D. y G. Schmidt. 1995. Manual práctico para la gestión sostenible de la pesca fluvial. Asociación para el estudio y mejora de los salmónidos. Madrid. 169 pp.

Hankin, D.G. y G.H. Reeves. 1988. Estimating total fish abundance and total habitat area in small streams based on visual estimation methods. Canadian Journal of Fisheries and Aquatic Sciences 45: 834-844.

Hüllermeier, E. 2005. Fuzzy methods in machine learning and data mining: Status and prospects. Fuzzy Sets and Systems 156: 387-406.

Jowett, I.G., J. Richardson, B.J.F. Biggs, C.W. Hickey y J.M Quinn. 1991. microhabitat preferences of benthic invertebrates and the development of generalized deleatidium spp habitat suitability curves, applied to 4 new-zealand rivers. New Zealand Journal of Marine and Freshwater Research 25: 187-199.

Kampichler, C., J. Barthel y R. Wieland. 2000. Species density of foliage-dwelling spiders in field margins: a simple, fuzzy rule-based model. Ecological Modelling 129: 87-99.

Leopold, L.B., M.G. Wolman y J.P. Miller. 1964. Fluvial processes in geomorphology. Freeman Co., San Francisco. 522 pp.

MacKenzie, D.I., J.D. Nichols, J.E. Hines, M.G. Knutson y A.B. Franklin. 2003. Estimating site occupancy, colonization, and local extinction when a species is detected imperfectly. Ecology 84: 2248-2255.

Mamdani, E. 1974. Application of fuzzy algorithms for control of a simple dynamic plant. Proceedings IEE 121: 1585-1588.

Meador, M.R., T.F. Cuffney, M.E. Gurtz. 1993. Methods for sampling fish communities as part of the National Water-Quality Assessment Program. U.S. Geological Survey Open-File Report 93-104.Raleigh. USA. 40 pp.

Michalewicz, Z. y D.B. Fogel. 2000. How to solve it: modern heuristics. Springer-Verlag, Berlin, Heidelberg. 467 pp.

Mouton, A.M., B. De Baets, E. Van Broekhoven y P.L.M. Goethals. 2009b. Prevalenceadjusted optimisation of fuzzy models for species distribution. Ecological Modelling 220: 1776-1786.

Mouton, A.M., B. De Baets y P.L.M. Goethals. 2009a. Knowledge-based versus data-driven fuzzy habitat suitability models for river management. Environmental Modelling \& Software 24: 982-993.

Mouton, A.M., I.G. Jowett, P.L.M. Goethals y B. De Baets. 2009c. Prevalence-adjusted optimisation of fuzzy habitat suitability models for aquatic invertebrate and fish species in New Zealand. Ecological Informatics 4: 215-225. 
Mouton, A.M., M. Schneider, A. Peter, G. Holzer, R. Müller, P.L.M. Goethals y N. De Pauw. 2008. Optimisation of a fuzzy habitat model for spawning European grayling (Thymallus thymallus L.) in the Aare river (Thun, Switzerland). Ecological Modelling 215: 122-132.

Mouton, A.M., M. Schneider, J. Depestele, P.L.M. Goethals y N. De Pauw. 2007. Fish habitat modelling as a tool for river management. Ecological Engineering 29: 305-315.

Peters, J., B. De Baets, N.E.C. Verhoest, R. Samson, S. Degroeve, P. De Becker y W. Huybrechts. 2007. Random forests as a tool for ecohydrological distribution modelling. Ecological Modelling 207: 304-318.

Pino-Mejías, R., M.D. Cubiles-de-la-Vega, M. Naya-Romero, A. Pascual-Acosta, A. JordánLópez y N. Bellinfante-Crocci. 2010. Predicting the potential habitat of oaks with data mining models and the R system. Environmental Modelling \& Software 25: 826-836.

Sánchez-Montoya, M.M., M.R. Vidal-Abarca, T. Puntí, J.M. Poquet, N. Prat, M. Rieradevall, J. Alba-Tercedor, C. Zamora-Muñoz, S. Toro, S. Robles, M. Álvarez y M.L. Suárez. 2009. Defining criteria to select reference sites in Mediterranean streams. Hydrobiologia 619: 39-54.

Shannon, C.E. y W. Weaver. 1963. Mathematical theory of communication. University of Illinois Press, Urbana, Illinois. 144 pp.

Van Broekhoven, E., V. Adriaenssens y B. De Baets. 2007. Interpretability-preserving genetic optimization of linguistic terms in fuzzy models for fuzzy ordered classification: An ecological case study. International Journal of Approximate Reasoning 44: 65-90.

Van Broekhoven, E., V. Adriaenssens, B. De Baets y P.F.M. Verdonschot. 2006. Fuzzy rulebased macroinvertebrate habitat suitability models for running waters. Ecological Modelling 198: 71-84.

Zadeh, L.A. 1965. Fuzzy sets. Information and Control 8: 338-353.

Žnidaršic, M., A. Jakulin, S. Džeroski y C. Kampichler. 2006. Automatic construction of concept hierarchies: The case of foliage-dwelling spiders. Ecological Modelling 191: 144158. 


\section{CAPÍTULO 9}

\section{CONCLUSIONES Y FUTURAS LÍNEAS DE INVESTIGACIÓN}

1. El análisis de la variabilidad de los ríos mediante los atributos físicos del hábitat, mediante tres clasificaciones, ríos, mesohábitats y ríos-mesohábitats aportó resultados significativos. Los resultados muestran que los ríos Villahermosa y Ebrón son más estables que Vallanca y Palancia, las corrientes y tablas son más estables que pozas y rápidos, y consecuentemente las pozas de los ríos Vallanca y Palancia son los hábitats más heterogéneos según el análisis por clases. Esto indicó que aunque el balance información-esfuerzo se ajustó a las posibilidades de la tesis, una clasificación de las pozas más detallada podría haber aportado resultados más significativos para distinguir sus características físicas.

2. En las pozas de los ríos Vallanca y Palancia se detectaron los factores que más influyen en su variabilidad, lo que ha permitido agrupar los hábitats profundos de estos dos ríos en cuatro grupos diferenciados según sus atributos físicos y detectar sus posibles causas de variabilidad espacial.

3. Existe una alta variabilidad de los parámetros poblacionales de la trucha común que vive en ríos de la Comunidad Valenciana. Éstas presentan un crecimiento en longitud grande en comparación con otras poblaciones del mundo. A la vez, hay una considerable variación en la densidad y biomasa media, con una producción anual baja y con valores de la tasa de renovación anual muy bajos.

4. El crecimiento somático en longitud es muy variable según los ríos y los años de muestreo. Además, se obtuvo una relación denso-dependiente entre la longitud de las truchas inmaduras y su densidad en los ríos menos caudalosos (Vallanca y Palancia). Sin embargo, no se observó este fenómeno en los ríos más caudalosos (Ebrón y Villahermosa). Las relaciones denso-independientes 
de trucha común con el caudal no pudieron ser evaluadas por falta de estaciones de aforo en los ríos muestreados. El avance en el conocimiento de la dinámica poblacional de la trucha mediterránea donde se comprueben mejor las relaciones deso-dependientes y denso-independiente sería una futura línea de investigación.

5. Los parámetros poblacionales se ajustan a la teoría de las poblaciones periféricas, en donde se describe cómo las poblaciones que habitan en el perímetro de su distribución son más variables debido a que el desarrollo de la especie está condicionado por los rangos periféricos del hábitat, principalmente como resultado de la mayor variabilidad de los factores abióticos en el medio mediterráneo, por lo que se darán procesos densoindependientes. Por el contrario, en las poblaciones centrales los rangos idóneos del hábitat están plenamente cubiertos, y por lo tanto tienen más relevancia los procesos denso-dependientes.

6. El estudio del hábitat a nivel de mesohábitats ha sido válido para recoger la variabilidad de los datos. Para los cuatro ríos estudiados, nueve de diez variables fueron significativas en alguno de los análisis realizados para la densidad de trucha inmadura y adulta. Por otro lado, para los dos grupos de mesohábitats (lentos/rápidos) nueve de doce variables fueron significativas en alguno de los análisis de densidades.

7. Los análisis han detectado un comportamiento distinto entre la trucha común inmadura y la adulta. Para la abundancia de trucha inmadura resultó relevante el volumen de los hábitats, mientras que para la trucha adulta fueron la profundidad, la distancia relativa entre rápidos (solo en segmentos asociados a mesohábitats lentos, tablas y pozas) y el índice de refugio en los rápidos (corrientes y rápidos).

8. A nivel general, esta tesis se ha centrado en el estudio de factores físicos del hábitat relacionados con las poblaciones de trucha, sin analizar otros factores que afectan a la selección del hábitat, como la competencia intraespecífica, competencia interespecífica (principalmente por la competencia con la trucha arco-iris) o la presencia de predadores. Indirectamente se ha observado que la combinación de estas características bióticas afecta al uso del hábitat por la trucha. Esta limitación plantea la posible continuidad de las investigaciones, 
mediante nuevos análisis, o bien nuevos muestreos con diferentes metodologías.

9. Los modelos de lógica difusa explicaron la selección de hábitat por la trucha común, a escala de mesohábitat, con un nivel de explicación elevado, y similar al realizado por Random Forests; los de lógica difusa aportaron además la ventaja de tener mayor trasparencia e interpretatividad en los resultados, siendo esto muy útil para los gestores.

10. Los modelos regionales de idoneidad del hábitat para la trucha común, basados en lógica difusa, consideran la interacción entre variables del hábitat físico, indicando que la especie prefiere tramos de ríos estrechos si la disponibilidad de refugio es moderada o alta. Si hay poca disponibilidad de refugio, prefieren tramos más anchos con velocidades menores. Por lo tanto la disponibilidad de refugio en los modelos multivariantes se presenta como una variable crítica en la selección del hábitat. No obstante, esta línea de trabajo se desea desarrollar más, mediante el desarrollo de modelos multivariantes en cada rio, separando clases de edad, o bien aplicando nuevos modelos.

11. Los resultados de esta tesis pueden ser una herramienta útil en la restauración de ríos y en la gestión de la trucha común mediterránea. En estos ríos de tamaño pequeño o mediano respecto a otros ríos trucheros europeos, el volumen y profundidad de los mesohábitats puede ser un factor limitante esencial, y el refugio también es de gran importancia, siendo elementos sobre los cuales la restauración fluvial puede actuar, contribuyendo a la gestión sostenible de la trucha común en el ámbito mediterráneo. 